Portland State University

PDXScholar

\title{
A Structural Analysis of Corporate Political Activity: An Application of Euclidean Modeling to the Study of Intercorporate Relations
}

Colleen Bridget Mullery

Portland State University

Follow this and additional works at: https://pdxscholar.library.pdx.edu/open_access_etds

Part of the Other Business Commons

Let us know how access to this document benefits you.

\section{Recommended Citation}

Mullery, Colleen Bridget, "A Structural Analysis of Corporate Political Activity: An Application of Euclidean Modeling to the Study of Intercorporate Relations" (1991). Dissertations and Theses. Paper 1303.

https://doi.org/10.15760/etd.1302

This Dissertation is brought to you for free and open access. It has been accepted for inclusion in Dissertations and Theses by an authorized administrator of PDXScholar. Please contact us if we can make this document more accessible: pdxscholar@pdx.edu. 
A STRUCTURAL ANALYSIS OF CORPORATE POLITICAL ACTIVITY:

AN APPLICATION OF EUCLIDEAN MODELING TO THE

STUDY OF INTERCORPORATE RELATIONS

by

COLIEEN BRIDGET MULLERY

A dissertation submitted in partial fulfillment of the requirements for the degree of

DOCTOR OF PHILOSOPHY

in

SYSTEMS SCIENCE

Portland State University

$\odot 1991$ 
TO THE OFFICE OF GRADUATE STUDIES:

The members of the committee approve the dissertation of Colleen Bridget Mullery presented June 4, 1991.

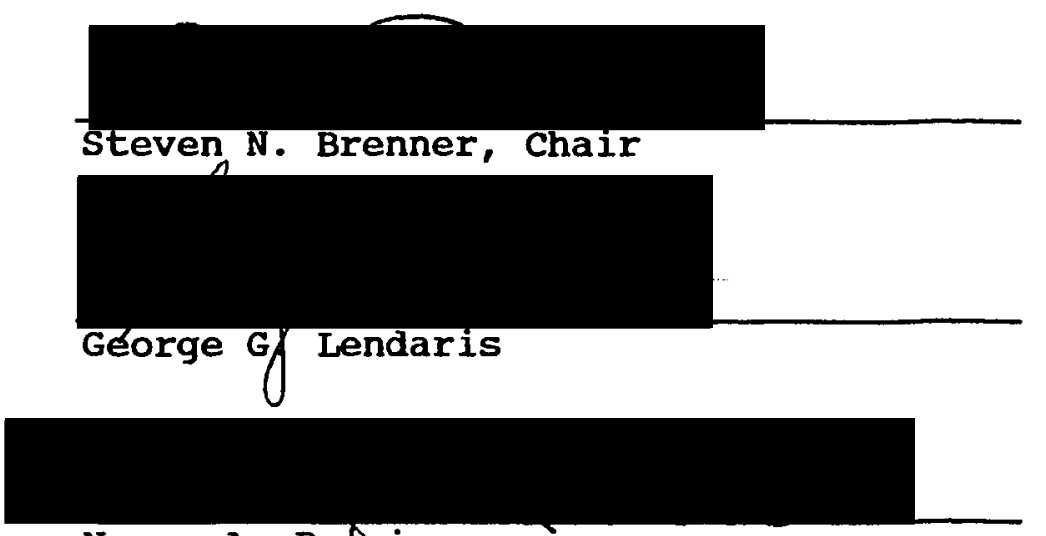

Nancy A. PeArin

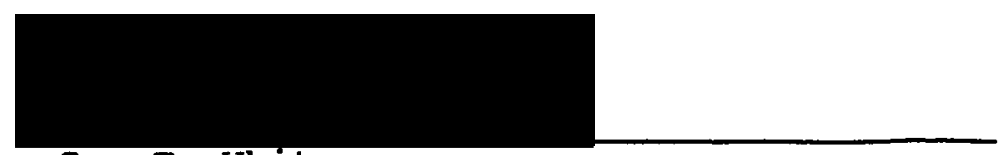

Sam E. White

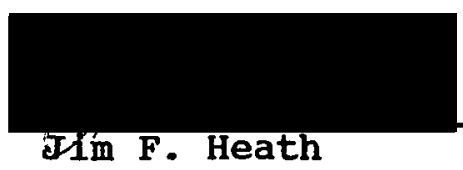

APPROVED:

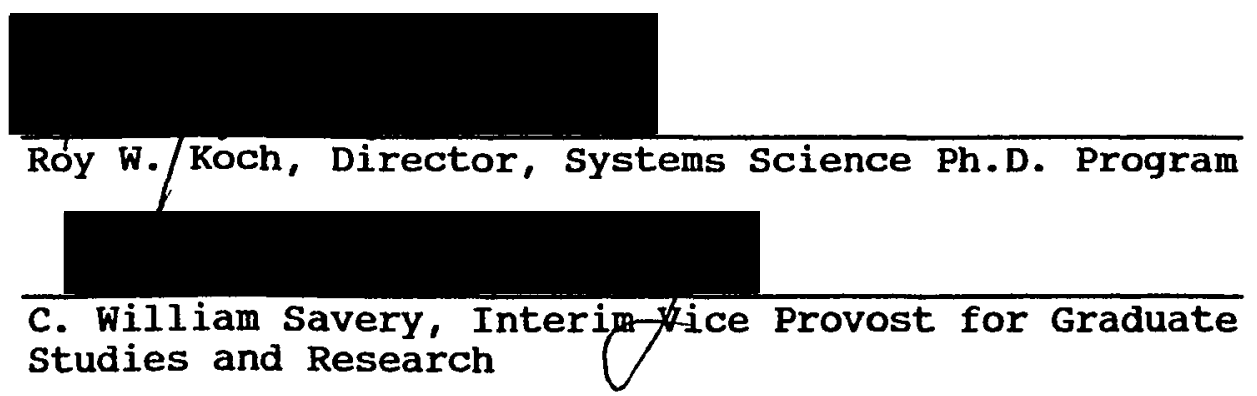


AN ABSTRACT OF THE DISSERTATION OF Colleen Bridget Mullery for the Doctor of Philosophy in Systems science presented June 4, 1991 .

Title: A Structural Analysis of Corporate Political Activity: An Application of Euclidean Modeling to the Study of Intercorporate Relations.

APPROVED BY THE MEMBERS OF THE DISSERTATION COMMITTEE:
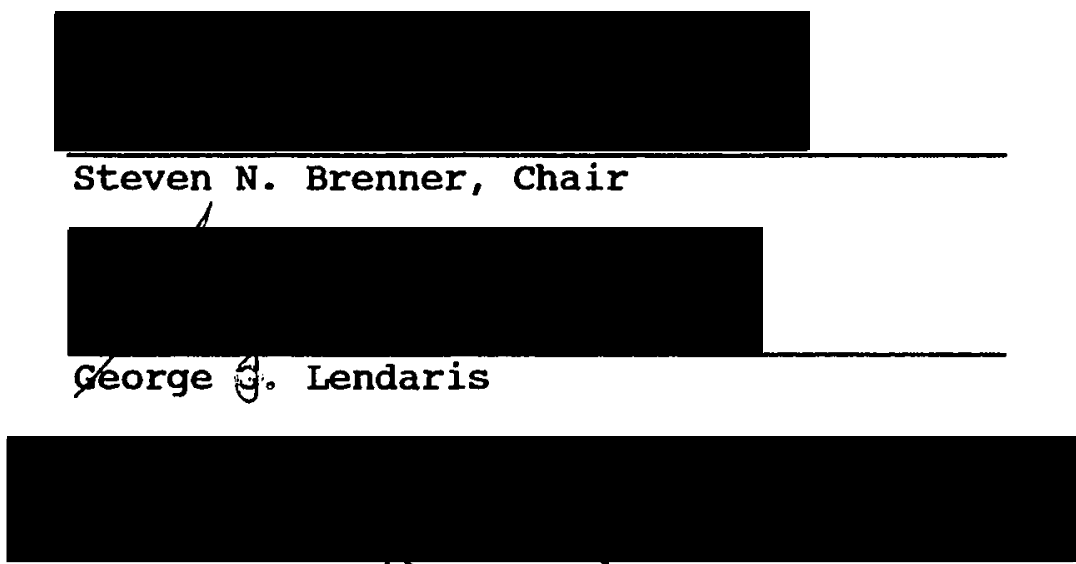

Nancy A. Perrin

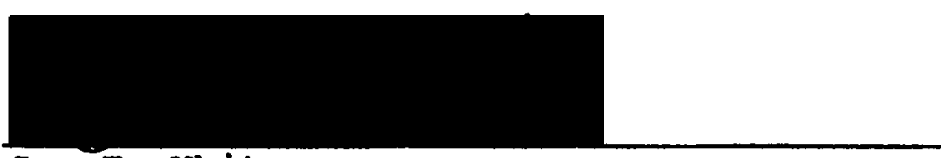

Sam E. White

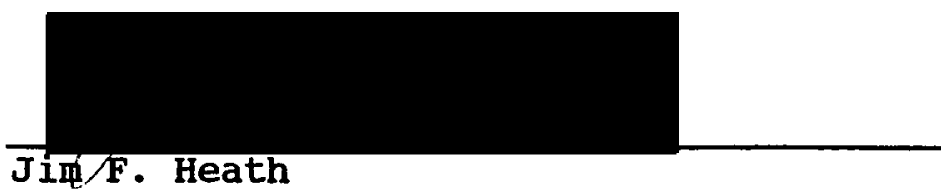

During the past two decades business has become increasingly active in the political process, and scholars 
continue to debate the extent to which this activity is organized. This fundamental issue is addressed by examining corporate political activity within the context of resource dependence and class cohesion theories.

Political action committee (PAC) campaign contributions, this study's measure for corporate political activity, are structurally analyzed to determine if either resource dependence or class cohesion theory explains the forces which drive business participation in the U.S. public policy process. The rationale which forty-two diverse corporate PACs exercise when selecting which congressional campaigns to support during two election cycles is explored. Resource dependence theory contends that a firm's behavior is a function of its dependence on the environment for resources. Successful firms attempt to manage this external dependence by controlling or manipulating their environment. Corporate involvement in politics, therefore, will reflect a firm's dependence on the government for sales, subsidies or regulation. The regulatory environment in which a firm operates is this study's measure of resource dependence.

Conversely, class cohesion theory argues that a firm's political activity is a function of its top management's inclusion in a network of corporate elites. Board members and chief executives from the nation's largest corporations coalesce to advance a political agenda which is compatible 
with the overarching goals of the business community rather than the parochial goals of an individual firm or even industry. Interlocking directorates, professional association memberships, shared educational experience and geographic proximity of headquarters locations are this study's indicators of a corporate elite network.

Two categories of analytical methodology are applied. Multidimensional scaling maps corporate patterns of support for congressional candidates based on a PAC contribution proximity measure. These patterns are subsequently subjected to discriminant analysis, canonical correlation, regression and chi-square analysis to test for Resource Dependent and Class Cohesive political behavior.

The results are conclusive: support of selected congressional campaigns is more likely fueled by fragmented business interests, as resource dependence theory suggests, rather than the collective motives of a corporate elite. In fact, no support emerged for class cohesion theory as an explanation for the observed patterns of intercorporate relations.

Further, a corollary proposition that PAC activity will vary with the ideology of white House administrations is not supported. Rather, PAC contribution patterns do not vary significantly between the carter and Reagan administrations. 
This research renders four significant contributions to scholarship:

1. It provides empirical evidence to clarify a central issue in business-government relations, i.e., the atomistic or collective nature of corporate political activity.

2. It introduces a rigorous mathematical technique to the business-government relations discipline.

3. It indirectly addresses an ongoing scholarly debate over the role of interest groups in a democracy. 4. It indirectly addresses the current public policy debate over campaign finance reform. 
To Honah Lee 


\section{ACKNOWLEDGEMENTS}

Professors, friends and loved ones joined to teach, guide and encourage me during all phases of my research. This work would not have been possible without their support.

Steven Brenner, my chairperson and mentor, introduced me to the Business in Politics literature in my first graduate school course. Later, he critiqued numerous research proposals and countless chapter drafts. I am grateful for his critical role in my development as a teacher and scholar. Nancy Perrin equipped me with the needed quantitative tools to do responsible empirical research, then made sure that I used them correctly. Her competent and caring teaching and counsel make her a true role model. George Lendaris would not accept the ordinary, but insisted on the extraordinary. As a result this work is considerably strengthened. Sam White's "what if" questions forced me to consider the unexpected results. Jim Heath offered words of encouragement when I needed them most. Thank you all:

Two other PSU professors influenced my development. Martin Zwick introduced me to systems science in a mindexpanding core course. John $0^{\prime} B r i e n$ taught me research design in a memorable seminar. 
Cards, letters, and phone calls from my mother, brother and sister brightened many long, lonely graduate school days. Their love and support was a warm reminder of what is most important in life.

Lastly, my husband, Bob--his selflessness, wisdom, and love were the sustenance that truly made this journey possible.

C. B.M.

Trinidad, California 
TABLE OF CONTENTS

PAGE

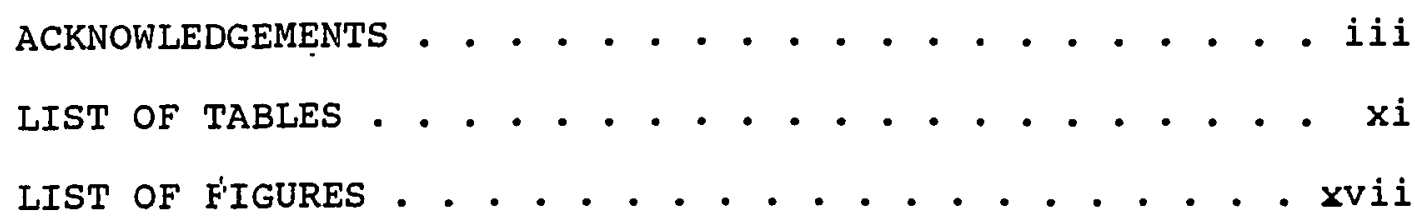

CHAPTER

I INTRODUCTION . . . . . . . . . . . . . . 1

The Research objective . . . . . . . . 1

structural Analysis . . . . . . . . . 2

Significance of the Research. . . . . . 3

Suprasystem Focus: Interest Group Theory

Subsystem Focus: Campaign Finance Reform

Definitions of Key Terms . . . . . . . 11

Structural Analysis

Class Cohesion Theory

Resource Dependence Theory

Corporate Political Activity

Ideological/Pragmatic PAC strategy

Regulatory Environment

Interlocking Directorates

Political Action Committees: PACs

Election Cycles

Chapter Summary and Thesis Overview . . . 18

II LITERATURE REVIEW . . . . . . . . . . . 23

The classics . . . . . . . . . 23

E. E. Schattschneider, Politics, Pressures, and the Tariff 
David Truman, The Governmental Process

Bauer, Pool and Dexter, American Business and Public Policy

Mancur Olson, The Logic of Collective Action

Edwin Epstein, The Corporation in American Politics

Corporate Political Activity,

Contemporary Research . . . . . . . 33

Corporate Political Activities and Strategy

The Legitimacy Issue

The Influence Issue

Conclusion

Intercorporate Relations . . . . . . . 49

The Evolution

Resource Dependence Theory

Class Cohesion Theory

A Synthesis

Current Research

Conclusion

Chapter Summary . . . . . . . . 64

III RESEARCH DESIGN . . . . . . . . . . . 67

Introduction . . . . . . . . . 67

Research Question .. . . . . . . 68

Hypotheses . . . . . . . . . . 69

Resource Dependence Hypothesis

Class Cohesion Hypotheses

A Political strategy Hypothesis

Exploratory Research . . . . . . . . 72

Measurement . . . . . . . . . 72

Corporate Political Activity

Similarity Measure

Political Strategy

Resource Dependence

Class Cohesion 
The Sampling strategy . . . . . . 88

Population

Sample Criterion: PAC Activity

Sample Criterion: Industry

Dispersion

Two Election cycles

Analytical Methodology . . . . . . . 92

Multidimensional scaling--

the Fundamentals

Hypothesis Testing . . . . . . . . 98

Resource Dependence Null Hypothesis

Class Cohesion Null Hypotheses

The Political strategy Null

Hypothesis

Conclusion . . . . . . . . . 100

IV THE 1977-78 ELECTION CYCLE . . . . . . . . 109

Introduction . . . . . . . . . 109

A Matter of Terminology

The Nature of the Proximity Data . . . 110

Extremes

Determining Dimensionality . . . . . . 111

Parameters

Dimensionality

The Final Test

Dimension Interpretation and

Labeling . . . . . . . . . . 117

Dimension one: Regulatory Dimension

Dimension Three: Strategy Dimension

Dimension Two: Regional Dimension

Correlations among Variables . . . . 123

Hypothesized Variables

PAC Characteristics

Regulatory Environment and PAC

Characteristics 
Resource Dependence . . . . . . . 126

The Hypothesis Test

Discussion

Summary of Resource Dependence Hypothesis Testing

Class Cohesion . . . . . . . . 135

The Hypothesis Tests

Discussion

Summary of Class Cohesion Hypothesis Testing

Chapter Summary . . . . . . . . . 141

V THE 1981-82 ELECTION CYCLE ... . . . . . . 169

The Nature of the 1981-82

Proximity Data . . . . . . . . 169

Extremes

Determining Dimensionality . . . . . . 171

The Final Test

Dimension Determination and

Labeling . . . . . . . . . . . . 174

Dimension One: Environment/Strategy Dimension

Dimension Two: Regional Dimension

Dimension Three: Outliers/Donees Dimension

Correlations among Variables . . . . . 183

Hypothesized Variables

PAC Characteristics

Regulatory Environment and PAC

Characteristics

Resource Dependence . . . . . . . . 185

The Hypothesis Test

Discussion

Class Cohesion . . . . . . . . . 191

The Hypothesis Tests

Discussion 


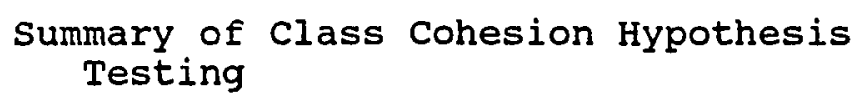

VI TWO ELECTION CYCLES COMPARED . . . . . . . . 228

The Political strategy

Hypothesis . . . . . . . . . . . 228

Paired Difference Experiment

Canonical Correlation Analysis

Patterns and Anomalies

Discussion . . . . . . . . . . . . .234

Chapter Summary . . . . . . . . 236

VII CONCLUSION . . . . . . . . . . . . . . 242

Introduction . . . . . . . . . . . . .242

Findings of Previous Research . . . . . 244

Hypotheses . . . . . . . . . . . . 247

Research Design . . . . . . . . . 249

Sample

Measure of Similar Political Behavior

Measure of Resource Dependence

Measures of Class Cohesion

Analytical Methodology

Results . . . . . . . . . . . 255

Scaling solution

Hypothesis Tests

Discussion, Conclusion and Future

Directions . . . . . . . . . . 258

Research Findings

Limitations

Theoretical Implications 
Managerial Implications

Avenues for Future Research

closing Thoughts

REFERENCES . . . . . . . . . . . . . . . . . 278 APPENDICES
A RESEARCH DESIGN . . . . . . . . . . . . 290
B 1977-78 SIMILARITY MATRIX . . . . . . . 294
C 1981-82 SIMILARITY MATRIX . . . . . . . . 298 


\section{LIST OF TABLES}

TABLE

PAGE

I

II

III

IV

V

VI

VII

VIII

IX

$x$

$X I$

The Research Context in a Systems Framework . . . . . . . . . 21

Empirical studies of Corporate PAC

Contributions and Firms' Political

Integration . . . . . . . . . 66

Measurement of Variables . . . . . 102

New Right PACs . . . . . . . . 103

Classifications and Predictions Based on

Resource Dependence Theory . . . 104

Five Major Business Associations and

Participants' Status . . . . . 105

Twelve Prominent Universities . . . . 106

Frequency of Headquarters Location by

State . . . . . . . . . 107

Composition of the Sample . . . . . 108

Distribution of 1977-78 similarity

Measures, Quartiles and

Interquartile Range . . . . . . 143

Firm Dyads Exhibiting Zero Political

Consensus, 1977-78 Election . . . 144 
$X I I$

XIII

XIV

$\mathrm{XV}$

XVI

XVII

XVIII

$\mathrm{XIX}$

$\mathrm{XX}$

$\mathrm{XXI}$

XXII
Firm Dyads Exhibiting High Political Consensus, 1977-78 Election . . . 145 Fit Indices for Five Euclidean Models, 1977-78 Similarity Data . . . . 146 Iteration History for the ThreeDimensional Solution, 1977-78 Election . . . . . . . . . . 147 Correlations between Dimension Three Coordinates and Candidate Type, 1977-78 Election . . . . . . . 148 Ideological PAC Contribution Patterns, 1977-78 Election . . . . . . . 149 Pragmatic PAC Contribution Patterns, 1977-78 Election . . . . . . . 150 Actual and MDS-Generated strategy Categories, 1977-78 Election . . . 151 Actual and MDS-Generated Strategy Categories, Chi-square Contingency Table, 1977-78 Election . . . . 152 Actual and MDS-Generated Headquarters Location, 1977-78 Election . . . 153 Actual and MDS-Generated Headquarters Location, Chi-square contingency Table, 1977-78 Election . . . . 154 Correlations between MDS Coordinates and Interpretive Variables . . . . . 155 
xiii

XXIII Descriptive Statistics for Interval Level

Variables, 1977-78 Election . . . 156

XXIV Resource Dependence and Class Cohesion

Variables Regressed Against MDS

Coordinates, 1977-78 Election . . 157

$\mathrm{XXV}$

Actual and Discriminant-classified

Regulatory Environment Categories, 1977-78 Election . . . . . . 158

XXVI Discriminant Analysis Classification Table

for Regulatory Environment, 1977-78 Election . . . . . . . 159

XXVII Actual and MDS-Classified Regulatory

Environment Categories, 1977-78

Election .......... . 160

XXVIII Actual and MDS-Classified Regulatory

Environment Categories, Chi-square

Contingency Table, 1977-78 Election. 161

XXIX Discriminant Analysis Classification Table

for Headquarters Location, 1977-78

Election .......... . . 162

$\mathrm{XXX}$

Distribution of 1981-82 Similarity

Measures, Quartiles and

Interquartile Range . . . . . 199

$\mathrm{XXXI}$

Firm Dyads Exhibiting Zero Political

Consensus, 1981-82 Election . . . 200 
xiv

XXXII Firm Dyads Exhibiting High Political Consensus, 1981-82 Election . . . 201

XXXIII Fit Indices for Five Euclidean Models, 1981-82 Similarity Data . . . . 202

XXXIV Iteration History for the Three-

Dimensional Solution, 1981-82

Election . . . . . . . . . 203

XXXV Firms for which Hypothesized Regulatory

Environment Classification Differed

from the MDS Classification . . . 204

XXXVI Correlations between MDS coordinates and Interpretive Variables . . . . . 205

XXXVII PAC Contribution Patterns, 1981-82 Election ........... 206

XXXVIII Ideological PAC Contribution Patterns, 1981-82 Election . . . . . . 207

XXXIX Pragmatic PAC Contribution Patterns, 1981-82 Election . . . . . . 208

XI Actual and MDS-Generated Headquarters Location, 1981-82 Election . . . 209

XLI Actual and MDS-Generated Headquarters Location, Chi-square Contingency Table, 1981-82 Election . . . . 210

XLII Number of Donees to Whom PACs Contributed, 1981-82 Election . . 211 
XIIII Actual and MDS-Generated Categories for Number of Donees, 1981-82 Election . . . . . . . . 212

XLIV Descriptive Statistics for Interval Level Variables, 1981-82 Election . . . 213

XLV Resource Dependence and Class Cohesion Variables Regressed Against MDS Coordinates, 1981-82 Election . . 214

XLVI Discriminant Analysis Classification Table for Regulatory Environment, 1981-82 Election . . . . . . 215

XLVII Actual and Discriminant-Classified Regulatory Environment Categories, 1981-82 Election . . . . . . 216

XLVIII Actual and MDS-Classified Regulatory Environment Categories, Chi-square Contingency Table, 1981-82 Election. 217

XIIX Actual and MDS-Classified Regulatory Environment Categories, 1981-82 Election ........... 218

A Comparison of Test statistics, 1977-78 and 1981-82 Data, Hypothesis One . . . . . . . 219

II A Comparison of Test statistics, 1977-78 and 1981-82 Data, Hypothesis Five . . . . . . . 220 
$x v i$

LII Discriminant Analysis Classification Table

for Headquarters Location, 1981-82

Election . . . . . . . . . . 221

LII Candidate-Type Contribution Proportions,

1977-78 and 1981-82 Elections . . 238

LIV Changes in Proportions of Dollar

Contributions to Types of

Candidates, 1977-78 to 1981-82 . . 239

LV Canonical Analysis of Contribution

Patterns for Two Election Cycles,

1977-78 and 1981-82 . . . . . . 240

LVI Standardized Scores for Differences

between Proportions Contributed to

Candidate Categories, 1977-78 and

1981-82 . . . . . . . . . . 241 


\section{LIST OF FIGURES}

FIGURE

PAGE

1. Growth in the Number of PACs by Type, 1977 through $1989 . . . . . . . . .22$

2. Frequency Distribution of the 1977-78

Similarity Measures . . . . . . . 163

3. MDS Fit Indices for the 1977-78 similarity Data .............. . 164

4. Scatter Plot of Nonlinear Fit for the Three-

Dimensional Solution with Distances on

the Vertical Axis and Observations on

the Horizontal Axis, 1977-78 Election . 165

5. Dimension One, Economic and Social Regulatory

Environments, 1977-78 Elections . . . 166

6. Dimension Three, Pragmatic and Ideological

Strategy, 1977-78 Elections . . . . . 167

7. Dimension Two, Regional Dimension, 1977-78

Elections . . . . . . . . . . 168

8. Frequency Distribution of the 1981-82

Similarity scores . . . . . . . . 222

9. MDS Fit Indices for the 1981-82 Similarity

Data . . . . . . . . . . . . 223 
xviii

10. Scatter Plot of Nonlinear Fit for the ThreeDimensional Solution with Distances on the Vertical Axis and Observations on the Horizontal Axis, 1981-82 Election . 224

11. Dimension One, Economic and Social Regulatory Environments, 1981-82 Elections . . . . 225

12. Dimension Two, Regional Dimension, 1981-82 Elections............ . . 226

13. Dimension Three, Outliers Dimension, 1981-82 Elections . . . . . . . . . . . . 227

14. Predicted Relationships: A Summary of Hypotheses .. . . . . . . . . . . 276 
CHAPTER I

\title{
INTRODUCTION
}

\begin{abstract}
Empirically, there is almost no research which directly addresses the fundamental issue--is there evidence which suggests that individual, familial, or class interests rather than organizational concerns explain behavior, and particularly, intercorporate or interorganizational behavior?
\end{abstract}

The key issue is whether there is a unified set of class interests that is transorganizational, extending across organizations, or whether organizational interests and actions are more fractionated. Given that different organizations sit in different positions in the network of interorganizational exchange, a resource dependence perspective would suggest at least some degree of conflict of interest. On the other hand, the social class perspective suggests a commonality of interests formed by common schooling, membership in social clubs, and sitting on overlapping and interlocking civic as well as corporate boards of directors. Thus, the question becomes, "To what extent can intercorporate relations be accounted for by patterns of resource interdependence?" or "To what extent do they reflect class interests and the homogeneity implied by this overarching conception?"

Pfeffer, 1987

\section{THE RESEARCH OBJECTIVE}

The objective of this research is to enhance understanding of business-government relations by examining corporate political activity within the context of resource dependence and class cohesion theories. Corporate political action committee (PAC) campaign contributions, this study's 
measure for corporate political activity, are structurally analyzed to determine if either resource dependence or class cohesion theory explains the forces which drive corporate participation in the U.S. public policy process. specifically, this research examines the rationale which corporations exercise when selecting Congressional campaigns to support. Are these decisions fueled by individual, self-serving business interests, as the resource dependence theory would suggest; or, are these decisions a function of membership in a corporate elite whose collective motives transcend short-term goals so as to ensure an economic stability conducive to long-term business interests, a position supported by class cohesion theorists?

STRUCTURAL ANALYSIS

Structural analysis is the preferred analytical approach for this research since its viewpoint parallels those of resource dependence and class cohesion theories. Structural analysis examines interrelationships among organizations in an effort to understand individual organizations' behaviors (Mizruchi and Schwartz 1987, i). Resource dependence and class cohesion theories both necessitate the study of interrelationships, the former in terms of similar constraints and the latter in terms of, for the most part, economic and social ties among executives. 
specifically, multidimensional scaling (MDS), a mathematical technique new to the study of businessgovernment relations, is used to structurally analyze corporate PAC contribution patterns. Regression, discriminant, canonical correlation, and chi-square hypothesis testing augment the MDS analysis. Research results provide evidence to explain the patterns of corporate political activity as exemplified by corporate PAC campaign contributions.

\section{SIGNIFICANCE OF THE RESEARCH}

This research analyzed intercorporate behavior patterns associated with PAC campaign activity in an effort to effect four significant contributions to the field of business-government relations:

1. Provide empirical evidence to clarify a central issue in business-government relations: the atomistic or collective nature of corporate political activity.

2. Introduce a rigorous mathematical technique to the business-government relations discipline.

3. Indirectly address an ongoing scholarly debate over the role of interest groups in a democracy, a debate with roots in questions that were first asked by the Founding Fathers.

4. Indirectly address a current public policy debate, the reform of Congressional campaign financing practices. 
It is useful to cast these four aims into a systems framework. One of the principal contributions of systems theory to research design is its ability to place the design in context by making explicit its relationship with a broader suprasystem and a more narrow subsystem and, further, by identifying its perceptual level as "Environment," "Unit," or "Subunit" (Lendaris 1986). The four aims of this research can be placed in this framework. The first two aims, to provide empirical evidence and introduce rigorous methodology, are at the unit level of the focal system. The third, the role of interest groups in society, is at the environment level of the focal system; and the fourth, campaign finance reform, is at the subunit level of the focal system. Table I summarizes this systems framework.

The two sections immediately following expand on the relevance of this research to the supra- and subsystems. The balance of the work deals with the focal perspective of this research.

\section{Suprasystem Focus: Interest} Group Theory

Madison, in his essay No. 10 from The Federalist Papers, foresaw a problem which results when a citizenry enjoys the freedom to form special interest groups (a contemporary example being a PAC) so as to influence government. If one faction attains a dominance which 
effectively quells the concerns of competing interest groups and the general populace, then democracy is threatened;

however, eliminating this basic political freedom--the right to organize and petition the government--would be, in Madison's words, "worse than the disease" (Berry 1989, 3). Berry (1989) describes this so-called "Madison's Dilemma" as follows:

Can an acceptable balance be struck between the right of people to pursue their own interests and the need to protect society from being dominated by one or more interests? That is, can we achieve true pluralism, or is a severe imbalance of interest group power a chronic condition in a free and open society? (4).

Madison's writings point toward offsets to the "mischiefs of factions," his term for interest group domination. He held that a republican form of government with checks and balances would enable the needs of the populace to be heard over the clamor of powerful special interest groups. He further believed that large numbers of diverse interest groups would create a competitive environment in which no one group could attain dominance (Berry 1989, 2-4).

Pluralist scholars have adopted this latter belief and argue forcefully that interest groups and democracy are compatible (Truman 1951; Dahl 1961). They contend that citizens can best influence the legislative process through groups of activists with shared goals. As issues emerge, so will appropriate interest groups. Given this vision, 
interest group activity serves the democratic process well. It emerges as an equilibrious mechanism for carrying the will of the people to their government. More recent research extends this argument to the question of corporate PACs (Epstein, Edwin 1984; Sabato 1984; Matasar 1986). Proponents of corporate PACs contend that the corporate sector's heterogeneity renders it incapable of deliberate collective political action. This business-PAC fragmentation along with the myriad special interest groups with free access to PACs are the Madisonian check to one segment's excessive power. Rather than undermine democratic principles, PACs buttress those principles by providing a vehicle though which all citizens can exercise their basic rights of free speech and association.

Power elite theory counters the pluralist argument (Mills 1956; Domhoff 1967, 1970, 1974; Whitt 1979, 1980; Useem 1980, 1982, 1984). It contends that a core group inevitably attains dominance and thereby overwhelms the pluralist ideal. This dominance, achieved through class cohesion, organizational skills, and access to resources denied others, is frequently associated with large corporations. Referred to as the "American business aristocracy" (Baltzell 1962), "governing class" (Domhoff 1967), or "power elite" (Mills 1956), this cohesive group is defined as: 
A social upper class which receives a disproportionate amount of a country's income, owns a disproportionate amount of a country's wealth, and contributes a disproportionate number of its members to the controlling institutions and key decision making groups in the country (Domhoff 1967, 142).

Power elite theorists maintain that a corporate elite is quite capable of championing a collective political strategy. These theorists describe an inner circle of the most wealthy and powerful corporate executives who coalesce to advance a specific business agenda. The resulting political clout undermines democratic principles. Berry (1989) ties PACs directly into the pluralistpower elite theory debate. He contends that the growing importance of PACs in the electoral process demands a reevaluation of this "classic dilemma of interest groups in a democratic society" (117).' He speculates why no new theory has emerged to explain interest group behavior and concludes that "the reason, in short, is that the task of formulating one is extremely difficult. . . it is almost pretentious for a social scientist to try" and, further, most scholars "find it more fruitful to work on narrower, and in their minds more realistic research problems" (13).

${ }^{1}$ At least part of the concern arises from the rapid growth of PACs. The reform of Federal election campaign legislation in the early 1970 s resulted in an environment in which PACs flourished. Between 1974 and 1980 the number of registered corporate PACs increased twelve-fold, from 89 to 1,109. While numbers in all six PAC categories increased, none approached the phenomenal growth rate of corporate PACs (see Figure 1) (U.S. Federal Election Commission 1990). 
My research pursues Berry's recommended path. It does not presume to advance a new theory which will resolve this centuries-old debate. However, its conclusions shed light on these core issues.

Subsystem Focus: Campaign Finance Reform

It will be recalled that the subsystem's unit focus is campaign finance and that its subunit is policy shapers. By examining patterns of PAC campaign contributions and by testing the resource dependence and class cohesion theories, this research should bear on both levels.

At the unit level, the accumulation and analysis of PAC campaign contribution data--irrespective of hypotheses tested in this study--will prove useful. Scholars will find them easily accessible and, it is to be hoped, applicable to further analysis from a different perspective.

At the subunit level, shapers of policy from government, business, labor, and issue-oriented groups such as common cause can extract valuable empirical evidence from this research. Results which lend support to the class cohesion theory would raise concerns regarding the potential influence of an industry-diverse corporate elite. Alternatively, results which support resource dependence theory would lend credence to the proposition that, while corporate PACs may fund the same campaigns, they do so from self-serving rather than collective motives; thus, the 
desired equilibrium among competing special interests can be achieved.

The importance of testing the two theories is reflected in recent events: the savings and loan debacle and its associated "Keating Five" scandal, the 1989 downfall of House Speaker James Wright, and the skyrocketing cost of Congressional campaigns have focused attention on Congressional ethics and campaign finance reform. ${ }^{2}$ Calls for reform have arisen from varied and diverse camps including the Democratic and Republican parties (Oreskes and Toner 1990), Common Cause, a liberal watchdog group (Abramson and Jackson 1990), even a member of the Fortune Top 50, American Express (Cabot and Sheekey 1990, 64). The extent of PAC Congressional campaign support inextricably involves PACs in the reform movement. First, nearly half of the representatives elected in 1988 received fifty percent or more of their campaign money from PACs. Seventeen senators elected in that same year earned the dubious status of "PAC millionaire," having received one million dollars or more from PACs (Wertheimer 1990, 45). Second, PAC contributions clearly favor incumbents. In 1978, sixty-eight percent of PAC support was channeled to House incumbents; in 1988, eighty-three percent. Incumbent

$2^{2}$ The 1988 congressional elections cost more than $\$ 400$ million; the average House seat's cost exceeded $\$ 350,000$, and the average senate seat nearly $\$ 4$ million (Cabot and Sheekey 1990, 62). 
Senators' campaigns have enjoyed a similar boost--from

forty-eight percent of PACs' Senate contributions in 1978 to sixty-four percent in 1988 (Oreskes and Toner 1990). Corporate-sponsored PACs may well be singled out for special attention in efforts at reform. First, corporatesponsored PACs constituted over forty percent of all PACs in 1990; this is in addition to the single issue and association-sponsored PACs that are supportive of corporate positions. 3 second, the dollars contributed from corporate-sponsored PACs have also maintained a vigorous growth rate--their 1988 contributions were up twenty-seven percent over 1987 (Abramson and Jackson 1990). Finally, research indicates a clear distinction between corporate and other PAC types in terms of incumbent support. Handler and Mulkern (1982) note:

The most significant development in PAC giving in the 1977-78 election cycle was the emergence of a set of corporate PACs that have defined a new identity for themselves and broken sharply from the incumbency-access orientation that the aggregate statistics seemed to show was the continuing dominant tendency in PAC giving (7).

Spiraling campaign costs and consequent fund-raising requirements have resulted in a congress perceived by many to be removed from ordinary citizen access. The 101st Congress, for example, is more indebted to special interests than any previous congress (Wertheimer 1990, 45). This fact

${ }^{3}$ For a roster of PAC types, see the definitions beginning on page 17 . 
leads to widespread agreement that campaign reform must be enacted, but there is little agreement on the shape such reform should take.

In summary, then, it would appear that the results of this research may have far-reaching effects because of the current political climate.

\section{DEFINITIONS OF KEY TERMS}

Fundamental to systems-oriented research is the recognition that each reader adopts a unique perspective which is dependent upon a variety of factors such as background, interest, and role. The preceding section set forth the research context so as to reveal the investigator's focal perspective. The following section defines some key terms so as to link other perspectives through a common vocabulary.

\section{Structural Analysis}

Structural analysis is an approach to the study of organizations which emerged in the late 1970s. It specifies relations among organizations as the fundamental unit of analysis. Individual organization behavior is examined within this interorganizational (e.g., intercorporate) framework.

Structural analysis of business examines a variety of strategic behaviors. Research in one area, the analysis of coordinated action among large corporations, has focused on 
a debate between two competing theories--resource dependence and class cohesion (both defined below). These theories are considered to be the two major structural perspectives on intercorporate relations (Mizruchi and Schwartz 1987).

\section{Class Cohesion Theory}

Class cohesion theory contends that members of the power elite, including corporate leaders, share a common mission: to enhance and preserve their privileged status and to bequeath the same perquisites to their progeny. To achieve their purposes, they are both capable and motivated to transcend their organizations' narrow interests if deemed necessary to perpetuate their version of capitalism (Mizruchi 1987).

\section{Resource Dependence Theory}

Like the class cohesion theory, resource dependence theory attempts to explain organization behavior by examining power relationships between and among organizations (e.g., intercorporate relations). Unlike the class cohesion theory, it contends that individual corporate interests are more meaningful than are classwide business interests in determining power relationships and the consequent organization behavior.

The theory posits that resource interdependencies (e.g., supplier-manufacturer or firm-regulatory agency interdependencies) are a major source of interaction and 
conflict within the business sector. Management will strive to reduce or manage the environmental uncertainties created by the interdependencies in a variety of ways, such as mergers, acquisitions, and/or corporate political activity (Pfeffer 1987).

Corporate Political Activity

The objective of corporate political activities is to influence the operation of the political system, most often by enhancing access to lawmakers and regulators. Edwin Epstein (1969) has defined two types of corporate political activities--electoral and governmental--as follows:

Governmental activities : . include both political involvement intended to influence the formulation and execution of policy by governmental decision makers and efforts designed to create a public opinion favorable to the corporation's political goals. Electoral activities center around the selection and support of candidates or of issues that come before the public (67).

Activities which are common to many politically active firms include, but are not limited to, coalition building, advocacy advertising, lobbying, constituency building, and campaign contributions through political action committees or, as they are widely known, PACs.

Ideological/Pragmatic PAC Strategy

Researchers have identified two dominant PAC types based on PAC expenditure patterns: ideological and pragmatic (Handler and Mulkern 1982, 14-15). 
An ideological PAC will target conservative or Republican candidates in an effort to change the overall composition of congress. Challengers and open-seat candidates are more likely to be supported by ideological than pragmatic PACs."

A pragmatic PAC will target incumbents in an effort to secure and maintain a high degree of access to legislators. These PACs place less emphasis on party affiliation or ideology; rather, they support those candidates who are more likely to be responsive to specific company-related issues owing to the candidate's Congressional committee assignments. Further, since incumbents are more likely to win an election, the probability of supporting a winner is enhanced.

Requlatory Environment

Two regulatory environment classifications, based on the emphasis and intensity of various business regulations, are defined.

Economic. Industries whose regulatory interface reflects economic policy are defined as operating in an economic environment. Industries impacted by economic regulations include securities, banking, trucking,

${ }^{4}$ While support of incumbents could certainly represent a PAC's ideological expression, past research generally regards incumbent support as a political strategy driven by rational, access-seeking objectives. 
railroads, utilities, and communications (Eismeier and

Pollock 1988, 43). Sometimes described as traditional, regulations based on economic policy are supported and often initiated by business. Economic regulations are defined as:

Government regulation that creates the necessary institutions for competition: government moneysupply management, enforcement of private contracts, protecting private property, patent and copyright protection, and so forth. The primary role of these regulations is to protect and enhance competitive forces in the economy, not to supplant them. On the other hand, when competitive forces are augmented by regulation as they often are--to limit entry into a field, such as traditional airline and trucking regulation--the results benefit specific businesses or industries (Fritschler and Ross 1980, 41).

Also included in the economic regulation category are industries with significant defense contracts since their profits are intimately tied to an accommodative rather than adversarial business-government relationship.

Social. A social environment characterizes those industries that are more directly impacted by the new regulations ushered in during the 1960s and early 1970s (e.g., mining, construction, and manufacturing). These regulations, directed at social rather than economic policy, are defined as:

Regulations defining what goods should or should not be produced. They provide product specifications and procedures in industrial processes designed for industrial safety. These regulations define modes of environmentally acceptable production, types of employees who should be hired, acceptable working conditions, pay conditions, retirement systems, and similar issues (Fritschler and Ross 1980, 42). 
These multi-industry regulations are regarded as a threat to corporate discretion and managerial autonomy and are therefore resented, contested, and sometimes ignored.

\section{Interlocking Directorates}

Interlocking directorates are created when company directors simultaneously serve on the boards of two or more companies. Interlocking directorates can be either direct or indirect.

A direct interlock exists when a director of one company sits as a director on the board of a second company. Thus, the two companies have a common director and are directly joined.

An indirect interlock exists when a director of a first company sits on the board of an intermediate company together with a director of a second company. Although the interlock between the two directors is direct, the route between the first and second companies is considered indirect since the connection takes place on the board of a third party (U.S. Congress, Senate 1980, 5).

Interlocking directorates provide a special opportunity for intercompany communication and consensus. The linkages at the board room table create personal connections through which information can be passed, arrangements can be made and policies formed (Useem 1984, chapter 2). 
Political Action Committees: PACS

A political action committee is a formal committee of an interest group which is created to solicit voluntary contributions from the group's membership. These funds are disbursed as contributions to or expenditures on behalf of candidates for federal office. PACs must register and file detailed financial records with the Federal Election Commission (FEC). The FEC defines PAC money as "separate, segregated funds to be utilized for political purposes" (U.S. Federal Election Commission 1986). Six categories of PACs are registered with the FEC: Corporation committees have reported a connection with a corporate entity. This research examines the corporate PAC category.

Nonconnected committees have not reported a connected organization, but rather have identified themselves with a single issue. These committees are sometimes referred to as ideologically based PACs; for example, the National Conservative Political Action Committee is dedicated to the election of conservatives to public office.

Trade/Membership/Health committees have reported a connection with a trade association, membership organization, or health-related organization; for example, National Association of Realtors, National Rifle Association, American Medical Association. 
Labor committees have reported a connection with a labor organization; for example, AFL-CIO.

Corporation without stock committees have reported a connectiọn with a corporation without capital stock; for example, Airplane Owners and Pilots Association.

Cooperative committees have reported a connection with a cooperative; for example, Allied Grape Growers.

As shown in Figure 1, as of December 31, 1989 the largest category of PACs was Corporate (1,796 registered), followed by Nonconnected $(1,060)$, Trade/Membership/Health (777), Labor (349), Corporation Without Stock (137), and Cooperative (59) (U.S. Federal Election Commission 1990).

\section{Election Cycles}

An election cycle is the two-year cycle associated with Congressional elections. The FEC records all PAC financial activity which occurs during each two-year cycle. For example, the election cycle 1977-78 includes all financial activity occurring between January 1, 1977 and December 31, 1978. Most PAC contributions and expenditures filed during this time period would be directed at those Federal candidates running in the November, 1978 general election.

\section{CHAPTER SUMMARY AND THESIS OVERVIEW}

This chapter introduced the research objective, the methodology employed to achieve this objective, the 
significance of the research, and an overview of the terminology which is used throughout the thesis.

The remaining chapters examine the following:

Chapter II reviews the literature bearing on businessgovernment relations and on the two theories to be examined, resource dependence and class cohesion. The former emphasizes research which examines corporate political activities and strategies, while the latter examines research that traces the evolution of resource dependence and class cohesion theories and their linkages to corporate political activity.

Chapter III describes the research design: The research question is identified; the hypotheses to be tested are enumerated; the variables and sampling strategy are explained; and the methodology is discussed.

Chapters IV and V deal with the 1977-78 and 1981-82 election cycles, respectively. The data are presented, the analytical logic is discussed, structural findings are displayed as "maps" of firms that engage in similar PAC behavior, hypotheses are tested with a variety of statistical tests, and conclusions are drawn.

Chapter VI compares the two election cycles. The null hypothesis tested is that there is no significant difference between political behaviors in the 1977-78 and 1981-82 election cycles. 
Chapter VII summarizes the results of this research, its overall conclusions, and its theoretical and managerial implications. Its limitations and some avenues for future research are also presented. 


\section{TABLE I}

THE RESEARCH CONTEXT IN A SYSTEMS PRAMEWORK

Perceptual

Levels

A

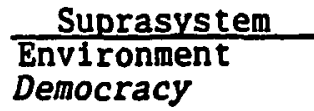

Focal System

Subsystem

B

Unit

Environment

Interest Groups Interest Groups

C

Subunit $\cdot \dot{R}$ Bi.

Butt -Govt. Rel.

Environment

Subunit

Campalgn Finance

Bus-Govt . Rel.

D

Unit

Campaign Fin.

E

Subunit

Policy Shapers

Note: A "System," by definition, incorporates three levels of perception: Environment, unit, and subunit. The unit level of the focal system corresponds to both the subunit level of a "Suprasystem" and the environment level of a "Subsystem." Clarifying the perceptual relationships among the three systems enables the systems practitioner to establish a context, a critical problem-solving step (Lendaris 1986). 


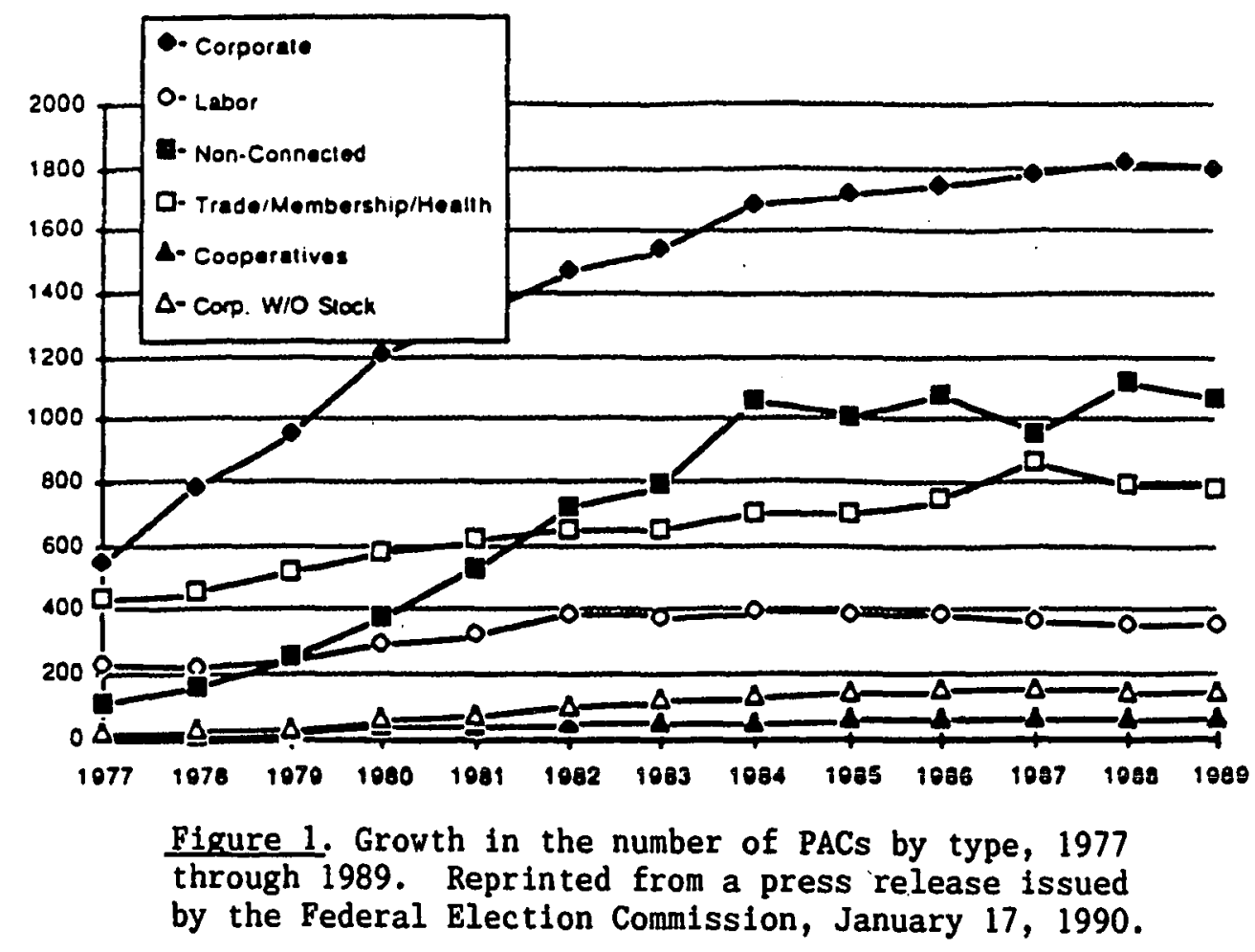




\section{CHAPTER II}

\section{LITERATURE REVIEW}

This chapter begins with a review of five works which are widely recognized as classics in the business-government relations and interest group theory literature. This review is followed by an examination of more current literature, with a special emphasis on research which focuses on corporate political activities, strategies, and influence as well as the legitimacy of business intervention in the public policy process. Finally, resource dependence and class cohesion, the two major theories of intercorporate relations, are discussed.

THE CLASSICS

The five works discussed as classics were released from mid-1930 to the end of the 1960s. These authors examined the business-government-society interface from various perspectives. A recurring theme among these works is power--whether interest groups exert too much power and thus negate the influence of the citizenry on the democratic process; and whether one interest group can tilt the balance of power and thus achieve dominance in the political arena. Linked to the issue of power are questions of oversight-- 
both self-regulation through such mechanisms as overlapping interest group memberships and legislated regulation are addressed. The origins of interest groups and the societal conditions which foster their emergence are also discussed. Finally, the age-old debate between pluralists and power elite theorists is woven through all of these works. The discussion attempts to identify meaningful connections between the works reviewed and three major elements of this research: resource dependence theory, class cohesion theory, and corporate political activity.

\section{E. E. Schattschneider, Politics,} Pressures, and the Tariff

E. E. Schattschneider's 1935 seminal case study in business-government relations can be viewed as a precursor. Resource dependence is foreshadowed in his conclusion that protected industries, reacting to the perceived threat of imports, brought about the 1929-1930 tariff revisions known as the Hawley-Smoot bill. He reported the power of wellorganized manufacturers, who descended on Congress in record numbers and lobbied for favorable tariff legislation under the ideological cloak of nationalism. These so-called "pressure groups" effectively blocked the counter position of less organized and lower status importers whose very existence was threatened by high tariffs.

This meticulously researched analysis depicts a complacent, uncritical Congress which crafted a bill 
attacked by both leading economists and the American Bar Association; yet, it passed with no real political opposition. Schattschneider concluded that it is organized special interests, not the public interest, which determines public policy and therefore "policies can be explained in terms of the processes by which pressures are shaped and modified" (5). He called for rigorous research that can explain, monitor and, perhaps, predict political behavior:

The connection of interest and political behavior, though real, bears close scrutiny. The task is to measure the strength of this drive in politics, to observe its direction and variability, and to note the manner in which it is deflected and controlled (4).

\section{David Truman, The Governmental}

\section{Process}

David Truman's 1951 work builds on Schattschneider's-he employs similar methodology, reaches similar conclusions, and, like schattschneider, foreshadows the pluralistic viewpoint and application of the resource dependence model to the study of corporate political behavior.

He concurs with the need to know more about the relationship between interest groups and government:

Significant amounts of power are wielded in American politics by those formations usually known as "pressure groups" . . . we have had no inclusive working conception of the general role of "pressure groups" or, as I prefer to call them, interest groups (vii).

Even more to the point, Truman's principal objective was to examine interest groups and their role in the formal institutions of government in order to provide an 
adequate basis for evaluating their significance in the American political process (505).

Truman is regarded as an early forerunner of pluralism (Berry 1989,8$)$. He advanced the thesis that political interest groups are not a unique phenomenon, but rather that they are simply a specialized combination of individuals with a common goal and a need to interact with the institution of government (ix). Indeed, he notes that

the persistence and the dispersion of such organizations [political interest groups] indicate rather that we are dealing with a characteristic aspect of our society (11).

Finally, Truman related the origins of groups and their formation rate to environmental conditions, a clear harbinger of resource dependence theory. His disturbance theory traced a cause-and-effect relationship between events which disrupt some societal equilibrium (e.g., the recession of the 1870s) and the consequent formation of offsetting associations (such as the growth of local granges to champion farm interests). Truman posits that the formation rate of interest groups is a product of both the complexity and dynamism of societal, political, and economic conditions. Thus, political interest groups emerge as natural conduits between the individual and the formal institutions and processes of government. He predicted that a just and desirable equilibrious position of the social system results from emergent group pressures. 
Truman held that

two elements in this conception of the political process in the United States . . . are of crucial significance - . multiple or overlapping membership and . . the function of unorganized interests, or potential interest groups (508).

He asserted that multiple group membership creates conflict for individual members which in turn reduces the cohesion in any given group and provides a "restraint upon the activities of organized groups" (510). Further, those who "assert that the organization and activity of powerful interest groups constitute a threat to representative government" (515) are ignoring the impact of counterbalancing groups which will emerge (e.g., potential consumer groups organized to offset excessive tariff proposals).

The advent of corporate PACs, well after Truman's time, introduced a new dimension to his model. To the extent that corporate PACs respond to environmental constraints (resource dependence), and to the extent that these constraints are perceived in similar fashion by managements otherwise independent of one another, corporate PACs will tend to act in rough unison even though there is no planned coalition.

Bauer, Pool and Dexter, American Business and Public Policy

This view of unplanned unity of purpose in PAC activity heightens interest in two of Bauer, Pool and 
Dexter's 1963 positions. First, they regard business as a highly atomistic interest group class with influence only on narrow issues. In the absence of PACs, this view could be contested only with difficulty but, if PACs tend to respond to similar environmental constraints in a similar manner, then business may not be as atomistic as it appears.

Second, Bauer, Pool and Dexter acknowledge that their work in some ways departs from Schattschneider's:

What we actually found, on the contrary, was that the most important part of the legislative decision process was the decision about which decisions to consider. The model of the legislative decision process toward which we inevitably moved . . . took as the relevant criterion for choice the overall needs of his [the legislator's] position, rather than the view on specific policies held by special groups of the public (405).

This conclusion, considering today's reality of mounting campaign costs, might raise two misgivings. Legislators' concerns obviously include reelection and, further, reelection requires money, which PACs can provide.

A related matter is that of overlapping memberships, a condition advanced by Truman as deleterious to cohesiveness among interest groups. In contrast, Theodore Lowi (1964) regards the predicted effects of overlapping memberships as "one of the most significant differences between the pluralists and Bauer, Pool and Dexter" (697). The influential Bauer, Pool and Dexter case study examined the political processes associated with foreign trade legislation during the Eisenhower and Kennedy administrations and found a direct, rather than an inverse, 
relationship between overlapping memberships and cohesion. Contrary to Truman's hypothesis, these authors argued that such overlapping permits the pursuit of more narrow goals by specialized interests within larger associations--goals which might be incompatible with the larger group--thus preserving the cohesion of the larger group.

The authors might have advanced another explanation for the direct relationship between overlapping memberships and cohesion. Class cohesion theory would suggest that multiple membership is a vital network, is to be expected and, indeed, is fundamental to cohesion.

Mancur olson. The Logic of Collective Action

In 1965, two years after Bauer, Pool and Dexter, Mancur olson added another dimension to group theory, one which is marked by its logic and simplicity. This important book has provided researchers a theory by which certain group behavior can be explained and predicted. Olson outlines his thesis as follows:

It is often taken for granted, at least where economic objectives are involved, that groups of individuals with common interests usually attempt to further those common interests... [this view] presumably is based upon the assumption that the individuals in groups act out of self-interests -. . but it is not in fact true that the idea that groups will act in their self-interest follow logically from the premise of rational and selfinterested behavior. . . indeed, unless the number of individuals in a group is quite small, or unless there is coercion or some other special device to make individuals act in their common interest, 
rational, self-interested individuals will not act to achieve their common or group interests [emphasis in original] $(1-2)$.

Mancur olson particularly questioned some of Truman's earlier conclusions regarding the inherent stabilizing attributes of interest group behavior. He doubted Truman's assertion that "'suffering,' 'dislocation,' and 'disturbance' will almost inevitably result in organized political pressure [emphasis in original]" (Olson 1965, 123). Olson notes that there have existed many disadvantaged groups who were subjected to serious disturbance yet did not organize (e.g., labor during the post-Civil War or the depression era).

Olson also questions overlapping membership as another latent restraint on interest group power. He views with skepticism Truman's contention that

tariff seeking manufacturers were also consumers, churchmen, and so on . . . [therefore] if the manufacturers' association went too far it would alienate some of its own members (Olson 1965, 124). This skepticism is entirely consistent with class cohesion theory which would suggest that the players' roles outside of the manufacturers' association are a mechanism by which class interests are communicated, understood, and supported. Finally, Olson also objected to Truman's negativity toward regulatory or constitutional reform proposals. Truman (1951) questioned the effectiveness of lobbying regulations referring to them as "minor weapons . . their 
political significance.. . [being] probably far less than the investigations that usually father them" (528); rather, "Guardianship will emerge out of the affiliations of the guardians" (535). Conversely, olson did not believe that an equilibrium created by overlapping memberships and group pressures alone would ensure a fair and just social system:

It does not follow that the results of pressuregroup activity would be harmless, much less desirable, even if the balance of power equilibrium resulting from the multiplicity of pressure groups kept any one pressure group from getting out of line (124).

Edwin Epstein, The Corporation in American Politics

Edwin Epstein's 1969 treatment of interest group regulatory reform falls somewhere in the middle of the Truman-oison continuum. He agrees with Truman's contention that much existing legislation is ineffective, but Epstein supports olson when he notes that some monitoring of all interest (not just corporate and labor) group activity is necessary $(304-314)$.

The Corporation in American Politics (1969) is recognized as a "landmark of scholarship on corporate political activity" (Mitnick 1989, 1). In it Epstein, a proponent of pluralism, argues that corporate political involvement is both inevitable and legitimate. The interdependence between business and government supports both an inevitability and a legitimacy thesis: 
In the pages that follow, we shall. . advance the thesis that corporations, just like other collective social interests, have legitimate political concerns, which are the consequences of organization goals and which therefore make political involvement inevitable (16).

A slightly different, but supportive, perspective is afforded by resource dependence theory along with the advent of corporate PACs. It can be argued that PAC activity arises from environmental constraints as well as organizational goals. Just as individual persons are, corporations and their PACs must be permitted selfpreserving reactions to outside pressures. Thus, patterns of corporate PAC activity are both legitimate, as natural reactions to external conditions, and inevitable, since the entity is not expected to sacrifice self-interest in the face of environmental constraints. Finally, inevitability is reinforced by the ease with which PAC activity can be undertaken.

Epstein contends that collective political action is a time-honored tradition which enables individuals to advance their special interests. Like Truman, he defends the role of group versus individual political activity in a democratic form of government. He credits Truman, among others, as a group theorist who regarded the "interaction of associational groupings as constituting the warp and woof of American politics" (269) and he challenges those, like R. M. MacIver, who predicted that the result of such interaction 
will be a public which is an "amorphous residuum that lies outside the contending pressure groups". (270).

Epstein dismisses the power elite model which posits that economic elites act cohesively on public policy issues. He cites the Bauer, Pool and Dexter study as evidence that intracorporate and intercorporate conflict, as well as a large corporation's sensitivity to its public image, curbs the potential political clout of the business community $(172,225,239)$. One might add, given the likelihood of unplanned unity, that PACs' reacting jointly to environmental constraints is a more parsimonious explanation than the power elite model.

CORPORATE POLITICAL ACTIVITY, CONTEMPORARY RESEARCH

In 1980 Epstein observed "Research regarding the political activities of American business is a backwater of intellectual effort" (1). He urged his colleagues to "leave the side-lines [sic] and to enter with adequate numbers and serious commitment the research arena on business and politics" (48). While the ensuing decade might not have yielded the "brave new theoretical frameworks and dazzling empirical breakthroughs" (1) awaited by Epstein, there have been significant contributions to this increasingly important and complex field.

The majority of the following work was published in the 1980s; two articles date back to the late 1970s; and 
Epstein's 1969 book is revisited. The section is divided into three topic areas: Corporate Political Activities and Strategy; The Legitimacy Issue; and The Influence Issue. As in the preceding section, an effort has been made to connect the works reviewed with my study's major elements.

\section{Corporate Political Activities} and strategy

Keim and Zeithaml (1986) propose a theoretical basis for determining effective corporate political strategies. Their "exchange model of legislative decision making" (828) and "typology of legislative decision situations" (831) are rooted in the assumption that reelection is a legislator's primary goal. Consequently, the corporate strategist should consider the majority voting constituents' predisposition toward an issue when an elected representative is asked for support. The authors recommend an analysis of three contingency factors in determining the most effective corporate political strategy: (1) the salience of an issue to voters; (2) the level of voter consensus or conflict; and (3) the corporate position on a specific issue vis-a-vis the voters' position.

This argument seems to miss an important connection between the legislator's primary goal, reelection, and PACs. While voters' predisposition toward an issue may be contrary to corporate interests and must be taken into account, the extent to which a legislator defers to that predisposition 
may be restrained by practical considerations imposed by the dollar cost of achieving the primary goal, reelection. If so, then PACs would appear to be useful as conduits of campaign financing. Further, money contributed to a legislator's campaign is unlikely to be wasted regardless of floor votes; it is likely to have a residual effect that can be brought into play later.

Maitland (1986) maintains that managements need to look beyond their firms' individual strategic imperatives. The atomistic nature of the business community prompts firms to adopt political strategies without regard for their collective interests. This "reciprocal noninterference" (70) dilutes business political resources. He reflects on Mancur olson's free rider dilemma when he suggests that a lobbying tithe be paid to encompassing organizations, such as the United States Chamber of Commerce, so that a coherent, broadly beneficial political agenda can be advanced.

Like Maitland, Ullmann (1985) notes that individual firms may adopt the "free rider" (143) rationale since many of the benefits derived from political strategies display collective-good properties. Also, as with Maitland, he recommends a pooling of political resources, but Ullmann urges coalition building rather than reliance on encompassing organizations. 
Ullmann examines political strategies within the context of the regulatory process. Corporate strategists may attempt to influence a regulation at any of its five life cycle stages: (1) Formation; (2) Formulation; (3) Implementation; (4) Administration; (5) Modification. Ullmann posits that the collective benefits resulting from corporate intervention in the regulatory process will be weakest in the later stages and strongest in the earlier stages; therefore, firms should pursue collective political strategies in the early stages of regulatory reform, and individual political strategies in the later stages. Ullmann's life cycle paradigm acknowledges the strategic role of PACs. "Not only the content of the life cycle but also its process can be influenced" (146), specifically by impacting a critical component of the overall regulatory process; that is, the composition of legislatures through political action committee campaign contributions.

The case study, as employed by schattschneider (1935) and Bauer, Pool and Dexter (1963), surfaces again in the work of Yoffie and Bergenstein (1985). They use two case studies to illustrate their proposition that political strategic planning, rather than a muddling-through approach, is necessary if business is to be effective in its interactions with government. They further contend that top level management involvement is crucial in both the planning 
and implementation stages (see also Post et al. 1983; Useem 1985; Miles 1987).

These authors acknowledge that the so-called ad hoc approach to corporate political activities was, at one time, adequate. The role of the corporate lobbyist, however, has undergone profound change. Whereas the corporate D.C. representatives of the 1950 s concentrated on government sales and marketing, today's Washington office is charged with the more political objective of securing access to key decision makers so that public policy issues of interest to the firm can be influenced.

Yoffie and Bergenstein's conceptual framework for political strategic planning is similar to formats recommended for market-oriented strategic planning. It stresses political goal definition, the integration of corporate goals with political goals, and the development of policies designed to accomplish these goals (see also Fischer 1983 for a similar conceptualization). Only then should tactics (PACs, lobbying, constituency building, etc.) be evaluated and implemented.

Perhaps the parallel with market-oriented strategic planning should be carried further. First, strategic management in general is under serious attack by both popular and scholarly management writers. Second, the proliferation of strategic models confuses the issue to the extent that there is some uncertainty as to what exactly is 
meant by strategy (Gilbert et al. 1988, 1-3). Finally, at least one eminent scholar suggests that strategies emerge from day-to-day activities and are crafted, much as an artist's work evolves, rather than being formulated by a group of all-knowing executives (Mintzberg 1987, 66-77). Once again, PACs appear to augment this model. If PAC activity is sensitive to the corporation's environment, and since it is simple and easy to implement--involving as it does relatively low risk decisions--it does not seem to require a strategic framework to be effective but certainly can be incorporated into one. This tactical flexibility, coupled with strategic usefulness, answers the critics who claim that managers spend too much time planning and not enough implementing, as well as those who claim to be confused about what strategy is. Finally, as noted earlier, PAC activity can be a learning process, entirely in line with Mintzberg's (1987) concept of emergent strategy. Another consideration has to do with the role of strategy and tactics. PAC activity is, very likely, best considered tactical. Tactics, in contrast to strategy, cannot rise above the here and now, tend to be situationspecific and, moreover, are chosen from a limited catalogue of options--a catalogue well known and available to all players. Significant proportions of PAC giving simply conform to expectations, e.g., buying tickets to a fund raiser is a minor expenditure, yet the penalty for not doing 
so can be severe. This is somewhat analogous to a salesperson's picking up the lunch tab.

Considered in this light, it becomes clear that PAC activity does not necessarily fall under the strategic rubric, but may do so. Certainly, as all tactics should, PAC activity should support strategy. Just as a marketoriented strategist may mandate a zero defects policy in order to implement a customer retention strategy, the politically-oriented strategist may attempt to rally stakeholders to effect a regulatory change. In the first instance, the strategist does not meddle in the details of statistical cuality control and, in the second, the strategist does not meddle in the details of PAC activity aimed at maintaining access to key political figures. These are tactical matters and, while important, can be entrusted to tacticians.

Finally, there are the questions of commitment and vision. Advocacy advertising, coalition building, constituency building, and lobbying--perhaps in that order-are visible to the world and expensive in money and executive energies. Entering into such visible, expensive strategies demands commitment, vision and careful consideration of corporate goals in the political arena. PAC activity, on the other hand, does not cast a long shadow. 
Keim and Baysinger (1988) employ a principal-agent model to "specify more clearly the conditions under which political activity of different types and levels produce (or fail to produce) different kinds of effects" (166). Two conditions are considered as the authors evaluate the potential effectiveness of various political activities: (1) the strength of opposing forces, and (2) the nature of the political objective. They contend that lobbying and PAC activities are easily and readily imitated by competing interest groups. Therefore, their use should be restricted to issues which generate little or poorly organized opposition, or to strategies aimed at the maintenance of a status quo objective. Alternatively, influence techniques such as advocacy advertising or constituency building of stakeholders should be activated when vigorous opposition is anticipated or when corporate political strategists are attempting to change the status quo.

This study supports an earlier Keim, zeithaml and Baysinger paper (1984) in which constituency building rather than PAC activity is predicted to become the dominant influence strategy of the 1980s. In a concurrent paper, Baysinger (1984) provides a rationale for this prediction. He contends that U. S. firms' increased use of constituency building and grass roots lobbying reflects a new corporate political objective, domain maintenance, defined as protecting managerial autonomy. 
Baysinger believes that the emergence of domain maintenance as a political objective is a corporate reaction to the social legislation explosion of the 1970s. He notes that, prior to the emphasis on protecting managerial autonomy created by the new regulatory environment, managements sought to achieve one of two traditional political objectives: (1) domain management, the pursuit of special favors from government; and (2) domain defense, a managerial response to government challenges on the corporation's purposes, the tobacco industry being the most visible example.

Baysinger concludes with a discussion on the legitimacy of corporate political activities. He contends that while domain management is at best a questionable business objective, and the legitimacy of domain defense is highly situation-specific, domain maintenance objectives are legitimate to the extent that some social legislation may be illegitimate.

Some very interesting questions emerge from this work. Most certainly, PAC activity is easily imitated, perhaps a matter of considerable frustration for the first PAC on the scene as its influence is diluted. Nevertheless, emulation may be the only way to stay in the race once the process begins. A corporation's standing aloof from PAC activity may, in many circumstances, be unrealistic--especially in the face of strong opposing forces. 
Even the most dedicated strategist recognizes that (1) the enterprise must function from day to day, (2) not all issues are major ones and (3) strategies must be implemented. Therefore, lobbying and PAC giving--the tactics that make strategies operable--are not likely to diminish significantly unless legally compelled to do so. Domain maintenance seems to speak for, rather than against, PAC activity as an ongoing, major element of corporate political activity. The very word maintenance connotes continuity, the sort of continuity achievable through regular contact with key figures in the political scene, whether in office or hoping to be. This is the sort of continuity that comes from well established, favorably regarded PACs as well as coalitions such as the United States Chamber of Commerce.

Achieving legitimacy also seems to speak for PACs. As argued earlier, to the extent that PAC activity responds to environmental constraints it is likely to be regarded as natural and, therefore, legitimate.

\section{The Legitimacy Issue}

Suggesting that PAC activity is nothing more odious than straightforward reaction to environmental constraints may seem imprudent in light of tine savings and loan scandals which invoived huge campaign contributions. on the other hand, it would be imprudent to suggest that PAC activity, alone of all political activity available to corporations, 
is inherently heinous. It is reasonable to suggest that legitimate conduct is seldom automatic in human endeavors; rather, it generally reguires careful stewardship. This theme runs through the literature on legitimacy. "Legitimacy: A Critical Issue," the title of chapter nine in Epstein's Corporation in American Politics (1969), establishes his concern for the legitimacy question. Epstein effectively argues from two perspectives that business has a right, even an obligation, to involve itself in the public policy process. From the internal perspective, management possesses the legitimate authority to involve the corporation in politics; from the external perspective, the corporation as one of many special interest groups is entitled to compete in the political arena. Epstein cautions, however, that all political participants, including business, should be subject to public scrutiny and review. He poses a fundamental question which he exhorts scholars to consider continuously: "What manner and what scope of corporate political activity are acceptable in a pluralistic democracy?" (286).

The legitimacy of corporate political activity was considered by Brenner (1979) in a study which analyzed 1978 survey results of executive and consumer attitudes toward selected corporate political activity issues, and then compared these responses to a similar 1968 survey. Two trends identified by the author--business's improved skill 
in corporate political activities and society's heightened disapproval of same--is reflected in the differing legitimacy views held by each sector.

Perhaps the most significant finding, the single result which business managers should not overlook, is that business and society have different views of corporate political activity. The former group believes it is necessary and proper for its views to be effectively and forcefully supported in the governmental process. The public seems less sure of and certainly less comfortable with corporate political activity (162).

Brenner notes that while the 1978 business sector appeared more savvy and able regarding political issues when compared to the 1968 sample, a concomitant increase in political influence did not ensue. He cautions that if managements pursue self-interest goals with no regard for the public interest, then business will "likely [become] an unwelcome participant in the nation's political processes, restricted from involvement in them" (163).

Resource dependence theory suggests at least a partial scenario. As public condemnation of corporate political activity has grown, it has become less an annoyance and more an environmental constraint. To the extent that corporate political activity has begun to factor real or potential public censure into the equation, one should begin to detect signs of intensified legitimacy-seeking such as expanded advocacy advertising; coalitions with highly visible, benign entities such as civil rights groups; compromises with 
traditional opponents such as environmentalists; and constituency building among corporate stakeholders.

Sethi (1982) agrees with Brenner's assessment when he contends that

the paramount issue [in corporate political involvement debates] is that of legitimacy or societal acceptance of corporate political action and their underlying motives (32).

Like Epstein, Sethi believes that our pluralistic society demands corporate political participation which "should ideally be developed in terms of strategic choices to meet carefully defined policy objectives" (33). Further, these political objectives and strategies should "embody a clear notion of the public interest" (34).

Sethi's conceptual model describes three modes of corporate behavior: defensive, accommodative and positive activism. He characterizes each mode's external and internal environmental conditions, and then recommends the political strategy most appropriate for varying contingencies.

Clearly, Sethi's position, along with those of Epstein and Brenner, reflects resource dependence. None of these scholars argues against the view that political behavior results from environmental constraints; rather, they argue that dealing with public opinion is a high priority action and, in several instances, recommend strategies. 
The Influence Issue

In 1977 Salamon and Siegfried tested their hypothesis that corporate influence on American politics and corporate economic power are positively related. Economic power was measured by firm size, industry size, market concentration within the industry, profit rate, and degree of geographical dispersion.

only the firm size variable supported their hypothesis; all other economic power variables correlated negatively, albeit weakly, with corporate political influence. These authors also draw on Olson's thesis to explain their results. They note:

To the extent that political power is reflected in such actual policy outcomes we can therefore say that larger firm size does indeed seem to yield greater political power. Also interesting are the findings suggesting that larger industries (as opposed to larger firms) are less successful politically, which supports the "free rider" hypothesis advanced by Mancur olson [see Olson, 1965], since larger industries in general have more firms than smaller industries. In addition, we found evidence that industries which are most visible and most fearful of government intervention because of their attractive (i.e. concentrated) market structure or profitability are more inclined to avoid (or are less successful at mounting) political influence efforts aimed at reducing their tax burdens (1042).

A major finding in Brenner's 1980 in-depth case study of twenty-nine firms, which examined how organizational and managerial factors were associated with political influence, can be contrasted with the Salamon and siegfried results. Brenner's (1980) dependency hypothesis was formulated with 
an important concept introduced by Bauer, Pool and Dexter (1963), the concept of self interest:

The concept of self-interest as defined in the Bauer, et al. research is comparable with dependency in this study. While self-interest was the most natural explanation for businessmen's communications with Congress over the tariff, dependency plays that role in the case of time-sharing firms (210).

Based on associations revealed by linkage analysis, Brenner concludes that the extent of corporate political activity cannot be fully described by economic determinism since the critical variable, dependency, was related to smaller firms which are less economically powerful and more vulnerable to environmental or governmental action. Brenner's results contrast, however, with Bauer, Pool and Dexter and salamon and siegfried regarding the firm size relationship. He notes that these conflicting results are owing to the strength of the dependency variable in his sample.

Edwin Epstein (1984) also considers the firm size and dependency variables in his article which examined the political behavior of corporate PACs and documented their growth in numbers and size. Epstein determined that both firm size and the extent of economic dependence on government decisions influences an individual firm's PAC (or nonPAC) activity. He acknowledges that relating PAC activity and the actual influence which they exert in governmental and electoral activities is a far more difficult proposition, yet scholars must come to grips with 
the "crucial issue . . the implication of corporate PAC activity for the political process and American democracy" $(474)$.

Epstein poses the question: "As a consequence of their PAC operations, [do] corporations as an identifiable constituency have an excessive impact on the political process" (483), and then concludes:

Although it is not possible to demonstrate the effect of specific PAC donations on particular public policy outcomes, it is not unreasonable to assert that the PAC phenomenon has contributed at the macro level to increasing the influence of the business community in the overall public policy process during the past several year... This does not mean, of course, that specific policy outcomes confcrm necessarily to the wishes of particular business interests or that the business community, perforce, gets its way in all, or even most cases. Rather, it suggests that, on the whole, critical issues of public policy are resolved in ways considered to be appropriate by mainstream business leadership (485-486).

Conclusion

one must conclude from a review of the managementrelated literature on business-government relations that most scholars accept the resource dependence model. Class cohesion theory occupies an analogous position in Sociology and, to a lesser extent, Political science. The chapter continues with an examination of both theories in the context of intercorporate relations. 
INTERCORPORATE RELATIONS

\section{The Evolution}

organization theory, in its ongoing attempt to explain organization behavior, has evolved from a focus on the firm's internal environment (Berle and Means 1932) to a recognition that the exigencies of the external environment dictate, at the very least, contingency planning (Lawrence and Lorsch 1967). Theories that have only recently entered the management literature, such as population ecology, suggest that corporate executives are even constrained in contingency planning; rather, they react to environmental forces wèll beyond their control (Aldrich 1979). Thus, organization behavior is shaped in a manner analogous to the evolution of living organisms.

Systems theorists' focus was, and is, largely on organizations' exchange relationships with external environments. Thompson's (1967) seminal work emphasized the open systems nature of firms--the environment is the source of inputs and the sink for outputs. Katz and Kahn (1978) noted the negative entropic nature of organizations suggesting that they, like any complex physical system, must import and store more energy from the environment than they expend--otherwise, they cannot avoid the universal phenomena of disintegration and death (McGowan 1980, 86). The premise that corporate behavior results from exchanges between firm and environment has two pivotal 
implications for organization theory. First, interorganizational power is likely to result from these system transactions (Pfeffer 1987, 26). Second, the fundamental unit of analysis becomes the relations among organizations-individual firm behavior is examined within this framework (Mizruchi and Schwartz 1987, i).

A structural approach to the study of business, which focuses on intercorporate relations, embraces these two pivotal implications. Resource dependence theory and class cohesion theory are the two major structural perspectives of intercorporate relations. Both attempt to explain organization behavior by examining the underlying basis of intercorporate relations; each represents an opposing view on the extent of cohesion within the business community.

\section{Resource Dependence Theory}

Resource dependence theory contends that organizational behavior is determined by economic and political constraints imposed by interdependent stakeholders operating in an uncertain environment. ${ }^{1}$ First proposed in the 1970s (Aldrich and Pfeffer 1976; Pfeffer and Salancik 1978), its five basic tenets are (Pfeffer 1987, 26-27): 1. Organizational behavior can best be understood by examining intercorporate relations; this approach dictates

\footnotetext{
'stakeholders capable of constraining a firm and affecting its behavior include labor, suppliers, financiers, customers, stockholders, and government regulators (Pfeffer $1987,35)$.
} 
that systems of organizations rather than individual firms be the fundamental unit of analysis.

2. Environmental constraints and interdependencies between a focal corporation and major stakeholders encroach upon management's autonomy.

3. This interdependent and labile environment results in an unpredictable future for the focal organization.

4. To enhance survival and future success, the executive team will proactively attempt to manage the external environment through cooptation, compromise, or persuasion so as to ensure a continuous resource flow and to reduce dependencies. Such actions result in a constantly changing pattern of intercorporate relationships.

5. Both interorganizational and intraorganizational power are products of organization interdependence; powerful organizations, wielding economic and/or political leverage, can demand compliant behavior from less powerful, dependent organizations.

Accordingly, managements proactively employ economic and political strategies to manage their environment, i.e., to reduce uncertainty and enhance the probability of achieving corporate objectives. Vertical integration to lock in raw material supplies exemplifies economic strategy. PAC campaign contributions, directed at government as an interdependert stakeholder wielding regulatory power, are an 
example of a political strategy designed to reduce political uncertainty.

Various theorists have examined the impact of regulatory power on corporate political behavior. Handler and Mulkern (1982) maintain

that there is a variety of regulatory environments within which corporations interact with government, and that these differing environments constitute the most powerful influence in generating PAC strategies (29).

This pcsition is supported by Burris (1987) whose results highlight the degree to which corporate political behavior is conditioned by the fiscal and regulatory relationship between corporations and the state (741).

Finally, Neustadtl and Clawson's (1988) network analysis revealed a large group of corporations united by shared conservative beliefs and a similar regulatory environment.

Resource dependence theory suggests, then, that corporations (1) facing similar constraints (2) imposed by similar stakeholders will (3) employ similar strategies. 2

2This prediction does not necessarily contradict research which demonstrates that firms within the same industry exhibit different external affairs strategies (see Brenner 1980; Miles 1987). As Pfeffer (1987) notes, resource dependence predictions are not "simple or unidimensional" (35). The theory acknowledges that firms, even within the same industry, can have varying sources and intensity levels of constraint which could override a system-wide (e.g., regulatory environment) constraint. PAC statistics, however, have revealed a correlation between ideological/pragmatic political strategies and social/economic regulatory environments (Handler and Mulkern $1982,29)$. 
The resource dependence prediction is that firms equally constrained by the same [emphasis in original] external agents [e.g. government regulators] should operate more or less similarly, and, indeed, engage in similar patterns of intercorporate relations (Pfeffer 1987, 35).

Finally, resource dependence theory suggests that political support activities are not coordinated and that similarities are spontaneous. A continual jockeying for interorganizational power precludes deliberate, uniform corporate political strategies (Glasberg and Schwartz 1983, 314). Madisonian pluralism prevails in the political arena much as the invisible hand reigns in the marketplace.

\section{Class Cohesion Theory}

A 1939 report of the United States National Resources Committee first suggested that the corporate class had both the motivation and means to unite on economic, social, and political issues (Glasberg and Schwartz 1983, 314).

Class cohesion theory thus challenged the managerialist position advanced by Berle and Means (1932). In the managerialist model, corporate managements pursue job security by avoiding risk, preferring profit satisficing to profit maximizing.

Rather than managerial caution as a restraint on untrammeled competition, class cohesion theory points to a coalition of the power elite as a restraining force. Members of the elite coalesce to maintain their quality of life and bequeath accompanying perquisites to upcoming 
generations. The resulting environment is one in which market territories are staked out and respected; injurious price competition is avoided; and industry profits are maximized (Glasberg and Schwartz 1983, 315). Incentives to compete individually are replaced with incentives to unite. Various means exist within the corporate class to define, transmit, and inculcate a set of common values and goals. Upper class socialization, via selected universities and social clubs, prepare initiates for power posts in corporations, policy planning organizations, interlocking directorates and, not incidentally, government itself. Domhoff $(1970,1974)$ maps school ties and membership in exclusive social clubs and business associations as the basis for a powerful communication network which helps to ensure a commonality of classwide interests. Useem (1980) notes: "If exclusive social clubs are a source of social cohesion, major business policy associations are the crucible of political cohesion" (57). Useem (1982) later notes that the

unplanned consequence of . . . interlocking directorates is the formation of a communication network that inevitably helps a segment of the corporate elite identify its members' shared political interests (211).

While geographic proximity is not a sine qua non of the corporate elite communication network, class cohesion theorists generally regard it as a variable which should be included in studies of class cohesion (Mizruchi 1989, 409). 
The geographic proximity of headquarters locations was one of the strongest predictors of similar political behavior between firm dyads in the Mizruchi (1989) study. Further, the Yankee-Cowboy theory, which hypothesizes political differences within the corporate elite along regional lines --an old money liberalism versus a new money conservatism division--was a primary determinant of political behavior in the Burris (1987) study.

Even though class cohesion theorists agree that this corporate elite will exhibit similar political behavior so as "to ensure conditions favorable to continued growth of company profits" (Useem 1982, 200), there is some disagreement as to how classwide interests translate into political strategy. A liberal-conservative spectrum is useful in illustrating this disagreement.

At the liberal end of the spectrum, an inner circle of corporate elite acknowledges what it perceives as, perhaps, an unpleasant reality. Useem (1984) explains that "welfare, labor, and other forms of government-managed reforms can be costly to individual firms," but that such reforms maintain a societal stability and thus "the entire business community and the future of the private economy will best prosper if it assumes a posture of compromise" (114).

At the conservative end of the spectrum, perceived class interests will dictate an ideological strategy. PACs with this orientation are prepared to risk the displeasure of powerful incumbents, even if this hurts 
their own company . . . in order to change the character of Congress (Clawson, Neustadtl and Bearden 1986, 798).

Class cohesion theorists postulate, regardless of the political strategy pursued, that the cohesiveness of this corporate elite, whose economic resources exceed many nations' GNPs, results in political clout which reduces pluralism's chances drastically.

\section{A Synthesis}

Both resource dependence and class cohesion theorists acknowledge the reality of intercorporate relations that is not entirely in accord with their core theories. Further, both sets of theorists point to a need for research that could reconcile this divergence.

Regarding the class cohesion theory, Mizruchi (1989) submits:

Elites in advanced capitalist societies cannot be said in the abstract to be either unified or fragmented. There are times in which elites act in a unified manner and times in which they do not. What is needed, therefore, is a study of the conditions [emphasis in original] under which elites act in a unified manner; in other words, the factors that determine whether elites will cohere on a particular issue or series of issues (402).

Regarding resource dependence theory, Pfeffer (1987) argues:

It is possible that organizations have, at once, both narrowly parochial interests and broader interests in economic stability and macroeconomic policies. . To predict the extent of coordinated activity, this [structural] approach would argue that examining the patterns and correspondence of resource interdependencies and market constraints would permit beginning to answer the question of 
under what circumstances coordinated action is likely to occur as opposed to witnessing the pursuit of more parochial objectives (50).

The prospect that corporate political activity could be understood by combining aspects of resource dependence and class cohesion theories is especially attractive in light of some plausible combinations. My research design does not preclude finding a cluster of firms that could be explained by both theories. For example, my scaling results could identify a cluster of firms with characteristics associated with both resource dependence (e.g., a common regulatory environment) and class cohesion (e.g., high incidence of interlocking directorates).

Consider a second example in which a cluster of firms, displaying similar political behavior, is found to be linked to class cohesion determiners but not by the resource dependence determiners, economic and social regulatory environments. My research tests the effect of a significant macroenvironmental shift in white House philosophy regarding business and its regulation. If the cluster's behavior shifts as well, then it cculd be defined as resource dependent while the cluster itself could be described as class cohesive. That is, while linked to a class network, these firms would be responding to a perceived environmental constraint, again at the macro level. 
Current Research

Some recent empirical work lays a foundation for my research. Four recent studies of the business community's political integration have drawn on elements of resource dependence and class cohesion theory and utilized PAC contributions data as a measure of corporate political activity. The following section discusses the data, measures, methodologies and results of these four studies, and explains how my research was designed to expand upon them. Key features of this previous work and its relationship to mine are summarized in Table II.

Mizruchi and Koenig (1986) tested the pluralist argument that "ties of trade will promote opposing or different political positions" (484), such ties measured by volume of transactions at the industry level ${ }^{1}$ and the class argument that "mechanisms exist that succeed in fostering consensus within the business community" (482), such mechanisms operationalized as economic leverage and the extent of interlocking directorates between industries. ${ }^{2}$

${ }^{1}$ A later study (Mizruchi 1989) questioned the use of volume of transactions in the Mizruchi and Koenig (1986) model. Two problems were cited: (1) interdependent industries are not necessarily politically opposed (e.g., automakers and auto parts suppliers) and (2) results which revealed a strong, opposite effect between constraint and volume of transactions may have been due to collinearity.

${ }^{2}$ Economic leverage data were drawn from a 1967 study which computed a constraint measure based on the "dependence of industry $i$ on sales and purchases from industry $j$, weighted by the concentration of industry $j "$ (Mizruchi and Koenig 1986, 485). 
Political consensus was determined by the similarity of Congressional candidates supported among fourteen industries. For each industry, the two largest firms' PAC contributions were pooled; a similarity measure then determined the extent to which each pair of industries contributed to the same candidates in the 1980 elections. This similarity measure was regressed onto three variables associated with either the pluralist or class theory position on business political integration. Twenty-three percent of the variation in similar political behavior was explained by this regression model. Further, the model revealed a negative relationship between similar political behavior and both volume of transactions (consistent with pluralist model) and direct interlocks (inconsistent with class model); economic leverage between industries was positively related to the similarity measure (consistent with class model).

The authors concluded that the lack of political consensus associated with increased levels of transactions is consistent with the pluralist argument since it implies that divergent economic interests result in political disunity. Further, since class theorists posit that board interlocks mediate political disputes and thus are directly related to political unity, these results disaffirm the class cohesion position. 
The results are mixed, however. Class theorists also argue that a direct relationship exists between political unity and economic leverage citing the capability of the latter to enforce political consensus within the business community. Mizruchi and Koenig conclude that the positive effects of economic leverage indicate that this is an important source of class cohesion within the business community. These authors called for subsequent researchers to examine other sources of class cohesion, specifically, social ties and memberships in business associations, two class cohesion measures employed in my research.

Burris (1987) evaluated six theories, all purporting to explain the political partisanship of American business. He examined the PAC contributions of 443 corporations to Congressional candidates in the 1982 election. Three measures of political partisanship--the percentage of total Congressional contributions to incumbents, Republicans, and New Right candidates--were regressed onto predictor variables associated with the six theories.

Burris found that two theories were supported by his data: the Yankee-Cowboy theory of regional political differences and the regulatory environment theory which posits that government regulation is a primary determinant of corporate political activity. ${ }^{3}$ His twelve-variable

${ }^{3}$ The four disconfirmed theories--the core-periphery, the inner-circle, the managerialist, and the domesticmultinational theories--hypothesized that some dominant 
model, however, explained just twenty-two percent of the variance in business partisanship, thus it can be faulted. Yet, this work provides a useful step in linking theory with empirical research.

Neustadtl and Clawson (1988) employed clique analysis to address:

One of the central theoretical issues in analyses of business political behavior. . . the degree to which business is able to unify and act together as an effective political block (172).

The PAC contributions of 230 corporations made during the 1980 elections served as Neustadtl and Clawson's measure of political activity. They derived a political consensus measure from the similarity of candidates supported between pairs of firms. Their findings revealed a large clique linked by a conservative ideology.

The authors concluded that the strength and size of the conservative clique evidenced stronger support for the social class theory rather than pluralism. One wonders, however, if this clique might not have been reacting to regulatory environment constraints. Economically regulated firms were noticeably absent from the conservative clique, and thus were exhibiting less conservative political activity. Such behavior is consistent with the regulatory environment theory of business partisanship and, by extension, resource dependence. insure long-term stability of the economic system. 
Neustadtl and Clawson call for future research which will consider corporate political groupings over time and also for analysis on corporate political strategies observed after the "critical election" (185) of 1980. My design addresses both of these recommended research directions.

Finally, Mizruchi's (1989) research was the primary catalyst for my study. He employed variables drawn from the resource dependence and class cohesion models to examine the sources of political similarities among fifty-seven large corporations. Similarity, his dependent variable, was defined as the extent to which pairs of corporate PACs contributed to the same Congressional candidates during the 1980 elections. This measure was regressed onto eight variables associated with either resource dependence or class cohesion theory. Seventy-one percent of the variation in similar political behavior was explained by this regression model. The two strongest predictors directly related to similar political behavior were whether firms' headquarters were located in the same state and whether firms were members of the same primary industry. Also significantly related to similar political behavior were indirect interlocks and common stockholdings with financial institutions, and market constraint.

Mizruchi concluded that both organizational and social network factors influenced political behavior similarity. He notes, however, that, regardless of the measures employed in 
studies of corporate political behavior, future "analysis must move to the triadic, cluster, and system-wide levels" (420). My research design, enriched by Mizruchi's and other scholars' work, moves the study of corporate political behavior to the system level.

\section{Conclusion}

The availability in recent years of reliable data on campaign contributions of political action committees has spurred empirical research on the sources of business political convergence. Yet, despite this, no consensus has emerged as to the underlying rationale which drives business participation in the U.S. public policy process.

Prior studies have examined dyadic relations between firms or industries as a measure of business political consensus. This study subjects dyadic measures to multidimensional scaling so that the intercorporate structure hidden in the data stands to be revealed.

A second characteristic of previous studies is their emphasis on the relationship between similar political behavior and organizational and social network variables (such as economic interdependence, interlocking directorates, and geographic proximity of headquarters locations) which are operationalized as mechanisms by which the corporate community can prevent, mediate, and/or resolve intercorporate conflict and thus advance a classwide political agenda. This study, building on Pfeffer and 
Salancik's (1978) resource dependence proposition which associates government regulation and corporate campaign contributions, incorporates regulatory environment as a predictor of similar political behavior (214).

Another departure is the use of data associated with two off-year Congressional elections. Prior work tended to focus on the 1980 elections since they marked a watershed of sorts in national politics, and because corporate PAC involvement was cited as influential in the outcomes (Ashford 1986). This work examines corporate political activity in 1982 which was conducted in the context of a Republican-controlled senate and a House seating thirtythree new Republican members. A further unique feature of this study is the corollary analysis of the 1978 elections which permitted a comparison of corporate political activity between two disparate white House administrations.

\section{CHAPTER SUMMARY}

The objective of this thesis was to improve our understanding of business-government relations by examining corporate political activity within the context of resource dependence and class cohesion theories. Consequently, this literature review first considered a selection of foundation works, classics from the social sciences, upon which business-government relations theory is built. This was followed by a review of some contemporary research which has 
studied corporate political activity, its influence, and its place in a democratic society. The intercorporate relations literature and current empirical research which links resource dependence and class cohesion theories to corporate political activities was reviewed. In conclusion, it was shown how my research design expands on this existing body of work. The following chapter presents the specifics of my research design. 
TABLE II

EMPIRICAL STUDIES OF CORPORATE PAC CONTRIBUTIONS AND FIRMS - POLITICAL INTEGRATION

Study

Mizruchi and
Koenig (1986);
puralism vs.
class theory

Burris, (1987); six theories of business partisanship

Neustad 1 and Clawson (1988); pluralist/elite theory debate.

Mizruchi (1989); sources of political convergence.
Methodology

Multiple regression, path analysis; 28 firms examined at industry level; dyadic measure of political similarity; 1980 elections.

Multiple regression, discriminant analysis; 443 firms; proportion of 1982 PAC dollars to incumbents, Republicans, and New RIght.

Clique analysis; 230 firms; dyadic measure of political similarity; 1980.

Multiple regression; 57 manufacturing firms; dyadic measure of political similarity; 1980 elections.
Mullery (1991); dependence vs. class cohesion.
Multidimensional scaling; 42 industrial and nonindustrial firms; dyadic measure of political similarity; 1978 and 1982 .
Findings

No relationship:

similarity measure with

(1) transactions volume (supports plural-1sm) and (2) direct interlocks (refutes class model). Positive relationship: similarity measure with economic leverage (supports class model).

Regional theory and regulatory environment theory supported.

A large conservative clique emerged which could support class theory.

Positive relationships: similarity with (1) Ho location, market constraint, common ties with financial firms (supports class model); (2) membership in same primary industry (supports resource dependence).

Positive relationship: similarity with regulatory environment (supports resource dependence); no relationship: similarity with class cohesion. Some support for reglonal model. 
CHAPTER III

\section{RESEARCH DESIGN}

INTRODUCTION

Epstein (1980) pondered the dearth of corporate political activity research in a literature review and offered several reasons why this "intellectual lode" has been "virtually unmined by business society scholars" (5). One was the "difficulty of obtaining 'hard data' or other forms of 'scientifically' verifiable evidence relating to the political behavior of business" (4): another was the reluctance of business practitioners and public officials to "discuss candidly their [political] actions, motivations, and ideologies" (4).

This research design addresses both the hard data and the candor issues. An extensive data bank maintained by the Federal Election Commission since 1975 confronts the former issue. Substituting observed behavior for self reporting of political actions, motivations, and ideologies confronts the latter. Finally, this design is tightly focused, thus avoiding Epstein's charge that Business in Politics research frequently has the "frustrating characteristic of assessing everything and nothing" (4). 
The overarching objective of this research design is to effect both theoretical and methodological progress in the Business in Politics literature. The research incorporates a systematic, empirical analysis formulated to confirm or deny several hypotheses. In so doing, it links existing theories, resource dependence and class cohesion, with empirical corporate political activity research. Further, the design's exploratory analysis component provides an opportunity to move beyond existing theory and contemplate new theory. Finally, this design introduces multidimensional scaling, a sophisticated mathematical technique used in structural analysis, to the Business in Politics literature.

Chapter III begins with a presentation of the research question. It then explicates the six research hypotheses; reviews the sampling strategy; identifies the measured variables and explains the measurement methods; and, finally, discusses the analytical methodology. Appendix A provides an overview of this research design.

\section{RESEARCH QUESTION}

Can resource dependence or class cohesion theory explain intercorporate patterns of corporate political activities, specifically political action committee (PAC) campaign contributions? 
HYPOTHESES

Hypotheses have been described as the "working instruments of theory," the "[bridge] between theory and empirical inquiry" (Kerlinger 1973, 20, 25). As such, the following hypotheses have been formulated to propose a relationship between a measure of corporate political activity, corporate PAC contributions, and measures of intercorporate behavior derived from resource dependence and class cohesion theories. The hypotheses, thus, focus the inquiry by clarifying those relations which are tested so that the applicability of existing theory in predicting corporate political activity can be confirmed or denied.

Five research hypotheses are presented--one resource dependence hypothesis and four class cohesion hypotheses. A sixth hypothesis considers the stability of political strategy over time.

Resource 'Dependence Hypothes is

As discussed in the previous chapter, resource dependence theory argues that corporate behavior results from interorganizational constraints which may well override such orthodox corporate goals as efficiency and profit maximization. ${ }^{1}$ Hypothesis one can be deduced from this theory and is supported by previously cited research.

${ }^{1}$ A source of interorganizational constraint of particular interest for this research is the government regulation of business. 
H1: Firms similarly constrained by government regulations will exhibit similar political behavior.

\section{Class Cohesion Hypotheses}

Chapter II also discussed class cohesion th.eory and related it to predictions regarding corporate political activity. Class cohesion theory's underlying premise is that some corporate political behavior results from a classwide unity of the power elite, a unity that is achieved through exclusive communication networks. ${ }^{2}$ Hypotheses two through four can be deduced from this theory and are supported by the previously cited research.

H2: Firms' number of interlocking directorates will relate directly to similar political behavior among firms.

H3: Firms' number of associations with certain prestigious business policy groups will relate directly to similar political behavior among firms.

H4: Shared educational experience among board chairmen and cEOs will relate directly to similar political behavior among firms.

H5: Geographically proximate headquarters will relate directly to similar political behavior among firms.

${ }^{2}$ Examples of hypothesized networks include interlocking directorates, membership in major business associations, and social interactions resulting from geographic proximity. 
A Political strategy Hypothesis

Additional insights regarding business in politics can be gained by examining the corporate political strategies pursued during two distinct white House administrations, Carter's and Reagan's. Therefore, PAC contribution patterns associated with two midterm election cycles were studied.

It is hypothesized that the change between the carter and Reagan administrations was significant enough to affect corporate political strategy. For example, a major legislative development during the first two years of the Carter administration was the tightening of regulations on the private sector and the expansion of government involvement in energy-related policies which included oil price controls (Easterling 1987, 245). In contrast, Reagan, during the first thirty days of his administration, established a Task Force on Regulatory Relief; froze all pending regulations; lifted oil price controls; eliminated the Council on Wage and Price Stability; and directed the office of Maragement and Budget to subject all future proposed regulations to a cost-benefit analysis (Miller $1988,70)$. Such dramatic policy changes could encourage corporations which had pursued the less risky, pragmatic political strategies to more actively support conservative challengers and open seat candidates. This line of reasoning results in the following research hypothesis: 
H6: The ideology of a sitting white House administration will influence corporate PAC contribution patterns.

\section{EXPLORATORY RESEARCH}

Kerlinger (1973) contends that even when hypotheses are not confirmed, valuable research can result since the "total universe of ignorance" has been reduced. Further, "uncharted hypotheses" can contribute to the "basic aim of science - . [thich is] theory" (26). The exploratory analysis component of this research design encourages the development of uncharted hypotheses to explain corporate political activities. Further, such explorations can provide the basis for the development of a new theory which might better explain the business-government interface or, more generally, interest group behavior in a pluralistic democracy. New propositions regarding corporate political activity are advanced based on unanticipated patterns revealed by the MDS spatial representation of intercorporate relations.

MEASUREMENT

Measures were developed for each of the research question's components: corporate political activity, resource dependence theory, and class cohesion theory. 
Table III summarizes the measured variables. The following sections further explain measurement methods.

Corporate Political Activity

Corporate PAC activity is a widely accepted measure of corporate political activity. While PAC activity is but one category of corporate political behavior, researchers generally agree that PAC contributions provide significant information about a firm's overall political strategy (Clawson, Neustadtl and Bearden 1986, 799; Burris 1987, 732733; Mizruchi 1989, 405). Further, as noted by Masters and Baysinger (1985), this activity, unlike other political activities, is readily interpretable:

Corporations engage in a variety of political activities, including lobbying, constituency building, and setting up public affairs units . . . PAC activity differs from these others in that it is a direct attempt to buy access to lawmakers, or influence them, through influencing elections (654).

Finally, PAC contribution records are accessible, reliable, and systematically maintained by a federal agency, an important characteristic from a scientific perspective since it enhances replication of this research. The extent to which corporate PACs support the same Congressional candidates is the end result of a myriad of factors. Some, such as voting records and committee assignments, are specific to candidates. others, such as intensity of competition and regulation, are specific to industries. Still others, such as a CEO's political sophistication and 
leadership abilities, are specific to individual firms and their PACs.

Onè cannot formulate a hypothesis for each possible factor--even if they could all be identified and measured-and test it. One can, however, utilize observed behavior as a proxy variable, a proxy that stands in for an undefined set of factors and can be observed without reference to that set of factors. Support for a candidate is such a proxy variable: It exists or it does not and can be observed without reference to candidate-specific, industry-specific, or PAC-specific factors. The similarity matrices, central to the analysis, are built from these hard data.

Actual measurement entails two stages. The first stage involves the recording of contributions to, on average, 650 Congressional candidates made by forty-two corporate PACs during two separate election cycles which span the Carter and Reagan administrations. The second stage compares the frequency with which every pair of corporate PACs (861 pairs) supported similar Congressional candidates during each of the two studied election cycles.

A measure which examines to whom, rather than how much, corporate PACs contribute is consistent with the research question. If the extent of influence business exerts on election outcomes were the research question, then measuring the level of PAC contributions would be critical. Instead, this research is concerned with patterns of 
activity that are indicative of similar political strategies pursued by large, disparate corporations. Therefore, the research design controls for the level of dollars expended to avoid spurious linkages among PACs. If, for example, two PACs contributed different amounts to the same campaign this design would count that event as a similarity; a design that does not control for dollar amounts could well count that same observation as a dissimilarity--a dissimilarity that would be spurious for purposes of this study, since similar strategy rather than the extent of political influence is the operative variable. In short, controlling for the level of expenditures ensures linking corporate PACs that support similar political agendas, yet differ in their PAC resource base (Neustadtl and clawson 1988,176$).^{3}$

\section{Similarity Measure}

The input data are arranged into two symmetric, square matrices, one for each election cycle. Each matrix, with rows and columns for each of the forty-two corporate PACs, contains the similarity measure for the 861 corporate dyads.

3 The ARCO PAC recorded negligible contributions (under twenty-five dollars) to some unlikely democratic candidates given the overall pattern of contributions made by this sample. For example, only ARCo contributed to Wendell Ford, John Glenn, and Edward Kennedy, and then in the amounts of six, five, and two dollars respectively. This suggests that such contributions are more indicative of nonsupport gestures ratrer than sincere support of certain congressional candidates. To control for this circumstance, all PAC contributions less than twenty-five dollars were eliminated. 
For example, the first matrix column shows the similarity measure between corporation one and each of the succeeding forty-one corporations. Similarity is defined as the relative frequency with which two corporate PACs contributed to different congressional candidates. The complete 1977-78 and 1981-82 similarity matrices appear in Appendices B and C, respectively.

Specifically, the similarity between corporate PACs $i$ and $j$ is defined as follows:

$$
s(i, j)=s(i, j) / \text { square root of }[n(i) * n(j)]
$$

where $s(i, j)$ is the similarity measure, $s(i, j)$ is the number of similar contributions, and $n(i)$ and $n(j)$ are the total number of contributions made by PACs $i$ and $j$, respectively. Mathematically, the denominator of the formula controls for the number of contributions made by each PAC while the numerator provides a measure of behavioral similarity. This formula has been used in previous research which examined both political consensus and interlocking directorates (Mizruchi 1989; Mizruchi and Koenig 1986; Mariolis 1975).

\section{Political strategy}

The MDS solution generates dimensions, but the researcher must establish their meaning. Information regarding the ideological bent of PAC contribution patterns can facilitate this process.

Researchers categorize a PAC's political strategy based upon its prcclivity to support incumbents or 
challengers (see, for example, Handler and Mulkern 1982, 1518; Matasar 1986, chapter 4; Stern 1988, chapter 3). PACS that try to impart a conservative tilt to congress by supporting conservative challengers over liberal incumbents, even when faced with supporting a probable loser, are labeled ideological. PACS that support incumbents, with slight regard for ideology, so as to protect their access to important Congressional leaders and committees, are labeled pragmatic (also see definitions, pages 13-14).

A useful classification system was developed by Burris (1987, 735). Three political partisanship measures are applied to each firm: the proportion of Congressional PAC contributions which supports (1) incumbents, (2) Republicans, and (3) New Right candidates.

Contributions to incumbents and Republicans are readily determined by examining Federal Election Commission documents, but determining contributions to New Right candidates requires the application of decision rules. Burris $(1987,735)$ associates this increasingly prominent candidate category with the extent of support received from New Right PACs.

Five nonconnected PACs (defined on page 17) are labeled New Right based on their identifiable conservative political philosophy (Sabato 1984, 21-22), however only four of the these five were in existence during the 1977-78 election cycle. These same New Right PACs were ranked in 
the Federal Election Commission's (FEC) "Top 10 Nonconnected PACs" category for both election cycles in which they were active; and, with the exception of the Fund for a Conservative Majority during the 1977-78 election cycle, were also ranked in the FEC Top 10 List for all Pac Categories (U.S. Federal Election Commission 1979, 1983). A listing of these New Right PACs appears in Table IV.

A New Right candidate is defined as one who received contributions from at least three of the five large New Right PACs which were active during the 1981-82 election cycle, or at least three of the four New Right PACs which were active during the 1977-78 election cycle. Sixty-seven candidates supported by the sampled corporate PACs qualified as New Right during the 1977-78 election cycle; sixty-eight qualified as such during the 1981-82 election cycle.

Burris (1987) contends that the three political partisanship measures, while interrelated, reveal different aspects of political strategy. The Republican support measure "provides a rough index of political conservatism or liberalism" (735). The incumbent support measure provides a rough index of pragmatism. He notes that the New Right measure, a rough index of ideological behavior, proved to be the most revealing:

The New Right PACs, whose choices define these candidates, specifically seek to identify those races in which their money can have the greatest partisan impact --those races with a sharp ideological difference between the candidates and where additional funds can alter the outcome of a close contest. Corporations that 
contribute disproportionately to these same candidates can be assumed to be pursuing a similar political strategy, or, in some cases, to be directly following the example and advice of the New Right PACs (735).

\section{Resource Dependence}

New or revitalized government regulations ushered in during the politically turbulent 1960s and early 1970s resulted in a widely recognized distinction between the newer, multi-industry social regulations and the traditional, single-industry economic regulations. Social regulation impacts managerial discretion and autonomy and is therefore frequently resented, even contested, by business. These regulations originate in agencies such as the Occupational Safety and Health Administration or the Consumer Product Safety Commission which control production processes and product quality, respectively.

Alternatively, economic regulation focuses on those restraints believed necessary to support capitalism and as such are often supported, even initiated, by business. These regulations originate in agencies such as the Interstate Commerce Commission or the Federal Communication Commission where competitive practices within one industry are controlled.

These two categories' effects are perceived quite differently. Generally, economic regulation is associated with industry stability since it protects existing competitors; whereas social regulation is associated with 
higher costs and reduced profits which can cut across many industries (Bateman and Zeithaml 1990, 257-259).4

Research has suggested a correlation between an industry's dominant regulatory environment, social or economic, and its prevailing political strategy, ideological or pragmatic (Handler and Mulkern 1982, 29-32; Burris 1987, 736; Neustadtl and clawson 1988, 183). That is, firms either less constrained by industry-specific regulations or more adversely affected by the costs associated with social regulations tend toward ideological political strategies with the intent of assembling a more business-friendly Congress; firms in traditionally regulated industries tend toward more pragmatic political strategies so as to maintain access and the good will of influential incumbents. The aerospace and electronics industries, with substantial ties to the Pentagon, also tend toward pragmatic political strategies so as to enhance access to those legislators sitting on military weapons appropriations committees Therefore, the regulatory environment faced by each of the sample firms was categorized as either social or economic based on its industry category as defined by the Fortune index and that industry's dominant regulatory environment as defined by prior research. Actual corporate patterns, derived from the PAC contributions similarity measure, were then compared against those patterns which

\footnotetext{
${ }^{4}$ See pages 14-16 for more complete definitions.
} 
resource dependent behavior would predict. Table V summarizes the regulatory environment measure.

\section{Class Cohesion}

As discussed in chapter II, researchers in the power elite tradition have attempted to identify those sources of class cohesion by which members of the corporate elite can exercise control over the economy and society in general and, simultaneously, enable the mediation and resolution of the intercorporate conflicts which inevitably emerge. Examples of class cohesion factors which have been hypothesized and studied include kinship, similar backgrounds, social club membership, professional association memberships, geographic proximity, interlocking directorates, the inner group, and government ties. 5

This research hypothesizes a relationship between corporate political activity and four sources of class cohesion: interlocking directorates, membership in professional associations, shared education experience, and geographic proximity. These measures were selected based on the availability of reliable data and their application in recent research as variables associated with collaborative corporate political activity.

${ }^{5}$ See Mizruchi (1987) for a good review of this literature.

${ }^{6}$ For example, membership in professional associations could be verified in the associations' annual reports or membership lists provided by the association. Social club 
Interlocking directorates. Class theorists have identified interlocking directorates as one of several mechanisms which foster elite unity (Mizruchi and Koenig 1986; Mizruchi 1989)..$^{7}$ While a measure of direct interlocks is straightforward--a count of firms with which the focal firm is directly linked through common board membership--the measure of indirect interlocks is more complex, since by definition, indirect interlocks (see page 16) require an intermediate organization to link a firm dyad.

Researchers have dealt with this methodological problem a number of ways. Some have used lists of large commercial banks and life insurance companies as the indirect link between firm dyads due to the repeated findings of financial institutions' centrality in networks of interlocking directorates (Mizruchi and Koenig 1986; Mizruchi.1989). Others do not distinguish between direct

membership is generally collected through numerous biographical references (the Marquis' Who's Who series, Standard \& Poor's Register of Corporations, Directors, and Executives, Dun \& Bradstreet's Reference Book of Corporate Manaqement); however, these data are self-reported, frequently incomplete and sometimes inaccurate. Whereas some CEOs list all past and present memberships in clubs, associations, boards, etc., others provide only their title and corporate address.

'It should be noted that resource dependence theorists have posited that interlocking directorates are one method by which managements attempt to reduce environmental uncertainty (Mizruchi and Koenig 1986; Useem 1983, 41). Unlike class cohesion theory, however, resource dependence theory does not associate the interlocking directorate measure with corporate political activity. 
and indirect interlocks but rather define interlocks as the number of shared board memberships the focal firm has with some cross-section of large nonfinancial and financial firms (Neustadtl and Clawson 1988; Burris 1987). Still others argue that indirect interlocks have little relevance for studies of intercorporate relations since the communicative benefits of direct interlocks overshadow the benefits of indirect interlocks and, further, since other forms of indirect access exit between firm dyads (Pennings 1980, 38).

The United States Senate (U.S. Congress, Senate 1980) study, Structure of corporate concentration, in examining one hundred companies which were "among the very largest in the nation, and indeed, in the world" (2), took yet another approach to counting interlocking directorates. It calculated both direct and indirect interlocks, the latter by counting all links between the 4,950 company dyads which were routed through intermediate firms. In describing this extensive study, the report noted that:

Interlocking [direct and indirect] directorates provide a special opportunity for intercompany communication and consensus. The linkages at the board room table are personal connections by which key information can be made and policies formed (5).

Since this thesis deals specifically with questions of "intercompany communication and consensus," it incorporated the United States Senate study's method of counting direct and indirect interlocks. The sample of forty-two firms is a subset of the one hundred firms in the U.S. Senate study 
(the sampling strategy is described in detail beginning on page 88 ), therefore the Senate study's data were recounted to reflect the direct and indirect interlocks between these 861 firm dyads.

A final note: The 1980 United States Senate study time frame does not match, but is straddled by the two time frames of the present study, 1977 to 1978 and 1981 to 1982. Research by Mariolis and Jones (1982) indicates that corporate interlock measures over a four-year period are highly réliable and stable (stability and reliability coefficients ranged from .929 to .997 for all corporations). Therefore, the 1980 interlock data is reasonable to use.

Major business associations. Numerous scholars have studied the central role which major business associations play in providing a forum to discuss, debate, and ultimately establish the corporate elite's position on selected public policy issues (Domhoff 1970; Useem 1980, 1984; Mizruchi 1987). These associations, unlike trade associations, involve a regionally diverse set of business firms which cut across a variety of industrial sectors. The commonality among these associations is the credentials of their policysetting members--only top-level executives from the nation's largest corporations are invited to join. Some restrict membership to CEOs and Board Chairmen.

Useem (1984) identifies five such associations as the most powerful and influential in expressing the American 
business viewpoint to the highest levels of government and the media. These include: the council on Foreign Relations, the undisputed corporate voice on foreign policy issues; the Conference Board, which conducts research and publishes studies on business economics and managerial practices; the Committee for Economic Development, whose "trustees meet with distinguished academic and business experts to develop statements on national policy" (Committee for Economic Development 1978); the Business Council, which works most closely with the Department of commerce and "hopes to generate greater understanding of major public policy issues and to help create the consensus for solutions" (Business Council 1990); and, the Business Roundtable, generally considered to be the most politically powerful business association (Useem 1984), which "examine[s] public issues that affect the economy and develop[s] positions which seek to reflect sound economic and social principles" (Business Roundtable 1990).

Table VI lists these five business associations and the member status which was applied in determining a firm's involvement in the organization's policy-setting coterie. Thus, this measure of class cohesion is calculated as the number of major business associations to which each sampled firm belongs. A zero count indicates no representation in these five business associations; a five count indicates 
representation in all of the five major business associations.

Education. Scholars examining the corporate elite have identified common schooling at prestigious universities as a source of class cohesion (Pierson 1969, 120-122; Domhoff 1970, 1974; Useem and Miller 1975, 142). Consequently, the number of associations between senior executives and selected universities was counted. The educational background of all chairmen and presidents from the sample firms was collected and compared to the university list which appears in Table VII.

Headquarters location. A reasonable hypothesis is that geographic proximity of headquarters and plant locations should be associated with similar political behavior, since the home state senatorial or local congressional district races should be of particular interest to PAC contributors. Alternatively, one could argue from two perspectives that geography will play a minor role, if any, in the candidate selection process. The pragmatic perspective would stress the access and influence motives; that is, some corporate PACs are seeking access to powerful congressional leaders and committee members and, therefore, favor incumbents regardless of the candidate's home state or district. The ideological perspective would maintain that some corporate PACs will tend to support 
conservative challengers and open seat candidates in close races, again, regardless of where that race is being run. Two studies examined headquarters locations as predictors of similar political behavior. One found "no relation between having a headquarters in the same city, state, or region and similarity of contributions" (Mizruchi and Koenig 1986, 486), while a later study found state headquarters location to be a strong predictor of similar political behavior yet found no relationship between plant locations and contribution patterns (Mizruchi 1989, 412). In the latter study, the strong correlation between headquarters located in the same state and similar political behavior (similarity measured by corporate PAC contributions) was at least partially explained by the social interaction patterns of top executives who generally live near their offices, a class cohesion argument. This argument was strengthened by the lack of association found between candidates supported and plant locations. Since headquarters location has been examined in previous research which studied the similarity of corporate political behavior, it is included in this thesis as a variable associated with PAC contribution patterns. Each firm's headquarters location was dummy coded by state. States which were represented by only one firm were classified in an "Other" category. New York and Connecticut were combined into one state category since the state 
boundary line, in this instance, was considered

inappropriate when social interaction patterns are the focus. Table VIII displays the headquarters' location for this sample, and the number of firms headquartered in each state.

\section{THE SAMPLING STRATEGY}

The sample for this study is comprised of forty-two of the largest United States corporations, drawn from fourteen diverse industrial and nonindustrial sectors, and headquartered in eleven different states which span the country. Their 1981 Fortune rankings ranged from one to seventy-seven. ${ }^{8}$ The following section details the population of interest and the sample selection criteria. The composition of the sample appears in Table IX.

\section{Population}

The population of interest is defined as the one hundred corporations selected for the United states senate (U.S. Congress, Senate 1980) study on interlocking directorates. That group is described as follows:

One hundred leading companies have been selected for the study, covering the areas of banking, insurance, utilities, transportation, retailing, and industrials. Their assets total over 20 percent of the assets of all

${ }^{8}$ Since Fortune bases its ranking on data from preceding years, the 1981 rank was used so that it was more comparable to the 1980 united states Senate study's data; also, industrials are ranked by sales while nonindustrials are ranked by assets. 
U.S. corporations. Because of the size and power of their operations, they have contributed substantially to the nation's economy and the standard of living of its citizens. . It is the purpose of this study to set forth the organizational data by which corporate concentration in American business can be understood and evaluated (U.S. Congress, Senate 1980, 1-2).

A population comprised of large, diverse corporations was required for the following reasons:

1. Large corporations are more likely to form PACs, this study's measure for corporate political activity. During the 1977-78 election cycle, forty percent of the Fortune five hundred industrials had formed PACs compared to just eight percent of the second five hundred largest industrial firms (Matasar 1986, 27).

2. The measured variables associated with class cohesion theory dictate that the population of interest be major corporations. Board members of major corporations are more likely to hold multiple directorships and to be invited to participate in major business associations.

3. The measured variable associated with resource dependence theory, regulatory environment, requires that sample firms be classified based on their dominant regulatory environment, social or economic. The diversity of the populations permits a representative sample in both categories.

While other populations would satisfy the "large, diverse" criterion, the 1980 United States Senate study's population was preferable for two reasons: (1) It includes 
data on indirect interlocks, with all intermediate companies, rather than interlocks based on a cross-sample of firms, and (2) its 1980 time frame is compatible with the present research design.

\section{Sample Criterion: PAC}

Activity

The overriding criterion for inclusion in the research sample is the existence of an active PAC during both election cycles since PAC contributions are the measured variable for corporate political activity. Fifty of the one hundred firms from the population had active PACs dating back to the 1977-78 cycle.

\section{Sample Criterion: Industry} Dispersion

Previous research suggests that firms in an industry sector will exhibit similar political behavior (Neustadtl and Clawson 1988, 173). This research design purposely diffuses the extraneous (to this study) effect of industry category by incorporating fourteen diverse industrial and nonindustrial sectors.

Given the previously described PAC activity criterion, a sample composed of one to four firms in each industrial sector resulted. The nonindustrial sectors of banking and transportation, however, were disproportionately weighted

${ }^{9}$ By the 1989-90 election cycle, ninety-three of the one hundred firms had PACs. 
with twelve and six firms respectively. In order to maintain a more evenly dispersed sample, the four largest transportation service firms (two air carriers and two rail) were selected based on Fortune 1981 rankings. Six banks (three from the East, one from the Midwest, and two from the West) were selected to permit a more geographically dispersed representation of the banking industry since it plays a prominent role in studies of both resource dependence and class cohesion theories.

\section{Two Election Cycles}

Two election cycles, 1977-78 and 1981-82, are purposively selected for analysis to satisfy four considerations.

First, the Federal Election Campaign Act (FECA), which directly fueled the corporate PAC growth explosion of the 1970s, was passed in 1971 with subsequent amendments in 1974 and 1976. The FECA was amended again in 1979, but with no direct effect on corporate PACs (Sabato 1984, 7-10). These rulings would suggest that a comparative study of corporate PAC behavior should not incorporate pre-1976 eras. Second, these cycles are compatible with the time frame of a comprehensive United States Senate (U.S. Congress, Senate 1980) study, Structure of Corporate Concentration, data from which are used to measure interlocking directorates. 
Third, these cycles are comparable in that they each monitor the financial activity for midterm elections during the first (and, for Carter, the last) term of two administrations.

Finally, these cycles provided an analytically useful contrast in two politically and philosophically distinct eras of business-government relations. The question as to whether changes in political behavior is a corporate reaction to perceived changes in the regulatory macroenvironment thus can be addressed. ${ }^{10}$

\section{ANALYTICAL METHODOLOGY}

This study employs multidimensional scaling to systematize the corporate political activity similarity measures of the sampled firms. The MDS output is then used to (1) test resource dependence and class cohesion theoryrelated hypotheses and (2) explore the revealed structure of intercorporate relationships so that new propositions can be formulated.

The following describes the fundamentals of multidimensional scaling, how it is applied in this

${ }^{10}$ While it was not the intent of this research to answer the question as to whether the Reagan era was one of deregulation, it is generally accepted among analysts that the Reagan administration was more "friendly" toward business than was Carter's. 
research, and how its output is used to test hypotheses and to conduct an exploratory analysis.

Multidimensional scaling

--the Fundamentals

Forrest young (1987), author of numerous MDS books, articles, and software, says it best: "Multidimensional scaling (MDS) rests on the premise that a picture is worth a thousand numbers" (3). This "picture," or the MDS map as it is more commonly known, is the distinctive characteristic of the various MDS procedures which have been developed to satisfy specialized research needs.

The map is a graphed configuration of points, derived from proximity data, which displays spatial relationships among objects or stimuli. These observed relationships can be subjected to hypothesis testing; but MDS's real strength lies in its ability to reveal to the researcher insights about a sample's structure of relationships which would otherwise be obscured by a mass of data. structure in this research is revealed by the configuration of points on the MDS-derived map which reflects the similarity of corporate political activity among the sampled firms.

The following gives a brief explanation of how MDS works in this study. In so doing, it draws extensively from the excellent introductory MDS text authored by Schiffman, Reynolds and Young (1981, chapter 1). MDS terminology will be introduced as the explanation unfolds. (Other books 
referenced include Kruskal and Wish 1978; Young 1987; SPSS Inc. 1988).

MDS input. The input for an MDS analysis is proximities--numbers which indicate how similar or dissimilar two objects are. These proximities are collected in a data matrix which contains all combinations of dyads for a given sample of objects or stimuli. ${ }^{11}$ This research has forty-two objects, that is, forty-two sampled firms. The proximity (or similarity) measure quantifies the similarity of corporate PAC contributions for all combinations of the forty-two firm dyads--861 combinations. ${ }^{12}$ Finally, since the similarity of corporate PAC contributions vary from one election to the next, two separate data matrices are entered, one for each of the studied time frames.

Measurement level. MDS can perform either metric or nonmetric scaling. Metric scaling, which assumes that the measurement level of the input data is interval or ratio, attempts to model the precise similarities to the distances between points on the map. Nonmetric scaling, which assumes a nominal or ordinal level of input, attempts to model the rank order of to the distances. Consistent with

${ }^{11}$ objects are concrete things or events, for example, a firm; stimuli are perceptions of objects, for example, an individual's ranking of firms along some attribute. measure.

${ }^{12}$ See pages 75-76 for a description of the similarity 
measurement properties, the interval or ratio levels can be subjected to nonmetric scaling, but the nominal or ordinal levels cannot be subjected to metric scaling. The similarity measures calculated for the input data matrix are at the ratio level; however, nonmetric scaling is used for the following theoretical and methodological reasons :

1. The measurement precision associated with metric scaling is unwarranted. An objective of this research is to examine intercorporate structure based on patterns of relationships between and among firms, not their exact relationships. Consequently, the nonmetric procedure can be a more realistic assumption about the underlying processes (Loehlin 1987, 198).

2. Nonmetric scaling is a better determiner of the MDS solution's dimensionality. This is because metric scaling can produce misleading exror measures owing to its greater precision requirements (Kruskal and Wish 1978, 76).

3. Schiffman, Reynolds and young (1981) recommend the use of nonmetric scaling noting that the "metric-nonmetric distinction rarely makes a crucial difference in the outcome of the analysis" (74). In a later chapter which describes the ALSCAI procedure (the MDS computer program used in this analysis), these same authors remark: "Analysis at the ratio level is not recommended" (171). 
4. Finally, F. W. Young (1981), a noted MDS practitioner and author of the MDS ALSCAL procedure, maintains that users of MDS algorithms enjoy great flexibility in assumptions regarding the measurement characteristics of their data (361).

MDS/ALSCAL procedure. The ALSCAL procedure, one of several MDS computer programs, attempts to fit the similarity measures to a derived map such that the distances between points on the map (points representing the forty-two firms in this research) are in the same rank order as the similarity measures used as input.

Conceptualiy, the best fit is a result of numerous iterations in which the MDS procedure moves the map's points to fit the input similarity measures. Each iteration produces a possible configuration of points and an error measure, SSTRESS. SSTRESS compares the distances between a configuration's points and the distances between similarity measures of the sampled firms. With each additional iteration, SSTRESS generally decreases until there is a very small change which halts the procedure. If the final map is judged by the researcher as a reasonably good model of the input data, based on a low SSTRESS level and a high fit measure, RSQ, then interpretation of the map's dimensions and other statistical analysis can ensue. ${ }^{13}$

${ }^{13} \mathrm{RSQ}$ : proportion of variance of the input data (or its monotonic transformation referred to as disparities when nonmetric scaling is used) accounted for by the MDS model. 
MDS output/analysis. Interpretation is the stage of the analysis where the previous knowledge, judgement, skill, and insights of the researcher dominate. It is also the stage where theoretical breakthroughs can occur.

Analysis of an MDS solution set begins with an interpretation of the map's dimensions. Dimensions are simply the coordinate axes of the derived map; therefore, a two dimensional map will be depicted by two perpendicular axes. A strength of MDS is that it produces a map with the fewest possible dimensions to explain observed similarities.

In this research, each dimension of the MDS map represents a possible explanation for the underlying unity or disunity of firms' corporate political activity as depicted by the intercorporate structure. Examples of possible dimensions that might signal structural divisions include geography, industry sector, regulatory environment, or communication networks.

Research employing MDS methodology frequently culminates with this interpretive, exploratory analysis; however, MDS' confirmatory use is increasingly appearing in the literature (see Young 1987, chapters 11 and 12). This research applies MDS in a confirmatory sense by testing the research hypotheses against the intercorporate structure revealed by the MDS map. The following section further elaborates on this process. 
HYPOTHESIS TESTING

The previous section demonstrated how the MDS solution lends itself to a visual interpretation of structural relationships. This same solution can also be compared to theoretical expectations through the application of multivariate statistical techniques which permit hypothesis testing--an objective of this research.

The following explains the statistical techniques which are applied to the MDS results so that the research hypotheses can be tested. Previously, the hypotheses had been stated in substantive language, that is, in terms of the expected relation between two or more variables (see page 67). This section restates the hypotheses in the form which permits scientific testing, that is the null form (Kerlinger 1973, 201-203).

\section{Resource Dependence} Null Hypothesis

$\mathrm{HO}_{1}$ : There is no significant relationship between a firm's MDS Coordinates and its regulatory environment classification.

Alternatively, if there is a significant relationship between a firm's regulatory environment and its MDS coordinates, then there is evidence for a pattern of corporations' exhibiting similar political activity owing to regulatory constraints. 
Class Cohesion Null

Hypotheses

$\mathrm{HO}_{2}$ : There is no significant relationship between a firm's MDS coordinates and its number of direct or indirect interlocks with the set of sampled firms.

$\mathrm{HO}_{3}$ : There is no significant relationship between a firm's MDS coordinates and its number of associations with major business policy groups.

$\mathrm{HO}_{4}^{\prime}:$ There is no significant relationship between a firm's MDS coordinates and a shared educational experience among Chairmen and CEOs.

$\mathrm{HO}_{5}$ : There is no significant relationship between a firm's MDS coordinates and its headquarters' location.

Alternatively, if there is a significant relationship between interlocking directorates, memberships, educational experience and/or geographic proximity and a firm's MDS coordinates, then there is evidence for a pattern of corporations' exhibiting similar political activity owing to class cohesion networks.

Statistical tests. The null hypotheses are tested with multiple regression models. A separate regression equation tests each resource dependence and class cohesion variable--the dependent variables; the firms' coordinates on the dimensions of the MDS map represent the independent variables. 
Each regression equation is first tested for its overall significance (F test). If significant, then the regression coefficients are examined to determine the significance of the MDS solution's dimensions (student $t$ tests). Additional insights are derived from examining the zero-order correlations.

The Political Strategy

Null Hypothesis

HO$_{6}$ : There is no significant change between patterns of corporate political spending exhibited during the 1977-78 election cycle and the 1981-82 election cycle.

Alternatively, contribution patterns which vary significantly provide evidence to support the contention that changing business-government relations environments will influence PAC strategy.

A paired difference comparison of contributions to three candidate categories (incumbents, Republicans, New Right) exhibited during each cycle and a canonical correlation between the two sets of contribution patterns test null hypothesis six.

\section{CONCLUSION}

Chapter III introduced the research question and hypotheses, the data analysis methodology, and the statistics employed to test hypothesized relationships. It 
is hoped that the reader is now prepared for, even curious about, what follows.

The remaining chapters present the analytical results, discuss the implications of this research including its strengths and weaknesses, point out some managerial implications, and suggest future research directions. 
TABLE III

MEASUREMENT OF VARIABLES

\begin{tabular}{l} 
Variable \\
\hline $\begin{array}{l}\text { Corporate political } \\
\text { activity }\end{array}$ \\
Resource dependence \\
Class cohesion
\end{tabular}

\begin{tabular}{l} 
Measurement \\
\hline Similarity scores \\
Regulatory environment \\
Direct interlocks \\
Indirect interlocks \\
Memberships \\
Education \\
Headquarters location
\end{tabular}

Level of Measurement

Continuous

Categorical

Continuous

Continuous

Continuous

Categorical

Categorical 
TABLE IV

NEW RIGHT PACS

Citizens for the Republic

Commit tee for the Survival of a Free Congress

National Conservative Political Action Committee

Fund for a Conservative Majority

National Congressional Club*

Not active during the 1977-78 Election Cycle 
TABLE V

\section{CLASSIFICATIONS AND PREDICTIONS BASED ON} RESOURCE DEPENDENCE THEORY

\begin{tabular}{|c|c|c|}
\hline $\begin{array}{c}\text { Regulatory } \\
\text { Environment } \\
\text { Classifications } \\
\end{array}$ & $\begin{array}{l}\text { Predicted } \\
\text { Political } \\
\text { Strategies } \\
\end{array}$ & $\begin{array}{l}\text { Industry } \\
\text { Groupings }\end{array}$ \\
\hline Social & Ideological & $\begin{array}{l}\text { Chemicals } \\
\text { Tobacco } \\
\text { Metal manufacturing } \\
\text { Industrial/farm equipment } \\
\text { Motor vehicles } \\
\text { Retailing }\end{array}$ \\
\hline Economic/Defense & Pragmatic & $\begin{array}{l}\text { Banking } \\
\text { Insurance } \\
\text { Diversified financials } \\
\text { Transportation services } \\
\text { Utilities } \\
\text { Electronics } \\
\text { Aerospace }\end{array}$ \\
\hline
\end{tabular}

See Neustadtl and Clawson 1988, 183; Burris 1987, 736; Handler and Mulkern 1982, 29-32 for similar industry groupings. 
TABLE VI

FIVE MAJOR BUSINESS ASSOCIATIONS AND PARTICIPANTS' STATUS

Business Roundtable (members)

Business Council (members)

Committee for Economic Development (trustees)

Conference Board (trustees and officers)

Council on Foreign Relations (trustees and officers)

Source: Useem 1984, 73 
TABLE VII

\section{TWELVE PROMINENT UNIVERSITIES}

\section{Harvard \\ Yale \\ Princeton \\ Columbia \\ Cornell \\ MIT}

\author{
Stanford \\ University of California, Berkeley \\ University of Illinois \\ University of Michigan \\ University of Pennsylvania \\ University of Wisconsin
}

Note: These twelve prominent schools were identified by Useem (1975, 142), based on Pierson's work (1969, 120-122) which examined schools most often attended by top executives of the largest corporations and financial institutions. 
TABLE VIII

FREQUENCY OF HEADQUARTERS LOCATION BY STATE

\section{State}

NY-Connecticut

California

Pennsylvania

Illinois

Michigan

Ohio

Minnesota

Missouri

North Carolina

Texas
Number of Firms

\section{6}

6

5

4

4

3

1

1

1

1

$N=42$ 
TABLE IX

COMPOSITION OF THE SAMPLE

\begin{tabular}{|c|c|c|c|}
\hline ID隹 & Firm & Industry & $\begin{array}{c}\text { Headquarters } \\
\text { Location }\end{array}$ \\
\hline 1 & ALCOA & Metals Manufacturing & PA \\
\hline 2 & American Electric Power & Utility & $\mathrm{OH}$ \\
\hline 3 & American Express & Diversified Financials & NY \\
\hline 4 & Arco & Petroleum Refinery & $\mathrm{CA}$ \\
\hline 5 & Bethlehem Steel & Metals Manufacturing & PA \\
\hline 6 & Chrysler & Motor Vehicles & MI \\
\hline 7 & Citicorp & Banking & NY \\
\hline 8 & Consolidated Edison & Utility & NY \\
\hline 9 & Dow & Chemicals & MI \\
\hline 10 & Federated Department Store & Retailing & $\mathrm{OH}$ \\
\hline 11 & First Chicago & Banking & IL \\
\hline 12 & Ford & Motor Vehicles & MI \\
\hline 13 & GE & Electronics & CT \\
\hline 14 & GM & Motor Vehicles & MI \\
\hline 15 & GTE & Utility & CT \\
\hline 16 & Goodyear & Rubber & $\mathrm{OH}$ \\
\hline 17 & Honeywell & Electronics & MN \\
\hline 18 & International Harvester & Farm Equipment & IL \\
\hline 19 & K Mart & Retailing & MI \\
\hline 20 & Lockheed & Aerospace & $\mathrm{CA}$ \\
\hline 21 & LTV & Metals Manufacturing & TX \\
\hline 22 & Manufacturers Hanover & Banking & NY \\
\hline 23 & Mellon & Banking & PA \\
\hline 24 & Metropolitan Life Insurance & Insurance & NY \\
\hline 25 & Monsanto & Chemicals & MO \\
\hline 26 & Pan American & Transportation & NY \\
\hline 27 & Penney & Retailing & NY \\
\hline 28 & Philip Morris & Tobacco & $\mathrm{NY}$ \\
\hline 29 & RJR & Tobacco & NC \\
\hline 30 & Rockwell & Aerospace & $\mathrm{CA}$ \\
\hline 31 & Sears & Retalling & IL \\
\hline 32 & Security Pacific & Banking & $\mathrm{CA}$ \\
\hline 33 & Southern Pacific & Transportation & $\mathrm{CA}$ \\
\hline 34 & Texaco & Petroleum Refinery & NY \\
\hline 35 & TWA & Transportation & NY \\
\hline 36 & Union Carbide & Chemicals & NY \\
\hline 37 & Union Pactfic & Transportation & NY \\
\hline 38 & United Air Lines & Transportation & IL \\
\hline 39 & USX & Metals Manufacturing & PA \\
\hline 40 & United Technologies & Aerospace & CT \\
\hline 41 & Wells Fargo & Banking & $\mathrm{CA}$ \\
\hline 42 & Westinghouse & Electronics & PA \\
\hline
\end{tabular}


CHAPTER IV

THE 1977-78 ELECTION CYCLE

Chapter IV presents the results of the

multidimensional scaling performed on the 1977-78 PAC

contribution data and the results of testing hypotheses one through five. The 1981-82 election cycle results are

presented in chapter $v$. Hypothesis six, which compares the two election cycles, is discussed in chapter VI.

\section{INTRODUCTION}

Various mathematical and statistical techniques are employed to cietermine if either resource dependence or class cohesion theory can explain patterns of corporate political activity as exemplified by the 1977-78 PAC contributions. The analysis begins with a nonmetric multidimensional scaling of the contribution similarity data. This scaling results in configurations, or MDS spaces, which display intercorporate structural patterns. These patterns are then interpreted by fitting the hypothesized resource dependence and class cohesion variables to them. The goodness of fit is measured by multiple regression, canonical correlation, and chi-square analysis. 
A Matter of Terminology

MDS procedures are indifferent between similarity and dissimilarity measures, but one term, proximity, designates either (Kruskal and Wish 1978, 7). Henceforward, proximity replaces both similarity and dissimilarity, except when the latter two are used to communicate specific meanings.

\section{THE NATURE OF THE PROXIMITY DATA}

The distribution of the 1977-78 proximity measures was first examined. Table $\mathrm{X}$ and Figure 2 display the descriptive statistics and frequency distribution histogram associated with the proximity data set.' The observed proximity scores, measured at the ordinal level, ranged from .000 to .594 with a median of $.199 .^{2}$ It should also be noted that the distribution exhibits a rather low variance. The scores cluster rather tightly around the median; approximately thirty-three percent of the range lies between quartiles one and three, compared with forty-eight percent above the third quartile.

\section{Extremes}

Extremes in similarity scores were then considered. Thirty, or approximately 3.5 percent of the 861 firm dyads,

${ }^{1}$ The complete 1977-78 proximity matrix appears in Appendix B.

${ }^{2}$ See chapter III, pages 93-95, for a discussion on the ordinal level of measurement as it applies to the proximity data. 
scored a zero similarity; these extreme scores are presented in Table XI. Mellon Bank, which scored a zero in ten instances, most frequently exhibits no similarity with other firms in terms of candidates supported.

High similarity scores, defined as exceeding .50, are displayed in Table XII. Seventeen, or approximately two percent of the 861 firm dyads, exhibited similarity scores greater than .50. The General Motors and United Technologies dyad, with a similarity score of .594, exhibited the maximum consensus in candidates supported. Not surprisingly, high similarity scores often characterized pairs of firms from the same industry (eight pairs or fortyseven percent share a common Fortune-defined industry grouping whereas just two of the thirty zero-scoring pairs share a common industry grouping).

\section{DETERMINING DIMENSIONALITY}

This section delineates the parameters of the multidimensicnal scaling program and then describes the guidelines used to determine the preferred dimensionality (the latter draws largely from Kruskal and Wish 1978, chapter 3).

\section{Parameters}

The proximity data were analyzed using the ALSCAL procedure available in the SPSS-X package (SPSS Inc. 1988, 338-364). The following parameters were designated for the 
ALSCAL program: Scaling model was specified as the Euclidean distance model; the measurement level was specified as ordinal; measurement process was specified as continuous; the number of dimensions was set at one, two, three, four, and five; the convergence criterion was set at .00001 ; and the iteration criterion was set at one hundred.

\section{Dimensionality}

Dimensionality determination began with an examination of the five dimensions resulting from a series of unweighted classical Euclidean multidimensional scalings. Fit indices from each of the five solutions were then compared.

A model with $\mathrm{n}$ dimensions is preferred if the fit of the data is only marginally improved at $\mathrm{n}+1$ dimensions, however making this marginality judgment and taking into account various complicating factors involve both objective and subjective concerns.

The ALSCAL procedure reports three fit indices: RSQ, STRESS, and SSTRESS. These fit measures for the five scalings are presented in Table XIII.

The RSQ measure is the squared multiple correlation between the Euclidean distances (distances between the points in the MDS space) and the disparities (monotonically transformed proximity input data). It is interpreted as the proportion of variance of the disparities that can be accounted for by the MDS solution. As with any squared 
correlation measures, RSQ can vary from zero to one, i.e., from no fit to perfect fit.

STRESS and SSTRESS, goodness-of-fit measures which can vary from zero to one, measure unexplained variance, therefore lower values indicate better fit. Both STRESS and SSTRESS are the square roots of a normalized residual sum of squares. STRESS is defined on the Euclidean distance and the disparities; SSTRESS is defined on the squared Euclidean distances and the squared disparities (Kruskal and Wish 1978, 49; Easterling 1987, 232).

One way to determine dimensionality is to plot the RSQ and STRESS fit indices against the number of dimensions. An elbow in the plot, indicative of a sudden rise in RSQ or fall in STRESS, signifies that additional dimensions will not substantively improve the fit of the model.

Plots for the 1977-78 proximity data's RSQ and STRESS measures appear in Figure 3. While these plots do not exhibit the sharp elbow which can denote the preferred solution, an examination of the fit indices in Table XIII along with the associated graph of Figure 3 provides support for a three-dimensional solution. STRESS and RSQ improve by .07 as dimensions increase from two to three. The marginal improvement is less, approximately .04, as dimensions increase from three to four. While this evidence is less than definitive, it provides a starting point. 
The subjective determiners of interpretability and ease of use were applied to the 1977-78 scaled solution (Kruskal and Wish 1978, 56). Increasing dimensionality should always improve goodness of fit measures. If all dimensions are not interpretable, however, then a configuration with fewer, but interpretable, dimensions should be used. Further, a solution composed of too many dimensions adapts to random error in the data, thereby invalidating analysis (Kruskal and Wish 1978, 57).

Ease of use and interpretability are somewhat complementary considerations. Higher-dimensional configurations can confound comprehension of the MDS space, thereby weakening MDS as a data reduction technique. Also, the interpretive aspect of the higher-dimensional space may duplicate revelations in lower dimensionality. Complex configurations should be avoided unless the additional dimensions reveal previously obscured relationships.

While a four-dimensional solution could be supported based on the previously discussed determiners, the fourth dimension was not interpretable. A statistical and visual examination of the fourth dimension did not display any recognizable intercorporate pattern.

Based on the objective determiners of dimensionality (the fit indices; correlations between MDS solutions and interpretive variables) and the subjective considerations 
(interpretability; ease of use) a three-dimensional solution is selected for further analysis.

The Final Test

Given the selection of a three-dimensional solution, its corresponding ALSCAL output was further examined to ensure that the model is suitable for analysis. Two pieces of evidence support its suitability.

First, the iteration history for the three-dimensional solution indicates that the minimum SSTRESS improvement level was reached at iteration twenty-three, yet the ALSCAL parameter allowed for one hundred iterations (see Table $X I V)$. Further, the convergence level parameter was set at a high precision level of .00001 . This suggests that a true or global minimum convergence level was reported rather than a local minimum. ${ }^{3}$

Second, the three-dimensional solution's scatter plot of the computed distances in the MDS space and the actual observations (proximity values) was examined. A central

${ }^{3}$ As previously noted, ALSCAL is an iterative algorithm which halts the procedure and reports results when improvement in SSTRESS reaches some minimum or when a maximum number of iterations is exceeded (Young and Lewyckyj $1979,45)$. The spss-X default values are a maximum of thirty iterations and a minimum SSTRESS improvement criterion of .001 . Increasing the maximum number of iterations and the minimum SSTRESS convergence value can help ensure, first, that a global--as opposed to a local-minimum goodness of fit value is obtained and, second, that convergence is complete. These parameters were set to an iteration value of one hundred and a convergence of .00001 . 
premise of multidimensional scaling is that the distances between points on the MDS map should correspond to the input proximities (Kruskal and Wish 1978, 19). Inspection of the scatter diagram presented in Figure 4 reveals that this relationship exists. Since the input data are similarities, then the 'computed distances between the map coordinates (horizontal axis in Figure 4) should diminish as the degree of similarity between firm dyads (vertical axis) increases. ${ }^{4}$ While Figure 4 reveals a rather large amount of scatter, a decreasing function satisfies the relationship requirements since nonmetric MDS rank orders proximities (Kruskal and Wish 1978, 22).

Given the preceding evidence and rationale, the threedimensional solution is selected for hypothesis testing and exploratory analysis. The MDS configurations for the threedimensional solution appear in Figures 5, 6, and 7 .

\footnotetext{
${ }^{4}$ Distances are calculated by the Pythagorean formula: the distance between points $i$ and $j$ in $R$-dimensional space is equal to

$$
d_{i j}=\text { square root of }\left[\left(x_{i 1}-x_{j 1}\right)^{2}+\ldots .++\left(x_{i R}-x_{j R}\right)^{2}\right]
$$

where $x_{i 1}$ equals the point corresponding to the $i^{\text {th }}$ firm on the first map dimension or axis (Kruskal and Wish 1978, 17).

Degree of similarity between firms is calculated by the similarity measure presented on page 76 .
} 


\section{DIMENSION INTERPRETATION AND LABELING}

Interpreting the three dimensions leads rather naturally to labeling them and, in the process, makes discussing them easier than if each was known only by a number. Dimension one reflects the sample firms' regulatory environment, social versus economic, and is labeled requlatory. Dimension two reflects the sample firms' geographic dispersion and, thus, is labeled regional. dimension three reflects PAC strategy, pragmatic versus ideological, and is labeled strategy.

\section{Dimension One: Requlatory} Dimension

The relationship between regulatory environment and similar political activity emerges from an examination of the group space in Figure 5. Firms subject to economic regulation tend to dominate the negative end of the dimension one horizontal axis while those subject to social regulation dominate the positive end.

Further, since the interpretation of MDS is based on the distances between points, the median position of a coordinate axis can be shifted so long as the orthogonality between axes is maintained (Kruskal and Wish 1978, 34). Shifting the dimension one median to coordinate .103 permits 
maximal discrimination between the two categories of regulatory environment. ${ }^{5}$

The MDS space in Figure 5 reveals some interesting anomalies. It is particularly useful to identify those firms in which the hypothesized and observed MDS solution differ. Eight firms that are preclassified as subject to economic regulation (see Table XXV) are classified as subject to social regulation by MDS.

Four of these eight are in the transportation industry: United Air, TWA, Union Pacific, and Southern Pacific. This concentration is especially noteworthy since there are just five transportation firms in the entire sample. Further, the correctly classified transportation firm, Pan American, is positioned at -.1749 , close to the median of -.103 .

One plausible explanation for the differing classifications is regulatory reform. Transportation deregulation was initiated by the carter administration and resulted in the 1978 Airline Deregulation Act, the 1980 Motor Carrier Reform Act (directed at the trucking industry), and the 1980 staggers Railroad Act (Schnitzer 1990, chapter 14).6

${ }^{5}$ This regulatory environment relationship is analyzed with chi-square and regression in a later section which tests the resource dependence hypothesis.

"While the rail and trucking acts were not passed until 1980, preliminary deliberations establish their relevance for the 1977-78 time frame. 
This legislation phased out the Civil Aeronautics Board, the regulatory commission which determined fares, rates, schedules, and routes, thus ending a forty-year era. Similarly, the Motor Carrier and the Staggers Rail Acts of 1980 removed rate-setting restrictions and other constraints which impeded free market competition within the trucking and rail industries. An industry which heretofore had been governed day-to-day by stable economic regulations found itself in transition facing a dynamic regulatory climate. The MDS space classified two aerospace firms and one electronics firm as subject to social rather than economic regulation and placed two others (one aerospace and one electronics) quite near the median. Honeywell, Rockwell, and United Technologies are squarely on the social side of the median while Lockheed and General Electric are barely on the economic side. These firms were categorized as subject to economic regulation because a high proportion of their sales is in defense. This intercorporate pattern suggests that defense contractors' regulatory environment is somewhat different than that of most firms that are subject to industry-specific regulations. One might even suspect that defense contractors operate in a third sort of regulatory environment--partly economic and partly social.

Dimension one, the regulatory dimension, certainly supports the proposition that there is a systematic relationship between the proximity of PAC contributions and 
a firm's regulatory environment. This dimension taken

alone, however, does not reveal PAC strategies, the issue of dimension three.

Dimension Three: Strategy

Dimension

The strategy dimension appears to discriminate quite well between pragmatic and ideological PAC strategies. Table XV displays significant positive correlation between dimension three coordinates and contributions to Republicans $(r=.63 ; p<.0001)$ and New Right candidates $(r=.47 ; p<$ .0017); further, as expected, it is negatively related to contributions to incumbents $(r=-.59 ; \mathrm{p}<.0001)$. Regressing dimension three coordinates onto the same three candidate types accounts for forty-six percent of its variance $(p<.0001)$.

Pragmatic/Ideological classification. PAC strategy classifications are determined in accord with the following two-step process which employs aggregate statistics drawn from the 1977-78 Federal Election Commission reports: First, a firm is labeled ideological based on two criteria: (1) its proportion of total PAC dollars contributed to Republican candidates must exceed the proportion of total corporate PAC dollars (.63) contributed to Republicans by all corporate PACs during the 1977-78 election cycle, and (2) its proportion of total PAC dollars contributed to incumbents must be less than the proportion 
of total corporate PAC dollars (.58) contributed to incumbents by all corporate PACs' during the 1977-78 election cycle. The reverse scenario yields a pragmatic label. Application of this first step resulted in the classification of thirty-three of the forty-two sample corporate PACs.

The nine unclassified PACs had exceeded the allcorporate PACs' mean for both candidate types. Therefore, a second criterion classified these PACs based on contributions to New Right candidates. A PAC is classified ideological when its proportion of total PAC dollars contributed to New Right candidates exceeds the sample mean proportion (.16); if less than the sample mean, then pragmatic. Tables XVI and XVII list the ideological and pragmatic PACs, respectively. MDS map. Dimension three's discrimination between strategies is presented visually in Figure 6 . This dimension tends to position firms pursuing an ideological PAC strategy on the positive end of the vertical axis while firms pursuing a pragmatic PAC strategy dominate the negative end. Again, as previously discussed, since the interpretation of MDS is based on distance between points, the median can be shifted to better discriminate between categories. Positioning the median at -.109 achieves maximal discrimination between PAC strategies pursued by the sample firms. 
Chi-square. A chi-square analysis examined the relationship between the MDS-classified PAC strategy and the actual PAC strategy. Table XVIII displays each firm's dimension three coordinate, its actual PAC strategy, and its strategy category as determined by MDS. A firm's coordinate greater than -.109 classified its strategy as ideological; if less than -.109, then the MDS-determined PAC strategy classification is pragmatic. Ten firms were misclassified by the MDS solution.

The contingency table displayed in Table XIX compares MDS-determined and actual classifications. The resulting chi-square statistic of $14.013(\mathrm{p}<.002)$ and a value of .578 for phi, a derived measure of association strength, provide support for a systematic relationship between dimension three coordinates and PAC strategy. ${ }^{7}$

Dimension Two: Regional

Dimension

The regional dimension can be interpreted from the group space displayed in Figure 7 . When the axis is segmented at .5174 and -.4889, three geographic divisions are detectable. California and New York-Connecticut firms dominate opposite ends of the horizontal axis; the remaining firms gravitate toward the center. These three segments have been labeled, from left to right: Frontier

${ }^{7} \mathrm{Phi}$ equals zero when no relationship exists; positive 1 when a perfect relationship exists. 
(California), Heartland (Pennsylvania, Ohio, Illinois, Michigan, North Carolina, Texas, Minnesota, Missouri), and Eastern Establishment (New York-Connecticut).

Chi-square. To order the data for chi-square, the three regions were coded: Eastern Establishment, 1; Heartland, 2; and Frontier, 3. Chi-square compares the observed distribution of firms along dimension two with the one-to-three classification.

Table XX displays each firm's dimension two coordinate, its actual HQ location, its MDS-determined HQ location, and those instances when the actual and MDS HQ locations did not match. The contingency table (see Table XXI) and its chi-square statistic (39.491; $\mathrm{p}<.001$ ) support a systematic relationship between the regional dimension and actual Hd location. Phi, the measure of association, is .97.

CORRELATIONS AMONG VARIABLES

Correlations among variables within two groups are computed and presented in Table XXII: the hypothesized variables (regulatory environment, direct and indirect interlocks, professional associations, education, and headquarters location), and PAC characteristics (number of donees, total contribution dollar amount, proportion contributed to incumbents, Republicans, and New Right candidates). To augment the correlation matrix, Table XXIII 
displays the means and standard deviations of the intervallevel variables.

Hypothesized Variables

Requlatory environment. Table XXII reveals no significant correlations between the resource dependence variable (regulatory environment) and any of the class cohesion variables (direct/indirect interlocks, professional associations, schools, and headquarters location). Class cohesion variables. Table XXII reveals significant correlations among various class cohesion variables.

As expected, the correlation between direct and indirect interlocks is high, .74 , and significant at the .0001 level. A firm which promotes multiple board membership among its directors is likely to be linked, both directly and indirectly, with other firms in the sample.

While the correlation is not as strong, there is also a significant relationship between the number of professional association memberships and interlocking directorates $(p<.003$ with direct and $p<.0006$ with indirect interlocks). This, again, is reasonable since activity on multiple boards is characteristic of the corporate executive who would be invited to participate in prestigious business associations. 
PAC Characteristics

The significant relationships among characteristics of PAC activity are consistent with expected patterns. Contributions to incumbents, on the one hand, and Republican or New Right candidates, on the other, are negatively correlated $(r=-.80 ; p<.00001$ and $r=-.84 ; p<.0001$, respectively). This pattern is consistent with the likelihood that a pragmatic PAC strategy, which favors incumbents, deemphasizes the candidate's party affiliation (Burris 1987, 735).

Two other correlations are also consistent with expected patterns. First, the positive correlation between contributions to New Right and Republican candidates ( $r=$ $.82 ; p<.0001)$ reflects the predominant party affiliation of New Right candidates. Second, the positive correlation between total dollars contributed and number of candidates supported $(r=.84 ; p<.0001)$ quite reasonably suggests that firms with larger PAC coffers will support more candidates.

Requlatory Environment and PAC Characteristics

To this point, the discussion of Table XXII has focused on correlations within the two categories-hypothesized variables and PAC characteristics. One correlation that crosses between these categories' 
boundaries is of interest because it reflects current theory.

Regulatory environment is negatively correlated with proportion of contributions going to Republicans and New Right candidates $(\mathrm{r}=-.33 ; \mathrm{p}<.03 ; \mathrm{r}=-.40 ; \mathrm{p}<.008$, respectively). As previously explained, regulatory environment was coded "l" for economic environment and "0" for social environment. Therefore, social environment is directly associated with Republican/New Right contributions.

This pattern agrees with the theory which holds that firms will favor an ideological PAC strategy when faced with greater social rather than economic regulatory pressures (see page 80 ). The next section, which examines the resource dependence component of the research question, expands on this preliminary finding.

\section{RESOURCE DEPENDENCE}

This section addresses the research question: Can resource dependence theory explain intercorporate patterns of corporate political activity, specifically political action committee (PAC) campaign contributions?

\section{The Hypothesis Test}

Research Hypothesis: Firms similarly constrained by government regulations will exhibit similar political behavior. 
Null Hypothesis: There is no significant relationship between a firm's MDS coordinates and its regulatory environment classification.

Requlatory Dimension. Dimension one, the regulatory dimension, provides a direct test of the hypothesis. The sample firms are positioned along the horizontal axis according to their similarities (Figure 5). Therefore, if groupings are coincident with regulatory environment, the null hypothesis is rejected and the research hypothesis supported. Three tests were employed to ascertain whether this coincidental condition holds.

Multiple regression. The resource dependence hypothesis was first tested with multiple regression. The independent variables are the sample firms' coordinates on the three-dimensional MDS solution, each coordinate serving as a distinct representation of corporate political activity as measured by similar PAC contributions. The dependent variable is a firm's regulatory environment classification-social or economic (Table V, page 103). The regression model, which attempts to predict a firm's regulatory environment classification based on its position in the MDS space, is:

REG ENV $=B_{0}+B_{1}(D I M I)+B_{2}(D I M 2)+B_{2}(D I M 3)+$ error

This model results in a multiple correlation coefficient of .45 , and a significant coefficient of determination of $.20(p<.05)$. The bulk of this 
relationship is accounted for by the regulatory dimension, dimension one: $\mathrm{b}=-.19625, \mathrm{p}<.01 ; \mathrm{r}=.425, \mathrm{p}<.01$ (see Table XXIV, equation (1)).

Therefore, based on multiple regression analysis, the null hypothesis that there is no significant relationship between regulatory environment and patterns of PAC activity is rejected.

Discriminant analysis. A discriminant analysis not only reinforced the regression results but also provided the means to determine the number of firms which are correctly classified by their MDS coordinates. Tables XXV and XXVI present a discriminant classification summary and the identity of the eight firms which were incorrectly classified based on their MDS coordinates.

The model is statistically significant with a squared canonical correlation of .20 and a Wilks' lambda of .80 ( $F=$ $3.146 ; \mathrm{p}<.04)$. As expected, given the regression results, the structure coefficient for dimension one is a high .95, while dimensions two and three structure coefficients are .38 and -.01 respectively. This indicates that 90 percent of the variance of dimension one is being accounted for by the discriminant function.

Chi-square. The chi-square test is useful because it does not require interval data and therefore is a conservative test of significance when interval data are redefined as ordinal or nominal. It can be applied in this 
instance because the regulatory environment classification resulted in mutually exclusive and exhaustive categories and in independent observations which can be reduced to a nominal-level variable. Dimension one provides a good measure of regulatory environment, so its coordinates serve to assign each firm into one of two nominal values of the observed regulatory environment; the predicted environment uses each firm's hypothesized classification. Chi-square tests the relationship between the predicted and observed regulatory environment classifications.

The chi-square statistic, 12.78 , is significant at the .0001 level, thereby supporting the research hypothesis. This support is confirmed by the measure of association, phi, at .55. Therefore, based on chi-square analysis, the null hypothesis that there is no significant relationship between regulatory environment and patterns of PAC activity is rejected (see Tables XXVII and XXVIII.)

\section{Discussion}

This support for the research hypothesis carries with it substantial theoretical and pragmatic consequences. First, an important question that has been discussed extensively in the literature is confirmed, i.e., resource dependence and political action are related. Second, by analyzing a firm's pattern of PAC contributions, the policy maker can determine whether that firm's behavior conforms to that expected because of its regulatory environment. If 
not, one would be prompted to examine other similar firms in search of a trend.

Previous research supported. Quadrants II and IV in Figure 6 represent the environment/strategy combinations suggested by earlier research (Handler and Mulkern 1982; Burris 1987; Neustadtl and Clawson 1988). This research posits that firms subject to social rather than economic regulations are inclined to pursue an ideological PAC strategy (quadrant II); firms subject to economic regulation are inclined toward pragmatic PAC strategy (quadrant IV). Firms positioned in quadrants II and IV in Figure 6 generally support this research. Six of the eight firms in quadrant IV (economic/pragmatic) and twelve of the nineteen firms located in quadrant II (social/ideological) are correctly mapped. Possible explanations for the incorrectly mapped defense contractors and transportation services firms have been proposed (see pages 118-119).

Previous research extended. The structure of firms mapped into quadrants I and III is more interesting, because it extends previously reported research rather than simply confirming it. Quadrant I (economic/ideological) contains eight firms and quadrant III (social/pragmatic) contains seven.

Six of the eight firms positioned in quadrant I (economic/ideological) are commercial banks, one is an insurance corporation, and one represents the aerospace 
industry. Financial institutions are subject to industryspecific regulations and therefore, according to previously reported research, inclined toward pragmatic political strategies.

To a greater or lesser extent, four of the six banks employed strategies counter to theory. Mellon and Security Pacific pursued a highly ideological strategy. ${ }^{8}$ First Chicago and Manufacturers Hanover Trust pursued what could be described as a mixed PAC strategy--they both supported incumbents, but favored Republican over Democratic incumbents (both their Republican support and incumbent support patterns exceeded the all-corporate PACs' means). Citicorp and Wells Fargo are classified as pragmatic with above-average incumbent support and below-average Republican support; however, Wells Fargo's New Right contribution pattern (thirteen percent contributed to New Right candidates) is relatively high for a pragmatic PAC.

Quite obviously, the PAC contribution behavior of the banks in this sample does not neatly conform to patterns previously reported in the literature. Neustadtl and Clawson (1988) noted that

[industry-specific] regulated industries are so heavily dependent on the specifics and details of Congressional

${ }^{8}$ Mellon National and Security Pacific each contributed thirty percent of their PAC dollars to New Right candidates (sample mean was sixteen percent). 
legislation that they pay a higher than usual cost for opposing incumbents. Hence, whatever their personal preferences, they are less likely to join others in conservative ideological. strategies (183).

Similarly, Burris (1987) reported that the traditionallyregulated industries and defense contractors exhibited the lowest contribution patterns to Republicans and New Right candidates $(736)$.

This apparent divergence from prior research suggests two considerations. First, a criterion for this research sample was inclusion of diverse industries. Consequently, any one industry is represented by a small number of firms. Therefore, the sample size precludes projection to the population, at least with any meaningful level of confidence. Nevertheless, since four of the six banks in this sample exhibited PAC contribution patterns which did not neatly conform to prior research (and a fifth exhibited some predilection for New Right candidates), further consideration is warranted.

Second, given the above proviso, pending deregulation is a credible explanation for the divergence. The deregulation pendulum was given a push from three sources during the late 1970s. Technological advances in electronic communication radically changed a financial institution's potential geographic scope; consumer advocates argued that regulated interest ceilings discriminated against small savers; and the Federal Reserve's attempts to combat doubledigit inflation resulted in skyrocketing interest rates-- 
banks were placed at a competitive disadvantage against their unregulated competitors such as money market or private pension funds. These pressures culminated in the landmark Depository Institutions Derequlation and Monetary Control Act $(1980)$ followed by the Depository Institution Act $\left(1982_{1}\right)$. This legislation removed interest rate ceilings on deposits, authorized interest-bearing checking accounts nationwide, and facilitated interstate banking (Schnitzer 1990, chapter 15).

Larger financial institutions benefit most from an extended geographic market. Thus, the large commercial banks would be expected to lobby for deregulation and support these lobbying efforts with pragmatic PAC strategies. Nevertheless, it is also quite reasonable to argue that major banks would have attempted to improve the chances of deregulation by supporting Republican and New Right challengers in an effort to move Congress to the right.

Seven firms are mapped in quadrant III (social/pragmatic). Two, R. J. Reynolds and Philip Morris, represent the tobacco industry, the very existence of which is threatened by social, political, and legal forces (Business Week 1987). Both firms have undertaken vigorous activity in two arenas subject to adverse federal scrutiny-aggressive acquisition programs (FTC and the Justice Department) and aggressive promotion of cigarettes overseas, 
especially in lesser developed nations (Department of Commerce and Department of state). Given such conditions, it is not surprising that a PAC contribution analysis would position these firms uniquely.

GTE is also curiously positioned in quadrant III. Theoretically, GTE should exhibit pragmatic tendencies given its economic regulatory environment--yet its actual contributions patterns are more indicative of an ideological strategy. The apparent inconsistencies might be explained by the dynamic environment confronting the telecommunications industry at that time. AT\&T was in the midst of landmark antitrust proceedings which spanned 1974 through 1982. Since AT\&T's breakup would open new markets to GTE, it could reasonably be argued that GTE management might practice contribution patterns which deviated from the norm with its sights set on the potential spoils from the demise of AT\&T's monopoly power.

Two transportation firms, Southern Pacific and TWA, are also positioned in quadrant III. As previously stated, this unpredicted mapping (theoretically, these two firms should be positioned with the economically regulated firms, that is, on the left side of the horizontal axis) could be attributed to the regulatory upheaval which was occurring in the transportation segment (see pages 118-119). 
Summary of Resource Dependence

Hypothesis Testing

Analysis of the 1977-78 PAC contribution data supports the hypothesis that firms similarly constrained by government regulations will exhibit similar political behavior, but it does not always support the prevalent theory concerning the nature of this behavior, i.e., the economic/pragmatic and social/ideological pairings.

Some explanations for this divergence from prior research 'were posited. These included the deregulation of transportation services and banking which occurred in the late 1970s and early 1980s; the unique social, political, and legal pressures on the tobacco industry; and the potential impact of the ongoing, landmark antitrust AT\&T case. Also, the inconsistent pattern among firms within the electronics and aerospace industry (equally divided on both social and economic domain and the ideological-pragmatic continuum) suggests that this particular industry segment is pursuing eclectic political strategies and should be researched separately.

CLASS COHESION

This section addresses the research question: Can class cohesion theory explain intercorporate patterns of corporate political activity, specifically political action committee (PAC) campaign contributions? 
The Hypothes is Tests

Class cohesion theory is tested with four research hypotheses--H2 through H5. These hypotheses and their associated null hypotheses are presented below:

H2: Firms' number of interlocking directorates will relate directly to similar political behavior among firms.

$\mathrm{HO}_{2}$ : There is no significant relationship between a firm's MDS coordinates and its number of direct or indirect interlocks with the set of sampled firms.

H3: Firms' number of associations with certain prestigious business policy groups will relate directly to similar political behavior among firms.

$\mathbf{H O}_{3}$ : There is no significant relationship between a firm's MDS coordinates and its number of associations with major business policy groups.

H4: Shared educational experience among Board Chairmen and CEOs will relate directly to similar political behavior among firms.

$\mathrm{HO}_{4}$ : There is no significant relationship between a firm's MDS coordinates and a shared educational experience among Chairmen and CEOs.

H5: Geographically proximate headquarters will relate directly to similar political behavior among firms.

$\mathrm{HO}_{5}$ : There is no significant relationship between a firm's MDS coordinates and its headquarters' location. 
Multiple reqression. The class cohesion hypotheses were tested with five regression models in which intercorporate networks (dependent variable) are predicted by MDS coordinates (independent variables). The respective intercorporate networks, or dependent variables, for each of the five models are: the number of direct interlocks (hypothesis 2); the number of indirect interlocks (hypothesis 2); the number of professional associations (hypothesis 3); a dummy-coded variable representing the chairman and/or president's education (hypothesis 4); and a dummy-coded variable indicating location of corporate headquarțers (hypothesis 5 ).

Table XXIV (equations 2 through 6) displays the regression, canonical, and correlation coefficients for each of the three coordinates from the MDS solution as it relates to the determinants of class cohesion theory. Also reported are the coefficients of determination and Wilks' lambda (where applicable), and associated $F$ values for each model. Asterisks indicate significance levels.

Null hypotheses two, three and four cannot be rejected. There is no apparent relationship between corporate political activity as measured by the proximity of PAC contributions and the extent of a corporation's interlocking directorates, its number of professional 
associations, or its president's and CEO's educational background. 9

The multiple regression analysis offers some support for the geographic proximity model of class cohesion. A significant wilks lambda of $.388(F=2.08 ; p<.01)$ calls for rejection of the null hypothesis, thereby supporting the model. As discussed in the next section, however, the support does not hold up under further examination.

Discussion

Discriminant analysis fails to support a model of political behavior driven by class cohesion. Logically, same-state headquarters should be more conducive to social cohesiveness among executives than headquarters spread over a multi-state region. Accordingly, if the geographic proximity model of class cohesion holds, one would expect discriminant analysis to perform fairly well in assigning firms to their correct states. On the contrary, the data in Table XXIX show that discriminant analysis misclassified twenty-five of the forty-two firms.

There is support for a regional model, both visually in the MDS map (Figure 7) and statistically. Eastern and western firms are positioned at opposite ends of the regional dimension, with Heartland firms positioned in the

'Equation two of Table XXIV indicates a weak association between dimension one's regression coefficient and direct interlocks; however the overall model is not significant. 
middle. Second, the chi-square test (Table XXI) shows a significant relationship between the eastern firms' pragmatic political behavior and the western firms' ideological political behavior. Further, the correlation between dimension two and the regional clusterings is significant $(p<.002)$ (Table XXII).

Reqional theory. Various regional theories of business partisanship emerged in the late 1970 s and early 1980s. The so-called Yankee-Cowboy theory has been advanced as an explanation for the emergence of the New Right as a political force. This theory argues that managements of the booming Sun Belt industries (defense, oil, agribusiness, textiles, construction) tended to be more conservative and ideological and thus were more likely to support New Right candidates. Adherents argue that these new Cowboys overshadowed the more politically moderate eastern industries (the Yankees). As a consequence, the 1980 s saw the Republican right wing gain power, resulting in a decade of business hegemony in American politics (Dye 1976, 178186; Sale 1976, 89-152; Crawford 1980, 78-110; Davis 1981, 39-43; Burris 1987, 734).

Burris' (1987) recent research, which examined the similarity of PAC contributions among corporations during the 1981-82 election cycle, supports the Yankee-Cowboy theory, but his conclusions are cautious. He suggests that this regional dichotomy may be too simplistic to capture the 
nuances of regional variation in business political partisanship. Burris reports that sun Belt industries did disproportionately support Republican and New Right candidates, but that there were notable exceptions. Similarly, defense contractors were not uniformly more conservative. Burris ponders the possible influence of the Sun Belt's distinctive political institutions and cultures or the impact of old family money versus new entrepreneurial money in affecting political attitudes but concludes that the underlying causes of regional differences in business political partisanship are still unknown.

Summary of Class Cohesion Hypothes is Testing

Analysis of the 1977-78 PAC contribution data provides some support for one hypothesis associated with the class cohesion theory: Firms with geographically proximate headquarters will exhibit similar behavior. New YorkConnecticut and california headquartered firms are positioned at opposite ends of dimension two on the MDS map which scales similar corporate PAC contributions; but no other pattern of headquarters clustered by state emerged. The observed intercorporate pattern lends more support to a regional than to a class cohesion theory of business partisanship. 
CHAPTER SUMMARY

Four major conclusions have resulted from this structural analysis of the 1977-78 PAC contribution proximity data.

1. The research question, can resource dependence theory explain intercorporate patterns of corporate political activity as measured by PAC campaign contributions, is answered in the affirmative. The null hypothesis is rejected at high confidence levels. Therefore, it can be concluded, in support of resource dependence, that firms similarly constrained by government regulations exhibited similar political behavior.

2. Minimal support emerged for the complementary research question which advanced class cohesion theory as an explanation for patterns of political consensus among corporate executives. No significant relationship was discovered between a firm's MDS coordinates and three determiners of a corporate network: Interlocking directorates, professional associations, and educational experience. The null hypothesis that there is no significant relationship between a firm's MDS coordinates and its headquarters location is rejected, however. There is an apparent relationship between geographically proximate headquarters locations and the selection of corporate PAC 
contribution recipients. A regional model of business partisanship rather than a class cohesion model emerges from the intercorporate structure.

3. Classes of firms are identified which deviate from prior research regarding expected regulatory environment. The observed pattern of intercorporate relations revealed by structural analysis suggests explanations for this divergence. These included the deregulation of banking and transportation services, the potential fall-out from the landmark AT\&T antitrust proceedings, and the unique social, political, and legal pressures on the tobacco industry.

4. Finally, no clear pattern emerged for firms which are highly dependent on government contracts. This suggests that the corporate political activity for this segment is eclectic. Consequently, further research which focuses strictly on this segment is recommended. 
TABLE $X$

DISTRIBUTION OF 1977-78 SIMILARITY MEASURES

OUARTILES AND INTERQUARTILE RANGE

\begin{tabular}{ll} 
Quartiles & Values \\
\cline { 2 - 2 } Maximum & 0.594 \\
03 & 0.308 \\
Median & 0.199 \\
01 & 0.110 \\
Minimum & 0 \\
Interquartile range & 0.197
\end{tabular}


TABLE XI

FIRM DYADS EXHIBITING ZERO POLITICAL CONSENSUS

1977-78 ELECTION

\section{Firm}

2. American Electric Power

7. Citicorp

8. Consolidated Edison

11. First Chicago

15. GTE

16. Goodyear

17. Honeywell

23. Mellon

28. Pan American

29. RJR

32. Security Pacific

33. Southern Pacific

35. TWA

36. Union Carbide

37. Union Pacific

41. Vells Fargo

Notes: 0 marks the 30 firm dyads which exhibit zero political consensus.

Mellon Bank, with ten instances of zero political consensus, exhibited the greatest frequency of dissimilar behavior.

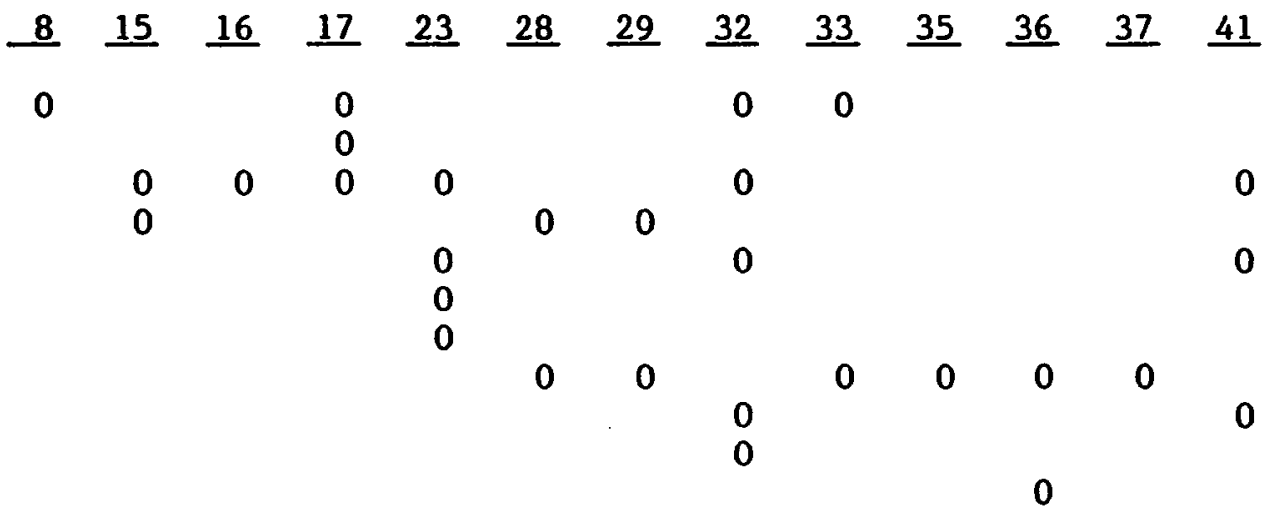

0

0

0

0

0

0 


\section{TABLE XII}

FIRM DYADS EXHIBITING HIGH POLITICAL CONSENSUS 1977-78 ELECTION

\begin{tabular}{l} 
Firm \\
\hline 4. Arco \\
7. Citicorp \\
12. Ford \\
13. GE \\
14. GM \\
19. K Mart \\
20. Lockheed \\
21. LTV \\
22. Manufacturers Hanover \\
27. Penney \\
31. Sears \\
32. Security Pacific \\
34. Texaco \\
35. United Technologies \\
41. Wells Fargo
\end{tabular}

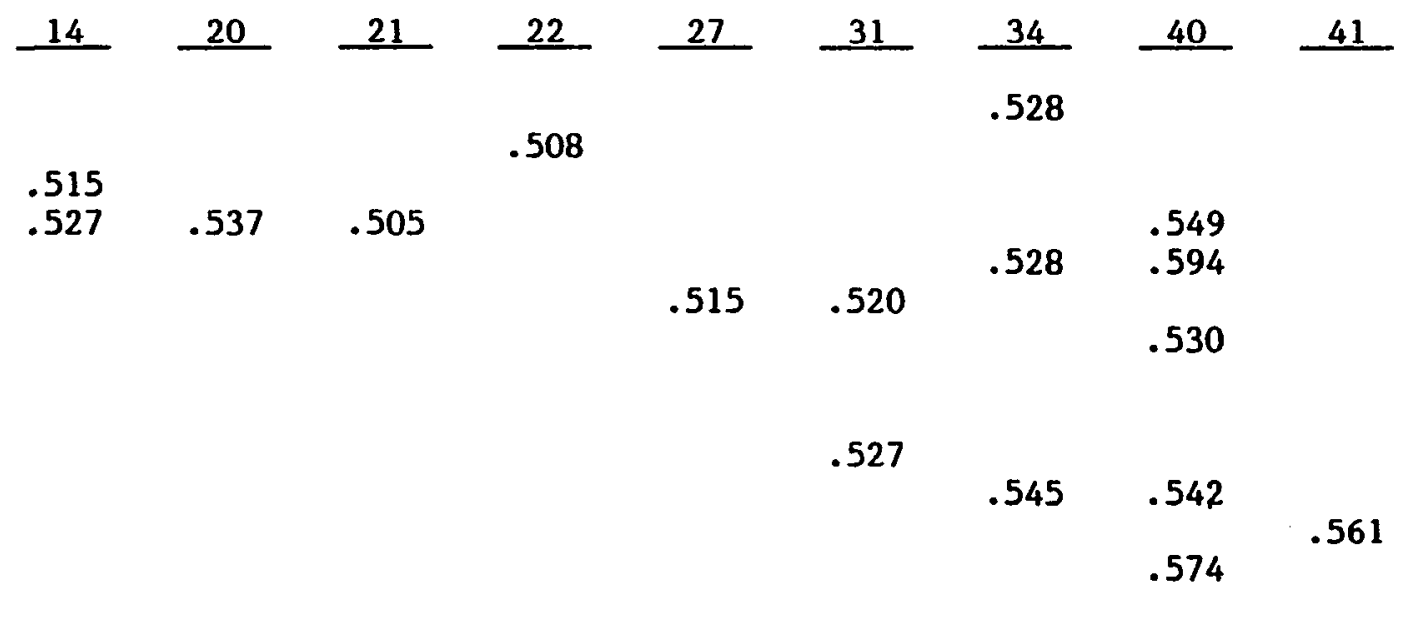

Note: Matrix cells identify the 34 dyads exhibiting high political consensus, defined as similarity scores greater then .50 . 


\section{TABLE XIII}

FIT INDICES FOR FIVE EUCLIDEAN MODELS

1977-78 SIMILARITY DATA

MDS

Dimensionality Stress SStress RSQ

$\begin{array}{llll}1 & .374 & .460 & .652 \\ 2 & .240 & .322 & .781 \\ 3 & .170 & .240 & .851 \\ 4 & .132 & .185 & .891 \\ 5 & .111 & .153 & .910\end{array}$


TABLE XIV

ITERATION HISTORY FOR THE THREE-DIMENSIONAL SOLUTION 1977-78 ELECTION

\section{Iteration SStress Improvement}

$\begin{array}{rll}1 & 0.457 & \\ 2 & 0.291 & 0.166 \\ 3 & 0.259 & 0.032 \\ 4 & 0.250 & 0.009 \\ 5 & 0.247 & 0.003 \\ 6 & 0.245 & 0.002 \\ 7 & 0.244 & 0.001 \\ 8 & 0.243 & 0.001 \\ 9 & 0.242 & 0.001 \\ 10 & 0.242 & 0.001 \\ 11 & 0.241 & 0.000 \\ 12 & 0.241 & 0.000 \\ 13 & 0.241 & 0.000 \\ 14 & 0.241 & 0.000 \\ 15 & 0.240 & 0.000 \\ 16 & 0.240 & 0.000 \\ 17 & 0.240 & 0.000 \\ 18 & 0.240 & 0.000 \\ 19 & 0.240 & 0.000 \\ 20 & 0.240 & 0.000 \\ 21 & 0.240 & 0.000 \\ 22 & 0.240 & 0.000 \\ 23 & 0.240 & 0.000\end{array}$

Note: Iterations stopped because SStress improved less than 0.000010 
TABLE XV

CORRELATIONS BETWEEN DIMENSION THREE COORDINATES AND CANDIDATE TYPE 1977-78 ELECTION

\begin{tabular}{|c|c|c|c|c|}
\hline & Dimension 3 & Incumbent & Republican & New Right \\
\hline Dimension 3 & $\begin{array}{l}1.000 \\
0.000\end{array}$ & $\begin{array}{r}-0.589 \\
0.000\end{array}$ & $\begin{array}{l}0.634 \\
0.000\end{array}$ & $\begin{array}{l}0.469 \\
0.002\end{array}$ \\
\hline Incumbent & & $\begin{array}{l}1.000 \\
0.000\end{array}$ & $\begin{array}{r}-0.801 \\
0.000\end{array}$ & $\begin{array}{r}-0.840 \\
0.000\end{array}$ \\
\hline Republican & & & $\begin{array}{l}1.000 \\
0.000\end{array}$ & $\begin{array}{l}0.821 \\
0.000\end{array}$ \\
\hline New Right & & & & $\begin{array}{l}1.000 \\
0.000\end{array}$ \\
\hline
\end{tabular}


TABLE XVI

IDEOLOGICAL PAC CONTRIBUTION PATTERNS 1977-78 ELECTION

$\longrightarrow$ Firm

ALCOA

Arco

Dow

Ford

GM

GTE

Goodyear

Honeywell

International Harvester

$\mathrm{K}$ Mart

Mellon

Rockwell

Sears

Security Pacific

Texaco

Union Carbide

United Air Lines

USX

United Technologies
Proportion of Dollars Donated to

Incumbent Republican New Right

$\begin{array}{lll}.574 & .657 & .214 \\ .579 & .743 & .223 \\ .314 & .909 & .460 \\ .586 & .717 & .191 \\ .687 & .701 & .177 \\ .551 & .650 & .067 \\ .448 & .875 & .323 \\ .182 & .944 & .338 \\ .622 & .773 & .178 \\ .425 & .738 & .298 \\ .385 & .597 & .298 \\ .808 & .653 & .206 \\ .514 & .755 & .298 \\ .489 & .667 & .241 \\ .413 & .844 & .406 \\ .670 & .706 & .168 \\ .693 & .644 & .164 \\ .596 & .624 & .212 \\ .592 & .769 & .214\end{array}$

Note: Categories overlap, e.g., a candidate can be a Republican incumbent. 
TABLE XVII

PRAGMATIC PAC CONTRIBUTION PATTERNS

1977-78 ELECTION

Proportion of Dollars Donated to

Firm

American Electric Power
American Express
Bethlehem Steel
Chrysler
Citicorp

Citicorp

Consolidated Edison

Federated Department Store

First Chicago

GE

Lockheed

LTV

Manufacturers Hanover

Metropolitan Life Insurance

Monsanto

Pan American

Penney

Philip Morris

RJR

Southern Pacific

TWA

Union Pacific

Wells Fargo

Westinghouse

Incumbent Republican

.765

.878

.693

.649

.771

.760

.825

.657

.701

.810

.693

.721

.786

.744

.866

.628

.787

.730

.754

.799

.640

.746

.677
.392

.403

.594

.555

.504

.290

.309

.651

.476

.519

.358

.636

.455

.521

.360

.591

.436

.502

.364

.317

.462

.535

.493
New Right

.118

.015

.218

.123

.069

.043

.024

.048

.097

.107

.050

.075

.053

.106

.036

.191

.181

.120

.091

.020

.144

.132

.115

Note: Categories overlap, e.g., a candidate can be a Republican incumbent. 
TABLE XVIII

ACTUAL AND MDS-GENERATED STRATEGY CATEGORIES 1977-78 ELECTION

\begin{tabular}{|c|c|c|c|c|}
\hline \multirow[b]{2}{*}{ ID\# } & \multirow[b]{2}{*}{ Firm } & \multirow{2}{*}{$\begin{array}{c}\text { Dimension } \\
\text { Three }\end{array}$} & \multicolumn{2}{|c|}{ Strategy Category } \\
\hline & & & Actual & MDS \\
\hline 1 & ALCOA & 0.866 & Ideological & Ideological \\
\hline 2 & American Electric Power & & Pragmatic & Pragmatic \\
\hline 3 & American Express & -0.214 & Pragmatic & Pragmatic \\
\hline 4 & Arco & 0.159 & Ideological & Ideological \\
\hline 5 & Bethlehem Steel & -1.700 & Pragmatic & Pragmatic \\
\hline 6 & Chrysler & 0.144 & Pragmatic & Ideological* \\
\hline 7 & Citicorp & 0.031 & Pragmatic & Ideological* \\
\hline 8 & Consolidated Edison & -0.719 & Pragmatic & Pragmatic \\
\hline 9 & Dow & 1.6 & Ideological & Ideological \\
\hline 10 & Federated Department Store & -0.8 & Pragmatic & Pragmatic \\
\hline 11 & First 'Chicago & 1.501 & Pragmatic & Ideological. \\
\hline 12 & Ford & 0.239 & Ideological & Ideological \\
\hline 13 & GE & -0.180 & Pragmatic & matic \\
\hline 14 & GM & -0.109 & Ideological & logical \\
\hline 15 & GT & -1.404 & Ideological & Pragmatic* \\
\hline 16 & Goodyear & 0.921 & Ideological & Ideological \\
\hline 17 & Honeywell & 35 & Ideological & Ideological \\
\hline 18 & International Harvester & & Ideological & Ideological \\
\hline 19 & $\mathrm{~K}$ Mart & 0.6 & Ideological & ological \\
\hline 20 & Lockheed & 0.3 & Pragmatic & ological. \\
\hline 21 & LTV & -0.634 & Pragmatic & jmatic \\
\hline 22 & Manufacturers Hanover & 0.621 & Pragmatic & ological. \\
\hline 23 & Mellon & & Ideological & Ideological \\
\hline 24 & Metropolitan Life Insurance & 0. & Pragmatic & Ideological* \\
\hline 25 & Monsanto & -0 . & Pragmatic & Pragmatic \\
\hline 26 & Pan American & -0 . & Pragmatic & gmatic \\
\hline 27 & Penney & & Pragmatic & ological. \\
\hline 28 & Philip Morris & -1 . & Pragmatic & gmatic \\
\hline 29 & RJR & -1 & Pragmatic & matic \\
\hline 30 & Rockwell & -0 . & Ideological & ological \\
\hline 31 & Sears & 0 . & Ideological & Ideological \\
\hline 32 & Security Pacific & & Ideological & Ideological \\
\hline 33 & Southern Pacific & -0 . & Pragmatic & Pragmatic \\
\hline 34 & Texaco & & Ideological & Ideological \\
\hline 35 & TWA & -1.438 & Pragmatic & Pragmatic \\
\hline 36 & Union Carbide & 0.160 & Ideological & Ideological \\
\hline 37 & Union Pacific & -0 . & Pragmatic & Ideological * \\
\hline 38 & United Air Lines & 0. & Ideological & Ideological \\
\hline 39 & USX & -0. & Ideological & Ideological \\
\hline 40 & United Technologies & 0.0 & Ideological & Ideological \\
\hline 41 & Wells Fargo & 0.7 & Pragmatic & Ideological. \\
\hline 42 & Westinghouse & -0.228 & Pragmatic & Pragmatic \\
\hline
\end{tabular}

Misclassified 


\section{TABLE XIX}

ACTUAL AND MDS-GENERATED STRATEGY CATEGORIES CHI-SQUARE CONTINGENCY TABLE

1977-78 ELECTION

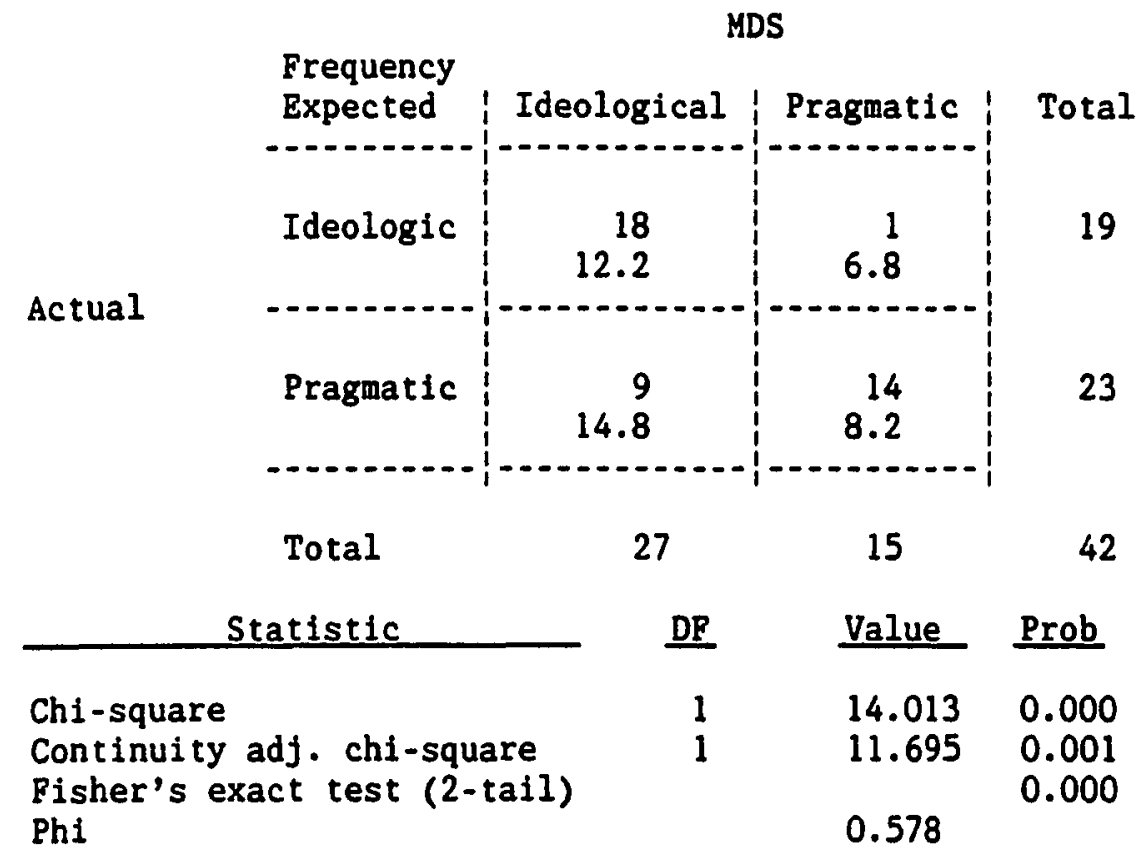

Sample size $=42$ 
TABLE XX

ACTUAL AND MDS-GENERATED HEADQUARTERS LOCATION 1977-78 ELECTION

\begin{tabular}{|c|c|c|c|c|}
\hline \multirow[b]{2}{*}{ ID\# } & \multirow[b]{2}{*}{ Firm } & \multirow{2}{*}{$\begin{array}{c}\text { Dimension } \\
\text { Two }\end{array}$} & \multicolumn{2}{|c|}{ Headquarters } \\
\hline & & & Actual & MDS \\
\hline 1 & ALCOA & 0.517 & CENTRAL & CENTRAL \\
\hline 2 & American Electric Power & -0.264 & CENTRAL & CENTRAL \\
\hline 3 & American Express & 0.649 & $\mathrm{NY}-\mathrm{CT}$ & $\mathrm{NY}-\mathrm{CT}$ \\
\hline 4 & Arco & -0.700 & CALIF & CALIF \\
\hline 5 & Bethlehem Steel & 0.158 & CENTRAL & CENTRAL \\
\hline 6 & Chrysler & 0.624 & CENTRAL & $\mathrm{NY}-\mathrm{CT}$ \\
\hline 7 & Citicorp & 0.775 & $\mathrm{NY}-\mathrm{CT}$ & NY-CT \\
\hline 8 & Consolidated Edison & 2.429 & $\mathrm{NY}-\mathrm{CT}$ & $\mathrm{NY}-\mathrm{CT}$ \\
\hline 9 & Dow & 0.437 & CENTRAL & CENTRAL \\
\hline 10 & Federated Department Store & -0.497 & CENTRAL & CALIF* \\
\hline 11 & First Chicago & -0.457 & CENTRAL & CENTRAL \\
\hline 12 & Ford & -0.307 & CENTRAL & CENTRAL \\
\hline 13 & GE & -0.118 & NY-CT & CENTRAL \\
\hline 14 & GM & 0.016 & CENTRAL & CENTRAL \\
\hline 15 & GTE & 2.245 & $\mathrm{NY}-\mathrm{CT}$ & $\mathrm{NY}-\mathrm{CT}$ \\
\hline 16 & Goodyear & 0.172 & CENTRAL & CENTRAL \\
\hline 17 & Honeywell & -0.033 & CENTRAL & CENTRAL \\
\hline 18 & International Harvester & 0.392 & CENTRAL & CENTRAL \\
\hline 19 & $\mathrm{~K}$ Mart & 0.037 & CENTRAL & CENTRAL \\
\hline 20 & Lockheed & -0.489 & CALIF & CALIF \\
\hline 21 & LTV & -0.344 & CENTRAL & CENTRAL \\
\hline 22 & Manufacturers Hanover & 1.175 & $\mathrm{NY}-\mathrm{CT}$ & $\mathrm{NY}-\mathrm{CT}$ \\
\hline 23 & Mellon & 0.121 & CENTRAL & CENTRAL \\
\hline 24 & Metropolitan Life Insurance & 1.174 & $\mathrm{NY}-\mathrm{CT}$ & $\mathrm{NY}-\mathrm{CT}$ \\
\hline 25 & Monsanto & 0.517 & CENTRAL & CENTRAL \\
\hline 26 & Pan American & -0. & NY-CT & CENTRAL \\
\hline 27 & Penney & -0.337 & NY $-\mathrm{CT}$ & CENTRAL \\
\hline 28 & Philip Morris & 0.937 & NY $-\mathrm{CT}$ & $\mathrm{NY}-\mathrm{CT}$ \\
\hline 29 & RJR & 0.506 & CENTRAL & CENTRAL \\
\hline 30 & Rockwell & -1.218 & CALIF & CALIF \\
\hline 31 & Sears & -0.244 & CENTRAL & CENTRAL \\
\hline 32 & Security Pacific & -2.461 & CALIF & CALIF \\
\hline 33 & Southern Pacific & -1.789 & CALIF & CALIF \\
\hline 34 & Texaco & 0.571 & NY $-\mathrm{CT}$ & $\mathrm{NY}-\mathrm{CT}$ \\
\hline 35 & TWA & -0.630 & NY-CT & CALIF * \\
\hline 36 & Union Carbide & 1.167 & NY-CT & $\mathrm{NY}-\mathrm{CT}$ \\
\hline 37 & Union Pacific & -1.232 & $\mathrm{NY}-\mathrm{CT}$ & CALIF * \\
\hline 38 & United Air Lines & -0.820 & CENTRAL & CALIF * \\
\hline 39 & USX & -0.155 & CENTRAL & CENTRAL \\
\hline 40 & United Technologies & 0.200 & $\mathrm{NY}-\mathrm{CT}$ & CENTRAL \\
\hline 41 & Wells Fargo & -2.454 & CALIF & CALIF \\
\hline 42 & Westinghouse & -0.134 & CENTRAL & CENTRAL \\
\hline
\end{tabular}

Misclassified 
TABLE XXI

ACTUAL AND MDS-GENERATED HEADQUARTERS LOCATION

CHI-SQUARE CONTINGENCY TABLE 1977-78 ELECTION

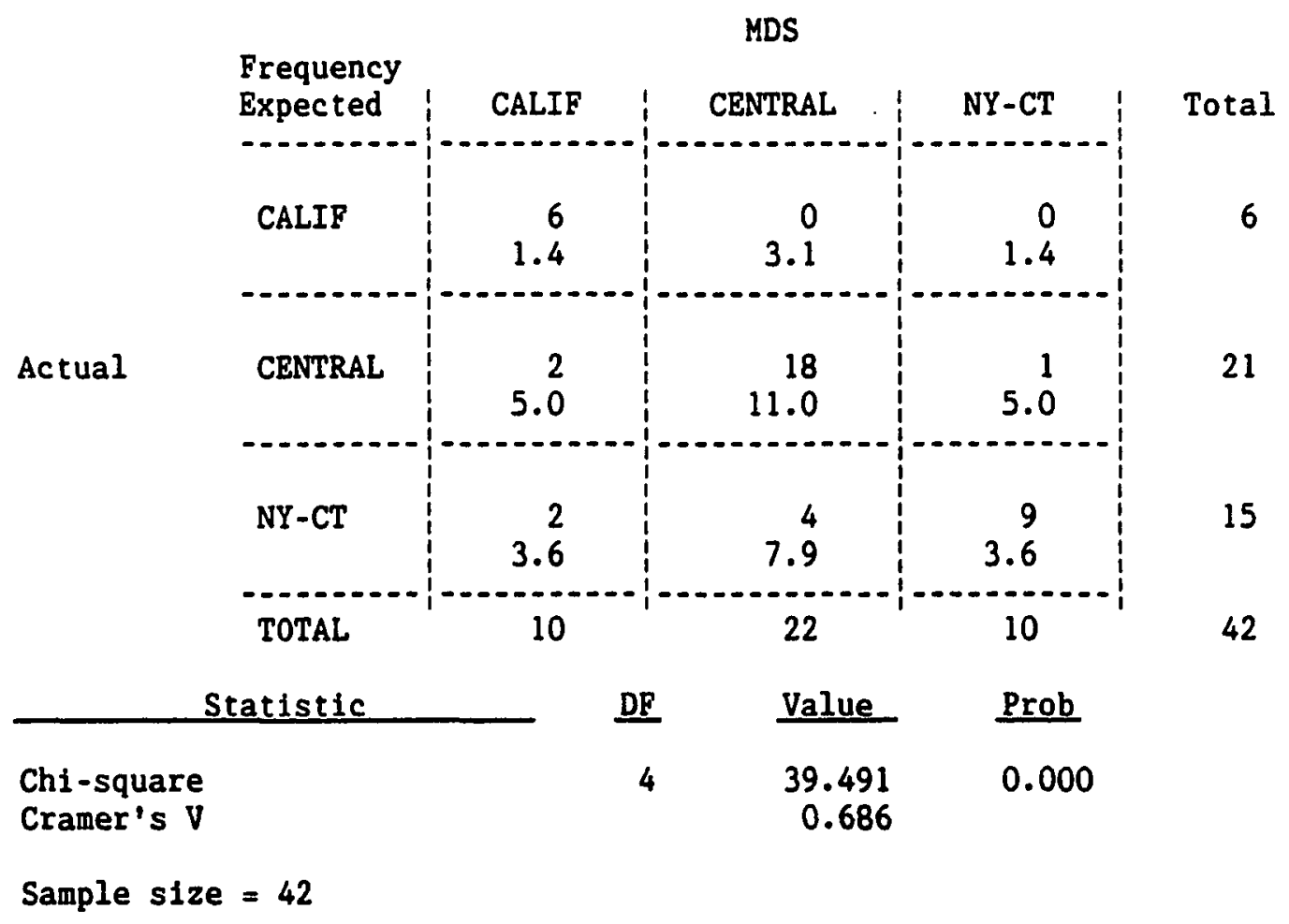


TABLE XXII

CORRELATIONS BETHEEN MDS COORDINATES AND INTERPRETIVE VARIABLES

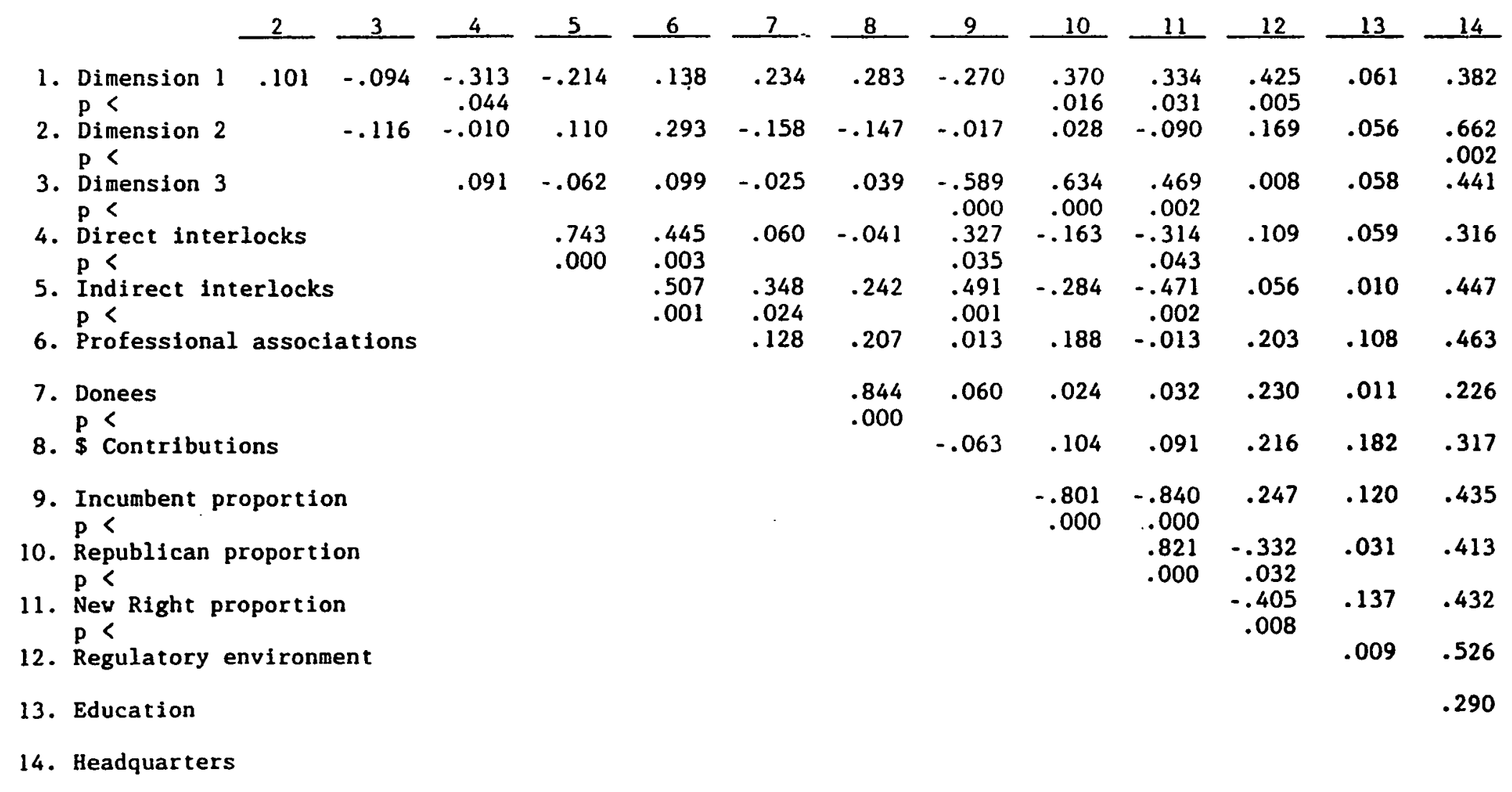

Note: Probability displayed only when $\mathrm{p}<.05$. 


\section{TABLE XXIII}

DESCRIPTIVE STATISTICS FOR INTERVAL LEVEL VARIABLES

1977-78 ELECTION

Variable

Direct interlocks

Indirect interlocks

Professional associations

Donees

$\$$ contributions

Incumbent proportion

Republican proportion

New Right proportion
Mean

$$
5.619
$$

166.405

2.357

91.976

$37,300.330$

0.648

0.587

0.163
Std Dev

3.723

90.929

1.394

64.411

$30,435.530$

0.154

0.169

0.106 
TABLE XXIV

RESOURCE DEPENDENCE AND CLASS COHESION VARIABLES

REGRESSED AGAINST MDS COORDINATES

1977-78 ELECTION

Equation

Resource Dependence Hypothesis

Regulatory environment
Class Cohesion Hypotheses

Direct interlocks
Indirect interlocks
Professional associations
Education

Headquarters location
Independent Variables Dimension 1 Dimension 2 Dimension 3

$\begin{array}{lllll}-.196 * \star & -.068 & -.024 & .200 & 3.15 * \\ (.425) & (.170) & (.000) & .446 & \end{array}$

$$
\begin{gathered}
-1.075 \star \\
(-0.313) \\
-19.824 \\
(-0.214) \\
.159 \\
(0.138) \\
-.034 \\
(.0612) \\
-.011
\end{gathered}
$$

$\begin{array}{ccc}.249 & .102 & .25 \\ (0.091) & .319 & \\ -6.486 & .068 & .93 \\ (-0.062) & .261 & \\ .207 & .118 & .18 \\ (0.099) & .344 & \\ -.030 & .011 & .14 \\ (.0581) & .105 & \\ -.415 & .388 & 2.08 \star \star\end{array}$

Note: the first cell entry under the three dimensions for the first five equations is that model's unstandardized regression coefficient; the second, parenthetical, entry is the model's zero-order correlations. The sixth equation required canonical analysis; therefore, the unstandardized canonical coefficients are reported in the first three columns, and Wilks' lambda in the fourth column.

$\star \mathrm{p}<.05$

$\star \star p<.01$ 
TABLE XXV

ACTUAL AND DISCRIMINANT-CLASSIFIED REGULATORY ENVIRONMENT CATEGORIES 1977-78 ELECTION

\begin{tabular}{|c|c|c|c|c|c|}
\hline \multirow[b]{2}{*}{ ID\# } & \multirow[b]{2}{*}{ Firm } & \multicolumn{2}{|c|}{ Category } & \multicolumn{2}{|c|}{ Coefficient } \\
\hline & & Actual & lassified & Economic & Social \\
\hline 1 & ALCOA & Social & Social & 0.149 & 0.851 \\
\hline 2 & American Electric Power & Economic & Social & 0.268 & $0.732^{\star}$ \\
\hline 3 & American Express & Economic & Economic & 0.935 & 0.065 \\
\hline 4 & Arco & Social & Social & 0.489 & 0.511 \\
\hline 5 & Bethlehem Steel & Social & Social & 0.366 & 0.634 \\
\hline 6 & Chrysler & Social & Social & 0.165 & 0.835 \\
\hline 7 & Citicorp & Economic & Economic & 1.000 & 0.000 \\
\hline 8 & Consolidated Edison & Economic & Economic & 1.000 & 0.000 \\
\hline 9 & Dow & Social & Social & 0.036 & 0.964 \\
\hline 10 & Federated Department Store & Social & Economic & 0.700 & $0.300^{*}$ \\
\hline 11 & First Chicago & Economic & Economic & 0.999 & 0.001 \\
\hline 12 & Ford & Social & Social & 0.192 & 0.808 \\
\hline 13 & GE & Economic & Social & 0.201 & $0.799^{*}$ \\
\hline 14 & GM & Social & Social & 0.160 & 0.840 \\
\hline 15 & GTE & Economic & Economic & 0.988 & 12 \\
\hline 16 & Goodyear & Social & Social & 0.046 & 0.954 \\
\hline 17 & Honeywell & Economic & Social & 0.030 & $0.970^{\circ}$ \\
\hline 18 & International Harvester & Social & Social & 0.051 & 0.949 \\
\hline 19 & K Mart & Social & Social & 0.107 & 893 \\
\hline 20 & Lockheed & omic & ial & 0.2 & 04 * \\
\hline 21 & LTV & Social & Social & 0.2 & 714 \\
\hline 22 & Manufacturers Hanover & Economic & Economic & 1.0 & 000 \\
\hline 23 & Mellon & Economic & Economic & 1.0 & 0.000 \\
\hline 24 & Metropolitan Life Insurance & Economic & Economic & 0.961 & 0.039 \\
\hline 25 & Monsanto & Social & Social & 0.155 & 0.845 \\
\hline 26 & Pan American & Economic & Social & 0.225 & $0.775^{\bullet}$ \\
\hline 27 & Penney & Social & Social & 0.230 & 0.770 \\
\hline 28 & Philip Morris & Social & Social & 0.497 & 503 \\
\hline 29 & RJR & Social & Social & 0.395 & 605 \\
\hline 30 & Rockwell & Economic & Economic & & 040 \\
\hline 31 & Sears & Social & Social & 0.167 & 0.833 \\
\hline 32 & Security Pacific & Economic & Economic & 1.000 & 0.000 \\
\hline 33 & Southern Pacific & Economic & Economic & 0.999 & 0.001 \\
\hline 34 & Texaco & Social & Social & 0.177 & 0.823 \\
\hline 35 & TWA & Economic & Economic & 0.836 & 0.164 \\
\hline 36 & Union Carbide & Social & Social & 0.296 & 0.704 \\
\hline & Union Pacific & Economic & Economic & 0.942 & 0.058 \\
\hline & United Air Lines & Economic & Ėconomic & 0.583 & 0.417 \\
\hline & USX & Social & Social & 0.171 & 0.829 \\
\hline & United Technologies & Economic & Soctal & 0.153 & $0.847^{*}$ \\
\hline & Wells Fargo & Economic & Economic & 1. & 0.000 \\
\hline & Westinghouse & Economic & Social & 0.274 & $0.726^{\circ}$ \\
\hline
\end{tabular}

Misclassified 


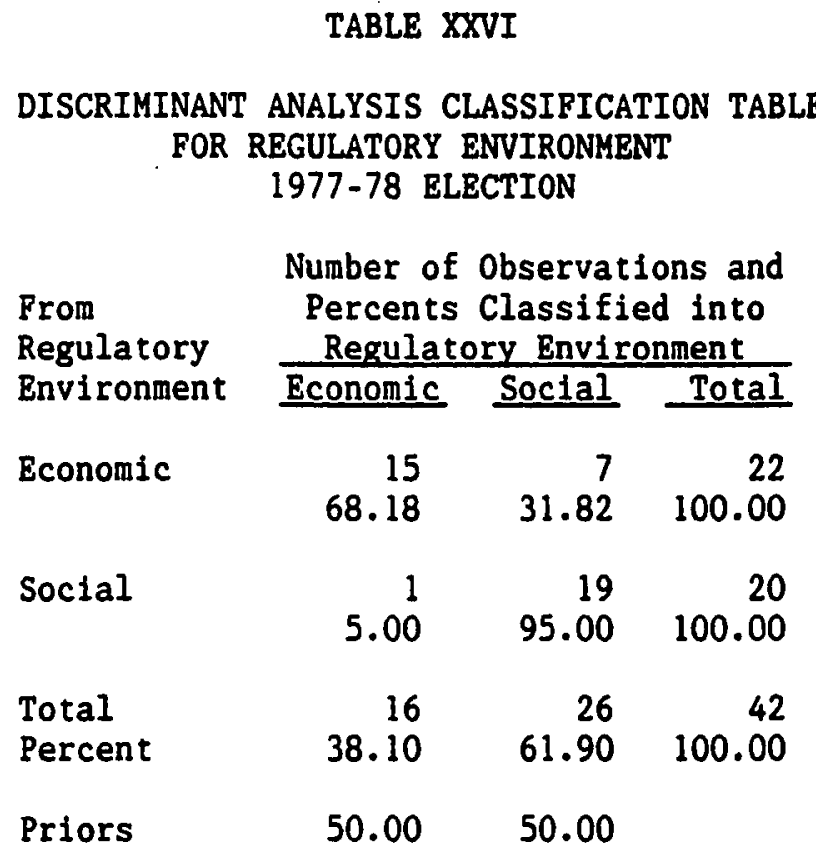


TABLE XXVII

ACTUAL AND MDS-CLASSIFIED REGULATORY ENVIRONMENT CATEGORIES 1977-78 BLECTION

\begin{tabular}{|c|c|c|c|c|}
\hline \multirow[b]{2}{*}{ ID聿 } & \multirow[b]{2}{*}{ Firm } & \multirow{2}{*}{$\begin{array}{c}\text { Dimension } \\
\text { One }\end{array}$} & \multicolumn{2}{|c|}{ Category } \\
\hline & & & Actual & MDS \\
\hline 1 & ALCOA & 0.416 & Social & Social \\
\hline 2 & American Electric Power & -0.614 & Economic & Economic \\
\hline 3 & American Express & -1.102 & Economic & Economic \\
\hline 4 & Arco & 0.550 & Social & Social \\
\hline 5 & Bethlehem Steel & -1.021 & Social & Economic \\
\hline 6 & Chrysler & 0.449 & Social & Social \\
\hline 7 & Citicorp & -2.121 & Economic & Economic \\
\hline 8 & Consolidated Edison & -1.560 & Economic & Economic \\
\hline 9 & Dow & 1.060 & Social & Social \\
\hline 10 & Federated Department Store & -1.654 & Social & Economic* \\
\hline 11 & First Chicago & -2.129 & Economic & Economic \\
\hline 12 & Ford & 0.587 & Social & Social \\
\hline 13 & GE & -0.011 & Economic & Economic \\
\hline 14 & GM & 0.197 & Social & Social \\
\hline 15 & GTE & 1.606 & Economic & Social * \\
\hline 16 & Goodyear & 1.715 & Social & Social \\
\hline 17 & Honeywell & 1.350 & Economic & Social* \\
\hline 18 & International Harvester & 0.933 & Social & Social \\
\hline 19 & $\mathrm{~K}$ Mart & 0.521 & Social & Social \\
\hline 20 & Lockheed & 0.102 & Economic & Economic \\
\hline 21 & LTV & 0.355 & Social & Social \\
\hline 22 & Manufacturers Hanover & -1.590 & Economic & Economic \\
\hline 23 & Mellon & -2.668 & Economic & Economic \\
\hline 24 & Metropolitan Life Insurance & -0.274 & Economic & Economic \\
\hline 25 & Monsanto & 0.422 & Social & Soctal \\
\hline 26 & Pan American & -0.175 & Economic & Economic \\
\hline 27 & Penney & 0.127 & Soctal & Social \\
\hline 28 & Philip Morris & 1.292 & Social & Social \\
\hline 29 & RJR & 1.505 & Social & Social \\
\hline 30 & Rockwell & 0.637 & Economic & Social. \\
\hline 31 & Sears & 0.463 & Social & Social \\
\hline 32 & Security Pacific & -1.220 & Economic & Economic \\
\hline 33 & Southern Pacific & 0.272 & Economic & Social* \\
\hline 34 & Texaco & 0.348 & Social & Social \\
\hline 35 & TWA & 0.797 & Economic & Social* \\
\hline 36 & Union Carbide & 0.830 & Social & Social \\
\hline 37 & Union Pacific & 0.347 & Economic & Social. \\
\hline 38 & United Air Lines & 0.267 & Economic & Social. \\
\hline 39 & USX & 0.350 & Social & Social \\
\hline 40 & United Technologies & 0.212 & Economic & Soctal* \\
\hline 41 & Wells Fargo & -1.203 & Economic & Economic \\
\hline 42 & Westinghouse & -0.365 & Economic & Economic \\
\hline
\end{tabular}

Misclassified 
TABLE XXVIII

ACTUAL AND MDS-CLASSIFIED REGULATORY ENVIRONMENT CATEGORIES

CHI-SQUARE CONTINGENCY TABLE

1977-78 ELECTION

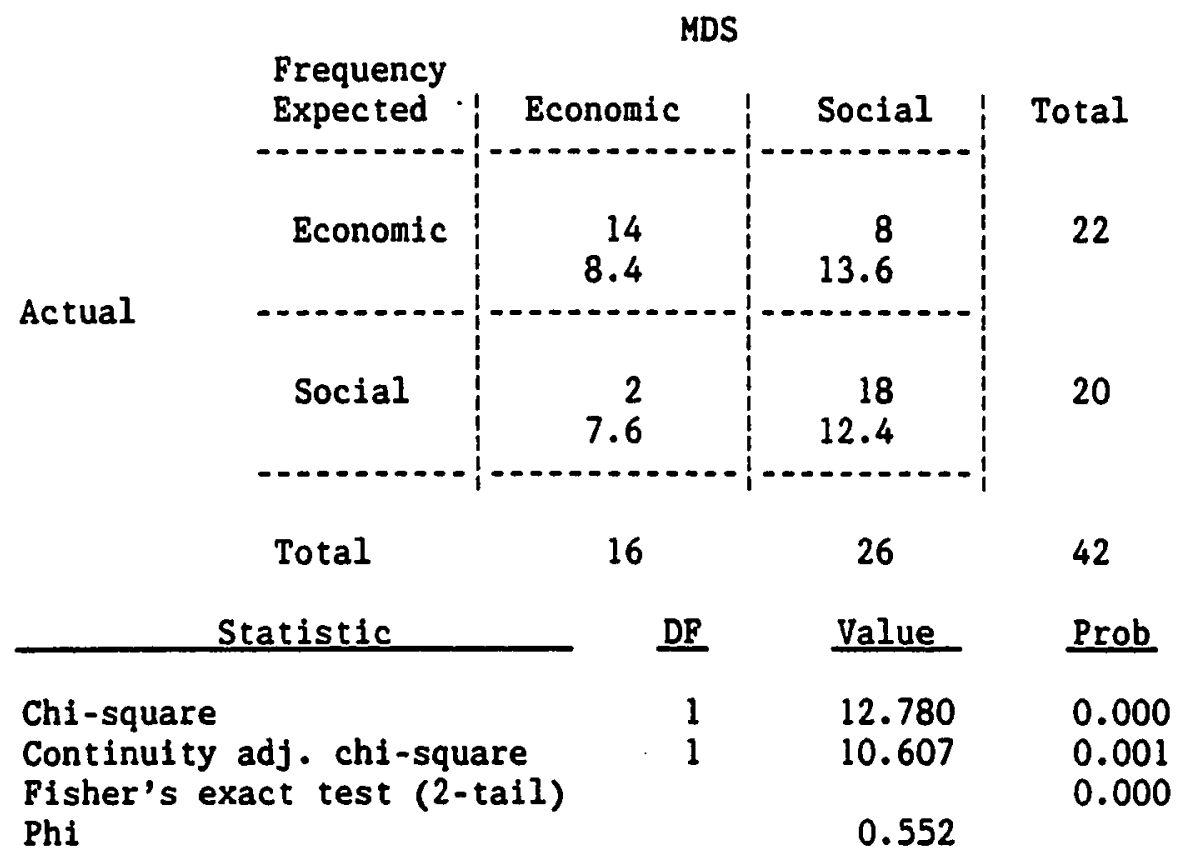

Sample size $=42$ 
TABLE XXIX

DISCRIMINANT ANALYSIS CLASSIFICATION TABLE

FOR HEADQUARTERS LOCATION

1977-78 ELECTION

\begin{tabular}{|c|c|c|c|c|c|c|c|c|}
\hline \multirow{2}{*}{$\begin{array}{c}\text { From } \\
\text { HO }\end{array}$} & \multicolumn{4}{|c|}{ Number of Observations and } & \multicolumn{4}{|c|}{ Classified into $\mathrm{HO}$} \\
\hline & 1 & 2 & 3 & 4 & 5 & 6 & 7 & Total \\
\hline 1 & $\begin{array}{r}8 \\
47.06\end{array}$ & $\begin{array}{r}0 \\
0.00\end{array}$ & $\begin{array}{r}1 \\
5.88\end{array}$ & $\begin{array}{r}0 \\
0.00\end{array}$ & $\begin{array}{r}2 \\
11.76\end{array}$ & $\begin{array}{r}5 \\
29.41\end{array}$ & $\begin{array}{r}1 \\
5.88\end{array}$ & $\begin{array}{r}17 \\
100.00\end{array}$ \\
\hline 2 & $\begin{array}{r}1 \\
16.67\end{array}$ & $\begin{array}{r}2 \\
33.33\end{array}$ & $\begin{array}{r}1 \\
16.67\end{array}$ & $\begin{array}{r}0 \\
0.00\end{array}$ & $\begin{array}{r}1 \\
16.67\end{array}$ & 16.67 & $\begin{array}{r}0 \\
0.00\end{array}$ & $\begin{array}{r}6 \\
100.00\end{array}$ \\
\hline 3 & $\begin{array}{r}0 \\
0.00\end{array}$ & $\begin{array}{r}0 \\
0.00\end{array}$ & $\begin{array}{r}3 \\
60.00\end{array}$ & $\begin{array}{r}0 \\
0.00\end{array}$ & $\begin{array}{r}0 \\
0.00\end{array}$ & $\begin{array}{r}2 \\
40.00\end{array}$ & $\begin{array}{r}0 \\
0.00\end{array}$ & 100.00 \\
\hline 4 & $\begin{array}{r}0 \\
0.00\end{array}$ & $\begin{array}{r}0 \\
0.00\end{array}$ & $\begin{array}{r}0 \\
0.00\end{array}$ & 25.00 & 25.00 & $50.00^{2}$ & $\begin{array}{r}0 \\
0.00\end{array}$ & $100.00^{4}$ \\
\hline 5 & $\begin{array}{r}0 \\
0.00\end{array}$ & $\begin{array}{r}0 \\
0.00\end{array}$ & $\begin{array}{r}0 \\
0.00\end{array}$ & $\begin{array}{r}0 \\
0.00\end{array}$ & 50.00 & 25.00 & $\begin{array}{r}1 \\
25.00\end{array}$ & 100.00 \\
\hline 6 & $\begin{array}{r}0 \\
0.00\end{array}$ & $\begin{array}{r}1 \\
50.00\end{array}$ & $\begin{array}{r}0 \\
0.00\end{array}$ & $\begin{array}{r}0 \\
0.00\end{array}$ & $50.00^{1}$ & $\begin{array}{r}0 \\
0.00\end{array}$ & $\begin{array}{r}0 \\
0.00\end{array}$ & $100.00^{2}$ \\
\hline 7 & $\begin{array}{r}1 \\
25.00\end{array}$ & $\begin{array}{r}0 \\
0.00\end{array}$ & $\begin{array}{r}0 \\
0.00\end{array}$ & $\begin{array}{r}0 \\
0.00\end{array}$ & 25.00 & 25.00 & $\begin{array}{r}1 \\
25.00\end{array}$ & 100.00 \\
\hline $\begin{array}{l}\text { Total } \\
\text { Percent }\end{array}$ & $\begin{array}{r}10 \\
23.81\end{array}$ & $\begin{array}{r}3 \\
7.14\end{array}$ & $\begin{array}{r}5 \\
11.90\end{array}$ & $\begin{array}{r}1 \\
2.38\end{array}$ & $\begin{array}{r}8 \\
19.05\end{array}$ & $\begin{array}{r}12 \\
28.57\end{array}$ & $\begin{array}{r}3 \\
7.14\end{array}$ & $\begin{array}{r}42 \\
100.00\end{array}$ \\
\hline Priors & 14.29 & 14.29 & 14.29 & 14.29 & 14.29 & 14.29 & 14.29 & \\
\hline
\end{tabular}


l

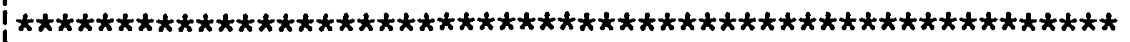

:

Frequency Frequency

0.08

0.11

0.14

0.17

0.23

0.26

0.29

0.32

0.35

0.38

0.41

0.44

0.47

0.50

0.53

0.56

0.59

1

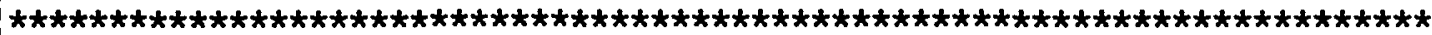

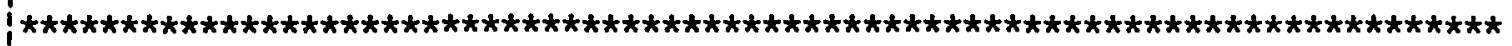

$78 \quad 78$

$110 \quad 188$

$144 \quad 332$

$144 \quad 476$

(t)

142

618
766 :

150

1066 1.

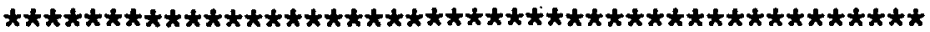

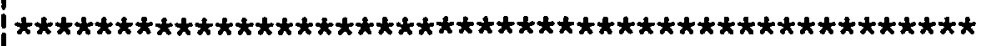

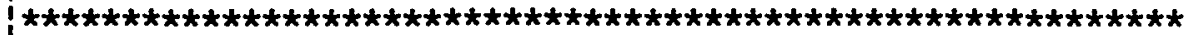

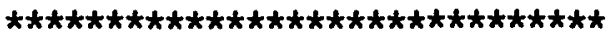

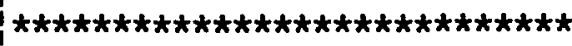

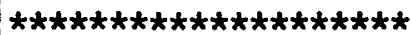

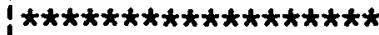

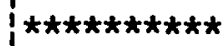

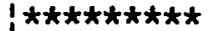

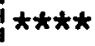

;*

Frequency

Figure 2. Frequency distribution of the 1977-78 similarity measures. 


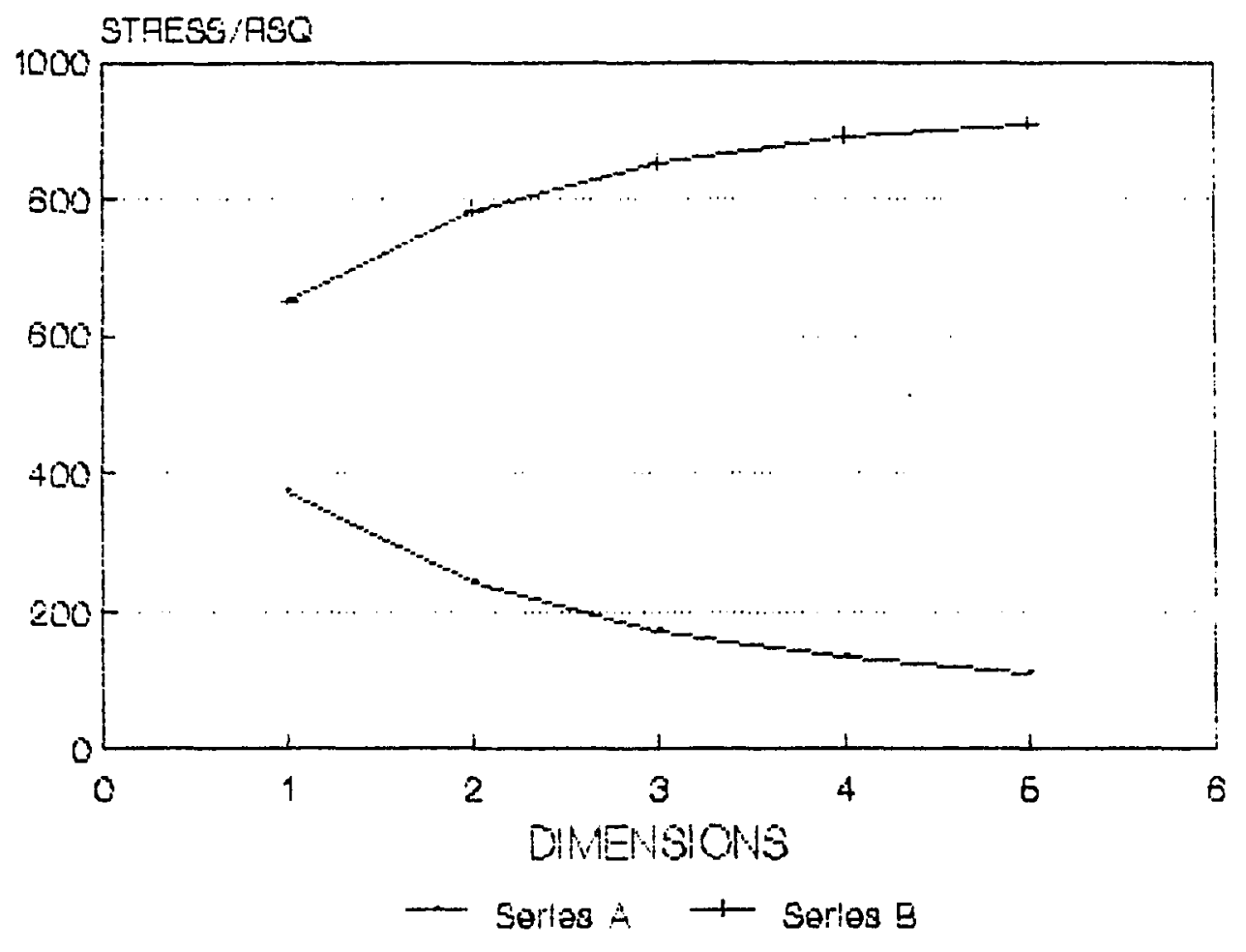

Figure 3. MDS fit indices for the 1977-78 similarity data. 


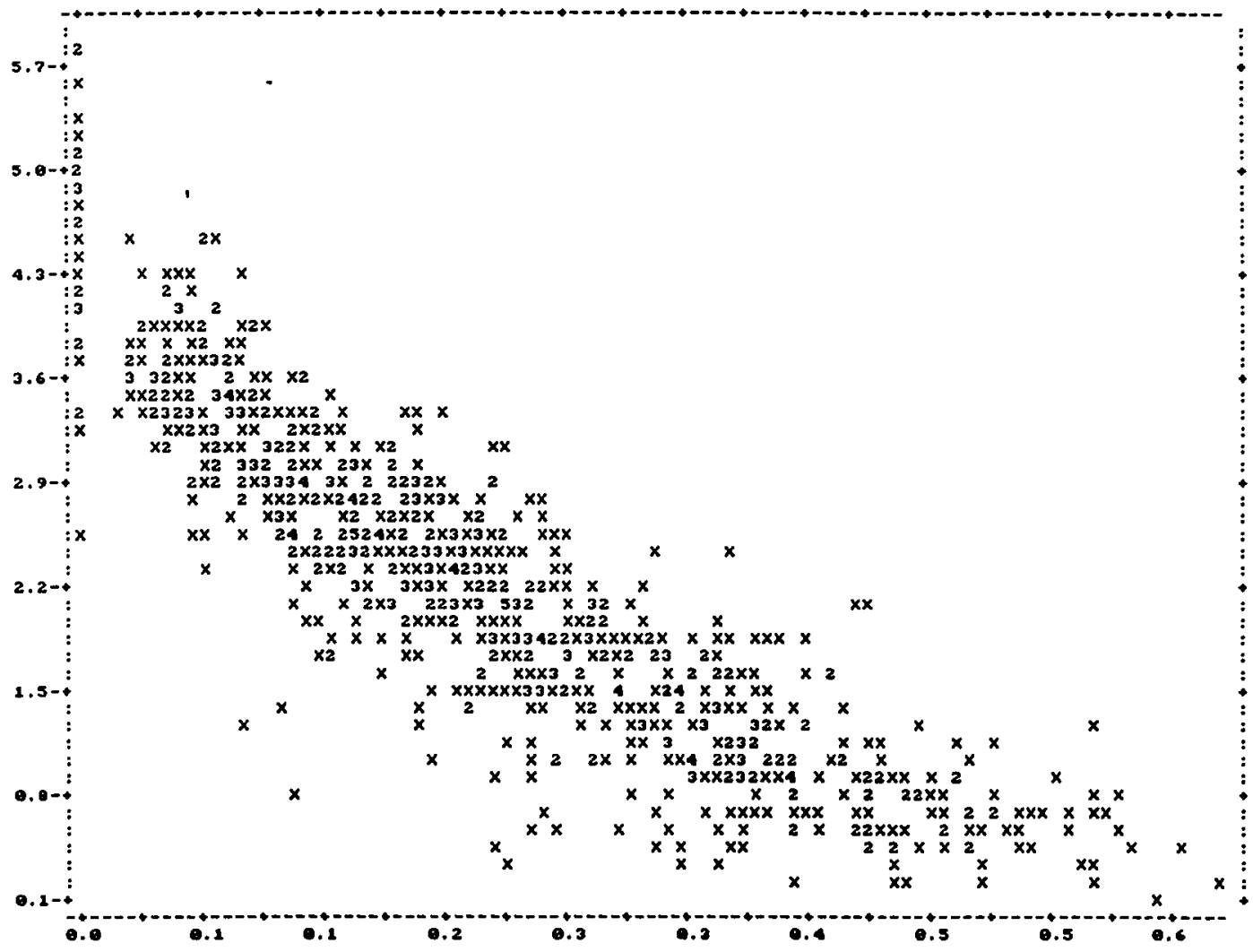

Figure 4. Scatter plot of nonlinear fit for the threedimensional solution with distances on the vertical axis and observations on the horizontal axis, 1977-78 election. 


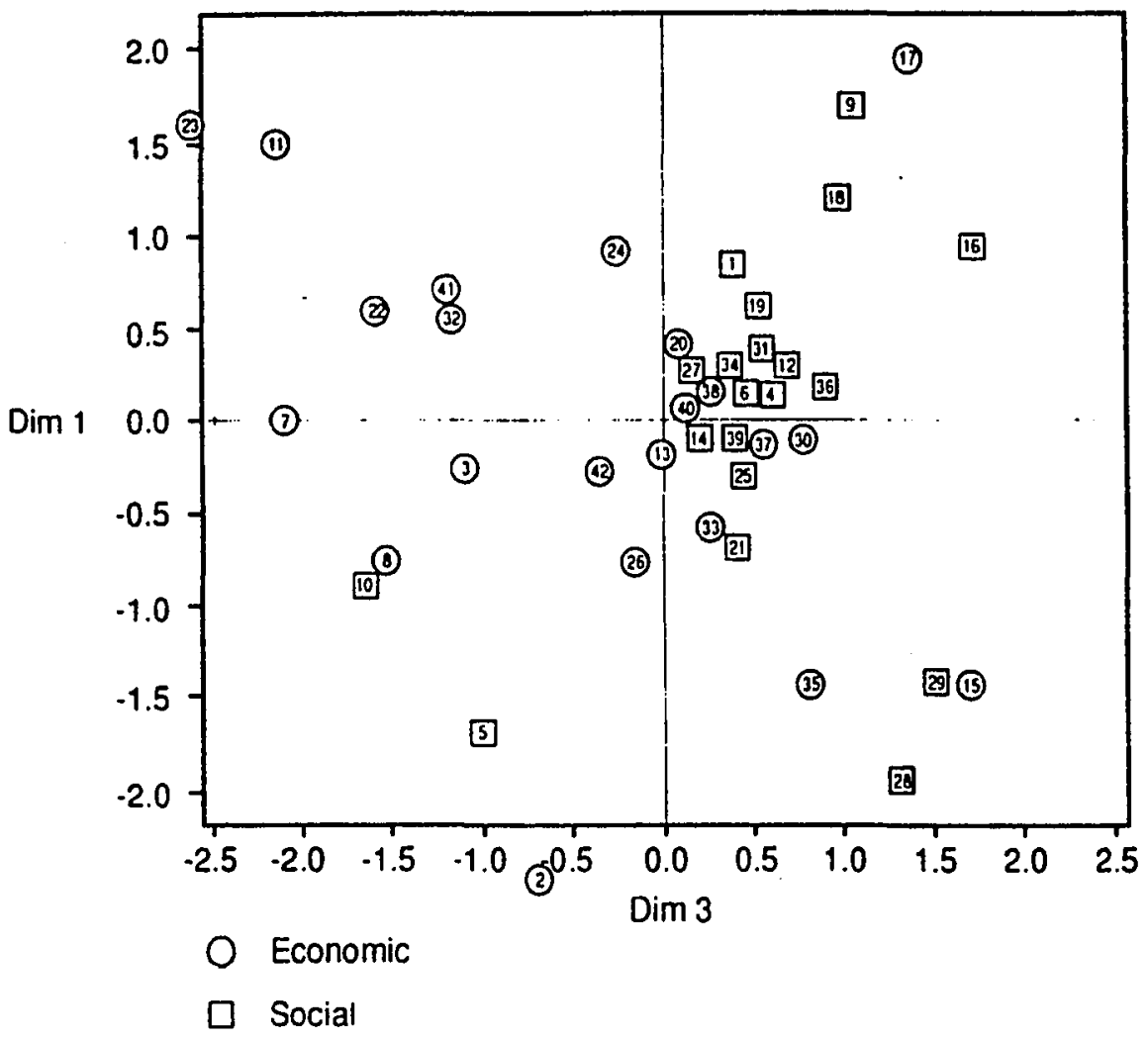

Figure 5. Dimension one, economic and social regulatory environments, 1977-78 elections. For definitions see pages 14-16. See Table XXVII for firm legend. 


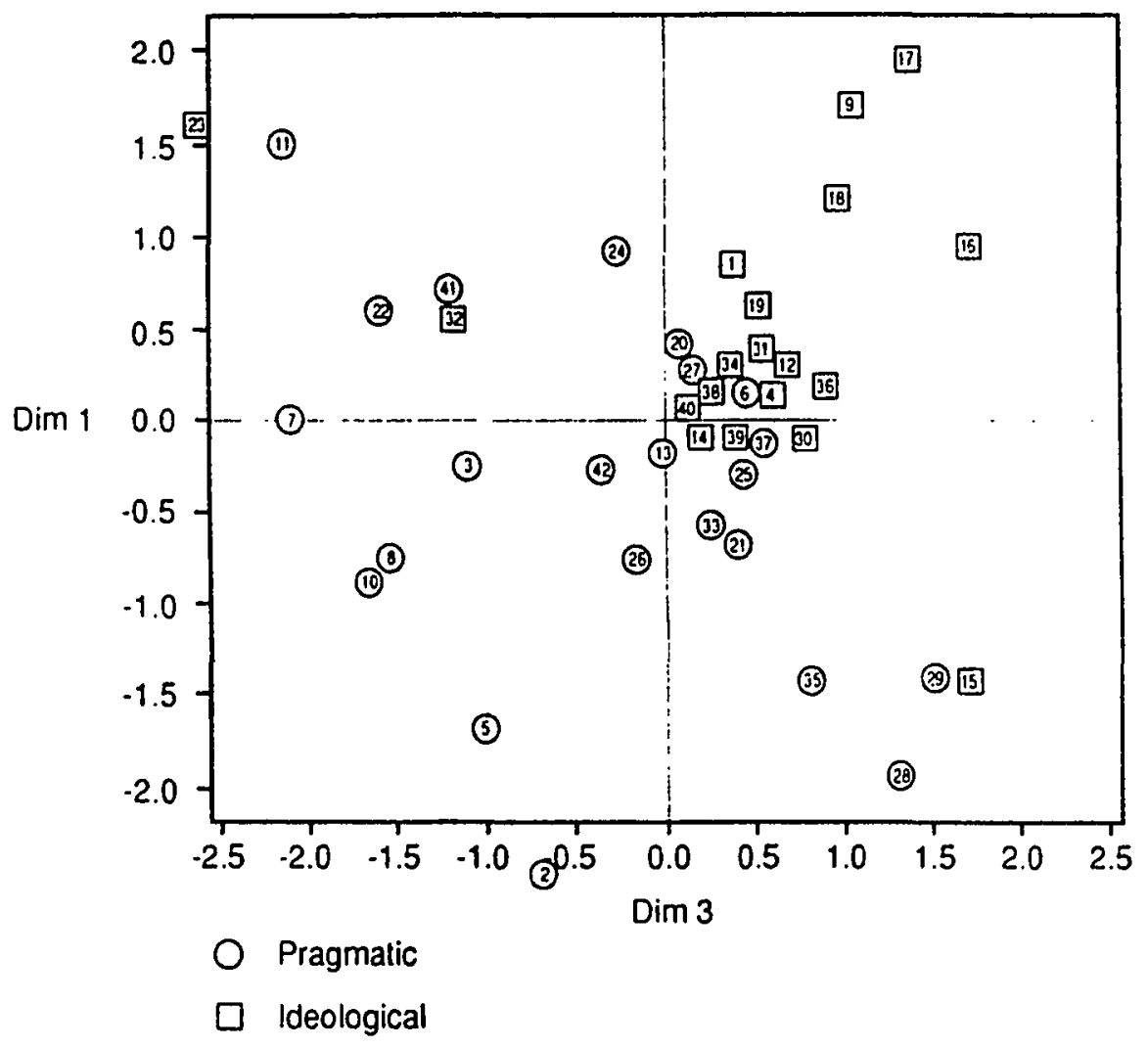

Figure 6. Dimension three, pragmatic and ideological strategy, 1977-78 elections. For definitions see pages 13-14. See Table XVIII for firm legend. 


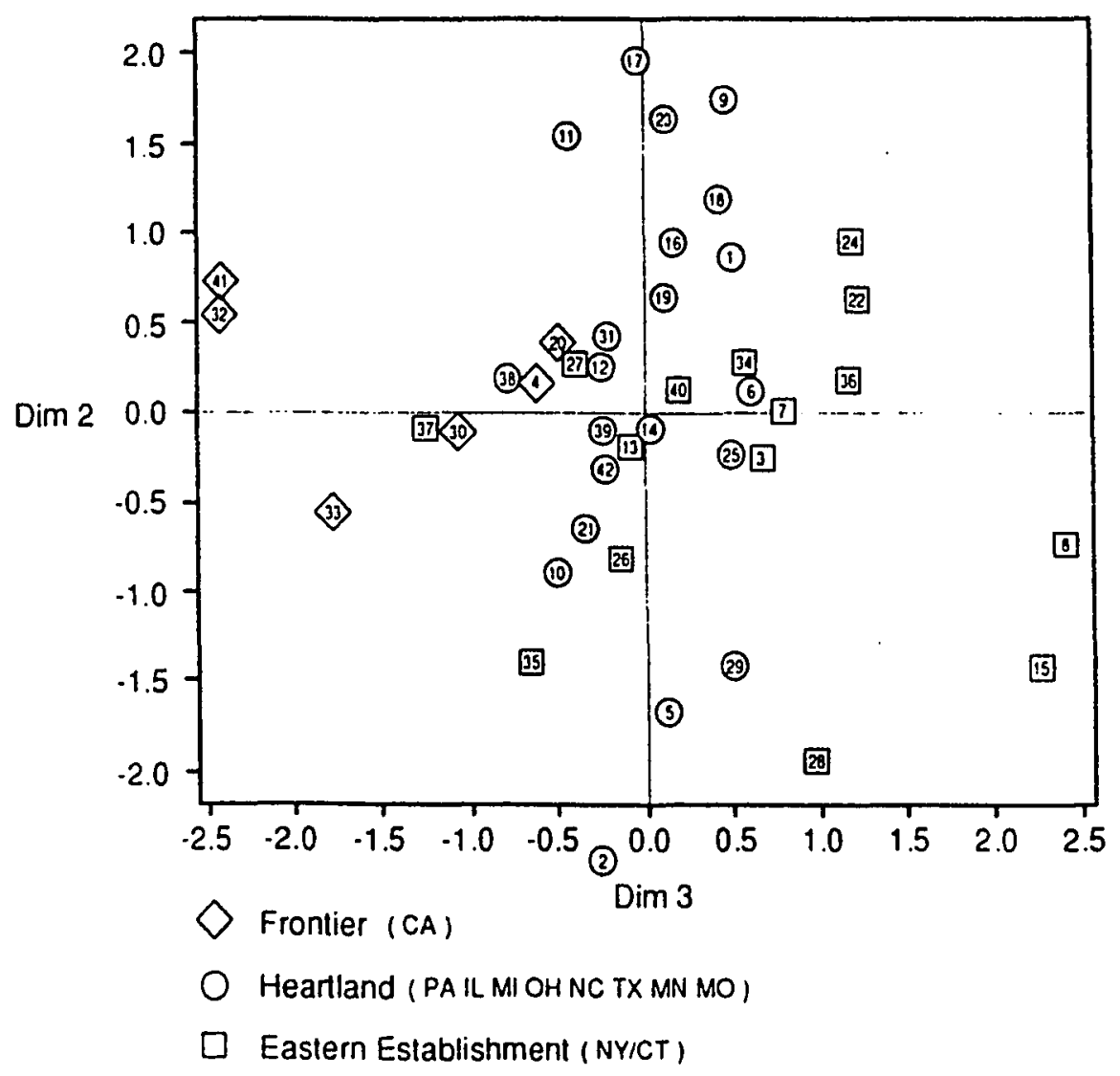

Figure 7. Dimension two, regional dimension, 1977-78 elections. See Table XX for firm legend. 


\section{CHAPTER V}

\section{THE 1981-82 ELECTION CYCLE}

Chapter $\mathrm{V}$ takes the same analytical approach as that of the previous chapter which deals with 1977-78 PAC contribution data. Similarly, chapter $\mathrm{V}$ presents the results of multidimensional scaling and hypothesis testing performed on the 1981-82 PAC data set. Consequently, the explanations in chapter IV regarding the use of various statistical techniques and decision rules are applicable to the 1981-82 data analysis and, therefore, are not repeated. Chapter IV may be consulted for details regarding the analytical model.

THE NATURE OF THE 1981-82 PROXIMITY DATA

Table XXX and Figure 8 display the descriptive statistics and frequency distribution histogram associated with the 1981-82 proximity data set. ${ }^{1}$ The observed proximity scores, measured at the ordinal level, ranged from .000 to .624 with a median of $.251 .^{2}$ It should also be

${ }^{1}$ The complete 1981-82 similarity matrix appears in Appendix $C$.

${ }^{2}$ See chapter III, pages 93-95, for a discussion on the ordinal level of measurement as it applies to the similarity data. 
noted that the distribution exhibits a rather low variance. The scores cluster rather tightly around the median; less than thirty percent of the range lies between quartiles one and three, compared with forty-five percent above the third quartile.

\section{Extremes}

Tables XXXI and XXXII, respectively, display the four corporate dyads that scored a zero similarity and the twenty-seven corporate dyads that exhibited high (greater than .50) similarity scores. The comparable results from the 1977-78 data set are thirty zero-scoring dyads and seventeen high-scoring dyads. This opening examination of the 1981-82 data set reveals that more firms exhibited similar Congressional support patterns and fewer exhibited unique patterns during the 1981-82 election cycle.

Two patterns do carry over between the two election cycles, however. First, Mellon Bank consistently exhibits the most frequent zero similarity with other firms.

Second, while high similarity scores often characterize pairs of firms from the same industry, the pattern is not entirely consistent. ${ }^{3}$ For example, the Security Pacific and Wells Fargo dyad, with a similarity score of .624 , exhibited the maximum consensus in candidates

${ }^{3}$ Eight of twenty-seven (thirty percent) highsimilarity pairs share a common Fortune-defined industry grouping in 1981-82, as compared with six of seventeen (thirty-five percent) in 1977-78. 
supported during the 1981-82 election cycle while another banking dyad, Mellon and Wells Fargo, scored a zero similarity.

Such discrepancies could be a reflection of the ideological expression of a strong corporate leader, despite Handler and Mulkern's 1982 research. Their conclusion was that, even when a CEO is active in PAC governance, the general direction of PAC contributions follows what would be expected "given the nature of the firm and the regulatory environment which it inhabits" (77). Yet, the extreme dissimilarity exhibited by Mellon and Wells Fargo suggests that, in an instance such as this, the personal ideologies of corporate executives should be explored for an explanation.

\section{DETERMINING DIMENSIONALITY}

Table XXXIII displays the fit measures resulting from a series of classical Euclidean multidimensional solutions scaled at one through five dimensions. The plotted fit measures are presented in Figure 9. As was true for the 1977-78 data set, the sharp elbow which can denote the preferred solution is not apparent. As expected, STRESS and RSQ improve as dimensionality increases, however, the level of improvement between the two- and three-dimensional and the three- and four-dimensional solutions is scarcely perceptible. A more marked improvement is noted between the 
one- and two-dimensional solution. The two-dimensional solution's STRESS and RSQ levels are troublesome, however--a .775 squared multiple correlation and .237 unexplained variance suggests a less than fully satisfactory model fit. Consequently, additional dimensionality determination techniques were applied to the data.

The subjective determiners of interpretability and ease of use were applied to the 1981-82 scaled solutions (Kruskal and Wish 1978, 56). The two-dimensional solution was readily interpretable; however, as previously discussed, this solution was eliminated due to its high STRESS and RSQ. Dimensions one and two of the three-dimensional solution are significantly correlated with hypothesized variables, thus are interpretable, but this was not the case for dimension three. Exploratory analysis, however, reveals some interesting corporate patterns along the dimension three axis. Therefore, the three-dimensional solution, with a STRESS of .181 and a RSQ of .837 , is selected for further analysis.

The Final Test

Given the selection of a three-dimensional solution, its corresponding ALSCAL output was further examined to ensure that the model is suitable for analysis. Two pieces of evidence support its suitability.

First, the iteration history for the three-dimensional solution indicates that the minimum SSTRESS improvement 
level was reached at iteration thirty, yet the ALSCAL parameter allowed for one hundred iterations (see Table XXXIV) . Further, the convergence level parameter was set at a high precision level of .00001 . This suggests that a true or global minimum convergence level was reported rather than a local minimum.

Second, the three-dimensional solution's scatter plot of the computed distances in the MDS space and the actual observations (proximity values) was examined. A central premise of multidimensional scaling is that the distances between points on the MDS map should correspond to the input proximities (Kruskal and Wish 1978, 19). Inspection of the scatter diagram presented in Figure 10 reveals that this relationship exists. Since the input data are similarities, then the computed distances between the map coordinates (horizontal axis in Figure 10) should diminish as the degree of similarity between firm dyads (vertical axis) increases." While Figure 10 reveals a rather large amount of scatter, a decreasing function satisfies the relationship

${ }^{4}$ Distances are calculated by the Pythagorean formula: the distance between points $i$ and $j$ in $R$-dimensional space is equal to

$$
d_{i j}=\left[\left(x_{i 1}-x_{j 1}\right)^{2}+\cdot \cdot \cdot+\left(x_{i R}-x_{j R}\right)^{2}\right]^{1 / 2}
$$

where $x_{i 1}$ equals the point corresponding to the $i^{\text {th }}$ firm on the first map dimension or axis (Kruskal and Wish 1978, 17).

Degree of similarity between firms is calculated by the similarity measure presented on page 75 . 
requirements since nonmetric MDS rank orders proximities (Kruskal and Wish 1978, 22).

Given the preceding evidence and rationale, the threedimensional solution is selected for hypothesis testing and exploratory analysis. The MDS configurations for the threedimensional solution appear in Figures 11,12 , and 13.

\section{DIMENSION INTERPRETATION AND LABELING}

As with the 1977-78 data analysis, the three dimensions associated with the 1981-82 MDS solution are labeled to facilitate discussion. Dimension one correlates with two hypothesized variables: Regulatory environment and PAC strategy. It is therefore labeled the Environment/Strategy dimension. Dimension two correlates with the headquarters hypothesized variable; thus, it is labeled Reqional. As previously noted; dimension three does not correlate with any hypothesized variables. Nevertheless, the pattern of firms along dimension three suggests that it is identifying those firms which exhibited zero similarity with another firm(s) within the sample (see Table XXXI). Dimension three also segments firms which contributed to fewer candidates (or "donees"). Therefore, it is labeled outliers/Donees. 
Dimension one: Environment/Strategy Dimension

Environment. The MDS group space displayed in Figure 11 reveals a division between firms in social and economic regulatory environments. Those firms more subject to economic regulations are clearly grouped on the negative side of the horizontal dimension one axis while those more subject to social regulations dominate the positive side. Maximal discrimination between the two regulatory environment categories is achieved by shifting the dimension one axis to coordinate $.12 .^{5}$

Misclassification common to both data sets. A comparison of the 1977-78 and 1981-82 environment dimensions supports the research model's reliability. First, the two regulatory environment dimensions are correlated at the .51 level $(p<.0006)$, an indicator that they are measuring the same phenomenon. Further, the 1977-78 MDS solution misclassified ten corporations on the environment dimension and the 1981-82 misclassified nine with five firms in common (see Table XXXV). Bethlehem steel, Federated Department Stores, GTE, Honeywell, and United Technologies were misclassified in both election cycles.

This reliability, while not conclusive evidence, implies that the regulatory environment indicated by the MDS

${ }^{5}$ This regulatory environment relationship is analyzed with chi-square and regression in a later section which tests the resource dependence hypothesis. 
coordinates is more likely to resemble the "true" regulatory environment than to be just an artifact of the data and, at the very least, that the misclassification is not random. First, the difference in the number of misclassified firms is only one. Second, and more compelling, is the five-firm commonality.

Misclassification unique to 1981-82 data set. MDS misclassified four firms in the 1981-82 data set that it had classified correctly in the 1977-78 set. Three are manufacturing firms and one is a retailer, J. C. Penney. That one is a retailer supports the argument that a category in addition to social and economic is needed (Burris 1987, 736). Of the three retailers included in the sample, MDS places two (Federated Department Stores and J. C. Penney) into the economic category, a category usually reserved for defense contractors and firms that operate under industryspecific regulation. Informed judgement, on the other hand, places retailers in the social regulatory environment in recognition of the affirmative action pressure experienced by large retailers when the enforcement authority of the Equal Employment Opportunity Commission was enhanced in 1972 (Schnitzer 1990, 275).

The third sample retailer, sears, was correctly mapped as social in both election cycles, but a strong case could be made for a hypothesized economic classification. A new CEO took over in 1978 and restructured the organization to 
the extent that, in 1981, Sears enlarged its financial services portfolio with the acquisition of Coldwell Banker and Dean witter Reynolds, largest and fifth-largest in their respective fields (Telling 1986).

International Harvester, a 1981-82 misclassified firm, also experienced radical changes. In 1982, on the verge of bankruptcy, IH was taken over by a new management team which sold off unprofitable operations, including its farm equipment business (Potts and Behr 1987, 36-37). These management upheavals may account for its changing pattern of PAC contributions from 1977-78 to 1981-82.

Finally, two of the three metal manufacturers are misclassified as economic in 1981-82: Bethlehem steel and LTV. The early 1980s were particularly hard on the steel industry as domestic demand for steel, battered by a global recession, was filled largely by a flood of high-quality, low-cost Japanese steel (Gilbert 1989). A reasonable conjecture is that the adverse economic and foreign competitive forces which confronted the sagging steel industry heralded a new business-government environment; a regulatory environment that was once preoccupied by costly social regulations evolved into one in which government intervention was sought.

The third metal manufacturer, United states Steel, maintained the social regulatory environment classification during both election cycles. It is notable, however, that 
it acquired the Marathon oil Company in the early 1980 s and subsequently changed its federal industry classification from steel to petroleum refining (Bateman and Zeithaml 1990, 193). Since petroleum refining is also classified as social, United States Steel's hypothesized and MDS classified social regulatory environment is reinforced. Strateqy. Dimension one can be examined from the PAC strategy perspective as well as that of the regulatory environment. Table XXXVI displays significant positive correlations between dimension one coordinates and contributions to Republicans and New Right candidates ( $r=$ .59 and .51 , respectively; $\mathrm{p}<.0001)$; further, as expected, it is negatively related to contributions to incumbents ( $\mathrm{r}=$ $-.57 ; \mathrm{p}<.0001)$. Regressing dimension one coordinates onto the same three candidate types accounts for forty percent of its variance $(p<.0001)$.

Pragmatic/Ideological classification. PAC strategy classifications are determined in accord with the following two-step process which employs aggregate statistics drawn from the 1981-82 Federal Election Commission reports. First, a firm is labeled ideological based on two criteria: (1) its proportion of total PAC dollars contributed to Republican candidates must exceed the proportion of total corporate PAC dollars (.65) contributed to Republicans by all corporate PACs during the 1977-78 election cycle, and (2) its proportion of total PAC dollars 
contributed to incumbents must be less than the proportion of total corforate PAC dollars (.73) contributed to incumbents by all corporate PACs' during the 1977-78 election cycle. The reverse scenario yields a pragmatic label. Application of this first step resulted in the classification of thirty-three of the forty-two sample corporate PACs.

Eight unclassified PACs had exceeded the all-corporate PACs' means for both candidate types; one unclassified PAC fell below the all-corporate PACs' means for both candidate types. Therefore, a second criterion classified these PACs based on contributions to New Right candidates. A PAC is classified ideological when its proportion of total PAC dollars contributed to New Right candidates exceeds the sample mean proportion (.14); if less than the sample mean, then pragmatic. Table XXXVII displays the proportion each PAC contributed to each candidate category, and Tables XXXVIII and XXXIX list the ideological and pragmatic PACs, respectively.

Dimension Two: Reqional Dimension

The Regional Dimension can be interpreted from the group space displayed in Figure 12. All firms headquartered in California appear below the -.75 vertical coordinate. Moving up the vertical axis, a cluster of Michigan-Missouri headquartered firms emerge between coordinates 
-.59 and -.29. Next, four Pennsylvania-Ohio firms are clustered between coordinates -.06 and .17 . Finally, six New York-Connecticut firms have a vertical coordinate of .24 or higher. Based on this visual inspection, the MDS map was segmented at $-.75,-.25$, and .18 resulting in four regional divisions.

Chi-square. To order the data for chi-square, the sample firms' headquarters locations were coded into the observed four regions. Seven firms are labeled "Other" and are not included in the chi-square analysis since MDS did not assign a regional classification. Three of the "other" firms are the sole representatives of their respective states: North Carolina, Texas, and Minnesota. The remaining four are based in a single state, Illinois, but are not grouped on the dimension two axis.

\section{Chi-square compares the observed distribution of} firms along dimension two with actual headquarters locations. Table XL displays each firm's actual HQ regional location, its MDS-classified HQ location, and those instances in which the two did not match. The contingency table (see Table XLI) and its chi-square statistic (43.659; $p<.0001)$ support a systematic relationship between the Regional Dimension and actual HQ location. Cramer's V, a measure of association, is . $645^{6}$

${ }^{6}$ Cramer's V statistic, a statistic comparable to phi, is more suitable for larger contingency tables (SPSS Inc. $1988,436)$. 
Dimension Three: Outlier/Donees

Dimension

As previously noted, dimension three does not correlate with any hypothesized variable. Nevertheless, an inspection of the group space displayed in Figure 13 (dimensicn three appears on the vertical axis) suggests two possible interpretations for the dimension three intercorporate pattern of firms.

outliers. First, an outlier pattern is evident. Most firms are clustered toward the center of the plane defined by dimension two and dimension three. In contrast, four firms (Mellon, Wells Fargo, ITV, and Consolidated Edison) are so far removed from the dominant cluster that their MDS location exceeded the boundaries of the computer-generated map. These same four firms were identified earlier in a list of five firms which exhibited zero consensus during the 1981-82 election cycle (see Table XXXI). The fifth firm of that zero consensus group, Honeywell, is also positioned apart from the dominant cluster. Therefore, zero consensus appears to be a factor which is influencing the configuration of firms along the dimension three axis.

Donees. A second pattern emerged when the number of candidates (termed donees) to whom PACs contributed was considered. Table XIII displays descriptive statistics on the donee variable. The research sample distribution exhibits a moderately high level of dispersion (range-to- 
standard deviation ratio $=3.75)$, with a range from 18 to 288, a mean of 122 , and a standard deviation of 72 .

The donee distribution's four quartiles were subsequently used to segment the group space displayed in Figure 13. Jabeling sample firms according to their respective quartiles reveals a division at both the high and low ends of the vertical axis (dimension three). Firms which contributed to a low number of candidates (low defined by quartile one), appear at the positive and negative extremes of dimension three; firms which contributed to an average to high number of candidates (defined by quartiles two through four) are clustered in the middle range of dimension three.

Chi-square. A chi-square test measured the extent of the association between number of candidate contributions and the three identified MDS segments. Firms were coded low or average-high according to the quartile representing their candidate contributions, and quartile one firms were further classified positive or negative as determined by a positive or negative dimension three coordinate (Table XLIII). When the actual number-of-donee contribution pattern was compared with the MDS generated contribution pattern, a significant chi-square statistic of $57.00(p<.0001)$ resulted; the chisquare derived measure of association (Cramer's V) is .824. Therefore, dimension three is labeled the outlier/Donee dimension. The outlier label is indicative of 
the MDS map's demarcation of those firms which exhibited zero political consensus. The dimension's interpretation derived from number of candidate contributions is represented by the donee label.

Identification of the outlier dimension could point to a future research direction. A reasonable assumption is that the personal ideology of a strong corporate leadership is influencing the atypical behavior of the outlier group. As was previously discussed, future research should examine the relationship between top management's personal and corporate political ideology.

\section{CORRELATIONS AMONG VARIABLES}

Correlations among variables within two groups are computed and presented in Table XXXVI: The hypothesized variables and PAC characteristics. To augment that correlation matrix, Table XLIV displays the means and standard deviations of the interval-level variables.

Hypothesized Variables

Requlatory environment. Table XXXVI reveals no significant correlations between the resource dependence variable (regulatory environment) and any of the class cohesion variables (direct/indirect interlocks, professional associations, schools, and headquarters location). Class cohesion variables. Table XXXVI reveals significant correlations among class cohesion variables. 
These relationships follow the same pattern revealed in the 1977-78 data set.

As expected, the correlation between direct and indirect interlocks is high, .74, and significant at the .0001 level. While the correlation is not as strong, there is also a significant relationship between the number of professional-association memberships and interlocking directorates $(p<.005$ with direct and $p<.0005$ with indirect interlocks). As previously discussed, these correlations suggest that corporations which encourage direct or indirect multiple board linkages also promote participation in prestigious business associations.

\section{PAC Characteristics}

The expected significant relationships among characteristics of PAC activity which were revealed in the 1977-78 data set are evident again in the 1981-82 data set. Contributions to incumbents, on the one hand, and Republican or New Right candidates, on the other, are negatively correlated $(x=-.81 ; p<.00001$ and $r=-.90 ; p<.0001$ respectively). This pattern is consistent with the likelihood that a pragmatic PAC strategy, which favors incumbents, deemphasizes the candidate's party affiliation (Burris 1987, 735).

Two other correlations are also consistent with expected patterns. First, the positive correlation between contributions to New Right and Republican candidates 
$(\mathrm{r}=.87 ; \mathrm{p}<.0001)$ reflects the predominant party

affiliation of New Right candidates. Second, the positive correlation between total dollars contributed and number of candidates supported $(r=.84 ; p<.0001)$ quite reasonably suggests that firms with larger PAC coffers will support more candidates.

Regulatory Environment and PAC Characteristics

As in the 1977-78 data set, this correlation analysis supports the resource dependence contention which holds that firms in economic regulatory environments will favor a pragmatic PAC strategy. Regulatory environment is correlated with percentage of contributions targeted to incumbents $(r=-.33 ; p<.03) .^{7}$ The next section, which examines the resource dependence component of the research question, expands on this preliminary finding.

\section{RESOURCE DEPENDENCE}

The 1981-82 intercorporate patterns are subjected to the same sort of hypothesis testing as the were the 1977-78 patterns. The results are then applied to the research question: Can resource dependence theory explain

${ }^{7}$ Since regulatory environment was dummy-coded 1 for economic environment and 0 for social environment, a social regulatory environment is negatively associated with incumbent contributions; and, conversely, firms with economic regulatory constraints are positively associated with contributions to incumbent candidates. 
intercorporate patterns of corporate political activity, specifically political action committee (PAC) campaign contributions?

\section{The Hypothesis Test}

Research Hypothesis: Firms similarly constrained by government regulations will exhibit similar political behavior.

Null Hypothesis: There is no significant relationship between a firm's MDS coordinates and its regulatory environment classification.

Requlatory dimension. Dimension one, the regulatory dimension, provides a direct test of the hypothesis. The sample firms are positioned along the horizontal axis according to their similarities (Figure 11). Therefore, if groupings are coincident with regulatory environment, the null hypothesis is rejected and the research hypothesis supported. Three tests were employed to ascertain whether this condition holds.

Multiple regression. The resource dependence hypothesis was first tested with multiple regression. The independent variables are the sample firms' coordinates on the three-dimensional MDS solution, each coordinate serving as a distinct representation of corporate political activity as measured by similar PAC contributions. The dependent variable is a firm's regulatory environment classification-social or economic (Table $V$, page 104). The regression 
model, which attempts to predict a firm's regulatory environment classification based on its position in the MDS space, is:

REG ENV $=B_{0}+B_{1}(D I M 1)+B_{2}(D I M 2)+B_{2}(D I M 3)+$ error

This model results in a multiple correlation coefficient of .53 , and a significant coefficient of determination of $.28(p<.005)$. The bulk of this relationship is accounted for by the regulatory dimension, dimension one: $\mathrm{b}=-.2443 ; \mathrm{p}<.001 ; \mathrm{r}=-.503 ; \mathrm{p}<.001$ (see Table XIV).

Therefore, based on multiple regression analysis, the null hypothesis that there is no significant relationship between regulatory environment and patterns of PAC activity is rejected.

Discriminant analysis. A discriminant analysis not only reinforced the regression results but also provided the means to determine the number of firms which are correctly classified by their MDS coordinates. Tables XLVI and XLVII present a discriminant classification summary and the identity of the twelve firms which were incorrectly classified based on their MDS coordinates.

The model is statistically significant with a squared canonical correlation of .29 and a Wilks' lambda of .71 (F = $5.066 ; \mathrm{p}<.005)$. As expected, given the regression results, the structure coefficient for dimension one is a high .94, while dimensions two and three structure 
coefficients are -.04 and -.33 respectively. This indicates that eighty-eight percent of the variance of dimension one is being accounted for by the discriminant function.

Chi-square. The chi-square test is useful because it does not require interval data and therefore is a conservative test of significance when interval data are redefined as ordinal or nominal. It can be applied in this instance because the regulatory environment classification resulted in mutually exclusive and exhaustive categories and in independent observations which can be reduced to a nominal-level variable. Dimension one provides a good measure of regulatory environment, so its coordinates serve to assign each firm into one of two nominal values of the observed regulatory environment; the predicted environment uses each firm's hypothesized classification. Chi-square tests the relationship between the predicted and observed regulatory environment classifications.

since the chi-square analysis utilizes dimension one, the dimension that best classified firms in the discriminant model, one might expect that the confounding effect of the other two dimensions is removed. Such appears to be the case, because the chi-square contingency table and table of misclassified firms show nine firms as misclassified, compared with the eleven misclassified by the discriminant model (see Tables XIVIII and XIIX). 
The chi-square statistic, 13.65 , is significant at the .0001 level, thereby supporting the research hypothesis. This support is confirmed by the measure of association, phi, at .57. Therefore, based on chi-square analysis, the null hypothesis that there is no significant relationship between regulatory environment and patterns of PAC activity is rejected.

Discussion

A comparison of the 1981-82 and 1977-78 hypothesis test results reveals a striking correspondence between these two independent data sets. Both analyses provide support for the resource dependence model and exhibit a pronounced commonality between the sets of firms which were misclassified in each election cycle (see pages 175-176 for discussion on misclassified firms.)

Table L compares some relevant coefficients and statistics for the two data sets. This table suggests that the relationship between political activity and resource dependence as exemplified by similar regulatory environments not only persisted from one election cycle to the other but, indeed, strengthened.

Coincident results. Three observations, two of which contradict current thinking, are bolstered by the coincidence between results from the 1977-78 and 1981-82 data sets. 
Three banks (Mellon, Security Pacific, and Wells Fargo) exhibit behavior which runs counter to expectations. All are traditionally associated with a single-industry, economic regulatory environment but exhibit ideological behavior. This finding strongly suggests that conventional wisdom regarding the banking industry's political behavior needs to be reexamined.

Rockwell, Honeywell, and United Technologies also exhibited unexpected behavior. These three large defense contractors contributed well over the median to Republicans and New Right candidates, yet pragmatic behavior by firms which generate a significant portion of revenue from government sales is anticipated. As with the banking industry, this research calls for a reexamination of corporate political activity patterns exhibited by defense contractors and other corporations dependent upon government sales.

Finally, as was the case in 1977-78, the sample's two representatives from the tobacco industry displayed pragmatic political behavior, both contributing well over the median to Democratic candidates (although R. J. Reynolds did support a large number of New Right candidates). This would seem to support the prior contention that the extreme social and political pressures on the tobacco industry have fostered a need to take the lower-risk strategy of supporting incumbents to enhance access to powerful 
legislators, as opposed to the riskier strategy of attempting to change the overall composition of congress.

\section{CLASS COHESION}

This section addresses the research question: Can class cohesion theory explain intercorporate patterns of corporate political activity, specifically political action committee (PAC) campaign contributions?

The Hypothesis Tests

Class cohesion theory is tested with four research hypotheses--H2 through H5. These hypotheses and their associated null hypotheses are presented below:

H2: Firms' number of interlocking directorates will relate directly to similar political behavior among firms. $\mathrm{HO}_{2}$ : There is no significant relationship between a firm's MDS coordinates and its number of direct or indirect interlocks with the set of sampled firms.

H3: Firms' number of associations with certain prestigious business policy groups will relate directly to similar political behavior among firms.

$\mathrm{HO}_{3}$ : There is no significant relationship between a firm's MDS coordinates and its number of associations with major business policy groups. 
H4: Shared educational experience among Board Chairmen and CEOs will relate directly to similar political behavior.

$\mathrm{HO}_{4}$ : There is no significant relationship between a firm's MDS coordinates and a shared educational experience among Chairmen and CEO's.

H5: Geographically proximate headquarters will relate directly to similar political behavior.

$\mathrm{HO}_{5}$ : There is no significant relationship between a firm's MDS coordinates and its headquarters' location. Multiple reqression and canonical discriminant. The class cohesion hypotheses were tested with four regression models and one canonical discriminant model in which intercorporate networks (dependent variable) are predicted by MDS coordinates (independent variables). The respective intercorporate networks for each of the five models are the number of direct interlocks (hypothesis 2); the number of indirect interlocks (hypothesis 2); the number of professional associations (hypothesis 3 ); a dummy-coded variable representing the chairman and/or president's education (hypothesis 4); and a dummy-coded variable indicating location of corporate headquarters (hypothesis 5).

Table XLV displays regression, canonical, and correlation coefficients for each of the three coordinates from the MDS solution as it relates to the determinants of 
class cohesion theory. Also reported are the coefficients of determination, squared canonical correlations, Wilks' lambda (where applicable), and associated $F$ values for each model. Asterisks indicate significance levels.

Analytical results for the 1981-82 data set closely paraliel the results for the 1977-78 data set. First, no apparent relationship was revealed between corporate political activity as measured by the proximity of PAC contributions and the extent of a corporation's interlocking directorates, its number of professional associations, or its president's and CEO's educational background. Second, there is only modest support for the fifth class cohesion hypothesis that firms with geographically proximate headquarters will exhibit similar political behavior. ${ }^{8}$

\section{Discussion}

The geographic proximity model argues that corporate elites are bound together because their offices are proximate. Logically, then, proximity's effect should be more pronounced among state groupings of firms than among regional 'groupings. Indeed, this contention is supported by the clustering of New York metropolitan area firms at one end of the MDS map in Figure 12 and California firms at the other end.

${ }^{8}$ The significant statistics from each of the two election cycle data sets, as they relate to HQ location, reveal a striking correspondence. These comparative statistics appear in Table LI. 
The argument is weakened considerably, however, when the entire sample is subjected to a state-by-state analysis. state by state, discriminant analysis misclassifies fifty percent of the sample (see Table LII), suggesting a regional interpretation of the MDS map

The regional configuration is imperfect, but its general outline is clear. The only truly western firms in the sample, those in California, occupy the negative end of dimension two, and firms located in New York and Connecticut occupy the positive end. Thus, the two coastal regions are established. A central clustering encompasses firms located from Missouri in the west to Pennsylvania in the east.

As stated, the alignment is imperfect, but it is supported statistically. Some New York firms are positioned close to the Michigan set, and First Chicago Corporation is positioned with the East. Despite these departures, the correlations and chi-square statistics indicate a significant relationship.

The final support for the regional model over the class cohesion. model is to be found in contributions to categories of candidates. Table XXXVI reveals significant negative,correlations between dimension two, the Regional Dimension, and contributions to Republicans ( $\mathrm{r}=-.45 ; \mathrm{p}<$ $.003)$ and New Right candidates $(r=-.52 ; p<.0003)$; further, as would be expected, dimension two is positively related to contributions to incumbents $(r=.49 ; p<.0009)$. 
These correlations, combined with the regional mapping, suggest that eastern-based firms are contributing more PAC dollars to incumbents, while California firms are contributing more to Republican and New Right candidates. Indeed, five of the six sample firms based in California were previously labeled ideological, and eleven of the fifteen firms based in New York/Connecticut were labeled pragmatic.

This mapping lends additional support to Burris's (1987) research which considered the influence of culture and lineage on political attitudes. The 1981-82 intercorporate structure of similar corporate PAC contributions reveals a tendency for the "Eastern Establishment" to be more progressive or at least politically moderate, while the "Western Cowboys" are generally more conservative and ideological.

Politics and geography. These analyses suggest an extension of my research and potentially fruitful research directions. PAC contributions to "home boy" candidates competing in national races can be factored out, thus isolating political activity in support of candidates from states other than the firms' headquarters location. Further, whether home-state and out-of-state strategies are consistent could be of considerable interest. For example, home-state incumbents may be targeted to enhance access 
opportunities, while conservative challengers in tight outof-state races may receive the balance of PAC funds.

\section{Summary of Class Cohesion}

\section{Hypothesis Testing}

Analysis of the 1981-82 PAC contribution data provides some evidence to support only one hypothesis associated with the class cohesion theory: Firms with geographically proximate headquarters will exhibit similar behavior. New York and California headquartered firms are positioned at opposite ends of dimension two on the MDS map which scales similar corporate PAC contributions. But a state-by-state discriminant analysis misclassified fifty percent of the sample, thus a regional rather than a class cohesion theory of business partisanship better explains the intercorporate structure. The regional theory hypothesis is strengthened by the significant relationship which was exhibited between regional headquarters' location and candidate-type contribution patterns.

\section{CHAPTER SUMMARY}

The structural analysis of the 1981-82 data set supports three of the four conclusions from the analysis of 1977-78 data in chapter IV and draws a further conclusion not reached in the earlier analysis. The two analyses show commonalities that suggest the model's reliability. 
Resource Dependence Theory

Both analyses support the contention that resource dependence theory, defined as similar patterns of intercorporate behavior emanating from a common set of constraints (a common regulatory environment) can explain intercorporate patterns of corporate political activity (patterns of PAC campaign contributions).

\section{Class Cohesion Theory}

Neither analysis supports the complementary contention which advanced class cohesion theory as an explanation for patterns of political consensus among corporate executives; that is, no significant relationship was discovered between a firm's pattern of PAC contributions and its number of interlocking directorates, professional associations, and educational background.

\section{Regional Theory}

Both analyses provide some support for a regional theory of business partisanship. There is an apparent relationship between regionally proximate headquarters locations and the selection of corporate PAC contribution recipients.

\section{Requlatory Environment/Strategy} Relationship

Both the 1977-78 and 1981-82 results lend support to previous research regarding the relationship between PAC 
strategy and regulatory environment. The conjecture that economically regulated firms will tend to pursue pragmatic PAC strategies, and socially regulated firms will tend to support ideological PAC strategies is supported. Nevertheless, both election cycles identified firms linked to the defense industry as deviating from expected patterns. An economic environment evoking pragmatic PAC behavior is expected, yet inconsistent patterns emerged.

\section{Reliability}

Finally, the comparison of the 1977-78 and 1981-82 results provides support for the research model's reliability. Specifically, while some firms' regulatory environment was not correctly classified by the MDS model, a striking commonality among the misclassified firms was observed. This suggests that the regulatory environment indicated by the MDS coordinates is more likely to resemble the "true" regulatory environment rather than a random misclassification. Further support is evidenced from the correlation between election cycles on the regulatory environment dimension $(r=.51 ; p<.0006)$. 


\section{TABLE XXX \\ DISTRIBUTION OF 1981-82 SIMILARITY MEASURES \\ QUARTILES AND INTERQUARTILE RANGE}

\begin{tabular}{ll} 
Quartiles & Values \\
\cline { 2 - 2 } Maximum & 0.624 \\
Q3 & 0.341 \\
Median & 0.251 \\
Q1 & 0.157 \\
Minimum & 0 \\
Interquartile range & 0.184
\end{tabular}


FIRM DYADS EXHIBITING ZERO POLITICAL CONSENSUS 1981-82 ELECTION

\begin{tabular}{lccc} 
& Con Ed & LTV & Nells Pargo \\
\cline { 2 - 3 } & 0 & 0 & 0 \\
Honeywell & 0 & 0 &
\end{tabular}

Note: 0 marks the four firm dyads which exhibited zero political consensus. 
TABLE XXXII

FIRM DYADS EXHIBITING HIGH POLITICAL CONSENSUS 1981-82 ELECTION

\begin{tabular}{|c|c|c|c|c|c|c|c|c|}
\hline Firm & 4 & 5 & 7 & 8 & 10 & 12 & 14 & 16 \\
\hline $\begin{array}{l}\text { 1. Arco } \\
\text { 2. Dow } \\
\text { 3. Ford } \\
\text { 4. GE } \\
\text { 5. GM } \\
\text { 6. GTE } \\
\text { 7. K Mart } \\
\text { 8. Lockheed } \\
\text { 9. Penney } \\
\text { 10. Philip Morris } \\
\text { 11. RJR } \\
\text { 12. Rockwell } \\
\text { 13. Sears } \\
\text { 14. Security Pacific } \\
\text { 15. Texaco } \\
\text { 16. Union Pacific } \\
\text { 17. USX } \\
\text { 18. United Tech. } \\
\text { 19. Wells Fargo } \\
\text { 20. Westinghouse }\end{array}$ & $\begin{array}{l}.554 \\
.532 \\
\\
.605 \\
.522 \\
.508 \\
\\
.533 \\
c \\
.535 \\
.547 \\
.577 \\
.563\end{array}$ & $\begin{array}{l}.537 \\
.512 \\
.534\end{array}$ & $\begin{array}{l}.544 \\
.514\end{array}$ & .590 & .526 & .516 & .624 & $\begin{array}{r} \\
.523 \\
.522 \\
.516 \\
.503\end{array}$ \\
\hline
\end{tabular}




\section{TABLE XXXIII}

FIT INDICES FOR FIVE BUCLIDEAN MODELS

1981-82 SIMILARITY DATA

MDS

Dimensionality Stress SStress RSQ

1

$.400 \quad .504$

$.237 \quad .348$

$.181 \quad .256$

$.131 \quad .193$

$.106 \quad .155$

.592

.775

3

5

.837

.895

.921 
TABLE XXXIV

ITERATION HISTORY FOR THE THREE-DIMENSIONAL SOLUTION

1981-82 ELECTION

Iteration SStress Improvement

$\begin{array}{rll}1 & 0.459 & \\ 2 & 0.306 & 0.153 \\ 3 & 0.281 & 0.025 \\ 4 & 0.272 & 0.009 \\ 5 & 0.267 & 0.005 \\ 6 & 0.264 & 0.003 \\ 7 & 0.262 & 0.002 \\ 8 & 0.261 & 0.001 \\ 9 & 0.261 & 0.001 \\ 10 & 0.260 & 0.001 \\ 11 & 0.260 & 0.001 \\ 12 & 0.259 & 0.001 \\ 13 & 0.259 & 0.001 \\ 14 & 0.258 & 0.000 \\ 15 & 0.258 & 0.000 \\ 16 & 0.257 & 0.000 \\ 17 & 0.257 & 0.000 \\ 18 & 0.257 & 0.000 \\ 19 & 0.257 & 0.000 \\ 20 & 0.257 & 0.000 \\ 21 & 0.256 & 0.000 \\ 22 & 0.256 & 0.000 \\ 23 & 0.256 & 0.000 \\ 24 & 0.256 & 0.000 \\ 25 & 0.256 & 0.000 \\ 26 & 0.256 & 0.000 \\ 27 & 0.256 & 0.000 \\ 28 & 0.256 & 0.000 \\ 29 & 0.256 & 0.000 \\ 30 & 0.256 & 0.000\end{array}$

Note: Iterations stopped because SStress improved less than 0.000010 
FIRMS POR UHICH HYPOTHESIZED REGULATORY ENVIRONMENT CLASSIFICATION DIRFERED FROM THE MDS CLASSIFICATION

$1977-78$

Bethlehem Steel' (E)

Pederated Department Store (E) GTE (S)

Honeywell (S)

Rockwell (S)

Southern Pacific (S)

TWA (S)

Union Pacific (S)

United Air Lines (S)

United Technologies (S)
$1981-82$

American Blectric Power (S)

Bethlehem Steel (E)

Federated Department Store (E) GTE (S)

Honeywell (S)

International Harvester (B)

LTV (E)

Penney ( $\mathrm{B}$ )

United Technologies (S)

Note: MDS classification is in parentheses. $E=$ Economic, $S=$ Social 
TABLE XXXVI

CORRELATIONS BETUEEN MDS COORDINATES AND INTERPRETIVE VARIABLES

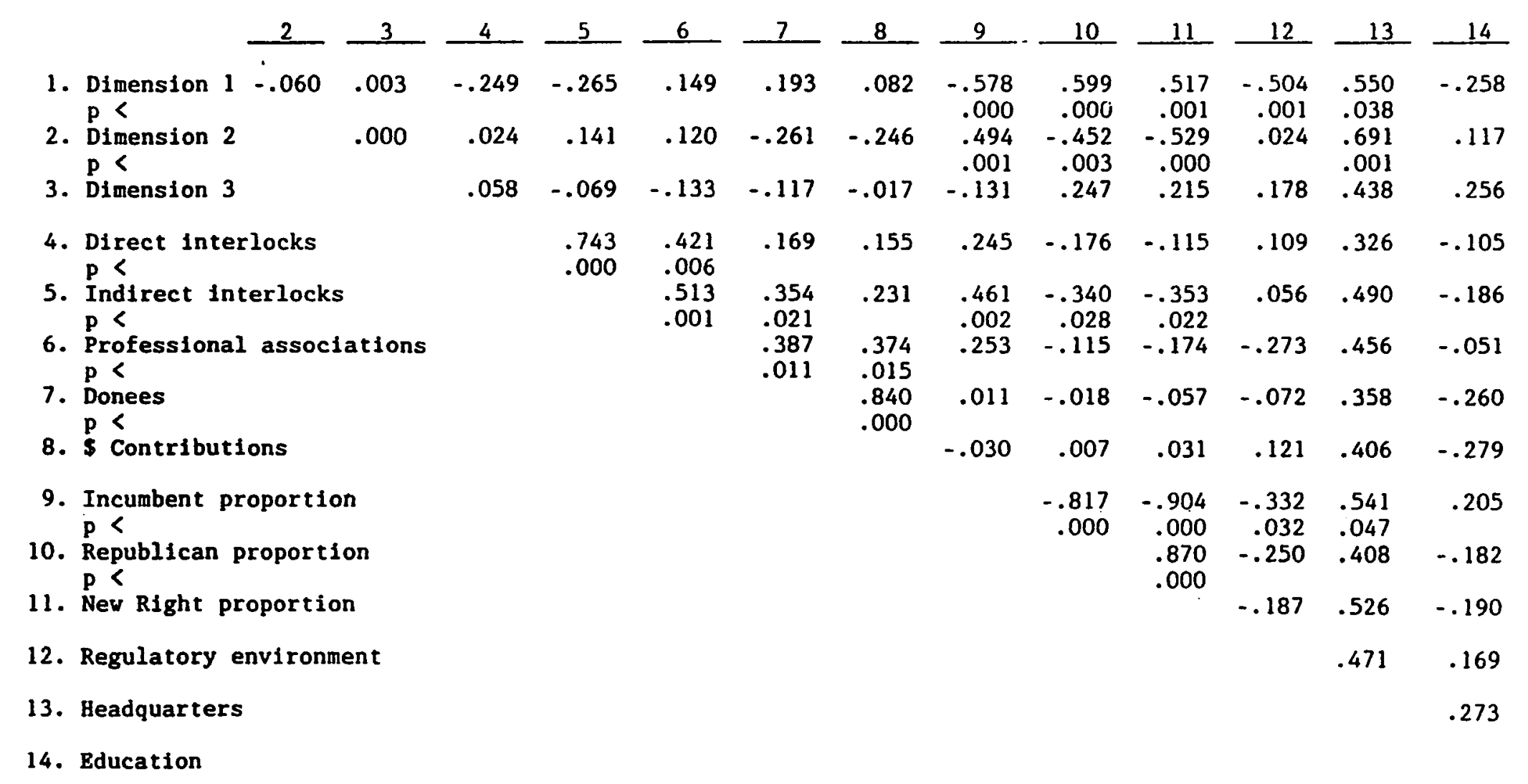

Note: Probability displayed only when $p<.05$. 
TABLE XXXVII

PAC CONTRIBUTION PATTERNS

1981-82 ELECTION

\begin{tabular}{|c|c|c|c|c|}
\hline \multirow{2}{*}{ IDE } & \multirow[b]{2}{*}{ Firm } & \multicolumn{3}{|c|}{ Proportion of Dollars Donated to } \\
\hline & & Incumbent & Republican & New RIgh \\
\hline 1 & ALCOA & .715 & .740 & .167 \\
\hline 2 & American Electric Power & .770 & .654 & .153 \\
\hline 3 & American Express & .962 & .389 & .035 \\
\hline 4 & Arco & .746 & .659 & .183 \\
\hline 5 & Bethlehem Steel & .945 & .457 & .065 \\
\hline 6 & Chrysler & .793 & .520 & .104 \\
\hline 7 & Citicorp & .818 & .539 & .158 \\
\hline 8 & Consolidated Edison & .893 & .415 & .101 \\
\hline 9 & Dow & .464 & .964 & .354 \\
\hline 10 & Federated Department Store & .875 & .418 & .104 \\
\hline 11 & First Chicago & .919 & .380 & .041 \\
\hline 12 & Ford & .843 & .609 & .131 \\
\hline 13 & GE & .931 & .520 & .061 \\
\hline 14 & GM & .806 & .755 & .145 \\
\hline 15 & GTE & .844 & .550 & .082 \\
\hline 16 & Goodyear & .843 & .619 & .115 \\
\hline 17 & Honeywell & .718 & .876 & .248 \\
\hline 18 & International Harvester & .867 & .598 & .032 \\
\hline 19 & $\mathrm{~K}$ Mart & .584 & .912 & .314 \\
\hline 20 & Lockheed & .793 & .531 & .140 \\
\hline 21 & LTV & .734 & .575 & .126 \\
\hline 22 & Manufacturers Hanover & .898 & .570 & .134 \\
\hline 23 & Mellon & .774 & .681 & .161 \\
\hline 24 & Metropolitan Life Insurance & .906 & .529 & .060 \\
\hline 25 & Monsanto & .734 & .720 & .223 \\
\hline 26 & Pan American & .981 & .492 & .019 \\
\hline 27 & Penney & .885 & .425 & .062 \\
\hline 28 & Philip Morris & .735 & .445 & .083 \\
\hline 29 & RJR & .809 & .533 & .163 \\
\hline 30 & Rockwell & .841 & .659 & .165 \\
\hline 31 & Sears & .632 & .778 & .206 \\
\hline 32 & Security Pacific & .554 & .784 & .359 \\
\hline 33 & Southern Pacific & .69 & .578 & .146 \\
\hline 34 & Texaco & .60 & .811 & .288 \\
\hline 35 & TWA & .93 & .511 & .039 \\
\hline 36 & Union Carbide & .652 & .819 & .271 \\
\hline 37 & Union Paciflc & .822 & .674 & .136 \\
\hline 38 & United Air Lines & .902 & .537 & .087 \\
\hline 39 & USX & .823 & .687 & .172 \\
\hline 40 & United Technologtes & .757 & .672 & .208 \\
\hline 41 & Wells Fargo & .687 & .740 & .277 \\
\hline 42 & Westinghouse & .878 & .471 & .100 \\
\hline & All Corporate PACs & .730 & .650 & \\
\hline & Sample & .790 & .610 & .140 \\
\hline
\end{tabular}

Federal Election Commission 
TABLE XXXVIII

IDEOLOGICAL PAC CONTRIBUTION PATTERNS 1981-82 ELECTION

\begin{tabular}{l} 
Firm \\
\hline ALCOA \\
American Electric Power \\
Arco \\
Dow \\
GM \\
Honeywell \\
K Mart \\
Mellon \\
Monsanto \\
Rockwell \\
Sears \\
Security Pacific \\
Southern Pacific \\
Texaco \\
Union Carbide \\
Union Pacific \\
USX \\
United Technologies \\
Wells Fargo
\end{tabular}

Proportion of Dollars Donated to

\begin{tabular}{ccc}
\hline Incumbent & Republican & New Right \\
\cline { 2 - 3 } .715 & .740 & .167 \\
.770 & .654 & .153 \\
.746 & .659 & .183 \\
.464 & .964 & .354 \\
.806 & .755 & .145 \\
.718 & .876 & .248 \\
.584 & .912 & .314 \\
.774 & .681 & .161 \\
.734 & .720 & .223 \\
.841 & .659 & .165 \\
.632 & .778 & .206 \\
.554 & .784 & .359 \\
.657 & .578 & .146 \\
.600 & .811 & .288 \\
.652 & .819 & .271 \\
.822 & .674 & .136 \\
.823 & .687 & .172 \\
.757 & .672 & .208 \\
.687 & .740 & .277
\end{tabular}

Note: Categories overlap, e.g., a candidate can be a Republican incumbent.

-Ideological leaning 
TABLE XXXIX

PRAGMATIC PAC CONTRIBUTION PATTERNS 1981-82 ELECTION

Proportion of Dollars Donated to

\begin{tabular}{|c|c|c|c|}
\hline \multirow[b]{2}{*}{ Firm } & & & \\
\hline & Incumbent & Republican & New Righ \\
\hline American Express & .962 & .389 & .035 \\
\hline Bethlehem Steel & .945 & .457 & .065 \\
\hline Chrysler & .793 & .520 & .104 \\
\hline Citicorp* & .818 & .539 & .158 \\
\hline Consolidated Edison & .893 & .415 & .101 \\
\hline Federated Department Store & .875 & .418 & .104 \\
\hline First Chicago & .919 & .380 & .041 \\
\hline Ford & .843 & .609 & .131 \\
\hline GE & .931 & .520 & .061 \\
\hline GTE & .844 & .550 & .082 \\
\hline Goodyear & .843 & .619 & .115 \\
\hline International Harvester & .867 & .598 & .032 \\
\hline Lockheed & .793 & .531 & .140 \\
\hline LTV & .734 & .575 & .126 \\
\hline Manufacturers Hanover & .898 & .570 & .134 \\
\hline Metropolitan Life Insurance & .906 & .529 & .060 \\
\hline Pan American & .981 & .492 & .019 \\
\hline Penney & .885 & .425 & .062 \\
\hline Philip Morris & .735 & .445 & .083 \\
\hline RJR & .809 & .533 & .163 \\
\hline TWA & .938 & .511 & .039 \\
\hline United Air Lines & .902 & .537 & .087 \\
\hline Westinghouse & .878 & .471 & .100 \\
\hline
\end{tabular}

Note: Categories overlap, e.g., a candidate can be a Republican incumbent.

Pragmatic leaning 
TABLE XL

ACTUAL AND MDS-GENERATED HEADOUARTERS LOCATION 1981-82 ELECTION

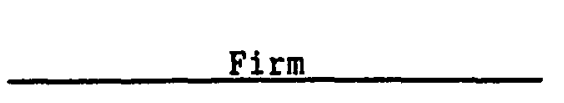

ALCOA

American Electric Power

American Express

Arco

Bethlehem Steel

Chrysler

Citicorp

Consolidated Edison

Dow

Federated Department Store

Ford

GE

GM

GTE

Goodyear

$\mathrm{K}$ Mart

Lockheed

Manufacturers Hanover

Mellon

Metropolitan Life Insurance

Monsanto

Pan American

Penney

Philip Morris

Rockwell

Sears

Security Pacific

Southern Pacific

Texaco

TWA

Union Carbide

Union Pacific

USX

United Technologies

Wells Pargo

Westinghouse
Dimension
Two

$-$

$-0.061$

1.442

0.821

$-1.323$

1.000

$-0.364$

0.473

1.799

$-0.428$

$-0.041$

$-0.295$

0.061

0.097

$-0.567$

0.944

$-0.594$

$-0.879$

2.030

1.182

0.242

$-0.418$

0.053

$-0.458$

0.469

$-0.752$

$-0.380$

$-1.713$

$-1.230$

$-0.798$

$-0.377$

0.162

$-0.254$

0.069

$-0.223$

$-2.962$

0.171
Headquarters

\begin{tabular}{ll}
\hline ACtUal & MDS \\
\cline { 2 - 3 } PA-OH & PA-OH \\
PA-OH & NY-CT \\
NY-CT & NY-CT \\
CALIP & CALIF \\
PA-OH & NY-CT \\
MI-MO & MI-MO \\
NY-CI & NY-CT \\
NY-CT & NY-CT \\
MI-MO & MI-MO \\
PA-OH & PA-OH \\
MI-MO & MI-MO \\
NY-CT & PA-OH \\
MI-MO & PA-OH \\
NY-CT & MI-MO \\
PA-OH & NY-CT \\
MI-MO & MI-MO \\
CALIF & CALIF \\
NY-CT & NY-CT \\
PA-OH & NY-CT \\
NY-CT & NY-CT \\
MI-MO & MI-MO \\
NY-CT & PA-OH \\
NY-CT & MI-MO \\
NY-CT & NY-CT \\
CALIF & CALIF \\
IL & MI-MO \\
CALIF & CALIP \\
CALIP & CALIP \\
NY-CT & CALIF \\
NY-CT & MI-MO \\
NY-CT & PA-OH \\
NY-CT & MI-MO \\
PA-OH & PA-OH \\
NY-CT & PA-OH \\
CALIF & CALIF \\
PA-OH & PA-OH \\
& \\
&
\end{tabular}

Misclassified 
TABLE XLI

ACTUAL AND MDS-GENERATED HEADQUARTERS LOCATION CHI-SQUARE CONTINGENCY TABLE

1981-82 ELECTION

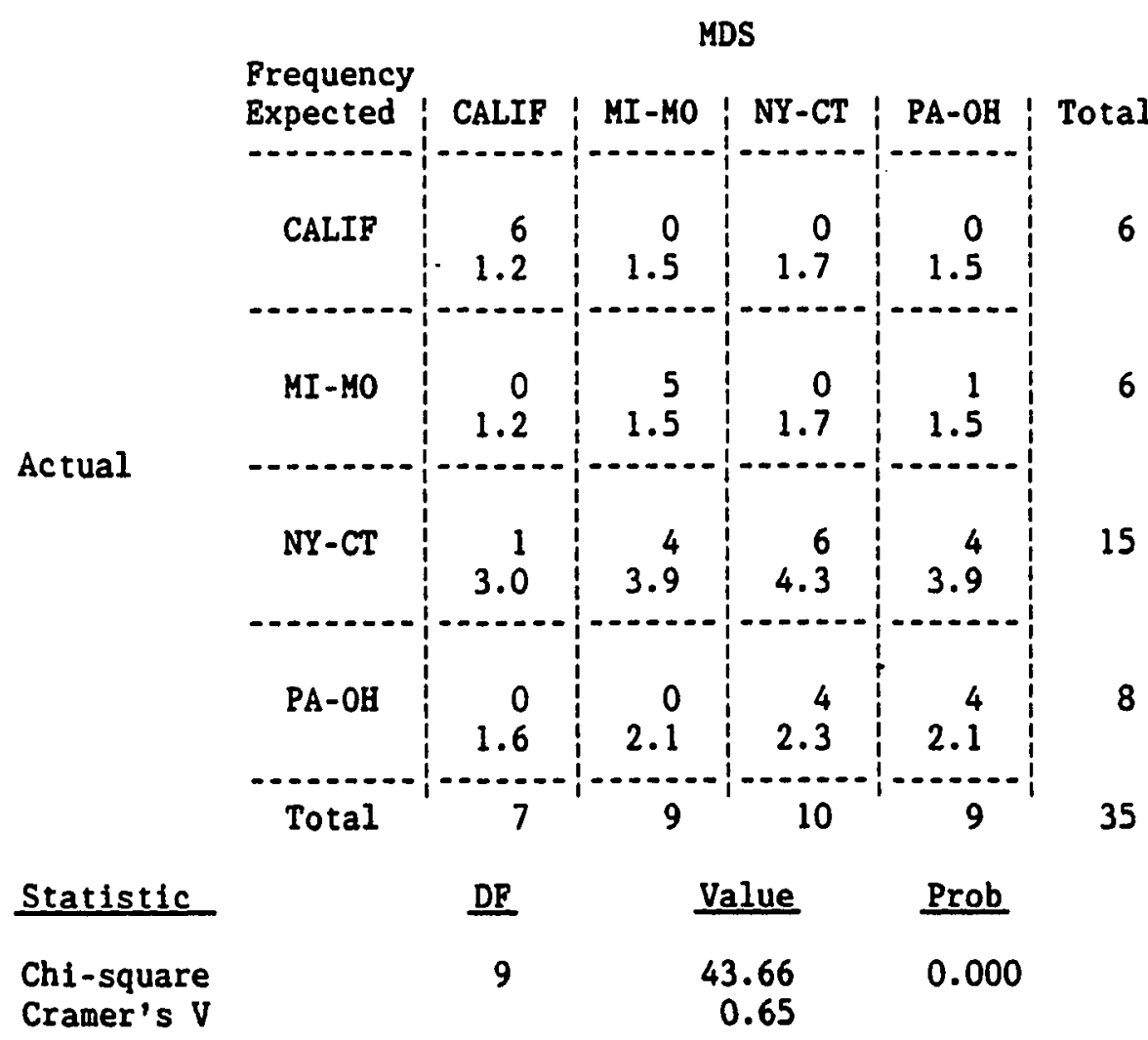

Effective sample size $=35$

Note: A significant chi-square of $30.156(p<.0001)$ results when 80 locations labeled "other" "are included. 
TABLE XLII

NUMBER OF DONEES TO WHOM PACS CONTRIBUTED

1981-82 ELECTION

Interval Level Statistics

Sample Size

Mean

Standard deviation
42

122.024

72.511

\begin{tabular}{lr}
\multicolumn{2}{c}{ Quartiles } \\
\hline \\
Maximum & 288 \\
03 & 193 \\
Median & 118 \\
01 & 57 \\
Minimum & 18
\end{tabular}


TABLE XLIII

ACTUAL AND MDS-GENERATED CATEGORIES

FOR NUMBER OF DONEES

1981-82 ELECTION

\begin{tabular}{|c|c|c|c|c|c|}
\hline \multirow[b]{2}{*}{ ID: } & \multirow[b]{2}{*}{ Firm } & \multirow{2}{*}{$\begin{array}{c}\text { Dimension } \\
\text { Three }\end{array}$} & \multirow[b]{2}{*}{ Donees } & \multicolumn{2}{|c|}{ Category } \\
\hline & & & & Actual & MDS \\
\hline 1 & ALCOA & 0.330 & 130 & AVG-HIGH & AVG-HIGH \\
\hline 2 & American Electric Power & -0.398 & 42 & LOW & AVG-HIGH - \\
\hline 3 & American Express & 0.869 & 80 & AVG-HIGH & AVG-HIGH \\
\hline 4 & Arco & -0.220 & 149 & AVG-HIGH & AVG-HIGH \\
\hline 5 & Bethlehem Steel & 0.205 & 81 & AVG-HIGH & AVG-HIGH \\
\hline 6 & Chrysler & 0.024 & 126 & AVG-HIGH & AVG-HIGH \\
\hline 7 & Citicorp & 0.235 & 157 & AVG-HIGH & AVG-HIGH \\
\hline 8 & Consolidated Edison & -2.169 & 45 & LOW & LOW \\
\hline 9 & Dow & 0.213 & 69 & AVG-HIGH & AVG-HIGH \\
\hline 10 & Federated Department Store & -0.057 & 124 & AVG-HIGH & AVG-HIGH \\
\hline 11 & First Chicago & 1.437 & 22 & LOW & LOW \\
\hline 12 & Ford & -0.193 & 144 & AVG-HIGH & AVG-HIGH \\
\hline 13 & GE & $-0 .(-1+x-1+2)$ & 288 & AVG-HIGH & AVG-HIGH \\
\hline 14 & GM & -0.0 & 200 & AVG-HIGH & AVG-HIGH \\
\hline 15 & GTE & -0.009 & 221 & AVG-HIGH & AVG-HIGH \\
\hline 16 & Goodyear & -0.019 & 65 & AVG-HIGH & AVG-HIGH \\
\hline 17 & Honeywell & 1.623 & 53 & LOW & LOW \\
\hline 18 & International Harvester & 0.098 & 58 & AVG-HIGH & AVG-HIGH \\
\hline 19 & $\mathrm{~K}$ Mart & 0.068 & 118 & AVG-HIGH & AVG-HIGH \\
\hline 20 & Lockheed & -0.311 & 208 & AVG-HIGH & AVG-HIGH \\
\hline 21 & LTV & -3.1 & 31 & LOW & LOW \\
\hline 22 & Manufacturers Hanover & 0. & 53 & LOW & AVG-HIGH \\
\hline 23 & Mellon & 3. & 18 & LOW & LOW \\
\hline 24 & Metropolitan Life Insurance & -0.822 & 121 & AVG-HIGH & AVG-HIGH \\
\hline 25 & Monsarto & -0. & 97 & AVG-HIGH & AVG-HIGH \\
\hline 26 & Pan American & -1.203 & 43 & LOW & LOW \\
\hline 27 & Penney & -0.143 & 170 & AVG-HIGH & AVG-HIGH \\
\hline 28 & Philip Morris & -0.391 & 214 & AVG-HIGH & AVG-HIGH \\
\hline 29 & RJR & -0 & 107 & AVG-HIGH & AVG-HIGH \\
\hline 30 & Rockwell & & 207 & AVG-HIGH & AVG-HIGH \\
\hline 31 & Sears & 0. & 263 & AVG-HIGH & AVG-HIGH \\
\hline 32 & Security Pacific & 1.415 & & LOW & LOW \\
\hline 33 & Southern Pacific & -0 . & 118 & AVG-HIGH & AVG-HIGH \\
\hline 34 & Texaco & -0.796 & 140 & AVG-HIGH & AVG-HIGH \\
\hline 35 & TWA & -0.439 & 60 & AVG-HIGH & AVG-HIGH \\
\hline 36 & Union Carbide & 0.8 & 73 & AVG-HIGH & AVG-HIGH \\
\hline 37 & Union Pacific & -0 & 237 & AVG-HIGH & AVG-HIGH \\
\hline 38 & United Air Lines & & 84 & AVG-HIGH & AVG-HIGH \\
\hline 39 & USX & & 190 & AVG-HIGH & AVG-HIGH \\
\hline 40 & United Technologies & -0 & 217 & AVG-HIGH & AVG-HIGH \\
\hline 41 & Wells Fargo & & 42 & LOW & AVG-HIGH * \\
\hline & Westinghouse & 0.200 & 205 & AVG-HIGH & AVG-HIGH \\
\hline
\end{tabular}


TABLE XLIV

DESCRIPTIVE STATISTICS FOR INTERVAL LEVEL VARIABLES 1981-82 ELECTION

\begin{tabular}{l} 
Variable \\
\hline Direct interlocks \\
Indirect interlocks \\
Professional associations \\
Donees \\
\$ Contributions \\
Incumbent proportion \\
Republican proportion \\
New Right proportion
\end{tabular}

\begin{tabular}{r} 
Mean \\
\hline 5.619 \\
166.405 \\
2.524 \\
122.024 \\
$76,853.950$ \\
0.794 \\
0.614 \\
0.148
\end{tabular}

Std Dev

3.722

90.929

1.330

72.511

$57,931.490$

0.119

0.146

$0.148 \quad 0.087$ 
TABLE XLV

RESOURCE DEPENDENCE AND CLASS COHESION VARIABLES REGRESSED AGAINST MDS COORDINATES

1981-82 ELECTION

Equation Dependent Variables Dim

Di

Resource Dependence Hypothesis

Regulatory environment

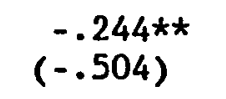$$
-.003
$$$$
(.024)
$$

$$
.286
$$

Class Cohesion Hypotheses

$$
\text { Direct interlocks }
$$

Indirect interlocks

Professional associations

\section{Education}

Headquarters location

-.886
$(-.249)$
-22.419
$(-.264)$
.200
$(.149)$
-.115
$(-.258)$
.249

$\begin{array}{cc}.224 & .065 \\ (.058) & \\ -6.345 & .091 \\ (-.069) & \\ -.181 & .057 \\ (-.133) & \\ .125 & .143 \\ (.256) & \\ -.063 & .485 \\ & .290\end{array}$

.065

.89

1.26

.76

2.11

$2.86 * \star$

Note: The first cell entry under the three dimensions for the first five equations is that model's unstandardized regression coefficient; the second, parenthetical, entry is the model's zero-order correlations. The sixth equation required canonical analysis; therefore, the unstandardized canonical coefficients are reported in the first three columns, and the squared canonical correction and Vilks' lambda in the fourth column.

$\star p<.005$

$\star \star \mathrm{p}<.001$ 
TABLE XLVI

\begin{tabular}{|c|c|c|c|}
\hline \multirow{2}{*}{$\begin{array}{l}\text { From } \\
\text { Regulatory } \\
\text { Environment }\end{array}$} & \multicolumn{3}{|c|}{$\begin{array}{l}\text { Number of Observations and } \\
\text { Percents Classified into } \\
\text { Regulatory Environment }\end{array}$} \\
\hline & Economic & Social & Total \\
\hline Economic & $\begin{array}{r}16 \\
72.73\end{array}$ & $\begin{array}{r}6 \\
27.27\end{array}$ & $\begin{array}{r}22 \\
100.00\end{array}$ \\
\hline Social & $\begin{array}{r}6 \\
30.00\end{array}$ & $\begin{array}{r}14 \\
70.00\end{array}$ & $\begin{array}{r}20 \\
100.00\end{array}$ \\
\hline $\begin{array}{l}\text { Total } \\
\text { Percent }\end{array}$ & $\begin{array}{r}22 \\
52.38\end{array}$ & $\begin{array}{r}20 \\
47.62\end{array}$ & $\begin{array}{r}42 \\
100.00\end{array}$ \\
\hline Priors & 50.00 & 50.00 & \\
\hline
\end{tabular}


TABLE XLVII

ACTUAL AND DISCRIMINANT-CLASSIFIED REGULATORY ENVIRONMENT CATEGORIES 1981-82 ELECTION

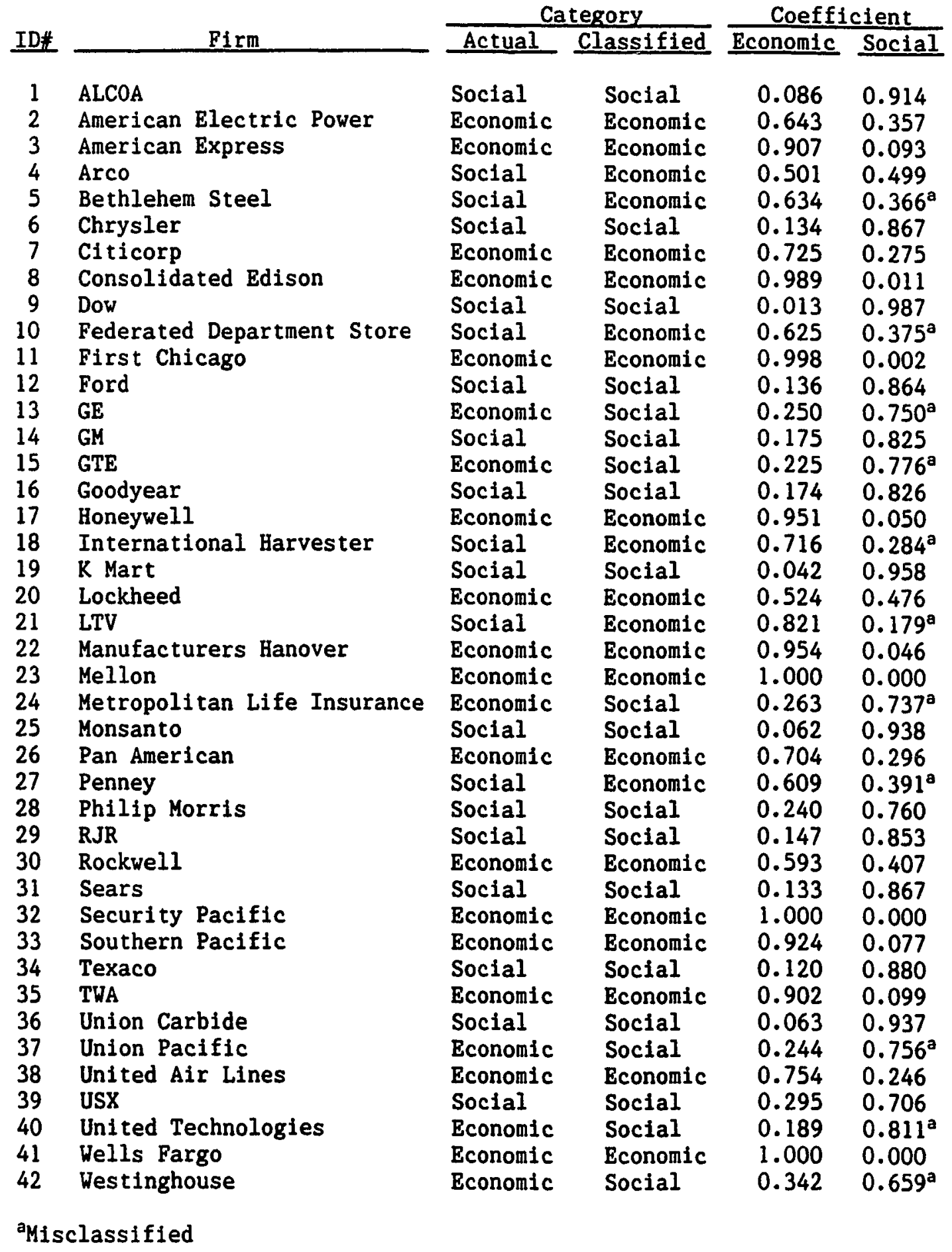


TABLE XLVIII

ACTUAL AND MDS-CLASSIFIED REGULATORY ENVIRONMENT CATEGORIES

CHI-SOUARE CONTINGENCY TABLE

1981-82 ELBCTION

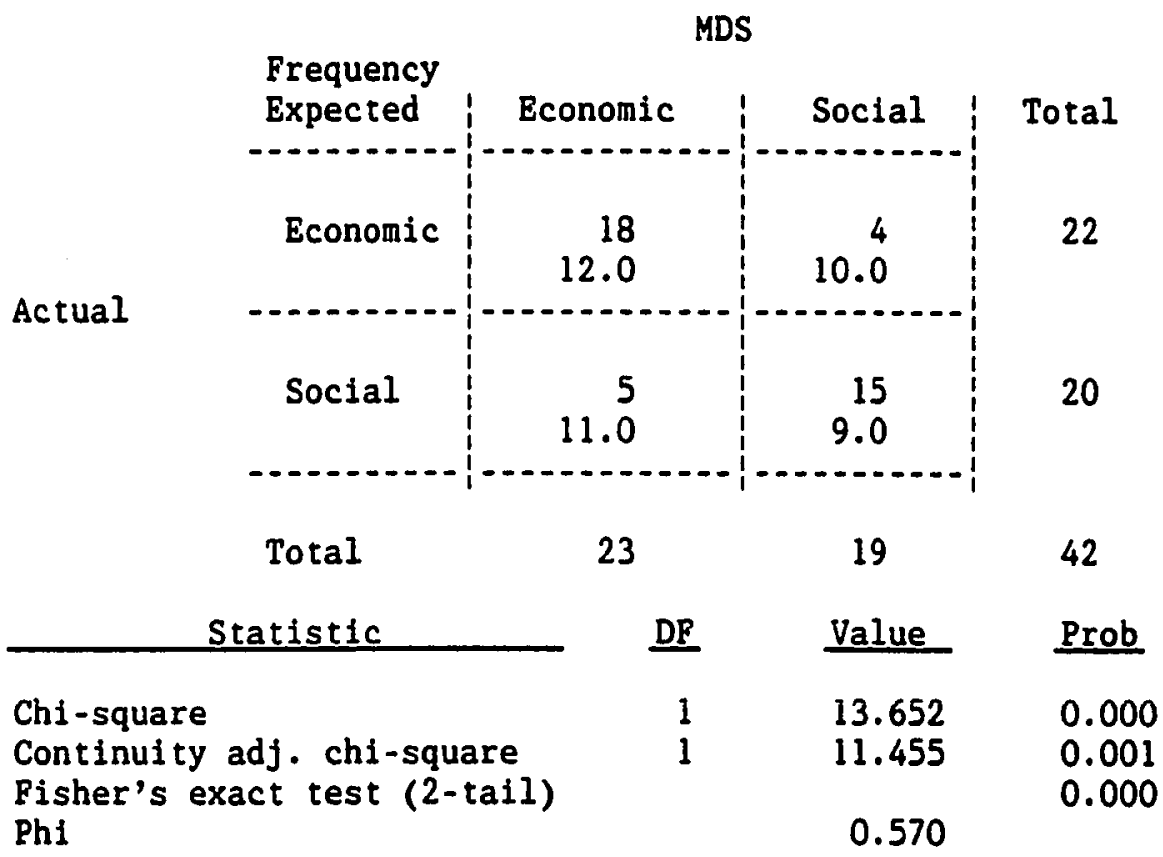

Sample size $=42$ 
TABLE XLIX

ACTUAL AND MDS-CLASSIFIED REGULATORY ENVIRONMENT CATEGORIES 1981-82 ELECTION

\begin{tabular}{|c|c|c|c|c|}
\hline \multirow[b]{2}{*}{ ID\# } & \multirow[b]{2}{*}{ Firm } & \multirow{2}{*}{$\begin{array}{c}\text { Dimension } \\
\text { One } \\
\end{array}$} & \multicolumn{2}{|c|}{ Category } \\
\hline & & & Actual & MDS \\
\hline 1 & ALCOA & 1.046 & Social & Social \\
\hline 2 & American Electric Power & 1.829 & Economic & Social* \\
\hline 3 & American Express & -1.141 & Economic & Economic \\
\hline 4 & Arco & 0.428 & Social & Social \\
\hline 5 & Bethlehem Steel & -0.667 & Social & Economic ${ }^{*}$ \\
\hline 6 & Chrysler & 0.694 & Social & Social \\
\hline 7 & Citicorp & -1.109 & Economic & Economic \\
\hline 8 & Consolidated Edison & -0.133 & Economic & Economic \\
\hline 9 & Dow & 2.323 & Social & Social \\
\hline 10 & Federated Department Store & -0.932 & Social & Economic ${ }^{*}$ \\
\hline 11 & First Chicago & -1.296 & Economic & Economic \\
\hline 12 & Ford & 0.601 & Social & Social \\
\hline 13 & GE & 0.038 & Economic & Economic \\
\hline 14 & GM & 0.383 & Social & Social \\
\hline 15 & GTE & 0.419 & Economic & Social. \\
\hline 16 & Goodyear & 1.685 & Social & Social \\
\hline 17 & Honeywell & 0.449 & Economic & Social• \\
\hline 18 & International Harvester & -0.444 & Social & Economic ${ }^{*}$ \\
\hline 19 & K Mart & 1.563 & Social & Social \\
\hline 20 & Lockheed & -0.175 & Economic & Economic \\
\hline 21 & LTV & -0.960 & Social & Economic* \\
\hline 22 & Manufacturers Hanover & -0.967 & Economic & Economic \\
\hline 23 & Mellon & -0.508 & Economic & Economic \\
\hline 24 & Metropolitan Life Insurance & -0.182 & Economic & Economic \\
\hline 25 & Monsanto & 1.352 & Social & Social \\
\hline 26 & Pan American & -2.288 & Economic & Economic \\
\hline 27 & Penney & -0.661 & Social & Economic* \\
\hline 28 & Philip Morris & 0.124 & Social & Social \\
\hline 29 & RJR & 0.981 & Social & Social \\
\hline 30 & Rockwell & -0.212 & Economic & Economic \\
\hline 31 & Sears & 0.773 & Social & Social \\
\hline 32 & Security Pacific & -1.075 & Economic & Economic \\
\hline 33 & Southern Pacific & -0.721 & Economic & Economic \\
\hline 34 & Texaco & 0.993 & Social & Social \\
\hline 35 & TWA & -1.943 & Economic & Economic \\
\hline 36 & Union Carbide & 1.460 & Social & Social \\
\hline 37 & Union Pacific & 0.110 & Economic & Economic \\
\hline 38 & United Air Lines & -1.257 & Economic & Economic \\
\hline 39 & USX & 0.150 & Social & Social \\
\hline 40 & United Technologies & 0.214 & Economic & Social* \\
\hline 41 & Wells Fargo & -0.841 & Economic & Economic \\
\hline 42 & Westinghouse & -0.105 & Economic & Economic \\
\hline
\end{tabular}




\section{TABLE L}

\section{A COMPARISON OF TEST STATISTICS \\ 1977-78 AND 1981-82 DATA \\ HYPOTHESIS ONE}

\begin{tabular}{|c|c|c|}
\hline Dependent Variable: Regulatory Environment & $1977-78$ & $1981-82$ \\
\hline Multiple correlation coefficient & .446 & .534 \\
\hline Coefficient of determination & .200 & .285 \\
\hline Dimension one regression coefficient & -.196 & -.244 \\
\hline Dimension one correlation coefficient & -.425 & -.503 \\
\hline Dimension one structure coefficient & .953 & .942 \\
\hline Chi-square (dimension one) & 12.780 & 13.652 \\
\hline Phi (associated with chi-square) & .552 & .570 \\
\hline
\end{tabular}


TABLE LI

A COMPARISON OF TEST STATISTICS

1977-78 AND 1981-82 DATA

HYPOTHESIS FIVE

Dependent Variable: Headquarters

$\underline{1977-78}$

$\underline{1981-82}$

Wilks' lambda

.38

.29

F value

$2.08 *$

$2.86 * \star$

Squared carionical correlation

.47

.48

Structure coefficient

.95

.97

Note: The independent variables are dimensions one, two, and three from the MDS solution. Structure coefficients are reported on the first discriminant function and dimension two for both data sets.

$\star \mathrm{p}<.01$

$\star \star \mathrm{p}<.001$ 


\section{TABLE LII}

DISCRIMINANT ANALYSIS CLASSIFICATION TABLE

FOR HEADQUARTERS LOCATION

1981-82 ELECTION

\begin{tabular}{|c|c|c|c|c|c|c|c|c|}
\hline \multirow{2}{*}{$\begin{array}{c}\text { From } \\
\text { HO }\end{array}$} & \multicolumn{8}{|c|}{ Number of Observations and Percents Classified into HQ } \\
\hline & 1 & 2 & 3 & 4 & 5 & 6 & 7 & Total \\
\hline NY-CT & $\begin{array}{r}7 \\
43.75\end{array}$ & $\begin{array}{r}0 \\
0.00\end{array}$ & $\begin{array}{r}0 \\
0.00\end{array}$ & $\begin{array}{r}3 \\
18.75\end{array}$ & $\begin{array}{r}1 \\
6.25\end{array}$ & $\begin{array}{r}1 \\
6.25\end{array}$ & $\begin{array}{r}4 \\
25.00\end{array}$ & $\begin{array}{r}16 \\
100.00\end{array}$ \\
\hline CALIF & $\begin{array}{r}1 \\
16.67\end{array}$ & $\begin{array}{r}2 \\
33.33\end{array}$ & $\begin{array}{r}1 \\
16.67\end{array}$ & 16.67 & $\begin{array}{r}1 \\
16.67\end{array}$ & $\begin{array}{r}0 \\
0.00\end{array}$ & $\begin{array}{r}0 \\
0.00\end{array}$ & $\begin{array}{r}6 \\
100.00\end{array}$ \\
\hline PA & $\begin{array}{r}0 \\
0.00\end{array}$ & $\begin{array}{r}0 \\
0.00\end{array}$ & $\begin{array}{r}4 \\
80.00\end{array}$ & $\begin{array}{r}0 \\
0.00\end{array}$ & $\begin{array}{r}0 \\
0.00\end{array}$ & $\begin{array}{r}0 \\
0.00\end{array}$ & $\begin{array}{r}1 \\
20.00\end{array}$ & 100.00 \\
\hline IL & $\begin{array}{r}1 \\
25.00\end{array}$ & $\begin{array}{r}0 \\
0.00\end{array}$ & $\begin{array}{r}0 \\
0.00\end{array}$ & $50.00^{2}$ & $\begin{array}{r}1 \\
25.00\end{array}$ & $\begin{array}{r}0 \\
0.00\end{array}$ & $\begin{array}{r}0 \\
0.00\end{array}$ & $\begin{array}{r}4 \\
100.00\end{array}$ \\
\hline MI-MO & $\begin{array}{r}0 \\
0.00\end{array}$ & $\begin{array}{r}0 \\
0.00\end{array}$ & $\begin{array}{r}0 \\
0.00\end{array}$ & $\begin{array}{r}0 \\
0.00\end{array}$ & $\begin{array}{r}3 \\
75.00\end{array}$ & $\begin{array}{r}0 \\
0.00\end{array}$ & $25.00^{1}$ & $100.00^{4}$ \\
\hline $\mathrm{OH}$ & $\begin{array}{r}1 \\
33.33\end{array}$ & $\begin{array}{r}0 \\
0.00\end{array}$ & $\begin{array}{r}0 \\
0.00\end{array}$ & $\begin{array}{r}0 \\
0.00\end{array}$ & $\begin{array}{r}0 \\
0.00^{\circ}\end{array}$ & $\begin{array}{r}2 \\
66.67\end{array}$ & $\begin{array}{r}0 \\
0.00\end{array}$ & $100.00^{3}$ \\
\hline OTHER & $\begin{array}{r}0 \\
0.00\end{array}$ & $\begin{array}{r}0 \\
0.00\end{array}$ & $\begin{array}{r}1 \\
25.00\end{array}$ & $\begin{array}{r}0 \\
0.00\end{array}$ & $\begin{array}{r}1 \\
25.00\end{array}$ & $\begin{array}{r}1 \\
25.00\end{array}$ & 25.00 & $100.00^{4}$ \\
\hline $\begin{array}{l}\text { Total } \\
\text { Percent }\end{array}$ & $\begin{array}{r}10 \\
23.81\end{array}$ & $\begin{array}{r}2 \\
4.76\end{array}$ & $\begin{array}{r}6 \\
14.29\end{array}$ & $\begin{array}{r}6 \\
14.29\end{array}$ & $\begin{array}{r}7 \\
16.67\end{array}$ & $\begin{array}{r}4 \\
9.52\end{array}$ & $\begin{array}{r}7 \\
16.67\end{array}$ & $\begin{array}{r}42 \\
100.00\end{array}$ \\
\hline Priors & 14.29 & 14.29 & 14.29 & 14.29 & 14.29 & 14.29 & 14.29 & \\
\hline
\end{tabular}




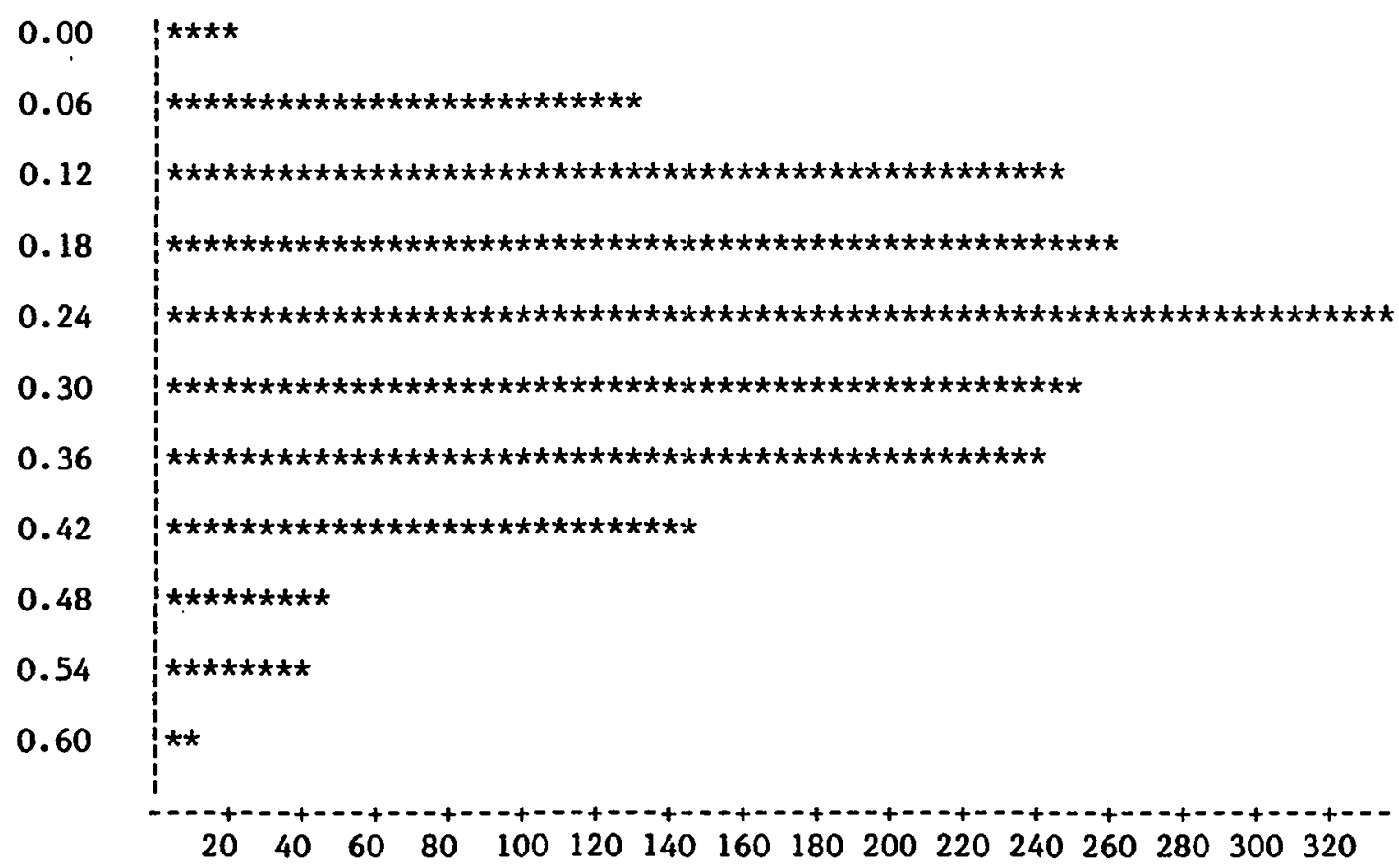

Figure 8. Frequency distribution of the 1981-82 similarity scores. 


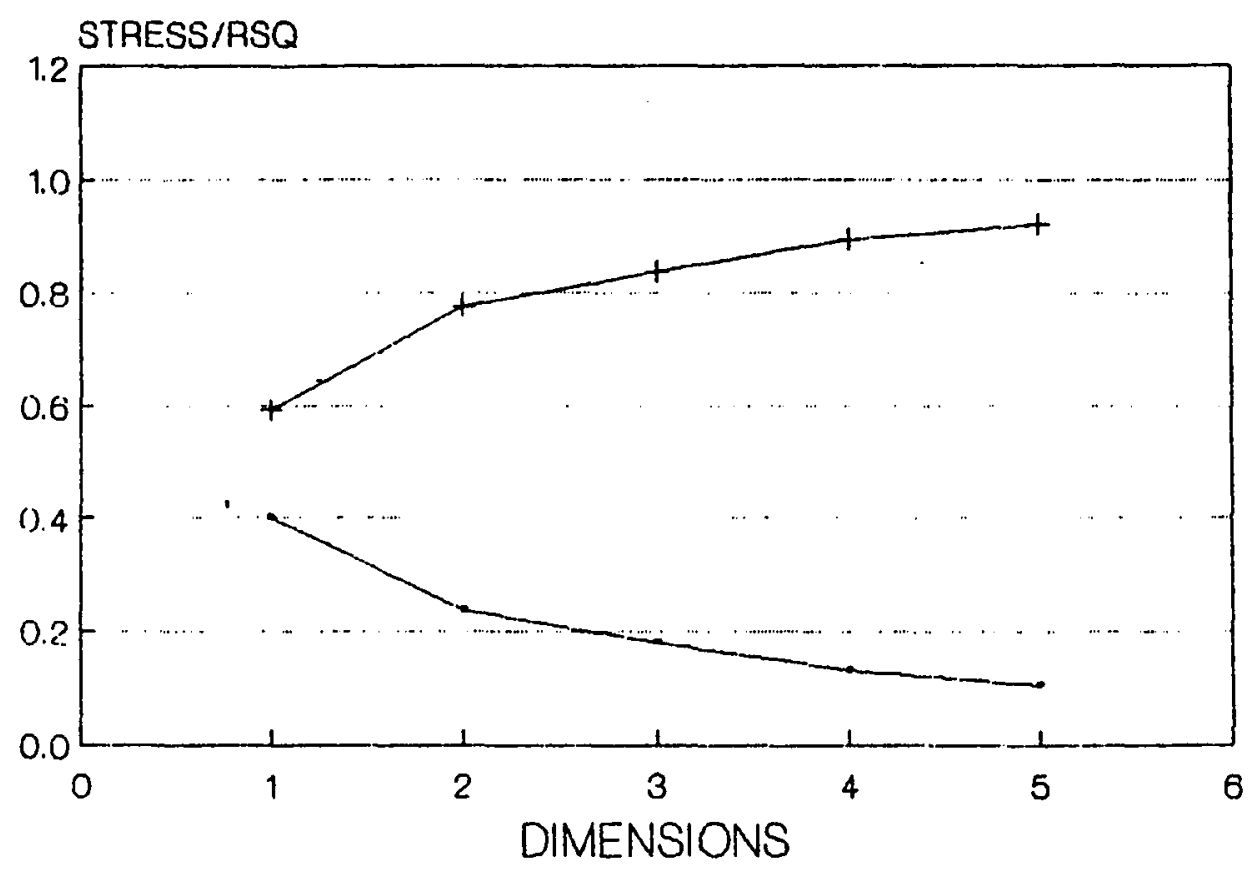

- Series A + Series B

Figure 9. MDS fit indices for the 1981-82 similarity data. 


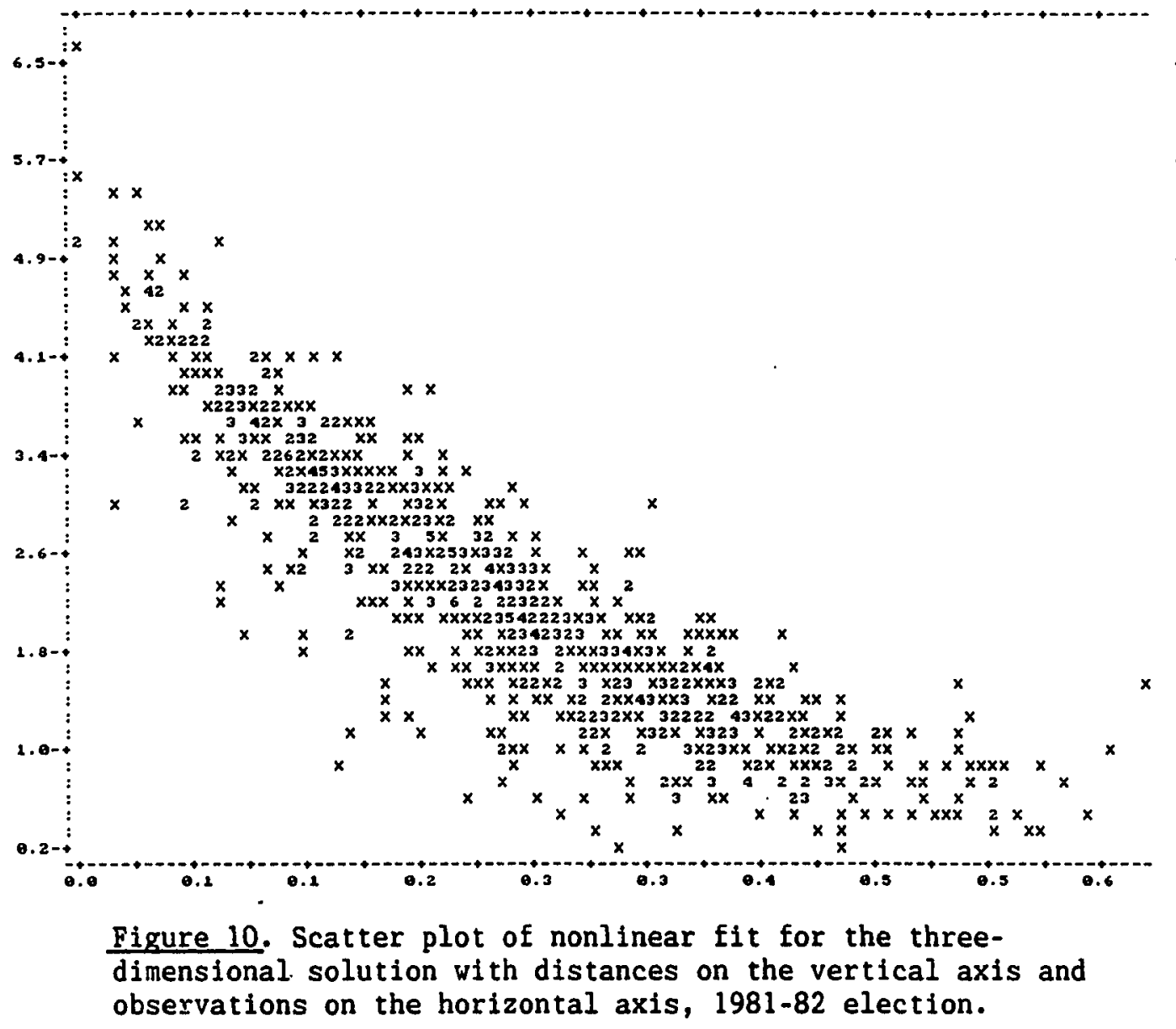




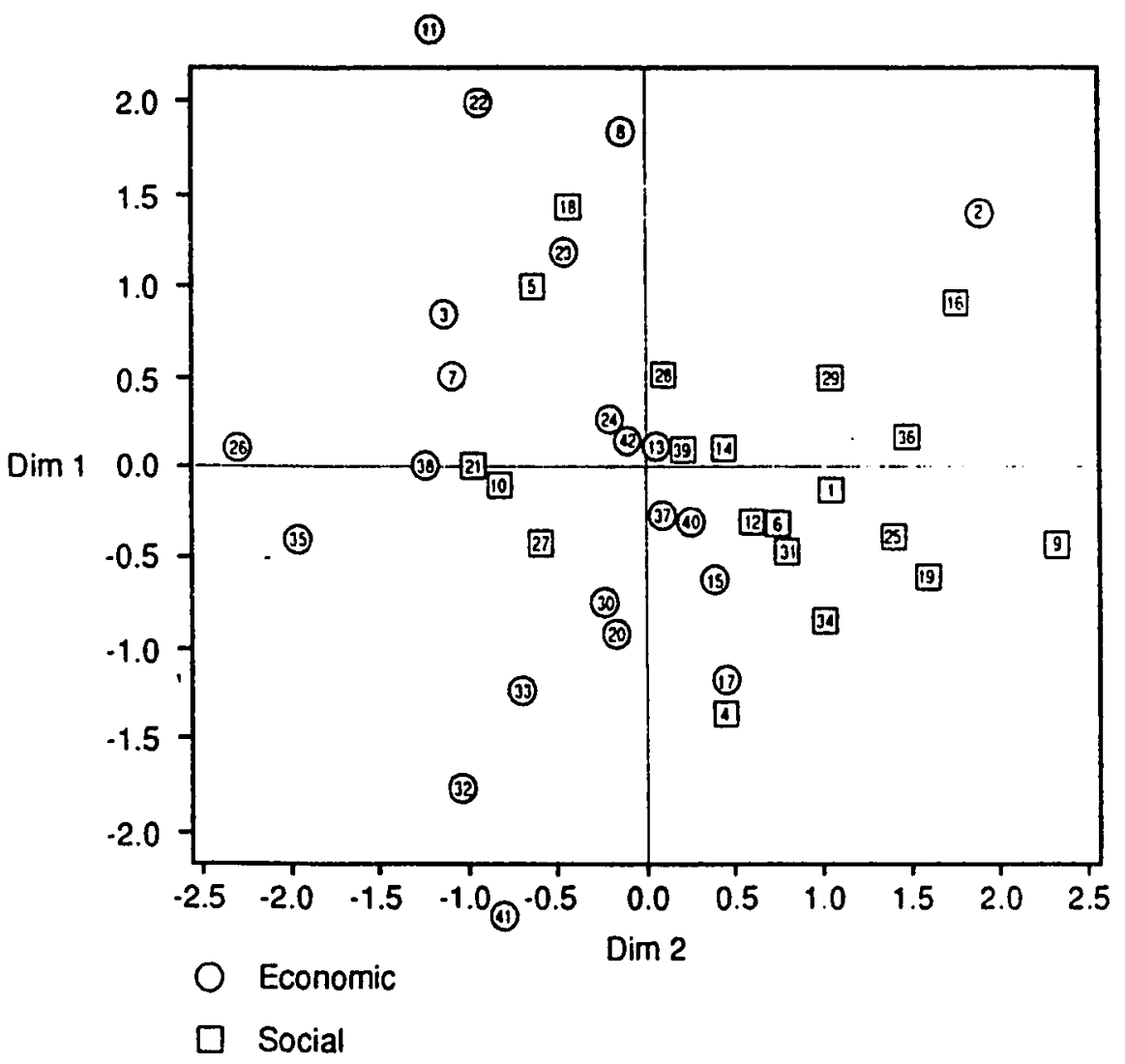

Figure 11. Dimension one, economic and social regulatory environments, 1981-82 elections. For definitions see pages 14-16. See Table XLIX for firm legend. 


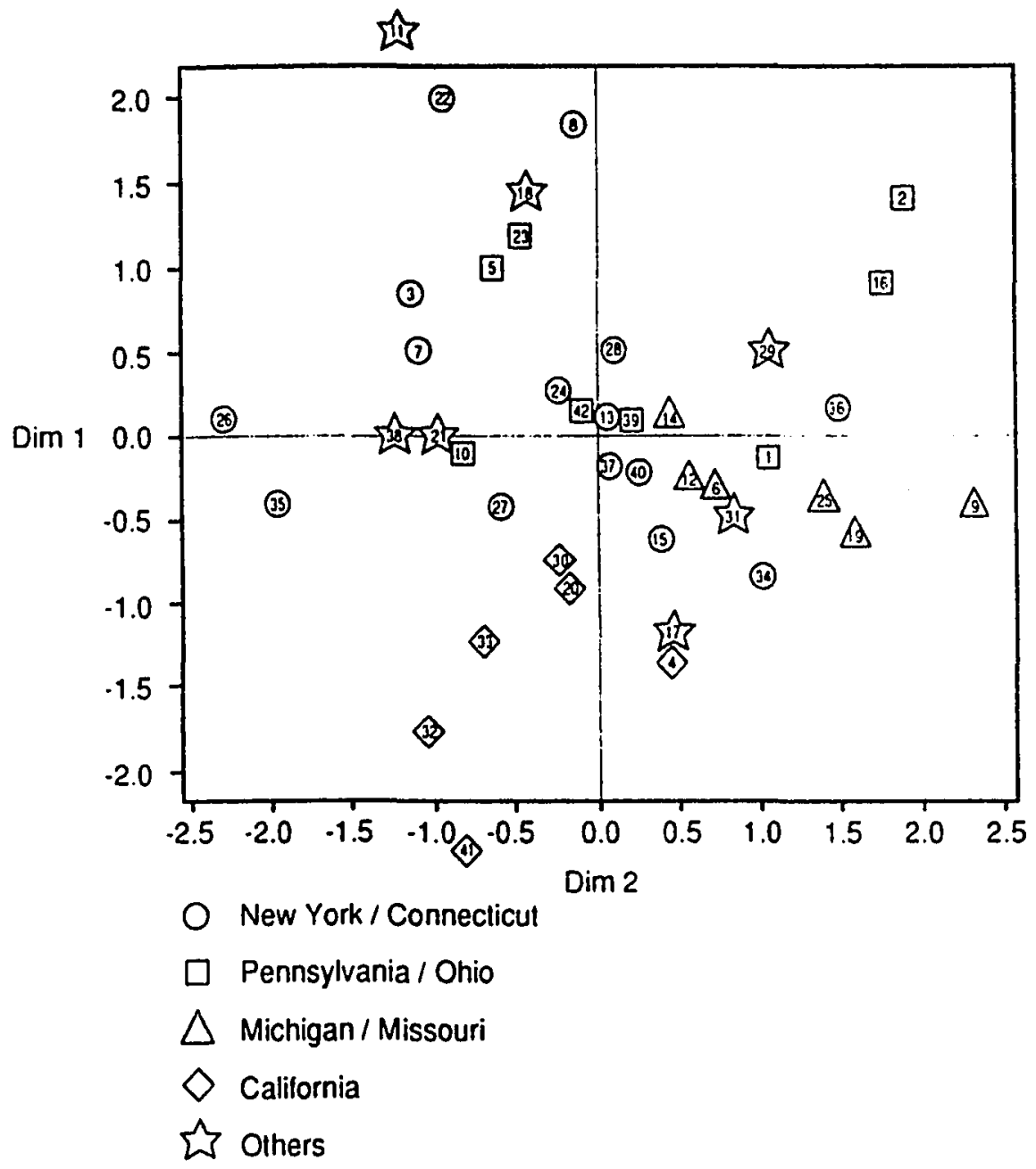

Figure 12. Dimension two, regional dimension, 1981-82 elections. See Table XL for firm legend. 
203

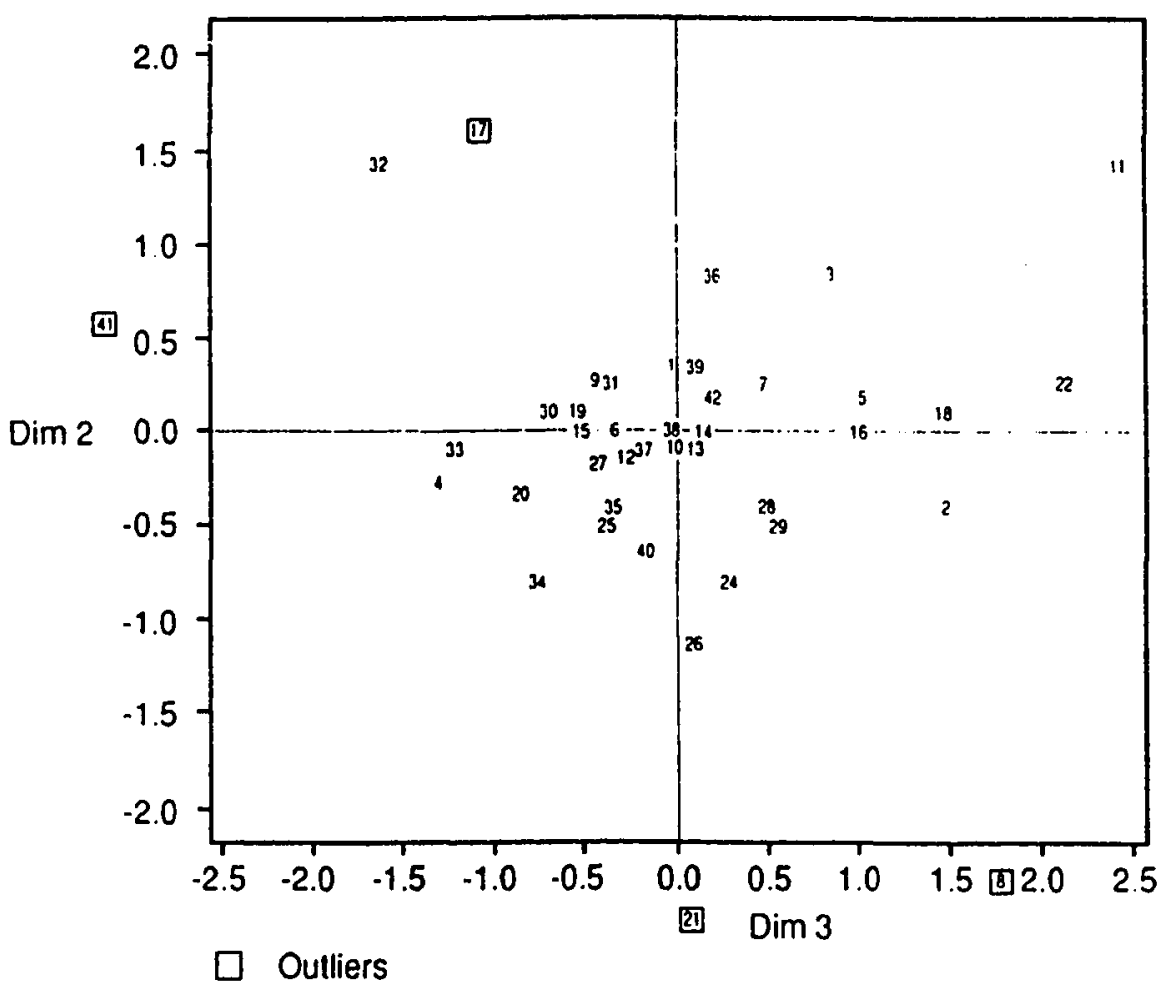

Figure 13. Dimension three, outliers dimension, 1981-82 elections. Outliers are firms which exhibited zero similarity with at least one other firm (see Table XXXI). See Table XLIII for firm legend. 
CHAPTER VI

TWO ELECTION CYCLES COMPARED

Chapters IV and $\mathrm{V}$ examined the intercorporate

structure revealed by patterns of corporate PAC

contributions expended during the 1977-78 and 1981-82

election cycles, respectively. Chapter VI presents the results of testing hypothesis six which compares, across two election cycles, the proportion of each PAC's contributions directed toward incumbents, Republicans, and New Right candidates (see Table IIII).

THE POLITICAL STRATEGY HYPOTHESIS

Research Hypothesis: The ideology of a sitting white House administration will influence corporate PAC contribution patterns.

Null Hypothesis: There is no significant change between patterns of corporate political spending exhibited during the 1977-78 election cycle and the 1981-82 election cycle.

Three statistical tests are employed to determine whether the null hypothesis should be rejected. The first is a paired difference comparison which computes a student's $t$ statistic for testing the hypothesis that the mean of the 
difference between percentage contributions to each candidate type (incumbent, Republican, New Right) in the two election cycles is equal to zero. The second test is a canonical correlation which tests the predictive strength between the two sets of data; that is, can the proportion of contributions directed toward incumbent, Republican, and New Right candidates by each PAC during the 1977-78 election cycle predict the corresponding 1981-82 contribution pattern. Finally, differences between the two cycles are tested using critical values of the normal distribution in order to identify PACs that deviate significantly from the group.

Paired Difference Experiment

The student $t$ statistic tested the null hypothesis that contributions to candidate type did not change between election 'cycles; that is, the mean difference between percentage contributions to candidate type is equal to zero. The mean of three paired differences, one for each candidate type, was first calculated.' The student $t$

${ }^{1}$ For example, mean difference for incumbent contributions is equal to:

where,

$$
\text { MID }=(\text { Inc78 }- \text { Inc82 }) / n
$$

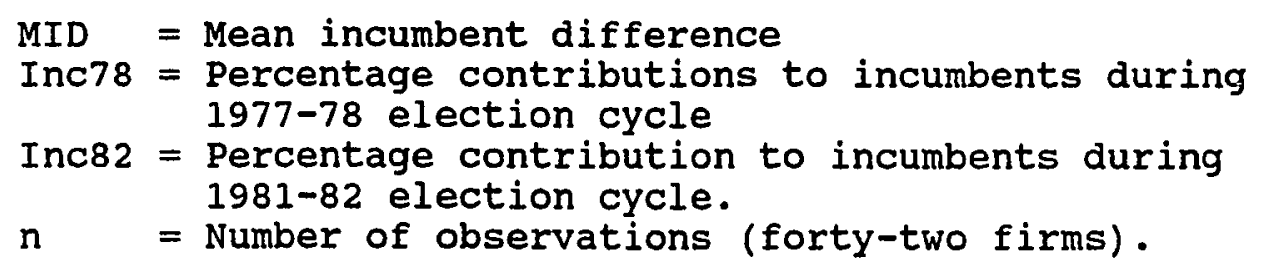


statistic was then calculated for each candidate category to test the null hypothesis that the differences' mean is equal to zero (SAS Institute Inc. 1985b, 795-799). Table LIV displays the results. The null hypothesis can be rejected for the incumbent category $(t=-7.34 ; p<.0001)$; however, it cannot be rejected for the Republican or New Right categories.

These results support the contention that the proportion of PAC dollars contributed to incumbents did exhibit change between the two election cycles. Contributions to Republican and New Right candidates did not significantly change between the two examined election cycles.

\section{Canonical Correlation Analysis}

A canonical correlation analysis explores the power to predict 1981-82 values from 1977-78 data. Accordingly, the 1977-78 data set is designated as the independent variable and the 1981-82 set the dependent variable.

Carionical correlation is somewhat analogous to the multiple regression model. The latter attempts to explain variance in the lone dependent variable by finding the best linear combination of the independent variables. The canonical model seeks the best linear combination of the dependent set of multiple variables as well as the independent set. In short, the best pair of linear combinations is sought since multiple variables appear on 
both sides of the equal sign. Further, it reiterates the process in successive attempts to explain residual variance. Canonical analysis, then, finds the linear combinations (termed canonical variates) which maximize the correlation between the paired linear combinations. If this canonical correlation is significant, then a canonical redundancy analysis provides a measure of the predictive strength between the two sets of variables, i.e., how effectively one is able to predict a value in the dependent set if the corresponding value in the independent set is known (Pedhazur 1982, 722-743; SAS Institute Inc. 1985b, $139-153)$.

Table LV displays the results from the canonical analysis. The first section in the table displays the correlation between the two data sets and provides a direct test of the hypothesis. The remaining sections present correlational details that serve to enrich the analysis.

The first canonical correlation (subsequent iterations did not produce significant results) of .7634 is significant at the .0001 level and explains about fifty-eight percent of the variance: The null hypothesis of no correlation is rejected and the alternative is supported.

The second section in Table LV presents the correlations between categories of recipients from the 197778 cycle to the 1981-82 cycle. The correlations in this matrix are all in the expected direction. Correlations are 
high between proportions of contributions going to each category of recipients in the two cycles: .58 for incumbents, .66 for Republicans, and .65 for New Right candidates. Positive correlations are also found between contributions to Republicans and New Right candidates, while correlations between incumbents and the other two categories are negative.

Within-set correlations are presented in the third section of Table LV. Again, all correlations are high and in the expected direction.

The structure coefficients (analogous to factor loadings in factor analysis) for each set of variables and its corresponding I inear combination, or canonical variate, are presented in the fourth section of Table LV. When squared, these loadings indicate the proportion of variance accounted for by the canonical variate. For example, the 1981-82 loadings indicate that the variance of contributions to incumbent, Republican, and New Right accounted for by the canonical variate is approximately seventy-six percent $\left(.87^{2}\right)$, ninety-seven percent $\left(-.98^{2}\right)$, and seventy-three percent $\left(-.85^{2}\right)$, respectively.

The final section in Table LV presents the redundancy analysis. Of particular interest is that almost half, forty-eight percent, of the variance in the 1981-82 variable set is predictable from the linear combination of the 197778 variables. Also notable is that approximately eighty-two 
percent of the variance of the 1977-78 set, and eighty-four percent of the variance of the 1981-82 set of variables is accounted for by the canonical variates.

In summary, the results from this canonical analysis, specifically the significant canonical correlation, the high between-set correlations, the high predictive variance as measured by the redundancy index, and the high variance accounted for by the canonical variates, support the contention that there is a significant relationship between the 1977-78 and 1981-82 contribution patterns.

Patterns and Anomalies

Results from the paired comparison test and canonical correlation analysis provide evidence regarding patterns of change for the set of sample firms, but the two neither identify PACs that bucked the trend nor provide insight into the pattern of change exhibited within the three candidate categories. Further analysis reveals that ten of the fortytwo firms exhibited significantly different behavior in the 1981-82 cycle and that the New Right category exhibited the least consistency in the direction of change (eighteen firms increased contributions to New Right candidates, twenty-two decreased, and two exhibited no change).

The test utilizes computed $Z$ scores to compare the difference between the proportions of contributions that each PAC directed to each candidate type. The null hypothesis is that there is no difference (the difference is 
equal to zero) in the proportion contributed to each candidate category--for example, a PAC contributed the same proportion to incumbents in 1981-82 as in 1977-78. Its purpose is to identify those firms which exhibited a significant difference in contributions between the election cycles, not to infer to a population. The test statistic is calculated as the ratio of the difference between a 1977-78 and a 1981-82 value $\left(x_{i}\right)$ to the standard deviation (S) of the array of forty-two differences: $z=\left(x_{i}-0\right) / S$. If this calculated value exceeds the critical value of 1.96 (alpha $=.05)$, the null hypothesis of zero difference is rejected and that value of $x_{i}$ is regarded as diverging from the norm.

Table LVI lists each firms' calculated $z$ scores for the three candidate types. As expected, given prior results, the incumbent category reveals a larger proportion of the sample firms diverging from the critical value. Nine firms' contribution patterns diverge from the norm in the incumbent category; three in the Republican category; and one in the New Right category. That one firm, Goodyear, also diverged from the norm in the other two categories.

\section{DISCUSSION}

The 1978 election is identified by PAC researchers as a turning point for corporate political strategy. Prior to 1978, corporate PACs overwhelmingly supported incumbents, 
complying with the progressive and rational-choice perspectives which argue that a corporate PAC's primary objective in candidate selection is access to lawmakers, regardless of the candidate's ideology. The 1978 election candidate-support decisions, however, were marked by a tilt toward Republicans and conservative challengers, a bellwether to the Republican triumph of 1980 (Handler and Mulkern 1982, chapter two; Eismeier and Pollock 1988, chapter five).

Eismeier and Pollock (1988), in their discussion of the role played by the corporate PAC sector in the pivotal 1980 election, note:

By all accounts the 1980 election was a partisan cataclysm. Not only was an incumbent president turned out of office in a landslide but Republicans captured thirty-three new House seats and a Senate majority for the first time in a generation. Among the several proximate causes of the upheaval in congressional elections was the unprecedented pouring of PAC money, especially that of corporate PACs, into the campaigns of Republican challengers and candidates for open seats (84).

Corporate PACs' Republican partisanship in the 1980 election carried over to some extent to the midterm 1982 election, but was mitigated by economic and political factors. The 1982 recession and intensified efforts by Democrats to market themselves to corporate PACs resulted in less risk-taking by corporate PACs. Business increased its spending on Republican incumbents, but its proportion of spending on conservative challengers was sharply curtailed. In 1982, more than two-thirds of all corporate PACs who had 
targeted challengers in 1980 had redirected their spending to incumbents (Eismeier and Pollock 1988, 87).

The spending patterns displayed in Tables LIII and LVI generally support these aggregate statistics. Thirty-five of the forty-two sampled firms increased their proportion of spending on incumbents. The nine firms identified as anomalies display significant increases in support for incumbents from 1978 to 1982 .

The Eismeier and Pollock finding that contributions to New Right challengers were "sharply curtailed" is not reflected in Table LVI. Most firms show no significant change, and what change there is almost evenly divides itself between increases and decreases. The one firm that diverges from the majority shows decreased support for conservative challengers.

\section{CHAPTER SUMMARY}

These data lead to rejection of a hypothesis originally formulated for this study, add a dimension to a major conclusion reached in chapters IV and $V$, and address prior research on contributions to incumbents. First, the hypothesis that PAC contribution patterns will vary with ideologically disparate White House administrations is rejected. While incumbent contribution patterns exhibited change between the election cycles, canonical correlation analysis revealed no significant 
change in the overall pattern of contributions. The implication is that a more or less business-friendiy presence in the white House is not a major driving force behind corporate-PAC-contribution strategies.

Second, the data lead to the conclusion that the influence of regulatory environment on corporate political activity is strong and stable. Its strength is evidenced by the probability of incorrectly rejecting the first null hypothesis--less than one in one hundred $(p<.01$; see Tables XXIV and XLV)--considerably better than the critical value for rejection of $.05 .^{2}$ stability is evidenced by the probability of incorrectly accepting the sixth null hypothesis--less than one in ten thousand $(p<.0001$; see Table LV, section 1$).^{3}$

Finally, the direction of change observed in the incumbent category agrees with previous research which examined aggregate corporate PAC statistics.

${ }^{2} \mathrm{HO}_{1}$ : There is no significant relationship between a firm's MDS coordinates and its regulatory environment classification.

${ }^{3} \mathrm{HO}_{6}$ : There is no significant change between patterns of corporate political activity spending exhibited during the 1977-78 election cycle and the 1981-82 election cycle. 
TABLE LIII

CANDIDATE-TYPE CONTRIBUTION PROPORTIONS

1977-78 AND 1981-82 ELECTIONS

\begin{tabular}{|c|c|c|c|c|c|c|}
\hline & \multicolumn{2}{|c|}{ Incumbent } & \multicolumn{2}{|c|}{ Republican } & \multicolumn{2}{|c|}{ New Right } \\
\hline & $77-78$ & $81-82$ & $77-78$ & $81-82$ & $77-78$ & $81-82$ \\
\hline ALCOA & 0.57 & 0.71 & 0.66 & 0.74 & 0.21 & 0.17 \\
\hline American Electric Power & 0.76 & 0.77 & 0.39 & 0.65 & 0.12 & 0.15 \\
\hline American Express & 0.88 & 0.96 & 0.40 & 0.39 & 0.02 & 0.03 \\
\hline Arco & 0.58 & 0.75 & 0.74 & 0.66 & 0.22 & 0.18 \\
\hline Bethlehem Steel & 0.69 & 0.95 & 0.59 & 0.46 & 0.22 & 0.07 \\
\hline Chrysler & 0.65 & 0.79 & 0.55 & 0.52 & 0.12 & 0.10 \\
\hline ticorp & 0.77 & 0.82 & 0.50 & 0.54 & 0.07 & 0.16 \\
\hline Consolidated Edison & 0.76 & 0.89 & 0.29 & 0.41 & 0.04 & 0.10 \\
\hline Dow & 0.31 & 0.46 & 0.91 & 0.96 & 0.46 & 0.35 \\
\hline Federated Department Store & 0.83 & 0.88 & 0.31 & 0.42 & 0.02 & 0.10 \\
\hline First Chicago & 0.66 & 0.92 & 0.65 & 0.38 & 0.05 & 0.04 \\
\hline ind & 0.59 & 0.84 & 0.72 & 0.61 & 0.19 & 0.13 \\
\hline G & 0.7 & 0.93 & & 0.52 & 0.10 & 0.06 \\
\hline GI & 0.6 & 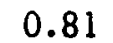 & & & 0.18 & 0.15 \\
\hline GT & 0.55 & 0.84 & 0.65 & 0. & 0.07 & 0.08 \\
\hline dyear & 0.45 & 0.84 & 0.8 & 0 . & 0. & 0.12 \\
\hline Hone & 0.18 & 0.72 & 0.94 & 0.88 & 0.34 & 0.25 \\
\hline International Harvester & 0.62 & 0.87 & 0.77 & 0.60 & 0.18 & 0.03 \\
\hline K Mart & 0.42 & 0.58 & 0.74 & 0.91 & 0.30 & 0.31 \\
\hline Lock! & 0.81 & 0 . & 0.52 & 0.53 & 0.11 & 0.14 \\
\hline LTV & 0.69 & & 0.36 & & 0.05 & 0.13 \\
\hline Manufacturers Hanover & 0.72 & 0. & 0 . & & 07 & 0.13 \\
\hline Mellon & 0.39 & 0.77 & 0.60 & 0. & 0.30 & 0.16 \\
\hline Metropolitan Life Insurance & 0.79 & 0.91 & 0.45 & 0.5 & 0.05 & 0.06 \\
\hline Monsanto & 0.74 & 0. & $0.1-1-1-1-1$ & 0. & 0.11 & 0.22 \\
\hline merican & 0.87 & 0 . & 0. & 0.2 & 0.04 & 0.02 \\
\hline Penney & 0.63 & 0. & 0. & 0.4 & 0. & 0.06 \\
\hline Philip Morris & 0.79 & & & 0. & 0.18 & 0.08 \\
\hline & & & & & & 0.16 \\
\hline kwell & 0.81 & & & & & 0.17 \\
\hline Sears & 0.51 & 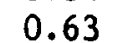 & 0. & 0 . & 0. & 0.21 \\
\hline Security Pacific & 0.55 & 0.5 & 0.67 & 0.78 & 0.24 & 0.36 \\
\hline Southern Pacific & 0.76 & 0. & 0.36 & 0.58 & 0.09 & 0.15 \\
\hline Texaco & 0.41 & 0 . & 0.84 & 0 . & 0.41 & 0.29 \\
\hline TWA & 0.80 & 0 . & 0.32 & 0 . & 0.02 & 0.04 \\
\hline Union Carbide & 0.67 & & & & 0.17 & 0.27 \\
\hline Union Pacific & 0.6 & & & & & 0.14 \\
\hline United Air Lines & 0.69 & & & & 0.16 & 0.09 \\
\hline USX & 0.60 & & 0.62 & 0. & 0.21 & 0.17 \\
\hline United Technologies & 0.59 & & & 0. & 0.21 & 0.21 \\
\hline Wells Fargo & 0.73 & 0 . & & 0 . & 0.13 & 0.28 \\
\hline Westinghouse & 0.68 & 0 . & 0.49 & 0.47 & 0.12 & 0.10 \\
\hline
\end{tabular}




\section{TABLE LIV}

\section{CHANGES IN PROPORTIONS OF DOLLAR CONTRIBUTIONS \\ TO TYPES OF CANDIDATES 1977-78 TO 1981-82}

\begin{tabular}{|c|c|c|c|c|}
\hline Variable & Mean & $\begin{array}{c}\text { Standard Error } \\
\text { of Mean }\end{array}$ & $t$ & Probability \\
\hline $\begin{array}{l}\text { Incumbent } \\
\text { Republican } \\
\text { New Right }\end{array}$ & $\begin{array}{r}-0.145 \\
-0.026 \\
0.015\end{array}$ & $\begin{array}{l}0.020 \\
0.020 \\
0.013\end{array}$ & $\begin{array}{r}-7.34 \\
-1.30 \\
1.20\end{array}$ & $\begin{array}{l}0.0001 \\
0.2013 \\
0.2373\end{array}$ \\
\hline
\end{tabular}


TABLE LV

\section{CANONICAL ANALYSIS OR CONTRIBUTION PATTERNS \\ POR TWO ELECTION CYCLES \\ 1977.-78 AND 1981-82}

Section 1: Correlation between the 1977-78 and 1981-82 data sets

$\begin{array}{ccccc}\begin{array}{c}\text { Canonical } \\ \text { Correlation }\end{array} & \begin{array}{c}\text { Squared Canonical } \\ \text { Correlation }\end{array} & \text { F } & \text { Probability } \\ 0.763 & 0.583 & 5.197 & 0.0001\end{array}$

Section 2: Correlations between the 1981-82 and 1977-78 contribution patterns

$\begin{array}{lcccc} & \text { Incumbent 77-78 } & \text { Republican 77-78 } & \text { New Right 77-78 } \\ \text { Incumbent 81-82 } & 0.580 & -0.474 & & -0.669 \\ \text { Republican 81-82 } & -0.690 & & 0.665 & 0.743 \\ \text { New Right 81-82 } & -0.566 & 0.520 & & 0.655\end{array}$

Section 3: Within set correlations

Incumbent 81-82 Republican 81-82 New Right 81-82

$\begin{array}{lrrr}\text { Incumbent 81-82 } & 1.000 & -0.817 & -0.904 \\ \text { Republican 81-82 } & -0.817 & 1.000 & 0.870 \\ \text { New Right 81-82 } & -0.904 & 0.870 & 1.000\end{array}$

Incumbent 77-78 Republ1can 77-78 New Right 77-78

$\begin{array}{lrrr}\text { Incumbent } 77-78 & 1.000 & -0.806 & -0.841 \\ \text { Republican } 77-78 & -0.806 & 1.000 & 0.821 \\ \text { New Right } 77-78 & -0.841 & 0.821 & 1.000\end{array}$

Section 4: Structure Coefficents

Correlations between the canonical variates and contribution patterns

CV $81-82$

Incumbent $81-82 \quad 0.870$

Republican $81-82 \quad-0.986$

New Right 81-82 -0.852
CV $77-78$

Incumbent 77-78 $\quad 0.915$

Republican $77-78 \quad-0.850$

New Right 77-78 $\quad-0.988$

Section 5: Canonical Redundancy Analysis

Standardized variance of the 1981-82 contribution pattern explained by the 1981-82 canonical variate: .819; the 1977-78 canonical variate: .477 .

Standardized variance of the 1977-78 contribution pattern explained by the 1977-78 canonical variate: .845; the 1981-82 canonical varlate: .493 . 
TABLE LVI

STANDARDIZED SCORES FOR DIFFERENCES BETWEEN PROPORTIONS

CONTRIBUTED TO CANDIDATE CATEGORIES

1977-78 AND 1981-82

\begin{tabular}{|c|c|}
\hline ID聿 & Firm \\
\hline 1 & ALCOA \\
\hline 2 & American Electric Power \\
\hline 3 & American Express \\
\hline 4 & Arco \\
\hline 5 & Bethlehen Steel \\
\hline 6 & Chrysler \\
\hline 7 & Citicorp \\
\hline 8 & Consolidated Edison \\
\hline 9 & Dow \\
\hline 10 & Federated Department Store \\
\hline 11 & First Chicago \\
\hline 12 & Ford \\
\hline 13 & GE \\
\hline 14 & GM \\
\hline 15 & GTE \\
\hline 16 & Goodyear \\
\hline 17 & Honeywell \\
\hline 18 & International Harvester \\
\hline 19 & $\mathrm{~K}$ Mart \\
\hline 20 & Lockheed \\
\hline 21 & LTV \\
\hline 22 & Manufacturers Hanover \\
\hline 23 & Mellon \\
\hline 24 & Metropolitan Life Insurance \\
\hline 25 & Monsanto \\
\hline 26 & Pan American \\
\hline 27 & Penney \\
\hline 28 & Philip Morris \\
\hline 29 & RJR \\
\hline 30 & Rockwell \\
\hline 31 & Sears \\
\hline 32 & Security Pacific \\
\hline 33 & Southern Pacific \\
\hline 34 & Texaco \\
\hline 35 & TWA \\
\hline 36 & Union Carbide \\
\hline 37 & Union Pacific \\
\hline 38 & United Air Lines \\
\hline 39 & USX \\
\hline 40 & United Technologies \\
\hline 41 & Wells Fargo \\
\hline 42 & Westinghouse \\
\hline & .05 \\
\hline
\end{tabular}

Category Incumbent Republican New Right

$\begin{array}{ccc}1.097 & 0.612 & -0.486 \\ 0.079 & 1.989 \star & 0.364 \\ 0.627 & -0.077 & 0.121 \\ 1.332 & -0.612 & -0.486 \\ 2.038 * & -0.995 & -1.822 \\ 1.098 & -0.230 & -0.243 \\ 0.392 & 0.306 & 1.093 \\ 1.019 & 0.918 & 0.729 \\ 1.176 & 0.383 & -1.336 \\ 0.392 & 0.842 & 0.972 \\ 2.038 * & -2.066 * & -0.121 \\ 1.959 \star & -0.842 & -0.729 \\ 1.803 & 0.306 & -0.486 \\ 0.941 & 0.383 & -0.364 \\ 2.273 * & -0.765 & 0.121 \\ 3.057 \star & -1.989 \star & -2.429 * \\ 4.232 \star & -0.459 & -1.093 \\ 1.959 * & -1.300 & -1.822 \\ 1.254 & 1.300 & 0.121 \\ -0.157 & 0.077 & 0.364 \\ 0.314 & 1.607 & 0.972 \\ 1.411 & -0.536 & 0.729 \\ 2.978 * & 0.612 & -1.700 \\ 0.941 & 0.612 & 0.121 \\ -0.078 & 1.530 & 1.336 \\ 0.862 & 0.994 & -0.243 \\ 1.959 * & -1.301 & -1.579 \\ -0.470 & 0.000 & -1.214 \\ 0.627 & 0.230 & 0.486 \\ 0.235 & 0.077 & -0.486 \\ 0.941 & 0.153 & -1.093 \\ 0.000 & 0.842 & 1.457 \\ -0.470 & 1.683 & 0.729 \\ 1.489 & -0.230 & -1.457 \\ 1.097 & 1.454 & 0.243 \\ -0.157 & 0.842 & 1.214 \\ 1.332 & 1.607 & 0.000 \\ 1.646 & -0.765 & -0.850 \\ 1.724 & 0.536 & -0.486 \\ 1.332 & -0.765 & 0.000 \\ -0.314 & 1.607 & 1.822 \\ 1.568 & -0.153 & -0.243 \\ & & \end{array}$


CHAPTER VII

CONCLUSION

This concluding chapter serves two purposes. First, it furnishes the reader a summary of the preceding chapters by highlighting some previous research, the research design, and hypothesis tests' results. Second, it deals with limitations, implications, and directions for future research.

\section{INTRODUCTION}

Ideologically, debates aplenty remain concerning whether "business"--that collective of diverse institutions and interests--enhances or detracts from the quality of American democracy.

Epstein, 1980

While business continues to become increasingly active in the political process (Post et al. 1982; Maitland 1986; Keim and Baysinger 1988), "debates aplenty remain" regarding the extent to which this activity is organized. A major motive of this research was the belief that a structural analysis of PAC campaign contributions, augmented with rigorous hypothesis testing of the resulting intercorporate patterns, would reveal the relationship between political activity and corporate objectives--that is, whether such 
contributions are driven by self-serving business interests, as resource dependence would argue, or the overarching goals of a cohesive corporate elite, a position supported by class cohesion theorists. The purpose of this research was to address this fundamental issue by examining PAC behavior as a measurable indicator of corporate political strategy within the context of the two major competing perspectives on intercorporate relations--resource dependence and class cohesion.

The availability in recent years of reliable data on campaign contributions of political action committees has spurred empirical research on the sources of business political convergence. Yet, despite this, no consensus has emerged as to the underlying rationale which drives business participation in the United States public policy process. Prior studies have examined dyadic relations between firms or industries as a measure of business political consensus. This study subjected dyadic measures to multidimensional scaling so that the intercorporate structure hidden in the data was revealed.

A second characteristic of previous studies is their emphasis on the relationship between similar political behavior and organizational and social network variables (such as,economic interdependence, interlocking directorates, and geographic proximity of headquarters locations) which are operationalized as mechanisms by which 
the corporate community can prevent, mediate, and/or resolve intercorporate conflict and thus advance a classwide political agenda. This study, building on Pfeffer and Salancik's $(1978,214)$ resource dependence proposition, which associates government regulation and corporate campaign contributions, incorporated regulatory environment as a predictor of similar political behavior. Another departure was the use of data associated with two off-year Congressional elections. Prior work tended to focus on the 1980 elections since they marked a watershed of sorts in national politics, and because corporate PAC involvement was cited as influential in the outcomes (Ashford 1986). This work examined corporate political activity in 1982 which was conducted in the context of a Republican-controlled senate and a House seating thirtythree new Republican members. A further unique feature of this study was the corollary analysis of the 1978 elections which permitted a comparison of corporate political activity between two disparate White House administrations.

\section{FINDINGS OF PREVIOUS RESEARCH}

Empirical research into the business community's political integration has evaluated sources of political consensus. Key features of three recent studies which laid the foundation for my work are reviewed briefly in this 
section and summarized in Table II which also displays the relationship of previous work and my research. ${ }^{1}$

Burris. (1987) constructed three measures of business political partisanship--the percentage of total dollars contributed to incumbent, Republican, and New Right candidates--for each of 443 corporate PACs active during the 1982 Congressional elections. He then regressed these measures onto twelve variables which were associated with six business partisanship theories.

Burris found that two theories were supported by his data: the Yankee-Cowboy theory of regional political differences and the regulatory environment theory which posits that government regulation is a primary determinant of corporate political activity. His twelve-variable model explained just twenty-two percent of the variance in business partisanship, thus it can be faulted. Yet, this work provides a useful step in linking theory with empirical research.

Neustadtl and Clawson (1988) employed clique analysis in an effort to resolve the pluralist-class theory debate as it relates to business involvement in the political arena. They examined the PAC behavior of 230 corporations which had

'An earlier work, Mizruchi and Koenig (1986), also used similar methodology in examining sources of corporate political consensus and is included in Table II. Mizruchi's (1989) study is a refinement of this earlier work and is therefore more applicable to current research. It is discussed in this summary. For a review of the 1986 research, consult the literature review in chapter II. 
contributed to the 1980 elections to determine if an otherwise fragmented business community is capable of uniting for political action. Their data, analyzed at the dyadic level (similarity of contributions between pairs of corporations was measured), revealed a large corporate clique linked by a conservative ideology.

The authors concluded that the strength and size of the conservative clique evinced stronger support for the social class theory rather than pluralism. One wonders, however, if this clique might not have been reacting to regulatory environment constraints. Economically regulated firms were noticeably absent from the conservative clique, and thus were exhibiting less conservative political activity. This behavior is consistent with the regulatory environment theory of business partisanship, and by extension, resource dependence.

Mizruchi's (1989) research was the primary catalyst for my study. He employed resource dependence and class cohesion concepts to examine the sources of similar political behavior among fifty-seven large corporations. The extent to which pairs of PACs contributed to the same Congressional candidates during the 1980 elections was measured and regressed onto eight variables associated with either resource dependence or class cohesion theory. Seventy-one percent of the variation in similar political behavior was explained by this multiple regression model. 
The two strongest predictors were whether firms' headquarters were located in the same state and whether firms were members of the same primary industry. Mizruchi concluded that both organizational and social network factors influenced political behavior similarity. He notes, however, that regardless of the measures employed in studies of corporate political behavior, future "analysis must move to the triadic, cluster, and system-wide levels" $(420)$.

My research, enriched by Mizruchi's and other scholars' work, moved the study of corporate political behavior to the system level by subjecting dyadic measures to multidimensional scaling.

\section{HYPOTHESES}

The resource dependence and class cohesion positions on corporate political involvement in politics were the sources for generating testable hypotheses. As noted by Pfeffer (1987):

It is in this domain [public policy and politics] in which resource dependence and the intraclass [class cohesion] perspective make different predictions, since the intraclass perspective hypothesizes a fundamentally unified set of business interests not tied to patterns of transactions (47).

Resource dependence contends that organizational behavior is determined by economic and political constraints imposed by interdependent stakeholders operating in an uncertain environment. For example, corporations can be 
dependent on one stakeholder, government, for purchases, subsidies, or regulation (Pfeffer and Salancik 1978, 214). Thus, PAC contributions can exemplify a political strategy formulated to reduce political uncertainty. Hypothesis one was derived from this theory and is supported by previous research (Handler and Mulkern 1982; Burris 1987; Neustadtl and Clawson 1988):

Hypothësis 1: Firms similarly constrained by government regulations will exhibit similar political behavior.

Conversely, class cohesion argues that corporate political behavior is premised on a classwide unity that supersedes the parochial goals of individual firms and even industries. This unity is achieved through a social structure of corporate elites facilitated by such mechanisms as interlocking directorates, memberships in prestigious business associations, and old school ties (Domhoff 1970, 1974; Useem 1980). Further, some theorists contend--albeit with mixed results (Mizruchi and Koenig 1986; Mizruchi 1989)--that the geographic proximity of headquarters locations facilitates social interaction among elites. Consequently, hypotheses two through five tested class cohesion theory and are supported by previous research:

Hypothesis 2: Firms' number of interlocking directorates will relate directly to similar political behavior. 
Hypothesis 3: Firms' number of associations with certain prestigious business associations will relate directly to similar political behavior.

Hypothesis 4: Shared educational experience among Board Chairmen and CEOs will relate directly to similar political behavior.

Hypothesis 5: Geographically proximate headquarters locations will relate directly to similar political behavior.

Finally, I believed additional insights regarding corporate political activity could be gained by examining PAC contributions during two disparate White House administrations. I hypothesized that the businessgovernment environment changed enough between the carter and Reagan administrations to affect corporate political activity. Thus,

Hypothesis 6: The ideology of a sitting White House administration will influence corporate PAC contribution strategies.

Figure 14 summarizes these six research hypotheses.

RESEARCH DESIGN

Sample

The population was defined as corporations included in the Senate (U.S. Congress 1980) study on interlocking directorates. This study provided reliable data on direct 
and indirect interlocks among corporations, a key variable associated with class cohesion theory. Further, this population satisfied three sampling criteria: Large corporations from diverse industry sectors examined during a time frame compatible with my research. To assure a sample that was evenly dispersed among industry sectors, a maximum of four firms, and only those with active PACs dating back to 1977, were selected from any one industry classification. Forty-two of the largest United States corporations constituted the sample. They represented fourteen industrial and nonindustrial sectors, headquartered in eleven states, active in both election cycles studied, 197778 and 1981-82.

\section{Measure of Similar Political Behavior}

Similar political behavior was determined by comparing lists of Congressional candidates supported by all pairs of firms (861 pairs) during the two election cycles. The degree of similarity between two firms was measured by the following formula:

$$
s_{i, j}=s_{i, j} /\left[\left(n_{i} * n_{j}\right)\right]^{1 / 2}
$$

where $s_{i, j}$ is the similarity measure, $s_{i, j}$ is the number of similar contributions made by PACs $i$ and $j$, and $n_{i}$ and $n_{j}$ are the total number of contributions made by PAC $i$ and $j$, respectively. Mathematically, the denominator of the formula controls for the number of contributions made by each PAC while the numerator provides a measure of 
behavioral similarity. This formula has been used in previous research which examined both political consensus and interlocking directorates (Mariolis and Jones 1982; Mizruchi and Koenig 1986; Mizruchi 1989).

\section{Measure of Resource Dependence}

Firms in the sample were placed into either of two widely recognized regulatory categories in which the environmental constraints differ. The economic regulatory environment is traditional and industry-specific, while the social regulatory environment is a more recent development and cuts across industries.' Accordingly, the regulatory environment faced by each firm was categorized as either social or economic, based on its industry category as defined by the Fortune index and that industry's dominant regulatory environment as defined by prior research.

The essential difference between economic and social regulation has been aptly characterized as conferring stability in the first instance and limiting profits in the second (Marcus 1987, 102-103). This distinction prompts one to suggest that stability is produced by regulatory activity reflecting traditional economic policy through selective enhancement or restriction of competition. A policy of enhancing competition is administered by the Federal Trade Commission and Justice Department in policing

${ }^{2}$ Also see pages 14-16 for definitions of economic and social regulation. 
mergers and acquisitions, as one example. A policy of restricting competition is administered by industry-specific agencies such as the Federal Communications Commission. Social regulatory activity reflects political sensitivity to social needs and impacts profitability. First, social regulation demands compliance with frequently costly regulations--for example, those associated with employee safety, health care, and benefits. Second, the very industries most likely to be socially rather than economically regulated (steel, autos, general metals manufacturing) are often least able to pass along these compliance costs because of general competitive conditions and the market's price sensitivity.

Considerations such as these presumably underlie Marcus's (1987) general rule:

A general rule is that firms in industries where economic (industry specific) regulation dominates will do better than firms in industries where social (health and safety) regulation dominates (102).

Associated political activity. Resource dependence theory associates distinct political responses with the two categories of constraints. The political activity associated with an economic regulatory environment is termed pragmatic, and that associated with a social regulatory environment is termed ideological. Firms competing in industries subject to economic regulation (and those with substantial economic ties to the Department of Defense) can be expected to value access to key legislators because 
regulatory agencies ultimately must look to Congress for funding and oversight. Such firms' political activity, then, would likely disregard a key legislator's politics in favor of maintaining an avenue of influence. Firms competing under conditions in which the effects of social regulation outweigh those of economic regulation are likely to perceive the political world differently. since social regulations encroach upon managerial autonomy rather directly, e.g., restrictions on plant closings, some managers' perception of Congress as anti-business is understandable. Therefore, political activity is likely to be directed at changing the ideological nature of Congress by helping to elect candidates likely to be more sympathetic to business's interests and politically courageous enough to resist the spread of social regulation:

Measures of Class Cohesion

Four class cohesion variables were operationalized: Interlocking directorates, membership in major business associations, educational background of top executives, and headquarters location.

The number of direct and indirect interlocks between each corporate dyad was derived from the 1980 senate study on interlocking directorates (U.S. Congress 1980). Each firm's associations in 1978 and 1982 with the Business Council, Business Roundtable, Committee for Economic Development, Conference Board, and Council on Foreign 
Relations were counted. Also counted were the number of associations between twelve prestigious universities (related to the corporate elite by prior research) and each firm's chairman/ceo and president.

Biographical data and headquarters location were collected from numerous sources such as Moody's Industrial Manual, Standard and Poor's Register and Marquis' Who's Who series.

Analytical Methodology

Multidimensional scaling. Two proximity matrices, one for each election cycle, which held the PAC contribution similarity measure for all firm dyads were analyzed using the ALSCAL procedure (SPSS Inc. 1988). The procedure generated two three-dimensional spatial maps, one for each election cycle. Since each point on a map represented a firm, similarities in political behavior became visually evident. Clustered points indicated similar behavior; points distant from one another indicated dissimilar behavior. Thus, underlying intercorporate structure, otherwise hidden, was revealed.

Statistical Analyses. Multiple and canonical regression were used to test the hypotheses. For hypotheses one through five, each resource dependence and class cohesion variable was regressed onto the firms' MDS map positions. Thus, this test determined whether a firm's location on the map could predict its regulatory 
environment, headquarters location, educational background of its chairman or president, number of interlocking directorates, or number of memberships with major business associations.

Testing hypothesis six utilized canonical correlation analysis. The proportion of total PAC dollars contributed by each firm to three candidate categories (incumbents, Republicans, and New Right challengers) in 1977-78 was used to predict the corresponding 1981-82 percentage contributions.

\section{RESULTS}

\section{Scaling solution}

Analysis of the MDS solutions began with a visual interpretation of each map's dimensions, i.e., its axes. Each dimension represents a possible explanation for the spatial positioning of firms relative to one another. The set of maps for both election cycles appears in Figures 5-7 and 11-13. Dimension one appears to discriminate firms based on their. regulatory environment in both election cycles. Firms subject to economic regulation tend to dominate the negative end of the horizontal axis while those subject to social regulations dominate the positive end. Dimension two for 1977-78 and dimension three for 1981-82 appear to segment firms along regional lines. All California firms are clustered on one end of the axis, and 
there is 'some concentration of New York and Connecticut firms at the opposite end with a Middle America grouping in the center.

Finally, the 1981-82 dimension three seemed to pull out four of the five firms which had scored zero similarity with at least one other firm.

\section{Hypothesis Tests}

Statistical tests were used to ensure that visually apparent relationships were genuine and to guard against overlooking less apparent relationships. Tables XXIV and $\mathrm{XLV}$ show the results of regressing the resource dependence and class cohesion variables onto each firm's map coordinates. Since these coordinates represent the firms' spatial position derived from similar political activity, hypotheses one through five are thereby tested.

The results of the first equation in both tables support hypothesis one which relates similar political behavior with similar regulatory environment. This confirms the visual interpretation since the regression coefficients indicate a statistically significant relationship between regulatory enivironment and dimension one.

Results of equations (2) through (5) (see Tables XXIV and XLV) do not support the class cohesion hypotheses which relate political behavior to elements of a corporate elite network. The sixth equation, however, does support a 
relationship between headquarters location and similar PAC behavior, again confirming the visual interpretation.

Table LV shows the canonical regression results in which the 1977-78 PAC contributions predict the 1981-82 pattern. Forty-eight percent of the variance in the 1981-82 contribution pattern is predictable from the linear combination of the 1977-78 pattern.

A corollary paired-comparison analysis tested the null hypothesis that the proportion of contributions directed to each candidate type did not change between election cycles; that is, the mean difference between the proportion contributed to candidate type is equal to zero. The results indicated that, while contributions to Republicans and New Right candidates did not change, the proportion of PAC dollars contributed to incumbents did increase. This supports the Eismeier and Pollock (1988) work which showed that the 1982 recession and intensified efforts by Democrats to market themselves to corporate PACs resulted in an increase in spending on incumbents by the business community .

This change in incumbent spending patterns may account for some of the unexplained variance associated with the canonical analysis. Whether further empirical research aimed at explaining more of this variance would be fruitful is a question at least worthy of serious consideration. 
Nevertheless, the squared canonical correlation of .583, the significant Wilks' lambda of $.35(F=5.197, p<$ $.0001)$, and the canonical redundancy analysis does not permit rejection of the null hypothesis. Rather, this results argue for a significant relationship between the two election cycles' contribution patterns. Thus, hypothesis six is not supported--disparate white House ideology did not significantly influence PAC contribution patterns.

\section{DISCUSSION, CONCLUSION AND FUTURE DIRECTIONS}

\section{Research Findings}

The multidimensional scaling and multivariate analysis suggest several conclusions. First, though several idiosyncracies of political behavior emerged, the findings are generally consistent with the resource dependence theory of organizational behavior. Specifically, the intercorporate structure revealed by both MDS configurations certainly supports the proposition that there is a systematic relationship between the similarity of PAC contributions and a firm's regulatory environment. Resource dependence holds that corporate political activity is a mechanism used by management to respond to constraints, such as regulation, imposed by government. The MDS pattern which separates firms more subject to social, multi-industry regulation from those subject to the traditional, economic regulation supports the contention that some corporate 
political behavior, at least PAC activity, is a function of a firm's dominant regulatory environment.

Class cohesion as a predictor of similar PAC contribution behavior was not effectively supported. No significance was detected between similar behavior and interlocks, professional associations, or shared educational experience.

Although a significant relationship between headquarters location and similar PAC behavior did emerge, the geographic patterns displayed by the MDS maps lend more support to a regional theory of business partisanship rather than a class theory. The latter links similar political strategy to the social interaction patterns of corporate officials whose headquarters offices are proximate. Logically, then, similar political behavior should be more pronounced among state groupings of firms than among regional groupings. Yet, a state-by-state discriminant analysis misclassified fifty percent of the sample (see Table LII).

Conversely, the regional theory, recently supported by Burris' (1987) work, contends that some political behavior is influenced by the distinctive cultural climates which characterize various regional sectors of the United States. The regional configurations displayed in Figures 7 and 12 are imperfect, but their general outline is clear, and they are supported statistically. All California-based firms 
occupy the negative end of the regional axis, and firms located in New York and Connecticut are more pronounced at the positive end. Thus, the two coastal regions are established. A central clustering encompasses firms located from Missouri in the west to Pennsylvania in the east. Firally, this is the first study which permitted a comparison of corporate PAC behavior between the carter and Reagan administrations. The null hypothesis that PAC contribution patterns will not vary with ideologically disparate White House administrations could not be rejected. Some change was noted, however, in the proportion contributed to incumbents between the two election cycles. subsequent research should be designed to more directly address the reasons why corporate PACs redirect their spending patterns. Nevertheless, the similar corporate political behavior displayed between disparate election cycles speaks to the research model's stability. Both analyses clearly revealed, both visually and statistically, a relationship between corporate PAC allocations and the nature of the PAC sponsors' regulatory environment.

A caution must be noted. Resource dependence theory apparently describes PAC contribution patterns better than the coalescing of a corporate elite. This conclusion cannot, however, be stretched to deny class cohesion theory or to imply that the public interest is better served by resource dependent corporate behavior. 
First, a corporate elite may choose other, less visible, forms of political action. A hypothesis that a corporate elite conducts lobbying with peers in the legislative and executive branches is certainly reasonable. Unfortunately, such actions are much more difficult to measure and test empirically.

Second, there is no evidence in this study's conclusions that denies dominance by corporate America or disallows its profound influence on public policy issues. Third, resource dependent behavior is not necessarily compatible with the public interest. One should keep in mind that political behavior resulting from regulatory constraints is undertaken to manage those constraints. From the pragmatic perspective, efforts are made to influence legislators who, in turn, can wield influence over the agencies administering the regulatory constraints. From the ideological perspective, help is tendered to Congressional candidates likely to hold a "reasonable" view of such matters as environmental protection, worker safety, discriminatory employment practices, and consumer rights.

\section{Limitations}

Several limitations of this research must be acknowledged. Predictions from these findings are limited by the population choice, the United States Senate study's set of one hundred major United States corporations in which interlocks were studied in detail. This choice is highly 
compatible with the research objectives, but a larger corporate population (e.g., Fortune 500 companies) would have enhanced the probability of capturing a broad spectrum of corporate interests.

The sample further poses two limitations. First, it was necessarily purposive rather than random; therefore, making reliable inferences to a larger population is risky at best. Second, it is not a large sample, although more than adequate for MDS. ${ }^{3}$ A larger sample would more likely capture differences among industry sectors. Subsequent research should also employ additional measures for resource dependent and class cohesive behavior. First, regulation is just one example of a dependence which business attempts to manage. Import and export restrictions or commission of corporate crimes (e.g., bribery, criminal fraud, illegal political contributions, tax evasion, or criminal antitrust violations) might also measure a firm's dependence on government action." second, common stock ownership, indirect interlocks through financial institutions, and economic interdependence have also been

\footnotetext{
${ }^{3} A$ rough rule of thumb for an MDS sample size is that the number of objects (firms) minus one should be greater than or equal to four times the number of dimensions; that is, for this research, $(42-1)>=(4 * 3)$ (Kruskal and Wish 1978,34 ).

${ }^{4} \mathrm{~A}$ summary of Fortune 500 firms which includes identification of "law violators" appears in Ryan, Swanson and Buchholz, Corporate Strateqy, Public Policy and the Fortune 500 1987.
} 
cited as network variables which reinforce political integration in the business community and, as such, could represent additional measures of class cohesion (Mizruchi 1989).

Finally, PAC activity is an accepted proxy for corporate political activity, and the opportunity to use accurate empirical data as input for MDS outweighs its drawbacks. This research, however, could be strengthened by multiple measures of corporate political activity (e.g., coalition building, grass roots organizing, and lobbying). Further, philanthropic contributions and individual contributions by top managers might be a strong predictor of a corporate culture's underlying political ideology.

Theoretical Implications

over twenty years ago, Epstein (1969), in a chapter entitled "Corporate Political Power: A Threat to Democracy?" notes:

Apprehension prompted by the purported superabundance of corporate political power underlies much of the opposition to corporate political involvement by critics from outside of the business community. To borrow Andrew Hacker's colorful language--"when General Electric, American Telephone and Telegraph, and Standard Oil of New Jersey enter the pluralist arena we have elephants dancing among the chickens" (187).

While the resources, stakeholders, and expertise of corporate America are real, the depiction of it as a puppeteer manipulating the strings of Congress is largely illusionary. As Epstein continues: "Hackler's metaphor is 
overstated and neglects to mention that other pachyderms are involved in the frolic" (187). The pachyderms are many and varied, including but not limited to competing interest groups' power, a societal commitment to pluralism, and a network of constraints within the business system (Epstein 1969, 240).

This research provides empirical evidence to support Epstein's pluralist view. One of the counterbalancing elephants is the set of environmental constraints, placed on all United states firms, that motivates self-serving behavior. When combined with the self-serving behavior of other interest groups, the result is a political environment that is almost as diverse and complex as the economic environment. This political environment--as is generally the case with massive, diverse, complex systems--leans toward stability and equilibrium.

Further, these research results provide a useful extension to Pfeffer and Salancik's (1978) work on organizational behavior by empirically relating corporate political behavior and environmental constraints. The MDS methodology revealed intercorporate patterns which appear to be competitive, rather than collaborative, thereby suggesting a parallel between political and economic strategizing. For example, R. J. Reynolds and Philip Morris have pursued similar diversification strategies in response to threats to their cash cow, tobacco. Yet it is unlikely 
that these similar corporate strategies emanated from a network linkage between the two corporate giants. Political strategies, like economic strategies, can be similar owing to similar environmental constraints. While the business community may be fragmented on public policy issues, sectors may be expected to behave in a seemingly cohesive manner when confronted with similar constraints. Finally, this study's results pertaining to headquarters location provides insights into the conflicting findings of Mizruchi and Koenig (1986) and Mizruchi (1989) on the relationship between geographic proximity of headquarters and PAC behavior. It is conceivable that, had geographic proximity been defined by region rather than by state, significance between political similarity and headquarters location would have been revealed in both studies.

Managerial Implications

Leqitimacy. Corporate management clearly views political activity in the pluralist tradition. Brenner's (1979) survey of Harvard Business Review subscribers compared managerial attitudes toward corporate political activities in 1968 and 1978. Both groups viewed political activity as a necessary counterbalance to other interest groups, especially unions (155). 
The same study reports that business and society hold divergent views of corporate political activity's legitimacy:

To put the results in perspective, it is useful to understand that two distinct and apparently contradictory trends have emerged relative to the political activities of business. Business has recently become better organized and more skillful at employing the political process, while society has shown substantial distaste for corporations' growing political muscle (Brenner 1979, 149).

Two recent surveys, conducted just before the 1990 general elections, support this conclusion. The CBS News/New York Times poll reported that seventy-one percent of those surveyed agreed that "Most members of Congress are more interested in serving special interest groups than the people they represent" (Alston 1991, 277). Similarly, the Time/Cabie News Network found that eighty-eight percent of voters surveyed agreed that "Money has too much influence on who wins elections" (Alston 1991, 280).

since business is generally regarded as a dominant special interest, these results support Brenner's (1979) contention that "the public seems less sure of and certainly less comfortable with corporate political activity" (162). The Iime/CNN survey produced another relevant result. It appears that people favor PACs over public funding as a source of campaign money (Alston 1991, 280). This suggests that federally regulated campaign financing by organized special interests through PACs, including corporate PACs, is 
considered preferable to transferring these costs directly to taxpayers.

The public's willingness to at least tolerate PACs, coupled with this study's conclusion that PAC activity is resource dependent, suggests a preferred outcome. First, management can expect that outlawing PACs in favor of direct bestowing of federal tax money is not likely. ${ }^{5}$ second, to the extent that resource dependence is tantamount to pluralism, managers can justifiably regard PAC activity as a natural result of environmental constraints. In fact, political activity can be viewed as a managerial obligation imposed by the necessity to manage external dependencies.

Given Epstein's (1969) caveat that a dynamic businessgovernment environment demands continual attention to the role and impact of the corporation in American politics, the corporation's legitimacy as an active political participant in our pluralistic society appears to be affirmed.

Strateqic management. A second implication relates to a strategic management model firmly based on economic considerations to the virtual exclusion of social considerations. Michael Porter (1985) states: "The

${ }^{5}$ The $102 \mathrm{~d}$ Congress is currently debating alternative versions of campaign finance reform bills. In at least one version, PAC contributions to federal campaigns would be banned. It is reasonable to speculate, however, that incumbents, especially House Democrats, are not likely to part with a system which keeps them in office (Alston 1991). Nonetheless, campaign reform, including curbing PACs, undoubtedly will continue to be a controversial issue. 
fundamental basis of above-average performance in the long run is sustainable competitive advantage" (emphasis in the original) (11). The insights derived from conducting this research, not all of which can be articulated, much less quantified, have led me to the conclusion that Porter's model needs expanding. Sustainable competitive advantage, the key to above-average performance, is fast becoming unattainable without proactive corporate political activity. That corporate political activity is closely tied to environmental constraints has now been empirically supported. This support, however, does not imply that corporate political activity should be in reaction to perceived external uncertainties.

A logical progression suggests, rather, that the contrary is a more realistic managerial posture. If, as Porter argues, the purpose of strategic management is to achieve sustainable competitive advantage; and if, as $R$. Edward Freeman (1984, 13-17) argues, the political process is central to strategic management; then it follows that the real lessons of the resource dependence/political activity model are, first, that anticipating moves by political rivals is as critical to proactive management as anticipating moves by economic competitors and, second, that anticipating political rivals is feasible through analysis of their political dependencies. 
Management practitioners must recognize that business and its political and economic environment are parts of a complex interactive system.6

Thus, managers must understand how government really works . . . how new issues arise and get on the agenda of Congresspersons and other government officials, and we must understand what organizational mechanisms are necessary for helping to shape the agenda. Tradition, in terms of "lobbying" or "voting Republican" or more recently "organizing PACs" need not be thrown away, but unless we are satisfied with the state of current business-government relations the need to rethink these strategies in other terms is critical (Freeman 1984, 26).

Avenues for Future Research

Some unexpected intercorporate relationships were revealed by the MDS maps. These relationships will be discussed first, followed by some consequent implications for further research.

The sample's major defense contractors split on the regulatory ervironment dimension in both election cycles. Defense contractors, like firms subject to economic regulations, are expected (Handler and Mulkern 1982, 31; Burris 1987,734 ) to engage in pragmatic political activity. As a minimum, they certainly need access to key legislators and committees involved with weapons procurement. These findings suggest a more complex pattern. Indeed, one might

\footnotetext{
This conceptualization is based on Preston and Post's (1975) model of interpenetrating systems which holds that corporations neither completely control, nor are they completely controlled by, the social and political environments. As a result, structural adaptation occurs over time $(25-28)$.
} 
even suspect that defense contractors operate in a third sort of environment--one characterized by both economic and social environment characteristics.

Two of the three metal manufacturers in the sample also exhibited unexpected patterns, but only for the 1981-82 election cycle. Industries such as steel and metal manufacturing are generally viewed as being subject to social regulation, yet ITV and Bethlehem steel were clearly positioned in the economic MDS sector. As a tentative explanation, one might suppose that the 1981-82 recession, which was particularly hard on the steel industry, contributed to a strategy shift. For years, the social regulatory environment had prompted combat against costly regulations. This industry sector, however, sought government intervention in the form of import restrictions and accepted the constraints which accompanies such intervention. Following the lead of the seminal works contributed by Schattschneider (1935) and Bauer, Pool and Dexter (1963), future research should empirically examine the effect of government intervention, such as foreign trade legislation, on political activity.

Previous research has reported similarities of political behavior based on common industries (Salamon and Siegfried 1977; Mizruchi and Koenig 1986; Mizruchi 1989). My research also revealed that pairs of firms from common industry groupings exhibited high similarity scores (see 
Tables XII and XXXII). Pairs of firms which exhibited zero similarity in PAC contributions with at least one other firm were also identified and, interestingly, this set included one banking dyad--Melion and Wells Fargo (see Tables XI and XXXI, and Figure 13).

These exceptional corporate PACs may be reflecting the ideological expression of a strong corporate leader, despite Handler and Mulkern's 1982 research. Their conclusion was that, even when a CEO is active in PAC governance, the general direction of PAC contributions follows what would be expected "given the nature of the firm and the regulatory environment which it inhabits" (77). Yet, the extreme dissimilarity, especially when exhibited by firms in common industry, suggests that the personal ideologies of corporate executives should be explored for an explanation.

Two of three retailers--J. C. Penney and Federated Department stores--were misclassified in the 1981-82 MDS map. A social regulatory environment had been established for retailing in recognition of the affirmative action pressure experienced by large retailers when the enforcement authority of the Equal Employment Opportunity Commission was enhanced in 1972. Perhaps industry sectors such as retailing operate in a neutral environment which precludes corporate political activity predictions based on regulatory constraint. A classification schema might acknowledge those industries which are not traditionally regulated and yet 
evince a reasonably good record of compliance with social regulations.

Finally, my results which supported a regional theory of business partisanship suggests an extension of my research and potentially fruitful research directions. PAC contributions to "home boy" candidates competing in national races can be factored out, thus isolating political activity in support of candidates from states other than the firms' headquarters location. Further, whether home-state and outof-state strategies are consistent could be of considerable interest. For example, home-state incumbents may be targeted to enhance access opportunities, while conservative challengers in tight out-of-state races may receive the balance of PAC funds.

These observations and further reflection prompt the following questions which scholars might consider when designing future research.

1. Does the economic-social typology adequately characterize the regulatory constraint on business?

The economic-social categorization of government regulation is widely accepted; however, as noted previously, this dichotomy may be overly simplistic and thereby conceal some important business-government interfaces which could account for similarities in corporate political activity. For example, domain defense objectives could result in yet another category of regulatory constraint. Such constraints 
move beyond production, personnel, or environmental issues (social regulations) and competitive forces (economic regulations). Rather, they threaten the very legitimacy of corporate objectives and thus demand a unique strategic response. Government intervention in the tobacco industry (distribution and advertising), the oil industry (windfall profits tax), and the chemical industry (superfund proposals) have been cited as examples of unique strategic challenges (Baysinger 1984, 253). It could be reasonably argued that such challenges might foster a combination political strategy--support of incumbents to preserve access coupled with support of conservative challengers--in an effort to reverse attacks on managerial autonomy. Further research could be directed at those industrial sectors where government intervention impacts corporate goals and purposes.

2. When is a pragmatic choice also an ideological expression?

Like the economic-social typology, the pragmaticideological dichotomy is generally accepted as descriptive of political strategy. The behavior which it characterizes can be observed and measured, an obvious research design plus. Whether corporate PACs' preference for incumbents over conservative challengers is uniformly driven by rational venality remains unproven, however. For example, corporate liberalism holds that executives of large 
corporations "have frequently adopted a more 'progressive' attitude toward unions, labor legislation, and social reform" (Useem 1984, 114). Thus, the progressive corporate leader might spurn conservative challengers and favor moderate incumbents--not just to maintain access, but to advance an ideological position. Such questions cannot be answered without complementary research which incorporates underlying motives into the political strategy equation.

3. Finally, does corporate political activity influence the outcome of elections or affect legislative behavior?

Unfortunately, the efficacy of corporate political activity is difficult to ascertain and largely unanswered. The causal relationship between contributions and legislative behavior is undefined and, indeed, may occur in either direction. The multiple influences on electoral and legislative politics--special interests, ideology, party, constituents--confounds the development of analytically useful empirical work that could confirm or deny the power of business to affect political decision making.

This research confirms that major corporations incorporate political strategies in their efforts to reduce dependencies and manage constraints, but it remains to be determined whether such strategies are effective. As with advertising, half of the resources dedicated to political 
strategy are likely to be wasted--the problem is not knowing which half.

\section{Closing Thoughts}

Preston and Post (1975) contend that, just as managements employ competitive strategies to shape and direct market forces, management should actively participate in the public policy process to shape and direct public policy (143).

This highly regarded position staked out by Preston and Post over a decade ago points toward a question that could support scholarly research. The extent to which corporate management integrates participation in the public policy process with economic strategy remains unclear.

My research clearly establishes the link between environmental constraints and PAC activity; much of the strategic management literature reflects a parallel resource dependence (see, for example, Porter 1985). It is to be hoped, then, that my research will help break down the intellectual barrier between economic and political strategies. Since both strategies are resource dependent, they are irrefutably coupled and should be treated as such.

It is apparent that management scholars should continue to scrutinize the business-government interface; at this point something so simple as a survey of the extent to which strategic integration of politics and economics is a factor recognized by corporate executives might well be in 
order. It is hoped that my research will prove to be a meaningful step on the journey to this integrated model of economic and political strategy. 
CORPORATE OBJBCTIVB

Economic regulatory environment prompts pragmatic political objective

Social regulatory environment prompts ideological political objective

Classwide unity prompts superordinate objectives

Unity strengthened by elite social network

\section{CORPORATB POLTTICAI. ACTIVITY}

*H1: Firms similarly constrained

* by govt regulation will exhibit*

-..- -

firms will relate directly to . .

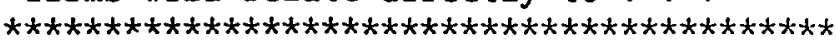

*H2: Number of interlocking directorates*

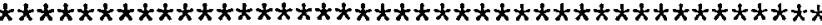

$\star$ H3: Number of memberships in major *

* business associations $\star$

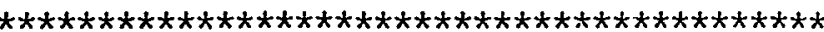

*H4: Shared educational experience *

* among top executives

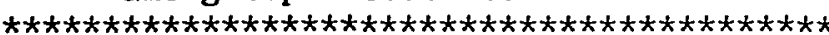

*H5: Proximity of HQ Location

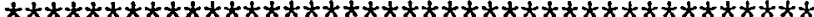

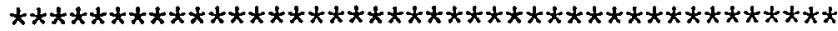

*H6: The ideology of a sitting White

Business-government environment

is affected by White House

ideology

Figure 14. Predicted relationships: a summary of hypotheses. 
REFERENCES

Abramson, Jill and Brooks Jackson. 1990. Debate over PAC money hits close to home as lawmakers tackle campaign finance bill. The Wall Street Journal. 7 March, A20 (W) -

Aldrich, Howard E. 1979. Organizations and environments. Englewood Cliffs, NJ: Prentice-Hall.

Aldrich, Howard E., and Jeffrey Pfeffer. 1976. Environments of organizations. In Annual Review of Sociology, vol. 2, ed. Alex Inkeles, James Coleman, and Neil Smelser, 79-105. Palo Alto, CA: Annual Reviews Inc.

Alston, Chuck. 1991. Image problems propel Congress back to campaign finance bills. Conqressional Quarterly, 2 February, 275-281.

Ashford, Kathryn L. 1986. The Role of Corporations in the 1980 U.S. Congressional Elections. Sociological Inquiry, 56: 409-431.

Baltzell, E. Digby. 1962. An American business aristocracy. New York: Collier Books.

Bateman, Thomas S. and Carl P. Zeithaml. 1990. Manaqement: Function and strategy. Homewood, IL: Irwin.

Bauer, Raymond A., Ithiel de Sola Pool and Lewis A. Dexter. 1963. American business and public policy: The politics of foreign trade. New York: Atherton Press.

Baysinger, Barry D. 1984. Domain maintenance as an objective of business political activity: An expanded typology. Academy of Management Review 9: 248-258.

Berle, Adolph, Jr. and Gardiner C. Means. 1932. The modern corporation and private property. New York: Macmillan.

Berkowitz, S. D. 1982. An introduction to structural analysis. Toronto: Butterworths.

Berry, Jeffrey M. 1989. The interest qroup society. Boston: Little, Brown and Company. 
Bock, Betty, Harvey J. Goldschmid, Ira M. Millstein and F. M. Scherer, ed. 1980. The impact of the modern corporation. New York: Columbia University Press.

Brenner, Steven. 1979. Business and politics--an update. Harvard Business Review, $57(6)$ : 149-163.

- 1980. Corporate political activity--an

exploratory study in a developing industry. In Research in corporate social performance and policy vol. 2, ed. L. Preston, 197-236. Greenwich, CT: JAI Press.

Burris, Val. 1987. The political partisanship of American business: A study of corporate political action committees. American Socioloqical Review, 52: 732744 .

Business Council. 1990. The Business Council membership list. Washington, D.C.: Business Council.

Business Roundtable. 1990. The Business Roundtable pamphlet. (July) New York: Business Roundtable.

Business Week. 1987. Big tobacco's fortunes are withering in the heat. 27 July, 47.

- 1989. The Business Week corporate elite: The chief executives of the 1000 most valuable publicly held U.S. companies. 20 October, 219-395.

Cabot, Edward S. and Kathleen D. Sheekey. 1990. Let's send corporate PACs packing. Business and Society Review, 72: 62-64.

Clawson, Dan, Alan Neustadtl and James Bearden. 1986. The logic of business unity: Corporate contributions to the 1980 congressional elections. American Socioloqical Review, 51: 797-811.

Committee for Economic Development. 1978. Annual report-Committee for Economic Development. Washington, D.C.: Committee for Economic Development.

- 1982. Annual report--Committee for Economic Development. Washington, D.C.: Committee for Economic Development.

Conference Board, Inc. 1978. Annual report--Conference Board. New York: Conference Board, Inc. 
- 1982. Annual report--Conference Board. New York: Conference Board, Inc.

Council on Foreign Relations, Inc. 1978. Annual report: September 1, 1977--June 30, 1978. New York:

Council on Foreign Relations.

- 1979. Annual report: July 1, 1978--June 30,

1979. New York: Council on Foreign Relations.

Crawford, Alan. 1980. Thunder on the right. New York: Pantheon.

Dahl, Robert A. 1959. Business and politics: A critical appraisal of political science. In Social science research on business: Product and potential, ed. Robert A. Dahl, Mason Haire and Paul F. Lazarsfeld, 3-44. New York: Columbia University Press.

- 1961. Who Governs? New Haven, CT: Yale University Press.

Dahl, Robert A., Mason Haire and Paul F. Lazarsfeld, ed. 1959. Social science research on business: Product and potential. New York: Columbia University Press.

Davis, Mike. 1981. The New Right's road to power. New Left Review, 28: 28-49.

Domhoff, 'G. William. 1967. Who rules America? Englewood cliffs, NJ: Prentice-Hall.

- 1970. The higher circles: The governing class in America. New York: Random House.

- 1974. The Bohemian Grove and other retreats: A study in ruling class cohesiveness. New York: Harper and Row.

ed. 1980. Power structure research. Beverly Hills, CA: Sage Publications.

Domhoff, G. William and Thomas R. Dye, ed. 1987. Power elites and organizations. Newbury, CA: Sage publications.

Dunn, Marvin G. 1980. The family office: Coordinating mechanism of the ruling class. In power structure research, ed. G. William Domhoff, 17-45. Beverly Hills, CA: Sage Publications. 
Dye, Thomas R. 1976. Who's running America? Englewood Cliffs, NJ: Prentice-Hall.

Easterling, Douglas. 1987. Using the generalized Euclidean model to study ideological shifts in the U.S. Senate. In Multidimensional scaling: History, theory and applications, Forrest $W$. Young and ed. Robert $M$. Hanier, 219-256. Hillsdale, NJ: Lawrence Erlbaum Associates.

Eismeier, Theodore J. and Philip H. Pollock, III. 1988. Business, money, and the rise of corporate PACs in American elections. New York: Quorum Books.

Epstein, David F. 1984. The political theory of the federalist. Chicago: University of Chicago Press.

Epstein, Edwin. 1969. The corporation in American politics. Englewood cliffs, NJ: Prentice-Hall.

- 1980. Business political activity: Research approaches and analytical issues. In Research in corporate social performance and policy vol. 2, ed. Lee Preston. Greenwich, CT: JAI Press.

- 1984. PACs and the modern political process. In The impact of the modern corporation, ed. Betty Bock, Harvey J. Goldschmid, Ira M. Millstein and F. M. Scherer, 399-496. New York: Columbia University Press.

Fischer, David w. 1983. Strategies toward political pressures: A typology of firm responses. Academy of Management Review, 8: 71-78.

Fortune. 1979. The Fortune directory of the 500 largest industrial corporations. 7 May, 268-295.

- 1979. The Fortune directory of the 50 largest U.S. utilities, life-insurance, diversified-financial, retailing, transportation, and commercial-banking companies. $16 \mathrm{July}, 156-170$.

- 1983. The Fortune directory of the 500 largest U.S. industrial corporations. 2 May, 226-253.

- 1983. The Fortune directory of the 500 largest U.S. non-industrial corporations. 13 June, 152-176.

Freeman, R. Edward. 1984. Strateqic management: A stakeholder approach. Boston: Pitman. 
Fritschler, A. Lee. 1983. Smoking and politics: Policymaking and the federal bureaucracy, $3 \mathrm{~d}$ ed. Englewood cliffs, NJ: Prentice-Hall, Inc.

Fritschler, $\dot{A}$. Lee and Bernard H. Ross. 1980. Business requlation and government decision making. Boston: Little, Brown and Company.

Gilbert, Daniel R., Edwin Hartman, John J. Mauriel and R. Edward Freeman. 1988. A logic for strategy. Cambridge, MA: Ballinger Publishing.

Gilbert, Nathaniel. 1989. Global strategies: Foreign resources drive U.S. steel revival. Management Review, $78(9): 52-56$.

Glasberg, Davita Silfen and Michael Schwartz. 1983. Ownership and control of organizations. In Annual Review of Sociology, vol. 9, ed. Ralph H. Turner and James F. Short, Jr., 311-332. Palo Alto, CA: Annual Reviews Inc.

Greer, Douglas F. 1987. Business, government, and society. 2d ed. New York: Macmillan.

Handler, Edward and John R. Mulkern. 1982. Business in politics. Lexington, MA: Lexington.

Inkeles, Alex, James Coleman and Neil Smelser, ed. 1976. Annual Review of Sociology, vol. 2. Palo Alto, CA: Annual Reviews Inc.

Inkeles, Alex, Neil J. Smelser and Ralph H. Turner, ed. 1980. Annual Review of Sociology vol. 6. Palo Alto, CA: Annual Reviews Inc.

Kalb, Marvin and Hendrik Hertzberg. 1988. Candidates ' 88. Dover, MA: Auburn House.

Katz, Daniel and Robert L. Kahn. 1978. The social psychology of organizations. 2d ed. New York: John Wiley -

Keim, Gerald and Barry Baysinger. 1988. The efficacy of business political activity: Competitive considerations in a principal-agent context. Journal of Management, 14: 163-180.

Keim, Gerald and Carl P. Zeithaml. 1986. Corporate political strategy and legislative decision making: A review and contingency approach. Academy of Management Review, 11: 828-843. 
Keim, Gerald, Carl P. Zeithaml and Barry D. Baysinger. 1984. SMR forum: New directions for corporate political strategy. Sloan Management Review 25: 5362 .

Kerlinger, Fred N. 1973. Foundations of behavioral research. 2d ed. New York: Holt, Rinehart and Winston, Inc.

Kotter, John P. 1979. Managing external dependence. Academy of Manaqement Review, 4: 87-92.

Kruskal, Joseph B. and Myron Wish. 1978. Multidimensional scaling. Beverly Hills, CA: Sage Publications.

Lawrence, Paul R. and Jay W. Lorsch. 1967. Organization and environment: Managing differentiation and integration. Boston: Harvard University Press.

Lendaris, George G. 1986. On systemness and the problem solver: Tutorial comments. IEEE Transactions on Systems, Man, and Cybernetics, SMC-16. (July/August): 603-610.

Loehlin, John C. 1987. Latent variable models: An introduction to factor, path, and structural analysis. Hillsdale, NJ: Lawrence Erlbaum Associates.

Lowi, Theodore J. 1964. American business, public policy, case-studies, and political theory. World Politics, 16: $677-715$.

MacIver, Robert. 1965. The web of government, revised edition. New York: The Free Press.

Mahon, John F. 1983. Corporate political strategies: An empirical study of chemical responses to superfund legislation. In Research in corporate social performance and policy, vol. 5, ed. L. Preston, 143182. Greenwich, CT: JAI Press.

Maitland, Ian. 1983. House divided: Business lobbying and the 1981 budget. In Research in corporate social performance and policy, vol. 5, ed. L. Preston, 1-25. Greenwich, CT: JAI Press.

1986. Self-defeating lobbying: How more is buying less in Washington. Journal of Business strateqy, 7: 67-74.

March, James G. and Herbert A. Simon. 1958. Orqanizations. New York: John Wiley \& Sons, Inc. 
Marcus, Alfred A. 1987. U.S. Firms' Responses to Regulation: Stonewalling and Opportunism. Long-Range Plannirig, 20: 98-104.

Mariolis, Peter. 1975. Interlocking directorates and coritrol of corporations. Social Science Quarterly, 56: 425-439.

Mariolis, Peter and Maria H. Jones. 1982. Centrality in corporate interlock networks: Reliability and stability. Administrative Science Quarterly, 7: 571584 .

Masters, Marick F. and Barry D. Baysinger. 1985. The determinants of funds raised by corporate political action committees: An empirical examination. Academy of Management Journal, 28: 654-664.

Matasar, Ann. 1986. Corporate PACs and federal campaign financing laws. New York: Quorum Books.

McGowan, Robert P. 1980. Enacting the environment: organization persistence and change. Public Administration Review, 40: 86-91.

Miles, Robert H. 1987. Manaqing the corporate social environment. Englewood Cliffs, NJ: Prentice-Hall, Inc.

Miller, William H. 1988. What's ahead in regulation. Industry Week, 1 October, 70-74.

Mills, C. Wright. 1956. The power elite. New York: oxford University Press.

Mintzberg, Henry. 1987. Crafting strategy. Harvard Business Review, 65(4): 66-77.

Mitnick, Barry M. 1980. The political economy of requlation. New York: Columbia University Press.

1989. Chasing elephants among chickens on a tilted field: Pluralism and political contestability in the work of Edwin Epstein. Paper for presentation at the forty-ninth annual meeting of the Academy of Management, Washington, D.C., August 13-16.

Mizruchi, Mark S. 1987. Why do corporations stick together: An interorganizational theory of class coliesion. In Power elites and organizations, ed. G. William Domhoff and Thomas R. Dye, 204-218. Newbury Park, CA: Sage Publications. 
- 1989. Similarity of political behavior among large American corporations. American Journal of Sociology, 95: 401-424.

Mizruchi, Mark S. and Thomas Koenig. 1986. Economic sources of corporate political consensus: An examination of interindustry relations. American Sociological Review, 51: 482-491.

Mizruchi, Mark S. and Michael Schwartz. 1987. The structural analysis of business: An emerging field. In Intercorporate relations: the structural analysis of business, ed. Mark S. Mizruchi and Michael Schwartz, 3-21. Cambridge, UK: Cambridge University Press.

Nelson, Candice J. and David B. Magleby. 1989. Congress and campaign money: The prospects for reform. The Brookings Review, 7: 4-41.

Neustadtl, Alan and Dan Clawson. 1988. Corporate political groupings: Does ideology unify business political

behavior. American Sociological Review 53: 172-190.

Olson, Mancur. 1965. The logic of collective action: Public qoods and the theory of groups. Cambridge, MA: Harvard University Press.

Oreskes, Michael with Robin Toner. 1990. Failures in a political system spur momentum for change. New York Times, 21 March, Al.

Palmer, Donald, Roger Friedland and Jitendra V. Singh. 1986. The ties that bind: organizational and class bases of stability in a corporate interlock network. American Sociological Review, 51: 781-96.

Pedhazur, Elazar J. 1982. Multiple reqression in behavioral research: Explanation and prediction. New York: Holt, Rinehart and winston.

Pennings, Johannes M. 1980. Interlocking directorates. San Francisco: Jossey-Bass.

Pfeffer, Jeffrey. 1982. Organizations and organization theory. Marshfield, MA: Pitman.

- 1987. A resource dependence perspective on intercorporate relations. In Intercorporate relations: The structural analysis of business, ed. Mark S. Mizruchi and Michael Schwartz, 25-55. Cambridge, UK: Cambridge University Press. 
Pfeffer, Jeffrey and Gerald R. Salancik. 1978. The external control of organization: A resource dependence perspective. New York: Harper and Row.

Pierson, G. W. 1969. The education of American leaders: Comparative contributions of U.S. colleges and universities. New York: Praeger.

Porter, Michael E. 1985. Competitive advantage. New York: The Free Press.

Post, James E., Edwin A. Murray, Jr., Robert B. Dickie and John F. Mahon. 1982. Public affairs function in American corporations: Development and relations with corporate planning. Long Range Planning, 15: 12-32.

- 1983. Managing public affairs: The public affairs function. California Management Review 26: 135-150.

Potts, M. and P. Behr. 1987. The leading edge. New York: McGraw-Hill.

Preston, Lee. 1980. Research in corporate social performance and policy, vol. 2. Greenwich, CT: JAI Press.

1983. Research in corporate social performance

Preston, Lee and James E. Post. 1975. Private management and public policy: The principle of public responsibility. Englewood Cliffs, NJ: Prentice-Hall.

Ryan, Mike H., Carl L. Swanson and Rogene A. Buchholz. 1987. Corporate strategy, public policy and the Fortune 500: How America's major corporations influence qovernment. Oxford, UK: Basil Blackwell Ltd.

Sabato, Larry J. 1984. PAC power: Inside the world of political action committees. New York: w. W. Norton and Co.

Salamon L. M. and J. J. Siegfried. 1977. Economic power and political influence--impact of industry structure on public policy. American Political Science Review, 71 (3): 1026-1043. 
Sale, Kirkpatrick. 1976. Power shift: The rise of the southern rim and its challenge to the eastern establishment. New York: Random House.

SAS Institute Inc. 1985a. SAS user's quide: Basics. 5th ed. Cary, NC: SAS Institute Inc.

- 1985b. SAS user's quide: Statistics. 5th ed. Cary, NC: SAS Institute Inc.

Schattschneider, E. 1935. Politics, pressures, and the tariff: A study of free enterprise in pressure politics as shown in the 1929-1930 revision of the tariff. New York: Prentice-Hall.

Schiffman, Susan S., M. Lance Reynolds and Forrest W. Young. 1981. Introduction to multidimensional scaling: Theory, methods and applications. New York: Academic Press.

Schnitzer, Martin C. 1990. Contemporary government and business relations. 4 th ed. Boston: Houghton Mifflin.

Sethi, S. Prakash. 1982. Corporate political activism. California Management Review, 24 (3): 32-42.

SPSS Inc. 1988. SPSS-X user's guide. 3d ed. Chicago: SPSS Inc.

Stern, Philip M. 1988. The best Congress money can buy. New York: Pantheon.

Stigler, George J. 1971. The theory of economic regulation. Bell Journal of Economics and Management, 2: 3-21.

Thompson, James D. 1967. Orqanizations in action: Social science bases of administrative theory. New York: McGraw-Hill.

Telling, Edward R. 1986. How Sears restructured for growth in financial services. Management Review 75(5): $31-40$.

Ticer, scott. 1988. Where there's smoke, there's trouble. Business Week, 18 January: 88-89.

Truman, David B. 1951. The governmental process: Political interests and public opinion. New York: Alfred A. Knopf. 
Turabian, Kate L. 1987. A manual for writers of term papers, theses, and dissertations. 5th ed. Chicago: University of Chicago Press.

Ullmann, Arieh A. 1985. The impact of the regulatory life cycle on corporate political strategy. California Management Review, 28: 140-151.

U.S. Congress. Senate. Committee on Governmental Affairs. 1980. Structure of corporate concentration: Institutional shareholders and interlocking directorates among major U.S. corporations. Report prepared by staff. 96th Cong., 2d sess. Committee Print.

U.S. Federal Election Commission. 1979. Press Release, June 29. Washington, D.C.: Government Printing office.

- 1983. FEC publishes final 1981-82 PAC study. Press Release, November 29. Washington, D.C.: Government Printing office.

1986. Campaiqn quide for corporations and labor orqanizations. Washington, D.C.: Government Printing office.

- 1990. Decrease in registered PACs reported by FEC. Press Release, January 17 . Washington, D.C.: Government Printing office.

Useem, Michael. 1980. Corporations and the corporate elite. In Annual Review of Sociology vol. 6, ed. Alex Inkeles, Neil J. Smelser and Ralph H. Turner, 4147. Palo Alto, CA: Annual Reviews Inc.

1982. Classwide rationality in the politics of managers and directors of large corporations in the U.S. and Great Britain. Administrative Science Quarterly, 27: 199-226.

1984. The inner circle: Large corporations and the rise of business political activity in the U.S. and U.K. New York: Oxford University Press.

- 1985. The rise of the political manager. Sloan Management Review, $27(1)$ : 15-26.

Useem, Michael and S. M. Miller. 1975. Privilege and domination: The role of the upper class in American higher education. Social Science Information, 14 (6): 115-145. 
Wertheimer, Fred. 1990. The urgent need for campaign finance reform. Common Cause Magazine, January/February, 42-45.

Whitt, J. Allen. 1979. Toward a class-dialectical model of power: An empirical assessment of three competing models of political power. American Sociological Review, 44: 81-100.

- 1980. Can capitalists organize themselves? In Power structure Research, ed. G. William Domhoff, 97113. Beverly Hills, CA: Sage Publications.

Yoffie, David G. and Sigrid Bergenstein. 1985. Creating political advantage: The rise of the corporate political entrepreneur. California Manaqement Review, 28: 124-137.

Young, Forrest W. 1981. Quantitative Analysis of Qualitative Data. Psychometrika, 46: 357-388.

- 1987. Multidimensional scaling: History, theory, and applications. Hillsdale, NJ: Lawrence Erlbaum Associates.

Young, Forrest $w$. and Rostyslaw Lewyckyj. 1979. ALSCAL-4 users quide. 2d ed. Chapel Hill, NC: Data Analysis and Theory Associates.

Zeitlin, Maurice. 1974. Corporate ownership and control: The large corporation and the capitalist class. American Journal of Sociology, 81: 1073-1119. 
APPENDIX A

RESEARCH DESIGN 
RESEARCH DESIGN

Research Question

Can resource dependence or class cohesion theory explain intercorporate patterns of corporate political activities, specifically political action committee (PAC) campaign contributions?

\section{Research Hypotheses}

\section{Resource Dependence Theory}

H1: $\quad$ Firms similarly constrained by government regulations will exhibit similar political behavior.

\section{Class Cohesion Theory}

H2: $\quad$ Firms' number of interlocking directorates will relate directly to similar political behavior among firms.

H3: Firms' number of associations with certain prestigious business policy groups will relate directly to similar political behavior among firms.

H4: Shared educational experience among Board Chairmen and CEOs will relate directly to similar political 'behavior among firms.

H5: Geographically proximate headquarters will relate directly to similar political behavior among firms.

\section{A Political Strateqy Hypothesis}

H6: The ideology of a sitting White House administration will influence corporate PAC contribution patterns.

Time Frame

Election Cycles: 1977-78 Carter Administration 1981-82 Reagan Administration 
RESEARCH DESIGN (cont.)

Sampling strategy

Population: 100 Large Corporations from 1980 U.S Senate study on Corporate concentration

Sample: 42 Corporations from 14 Diverse Industry Sectors

Measured Variables

Corporate Political Activity: Measured by PAC campaign contributions.

Regulatory Envi ronment: Measured as either Economic or Social

Professional and Social Networks: Measured by

* Interlocking Directorates

* Memberships in Major Business Associations

* Prestigious University Attendance

* Headquarters Location

Methodology

Data Analysis: Multidimensional scaling

Hypothesis Testing: Multiple Regression

Canonical Analysis

Discriminant Analysis

Chi Square Goodness of Fit 
RESEARCH DESIGN (cont.)

\section{Null Hypotheses}

Ho,: There is no significant relationship between a firm's MDS Coordinates and its regulatory environment classification.

$\mathrm{HO}_{2}$ : There is no significant relationship between a firm's MDS coordinates and its number of direct or indirect interlocks with the set of sampled firms.

$\mathrm{HO}_{3}: \quad$ There is no significant relationship between a firm's MDS coordinates and its number of associations with major business policy groups.

$\mathrm{HO}_{4}$ : There is no significant relationship between a firm's MDS coordinates and its number of associations with prestigious universities.

$\mathrm{HO}_{5}$ : There is no significant relationship between a firm's MDS coordinates and its headquarters' location.

$\mathrm{HO}_{6}$ : There is no significant change between patterns of corporate political spending exhibited during the 1977-78 election cycle and the 1981-82 election cycle. 
APPENDIX B

1977-78 SIMILARITY MATRIX 
1977-78 SIMILARITY MATRIX

RAW (UNSCALED) DATA

\begin{tabular}{|c|c|c|c|c|c|c|c|c|c|c|}
\hline 1 & $\begin{array}{c}1 \\
0.000\end{array}$ & 2 & 3 & 4 & 5 & 6 & 7 & 8 & 9 & 10 \\
\hline 2 & 0.093 & 0.000 & & & & & & & & \\
\hline $\begin{array}{l}3 \\
4\end{array}$ & 0.248 & 0.063 & 0.000 & & & & & & & \\
\hline $\begin{array}{l}4 \\
5\end{array}$ & 0.312 & 0.099 & $\begin{array}{l}0.216 \\
0.154\end{array}$ & $\begin{array}{l}0.000 \\
0.193\end{array}$ & & & & & & \\
\hline 6 & $\begin{array}{l}0.218 \\
0.355\end{array}$ & $\begin{array}{l}0.181 \\
0.175\end{array}$ & 0.249 & $\begin{array}{l}0.193 \\
0.325\end{array}$ & $\begin{array}{l}0.000 \\
0.226\end{array}$ & 0.000 & & & & \\
\hline 7 & 0.141 & 0.044 & 0.330 & 0.143 & 0.166 & 0.172 & 0.000 & & & \\
\hline $\begin{array}{l}8 \\
9\end{array}$ & 0.072 & 0.000 & 0.147 & 0.077 & 0.056 & 0.085 & 0.270 & 0.000 & & \\
\hline $\begin{array}{r}9 \\
10\end{array}$ & 01.246 & 0.071 & 0.084 & 0.274 & 0.096 & 0.245 & 0.046 & 0.055 & 0.000 & \\
\hline $\begin{array}{l}10 \\
11\end{array}$ & 0.109 & 0.118 & 0.205 & 0.140 & 0.085 & 0.155 & 0.206 & 0.061 & 0.063 & 0.000 \\
\hline $\begin{array}{l}11 \\
12\end{array}$ & 0.130 & 0.056 & 0.213 & 0.084 & 0.092 & 0.130 & 0.258 & 0.044 & 0.060 & 0.133 \\
\hline $\begin{array}{l}12 \\
13\end{array}$ & 0.337 & 0.146 & 0.230 & 0.339 & 0.184 & 0.455 & 0.111 & 0.038 & 0.349 & 0.186 \\
\hline $\begin{array}{l}13 \\
14\end{array}$ & 0.363 & 0.192 & 0.371 & 0.414 & 0.252 & 0.431 & 0.252 & 0.124 & 0.221 & 0.246 \\
\hline $\begin{array}{l}14 \\
15\end{array}$ & 0.353 & 0.223 & 0.299 & 0.442 & 0.262 & 0.488 & 0.183 & 0.144 & 0.267 & $\begin{array}{l}0.220 \\
0.088\end{array}$ \\
\hline $\begin{array}{l}15 \\
16\end{array}$ & 0.069 & 0.075 & 0.106 & 0.089 & 0.081 & 0.122 & 0.049 & 0.000 & 0.079 & 0.088 \\
\hline $\begin{array}{l}16 \\
17\end{array}$ & 0.271 & 0.049 & 0.092 & 0.246 & 0.079 & 0.240 & 0.064 & 0.000 & 0.234 & $\begin{array}{l}0.086 \\
0.055\end{array}$ \\
\hline $\begin{array}{l}17 \\
18\end{array}$ & 0.258 & 0.000 & 0.110 & 0.207 & 0.050 & 0.198 & 0.000 & 0.000 & $\begin{array}{l}0.247 \\
0.218\end{array}$ & $\begin{array}{l}0.053 \\
0.176\end{array}$ \\
\hline $\begin{array}{l}18 \\
19\end{array}$ & $\begin{array}{l}0.242 \\
0.348\end{array}$ & $\begin{array}{l}0.075 \\
0.100\end{array}$ & $\begin{array}{l}0.176 \\
0.237\end{array}$ & $\begin{array}{l}0.244 \\
0.365\end{array}$ & $\begin{array}{l}0.081 \\
0.245\end{array}$ & $\begin{array}{l}0.306 \\
0.371\end{array}$ & 0.115 & 0.019 & 0.360 & 0.207 \\
\hline 20 & 0.293 & 0.063 & 0.299 & 0.413 & 0.160 & 0.346 & 0.193 & 0.131 & 0.213 & 0.212 \\
\hline 21 & 0.302 & 0.184 & 0.270 & 0.358 & 0.133 & 0.382 & 0.134 & 0.079 & 0.109 & 0.169 \\
\hline 22 & 0.151 & 0.041 & 0.232 & 0.218 & 0.111 & 0.241 & 0.508 & 0.379 & 0.130 & 0.169 \\
\hline 23 & 0.216 & 0.067 & 0.126 & 0.059 & 0.108 & 0.088 & 0.131 & 0.000 & 0.071 & 0.079 \\
\hline 24 & 0.331 & 0.072 & 0.237 & 0.181 & 0.058 & 0.341 & 0.188 & 0.111 & 0.133 & 0.233 \\
\hline 25 & 0.331 & 0.159 & 0.238 & 0.275 & 0.158 & 0.331 & 0.156 & 0.082 & 0.169 & 0.203 \\
\hline 26 & 0.241 & 0.160 & 0.360 & 0.357 & 0.174 & 0.336 & 0.184 & 0.186 & 0.096 & 0.213 \\
\hline 27 & 0.346 & 0.142 & 0.336 & 0.422 & 0.183 & 0.420 & 0.221 & 0.055 & & $\begin{array}{l}0.273 \\
0.135\end{array}$ \\
\hline $\begin{array}{l}28 \\
29\end{array}$ & 0.148 & 0.137 & 0.173 & 0.203 & 0.124 & $\begin{array}{l}0.150 \\
0.171\end{array}$ & $\begin{array}{l}0.090 \\
0.049\end{array}$ & $\begin{array}{l}0.035 \\
0.058\end{array}$ & $\begin{array}{l}0.024 \\
0.099\end{array}$ & $\begin{array}{l}0.135 \\
0.088\end{array}$ \\
\hline $\begin{array}{l}28 \\
30\end{array}$ & $\begin{array}{l}0.242 \\
0.336\end{array}$ & $\begin{array}{l}0.112 \\
0.151\end{array}$ & $\begin{array}{l}0.116 \\
0.200\end{array}$ & $\begin{array}{l}0.2211 \\
0.278\end{array}$ & 0.164 & 0.298 & 0.059 & 0.047 & 0.145 & 0.125 \\
\hline 31 & 0.373 & 0.096 & 0.245 & 0.462 & 0.187 & 0.347 & 0.138 & 0.030 & 0.317 & 0.204 \\
\hline 32 & 0.045 & 0.000 & 0.139 & 0.246 & 0.053 & 0.048 & 0.192 & 0.000 & 0.026 & 0.144 \\
\hline 33 & 0.191 & 0.000 & 0.153 & 0.315 & 0.112 & 0.145 & 0.039 & 0.068 & 0.110 & 0.139 \\
\hline 34 & 0.374 & 0.162 & 0.208 & 0.528 & 0.200 & 0.372 & 0.166 & 0.143 & 0.393 & 0.136 \\
\hline 35 & 0.143 & 0.197 & 0.253 & 0.226 & 0.122 & 0.287 & 0.074 & 0.065 & 0.075 & 0.083 \\
\hline 36 & 0.271 & 0.058 & 0.194 & 0.321 & 0.143 & 0.346 & 0.134 & 0.159 & 0.233 & 0.069 \\
\hline 37 & 0.216 & 0.123 & 0.174 & 0.415 & 0.106 & 0.242 & 0.096 & 0.057 & 0.143 & $\begin{array}{l}0.145 \\
0.177\end{array}$ \\
\hline 38 & 0.282 & 0.058 & 0.234 & 0.311 & 0.173 & 0.315 & 0.114 & 0.068 & 0.108 & $\begin{array}{l}0.172 \\
0.173\end{array}$ \\
\hline 39 & 0.397 & 0.209 & 0.208 & 0.411 & 0.295 & 0.413 & 0.096 & 0.065 & 0.267 & $\begin{array}{l}0.173 \\
0.146\end{array}$ \\
\hline 40 & 0.370 & 0.171 & $\begin{array}{l}0.270 \\
0.091\end{array}$ & $\begin{array}{l}0.424 \\
0.199\end{array}$ & $\begin{array}{l}0.268 \\
0.078\end{array}$ & 0.450 & $\begin{array}{l}0.174 \\
0.126\end{array}$ & $\begin{array}{l}0.133 \\
0.000\end{array}$ & $\begin{array}{l}0.334 \\
0.077\end{array}$ & $\begin{array}{l}0.140 \\
0.170\end{array}$ \\
\hline $\begin{array}{l}41 \\
42\end{array}$ & $\begin{array}{l}0.044 \\
0.354\end{array}$ & $\begin{array}{l}0.048 \\
0.109\end{array}$ & $\begin{array}{l}0.0910 \\
0.310\end{array}$ & 0.344 & 0.260 & 0.337 & 0.186 & 0.186 & 0.128 & 0.193 \\
\hline
\end{tabular}




\begin{tabular}{|c|c|c|c|c|c|c|c|c|c|c|}
\hline 11 & $\begin{array}{c}11 \\
0.000\end{array}$ & 12 & 13 & 14 & 15 & 16 & 17 & 18 & 19 & 20 \\
\hline 12 & 0.164 & 0.000 & & & & & & & & \\
\hline 13 & 0.176 & 0.438 & 0.000 & & & & & & & \\
\hline 14 & 0.188 & 0.515 & 0.527 & 0.000 & & & & & & \\
\hline 15 & 0.000 & 0.163 & 0.143 & 0.104 & 0.000 & & & & & \\
\hline 16 & 0.082 & 0.302 & 0.223 & 0.299 & 0.109 & 0.000 & & & & \\
\hline 17 & 0.078 & 0.338 & 0.212 & 0.246 & 0.052 & 0.305 & 0.000 & & & \\
\hline 18 & 0.220 & 0.353 & 0.277 & 0.312 & 0.083 & 0.355 & 0.233 & 0.000 & & \\
\hline 19 & 0.106 & 0.448 & 0.416 & 0.412 & 0.084 & 0.294 & 0.262 & 0.308 & 0.000 & \\
\hline 20 & 0.160 & 0.384 & 0.537 & 0.476 & 0.094 & 0.278 & 0.220 & 0.271 & 0.325 & 0.000 \\
\hline 21 & 0.121 & 0.320 & 0.505 & 0.467 & 0.091 & 0.164 & 0.142 & 0.183 & 0.292 & 0.465 \\
\hline 22 & 0.207 & 0.178 & 0.245 & 0.205 & 0.091 & 0.060 & 0.085 & 0.137 & 0.138 & 0.207 \\
\hline 23 & 0.113 & 0.073 & 0.080 & 0.074 & 0.000 & 0.000 & 0.000 & 0.037 & 0.125 & 0.063 \\
\hline 24 & 0.151 & 0.274 & 0.335 & 0.309 & 0.040 & 0.210 & 0.174 & 0.180 & 0.242 & 0.294 \\
\hline 25 & 0.179 & 0.319 & 0.375 & 0.406 & 0.148 & 0.213 & 0.147 & 0.237 & 0.339 & 0.310 \\
\hline 26 & 0.119 & 0.329 & 0.491 & 0.441 & 0.090 & 0.103 & 0.112 & 0.202 & 0.249 & 0.456 \\
\hline 27 & 0.150 & 0.427 & 0.495 & 0.491 & 0.099 & 0.234 & 0.272 & 0.308 & 0.515 & 0.427 \\
\hline 28 & 0.000 & 0.166 & 0.186 & 0.191 & 0.102 & 0.134 & 0.032 & 0.102 & 0.189 & 0.115 \\
\hline 29 & 0.000 & 0.231 & 0.269 & 0.291 & 0.167 & 0.164 & 0.078 & 0.146 & 0.196 & 0.236 \\
\hline 30 & 0.051 & 0.319 & 0.327 & 0.354 & 0.034 & 0.199 & 0.189 & 0.152 & 0.261 & 0.392 \\
\hline 31 & 0.114 & 0.434 & 0.447 & 0.482 & 0.129 & 0.281 & 0.227 & 0.290 & 0.520 & 0.437 \\
\hline 32 & 0.124 & 0.178 & 0.211 & 0.163 & 0.000 & 0.036 & 0.034 & 0.027 & 0.073 & 0.339 \\
\hline 33 & 0.025 & 0.236 & 0.325 & 0.213 & 0.033 & 0.086 & 0.061 & 0.115 & 0.210 & 0.335 \\
\hline 34 & 0.098 & 0.412 & 0.455 & 0.528 & 0.103 & 0.321 & 0.225 & 0.219 & 0.452 & 0.372 \\
\hline 35 & 0.071 & 0.308 & 0.379 & 0.353 & 0.063 & 0.103 & 0.059 & 0.189 & 0.180 & 0.232 \\
\hline 36 & 0.049 & 0.309 & 0.337 & 0.399 & 0.163 & 0.257 & 0.142 & 0.261 & 0.319 & 0.361 \\
\hline 37 & 0.083 & 0.348 & 0.418 & 0.355 & 0.055 & 0.251 & 0.136 & 0.192 & 0.313 & 0.372 \\
\hline 38 & 0.196 & 0.307 & 0.398 & 0.405 & 0.097 & 0.191 & 0.182 & 0.325 & 0.251 & 0.423 \\
\hline 39 & 0.177 & 0.412 & 0.423 & 0.473 & 0.094 & 0.230 & 0.117 & 0.340 & 0.402 & 0.371 \\
\hline 40 & 0.113 & 0.499 & 0.549 & 0.594 & 0.170 & 0.279 & 0.238 & 0.287 & 0.480 & 0.530 \\
\hline 41 & 0.162 & 0.175 & 0.173 & 0.120 & 0.000 & 0.035 & 0.067 & 0.027 & 0.108 & 0.303 \\
\hline 42 & 0.111 & 0.318 & 0.472 & 0.414 & 0.049 & 0.192 & 0.182 & 0.195 & 0.304 & 0.428 \\
\hline
\end{tabular}




\begin{tabular}{|c|c|c|c|c|c|c|c|c|c|c|}
\hline 22 & 0.150 & 0.000 & & & & & & & & \\
\hline 23 & 0.082 & 0.122 & 0.000 & & & & & & & \\
\hline 24 & 0.252 & 0.175 & 0.107 & 0.000 & & & & & & \\
\hline 25 & 0.349 & 0.130 & 0.079 & 0.242 & 0.000 & & & & & \\
\hline 26 & 0.454 & 0.209 & 0.040 & 0.269 & 0.319 & 0.000 & & & & \\
\hline 27 & 0.386 & 0.185 & 0.107 & 0.277 & 0.396 & 0.374 & 0.000 & & & \\
\hline 28 & 0.224 & 0.056 & 0.000 & 0.123 & 0.145 & 0.206 & 0.243 & 0.000 & & \\
\hline 29 & 0.251 & 0.046 & 0.000 & 0.140 & 0.237 & 0.213 & 0.219 & 0.357 & 0.000 & \\
\hline 30 & 0.287 & 0.037 & 0.060 & 0.227 & 0.252 & 0.227 & 0.266 & 0.166 & 0.068 & 0.000 \\
\hline 31 & 0.364 & 0.141 & 0.115 & 0.268 & 0.343 & 0.300 & 0.527 & 0.171 & 0.236 & 0.357 \\
\hline 32 & 0.105 & 0.120 & 0.049 & 0.026 & 0.078 & 0.132 & 0.208 & 0.000 & 0.000 & 0.199 \\
\hline 33 & 0.261 & 0.072 & 0.000 & 0.047 & 0.152 & 0.310 & 0.282 & 0.101 & 0.164 & 0.213 \\
\hline 34 & 0.382 & 0.255 & 0.115 & 0.273 & 0.312 & 0.347 & 0.419 & 0.126 & $0: 194$ & 0.356 \\
\hline 35 & 0.354 & 0.052 & 0.000 & 0.166 & 0.257 & 0.440 & 0.255 & 0.174 & 0.205 & 0.204 \\
\hline 36 & 0.286 & 0.251 & 0.000 & 0.236 & 0.290 & 0.308 & 0.343 & 0.140 & 0.229 & 0.225 \\
\hline 37 & 0.345 & 0.120 & 0.000 & 0.184 & 0.224 & 0.339 & 0.346 & 0.084 & 0.151 & 0.222 \\
\hline 38 & 0.329 & 0.125 & 0.087 & 0.187 & 0.335 & 0.480 & 0.333 & 0.119 & 0.211 & 0.237 \\
\hline 39 & 0.430 & 0.115 & 0.168 & 0.304 & 0.383 & 0.371 & 0.413 & 0.201 & 0.222 & 0.332 \\
\hline 40 & 0.443 & 0.233 & 0.114 & 0.327 & 0.348 & 0.401 & 0.472 & 0.195 & 0.277 & 0.362 \\
\hline 41 & 0.073 & 0.117 & 0.096 & 0.052 & 0.095 & 0.101 & 0.217 & 0.000 & 0.027 & 0.196 \\
\hline 42 & 0.434 & 0.174 & 0.175 & 0.258 & 0.321 & 0.407 & 0.378 & 0.209 & 0.207 & 0.326 \\
\hline & 31 & 32 & 33 & 34 & 35 & 36 & 37 & 38 & 39 & 40 \\
\hline 31 & 0.000 & & & & & & & & & \\
\hline 32 & 0.155 & 0.000 & & & & & & & & \\
\hline 33 & 0.229 & 0.409 & 0.000 & & & & & & & \\
\hline 34 & 0.545 & 0.068 & 0.183 & 0.000 & & & & & & \\
\hline 35 & 0.260 & 0.062 & 0.224 & 0.224 & 0.000 & & & & & \\
\hline 36 & 0.311 & 0.000 & 0.155 & 0.354 & 0.198 & 0.000 & & & & \\
\hline 37 & 0.346 & 0.269 & 0.476 & 0.365 & 0.280 & 0.215 & 0.000 & & & 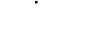 \\
\hline 38 & 0.301 & 0.213 & 0.295 & 0.292 & 0.393 & 0.229 & 0.299 & 0.000 & & \\
\hline 39 & 0.464 & 0.107 & 0.213 & 0.450 & 0.283 & 0.331 & 0.316 & 0.338 & 0.000 & \\
\hline 40 & 0.542 & 0.153 & $0 . \overline{c 02}$ & 0.574 & 0.290 & 0.409 & 0.280 & 0.357 & 0.466 & 0.000 \\
\hline 41 & 0.179 & 0.561 & 0.402 & 0.050 & 0.041 & 0.000 & 0.229 & 0.167 & 0.075 & 0.110 \\
\hline 42 & 0.364 & 0.160 & 0.212 & 0.355 & 0.286 & 0.239 & 0.289 & 0.323 & 0.370 & 0.467 \\
\hline & 41 & 42 & & & & & & & & \\
\hline 41 & 0.000 & & & & & & & & & \\
\hline 42 & 0.110 & 0.000 & & & & & & & & \\
\hline
\end{tabular}


APPENDIX C

1981-82 SIMILARITY MATRIX 
1981-82 SIMILARITY MATRIX

RAW (UHSCALED) DATA

$\begin{array}{llll} & & & \\ 1 & 0.000 & & 3 \\ 2 & 0.274 & 0.000 & \\ 3 & 0.224 & 0.142 & 0.000 \\ 4 & 0.357 & 0.181 & 0.193 \\ 5 & 0.288 & 0.190 & 0.256 \\ 6 & 0.296 & 0.223 & 0.248 \\ 7 & 0.223 & 0.138 & 0.409 \\ 8 & 0.132 & 0.138 & 0.154 \\ 9 & 0.320 & 0.241 & 0.097 \\ 10 & 0.261 & 0.199 & 0.370 \\ 11 & 0.095 & 0.099 & 0.220 \\ 12 & 0.393 & 0.245 & 0.240 \\ 13 & 0.445 & 0.246 & 0.379 \\ 14 & 0.391 & 0.263 & 0.269 \\ 15 & 0.436 & 0.249 & 0.262 \\ 16 & 0.264 & 0.268 & 0.142 \\ 17 & 0.369 & 0.064 & 0.223 \\ 18 & 0.270 & 0.184 & 0.304 \\ 19 & 0.449 & 0.185 & 0.222 \\ 20 & 0.334 & 0.172 & 0.256 \\ 21 & 0.113 & 0.056 & 0.126 \\ 22 & 0.174 & 0.065 & 0.289 \\ 23 & 0.155 & 0.077 & 0.201 \\ 24 & 0.317 & 0.198 & 0.368 \\ 25 & 0.308 & 0.157 & 0.129 \\ 26 & 0.115 & 0.075 & 0.130 \\ 27 & 0.306 & 0.157 & 0.368 \\ 28 & 0.403 & 0.234 & 0.324 \\ 29 & 0.309 & 0.298 & 0.244 \\ 30 & 0.382 & 0.141 & 0.227 \\ 31 & 0.459 & 0.221 & 0.186 \\ 32 & 0.144 & 0.042 & 0.186 \\ 33 & 0.263 & 0.128 & 0.223 \\ 34 & 0.376 & 0.160 & 0.178 \\ 35 & 0.183 & 0.139 & 0.133 \\ 36 & 0.358 & 0.128 & 0.163 \\ 37 & 0.449 & 0.253 & 0.294 \\ 38 & 0.274 & 0.136 & 0.342 \\ 39 & 0.450 & 0.238 & 0.270 \\ 40 & 0.382 & 0.190 & 0.243 \\ 41 & 0.110 & 0.048 & 0.106 \\ 42 & 0.374 & 0.206 & 0.330 \\ & & & \end{array}$

5

8

9

10

0.000
0.193

0.000

0.225
0.257

0.000

$\begin{array}{ll}.177 & 0.245\end{array}$

$\begin{array}{ll}0.113 & 0.167 \\ 0.192 & 0.121\end{array}$

0.192

0.309

0.054

0.330

0.426
0.382

0.390

0.219

0.268
0.211

0.211
0.355

0.138

0.129

0.063

0.346

0.266

0.136

0.329
0.324

0.284

0.403
0.397

0.397

0.260
0.419

0.449

0.195

0.518

0.250

0.121

0.237
0.095

0.290
0.350

0.294
0.286

0.286
0.236

0.217
0.281

0.281
0.185

0.273

0.163

0.157

0.224

0.328
0.217

0.200

0.298

0.292

0.227

0.202

0.151

0.269
0.203

0.303

0.265

0.323

0.346

0.386

0.413

0.419

0.283

0.318

0.369

0.000
0.285
0.121
0.228
0.241
0.154
0.445
0.367
0.423
0.352
0.257
0.263
0.263
0.307
0.333
0.165
0.139
0.090
0.339
0.313
0.146
0.311
0.292
0.244
0.331
0.314
0.195
0.242
0.249
0.268
0.278
0.320
0.249
0.345
0.401
0.125
0.361

0.000
0.339
0.195
0.351
0.225
0.258
0.393
0.271
0.262
0.151
0.202
0.247
0.209
0.339
0.163
0.398
0.142
0.335
0.215
0.158
0.299
0.329
0.220
0.280
0.303
0.273
0.240
0.238
0.178
0.231
0.320
0.224
0.274
0.333
0.200
0.376

0.000
0.108
0.261
0.095
0.199
0.238
0.201
0.130
0.148
0.041
0.079
0.082
0.145
0.082
0.292
0.000
0.219
0.152
0.193
0.152
0.257
0.159
0.126
0.158
0.020
0.124
0.155
0.115
0.088
0.186
0.099
0.142
0.245
0.023
0.230

$\begin{array}{ll}0.000 & \\ 0.199 & 0.000 \\ 0.051 & 0.177 \\ 0.252 & 0.277 \\ 0.256 & 0.408 \\ 0.325 & 0.334 \\ 0.251 & 0.341 \\ 0.179 & 0.206 \\ 0.267 & 0.268 \\ 0.112 & 0.232 \\ 0.510 & 0.203 \\ 0.201 & 0.308 \\ 0.044 & 0.151 \\ 0.152 & 0.232 \\ 0.030 & 0.092 \\ 0.155 & 0.371 \\ 0.295 & 0.235 \\ 0.059 & 0.194 \\ 0.123 & 0.397 \\ 0.191 & 0.349 \\ 0.198 & 0.294 \\ 0.195 & 0.279 \\ 0.405 & 0.309 \\ 0.081 & 0.236 \\ 0.122 & 0.289 \\ 0.281 & 0.207 \\ 0.047 & 0.202 \\ 0.357 & 0.186 \\ 0.324 & 0.338 \\ 0.106 & 0.305 \\ 0.221 & 0.332 \\ 0.247 & 0.315 \\ 0.111 & 0.199 \\ 0.220 & 0.304 \\ 0 & \end{array}$




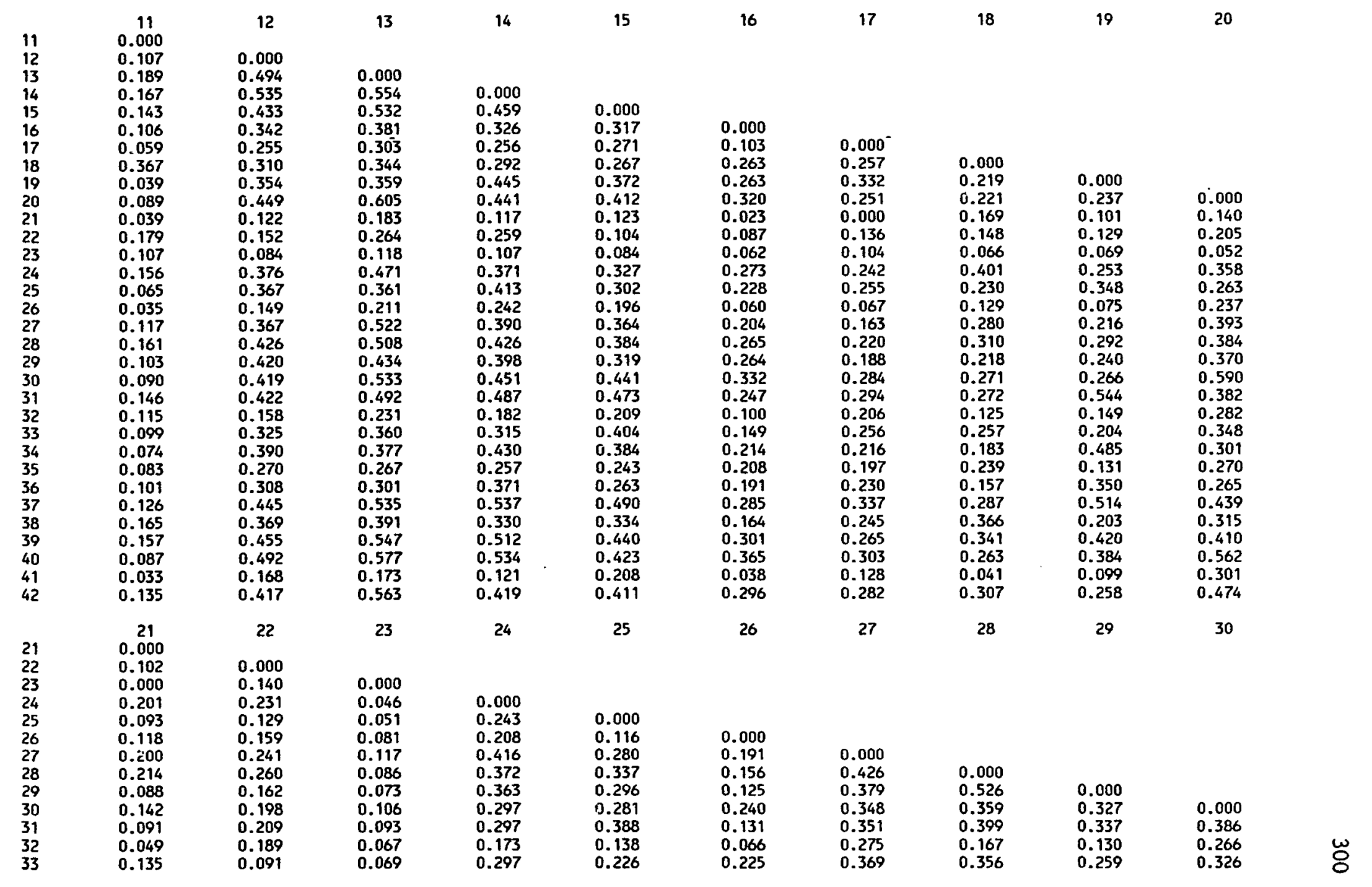




\begin{tabular}{|c|c|c|c|c|c|c|c|c|c|c|}
\hline $\begin{array}{l}34 \\
35 \\
36 \\
37 \\
38 \\
39 \\
40 \\
41 \\
42\end{array}$ & $\begin{array}{c}21 \\
0.126 \\
0.024 \\
0.043 \\
0.180 \\
0.161 \\
0.107 \\
0.137 \\
0.028 \\
0.128\end{array}$ & $\begin{array}{c}22 \\
0.169 \\
0.108 \\
0.199 \\
0.221 \\
0.170 \\
0.185 \\
0.230 \\
0.022 \\
0.246\end{array}$ & $\begin{array}{c}23 \\
0.022 \\
0.032 \\
0.089 \\
0.098 \\
0.083 \\
0.202 \\
0.034 \\
0.000 \\
0.193\end{array}$ & $\begin{array}{c}24 \\
0.348 \\
0.249 \\
0.294 \\
0.373 \\
0.375 \\
0.404 \\
0.426 \\
0.099 \\
0.431\end{array}$ & $\begin{array}{c}25 \\
0.379 \\
0.211 \\
0.412 \\
0.382 \\
0.203 \\
0.368 \\
0.342 \\
0.079 \\
0.322\end{array}$ & $\begin{array}{c}26 \\
0.112 \\
0.356 \\
0.077 \\
0.256 \\
0.340 \\
0.250 \\
0.255 \\
0.075 \\
0.228\end{array}$ & $\begin{array}{c}27 \\
0.325 \\
0.253 \\
0.260 \\
0.442 \\
0.372 \\
0.426 \\
0.380 \\
0.242 \\
0.423\end{array}$ & $\begin{array}{c}28 \\
0.369 \\
0.178 \\
0.253 \\
0.461 \\
0.312 \\
0.430 \\
0.372 \\
0.106 \\
0.425\end{array}$ & $\begin{array}{c}29 \\
0.326 \\
0.125 \\
0.252 \\
0.381 \\
0.320 \\
0.370 \\
0.377 \\
0.075 \\
0.400\end{array}$ & $\begin{array}{c}30 \\
0.317 \\
0.273 \\
0.259 \\
0.454 \\
0.312 \\
0.430 \\
0.516 \\
0.250 \\
0.475\end{array}$ \\
\hline $\begin{array}{l}31 \\
32 \\
33 \\
34 \\
35 \\
36 \\
37 \\
38 \\
39 \\
40 \\
41 \\
42\end{array}$ & $\begin{array}{c}31 \\
0.000 \\
0.227 \\
0.247 \\
0.468 \\
0.137 \\
0.340 \\
0.523 \\
0.241 \\
0.467 \\
0.468 \\
0.211 \\
0.358\end{array}$ & $\begin{array}{c}32 \\
0.000 \\
0.374 \\
0.210 \\
0.122 \\
0.144 \\
0.239 \\
0.208 \\
0.169 \\
0.166 \\
0.624 \\
0.218\end{array}$ & $\begin{array}{l}0.000 \\
0.335 \\
0.239 \\
0.208 \\
0.443 \\
0.255 \\
0.347 \\
0.278 \\
0.414 \\
0.318\end{array}$ & $\begin{array}{l}0.000 \\
0.145 \\
0.328 \\
0.522 \\
0.191 \\
0.368 \\
0.378 \\
0.133 \\
0.309\end{array}$ & $\begin{array}{l}0.000 \\
0.153 \\
0.305 \\
0.371 \\
0.256 \\
0.318 \\
0.060 \\
0.254\end{array}$ & $\begin{array}{l}0.000 \\
0.358 \\
0.170 \\
0.358 \\
0.333 \\
0.055 \\
0.308\end{array}$ & $\begin{array}{l}0.000 \\
0.348 \\
0.516 \\
0.503 \\
0.203 \\
0.419\end{array}$ & $\begin{array}{l}0.000 \\
0.382 \\
0.355 \\
0.119 \\
0.341\end{array}$ & $\begin{array}{l}0.000 \\
0.432 \\
0.136 \\
0.444\end{array}$ & $\begin{array}{l}0.000 \\
0.148 \\
0.470\end{array}$ \\
\hline $\begin{array}{l}41 \\
42\end{array}$ & $\begin{array}{c}41 \\
0.000 \\
0.141\end{array}$ & $\begin{array}{c}42 \\
0.000\end{array}$ & & & & & & & & \\
\hline
\end{tabular}

